$$
\text { by }
$$

\author{
Chelsea Blair LeBlanc
}

Bachelor of Science Physical Geography, Brock University, 2010

\author{
A thesis \\ presented to Ryerson University \\ in partial fulfillment of the \\ requirements for the degree of \\ Master of Applied Science \\ in the Program of \\ Environmental Applied Science and Management
}

Toronto, Ontario, Canada, 2013

CChelsea Blair LeBlanc 2013 


\section{AUTHOR'S DECLARATION FOR ELECTRONIC SUBMISSION OF A THESIS}

I hereby declare that I am the sole author of this thesis. This is a true copy of the thesis, including any required final revisions, as accepted by my examiners.

I authorize Ryerson University to lend this thesis to other institutions or individuals for the purpose of scholarly research.

I further authorize Ryerson University to reproduce this thesis by photocopying or by other means, in total or in part, at the request of other institutions or individuals for the purpose of scholarly research.

I understand that my thesis may be made electronically available to the public. 


\title{
Environmental Stress Effects on Illness in Southern Ontario
}

MASc., Fall 2013, Chelsea Blair LeBlanc, Environmental Applied Science and Management, Ryerson University

\begin{abstract}
A spatial analysis of smog events in Southern Ontario and prevailing winds reveals various patterns that occur during smog advisories. Smog events cause numerous excess deaths and illnesses each year throughout Southern Ontario due to high levels of air pollutants that are generated in North America. Cardiovascular and respiratory illnesses are the main hospital admissions that occur during summer smog episodes. These effects are experienced throughout regions located along the Windsor-Quebec corridor, but there are variations in the numbers of affected people due to the effects of surrounding geographical features and the local contribution of air contaminants. Meteorological differences play a major role in the effects of smog events with factors such as temperature and prevailing winds. This study examines the effects of long distance transport of contaminants from origins in the United States into Canada as indicated by respiratory and cardiovascular mortality and morbidity effects during 9 smog events. This study found that during certain conditions there is a correlation between wind direction and smogrelated mortality and morbidity.
\end{abstract}




\section{Acknowledgements}

I would like to express my gratitude to my supervisor, Dr. Ronald Pushchak for his guidance and aid throughout this research project. I would also like to thank my friends and family for their support and encouragement that allowed me to continue and complete this thesis. Without the constant help of Azim Bhamani, Senior Analyst at the Canadian Institute for Health Information, I would not have had the access to the data that was required for completion of this project; my sincere appreciation goes out to you. I also extend my thanks to the Ryerson Geospatial Map and Data Centre for the continual assistance that was required in the GIS portion of this project. Special thanks to Brian Ceh for his help with the spatial statistics for this thesis. To my partner, Grant McCartney I owe my strength and will to continue this research project, without his interminable support that helped me over the obstacles that this project presented, I would not have been able to complete my masters. 


\section{Dedication}

This thesis is dedicated to my partner and best friend, Grant McCartney.

"In our headlong gallop into the future it is hard to listen. But without listening to trees, how can we see them as our partners in creating a better world?"

A. K. Hellum, listening to trees 


\section{Table of Contents}

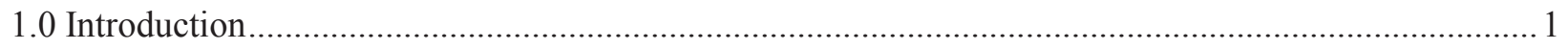

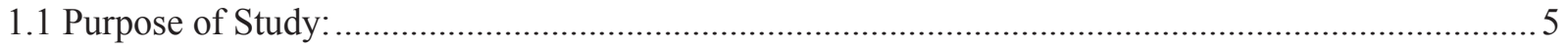

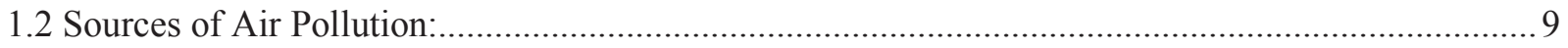

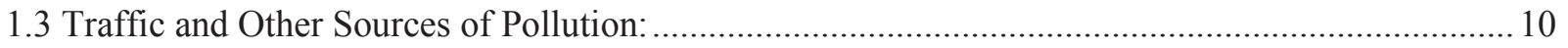

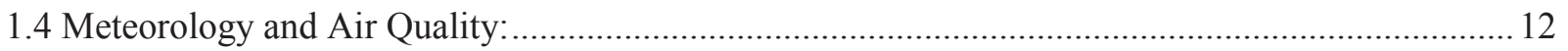

1.5 Policies and Legislation for Controlling Air Pollution: .............................................................. 13

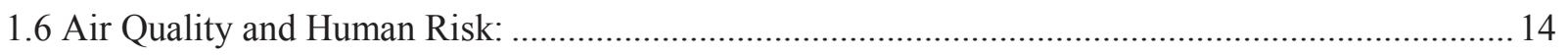

1.7 Spatial Analysis of Air Pollution and Health Effects: ............................................................ 16

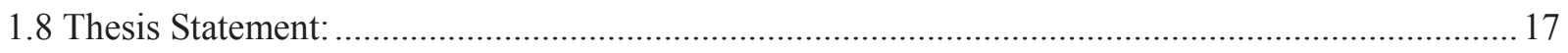

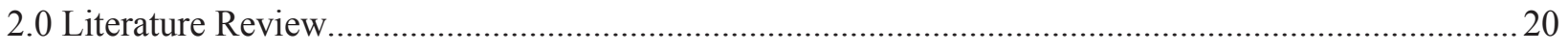

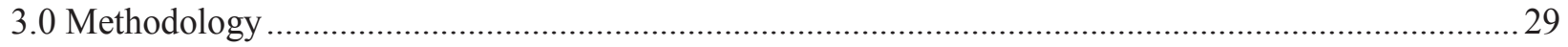

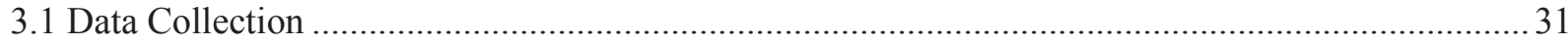

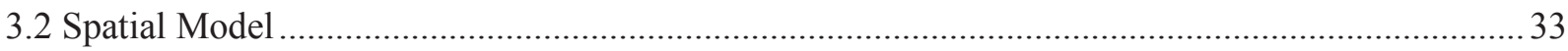

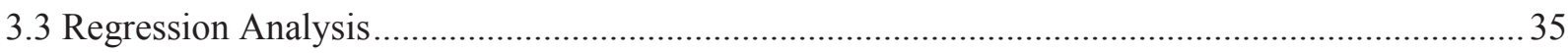

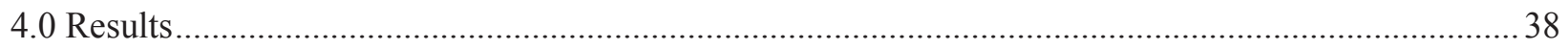

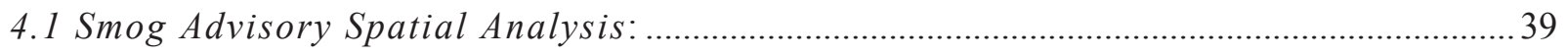

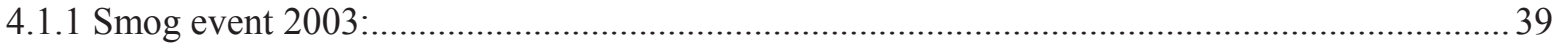

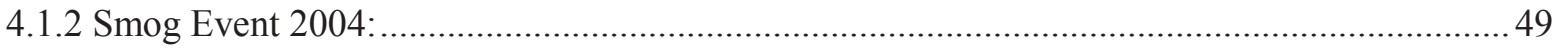

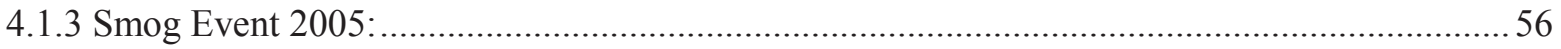

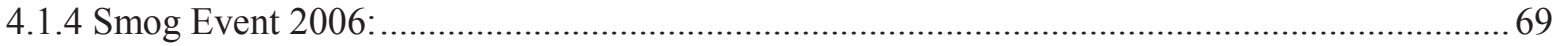

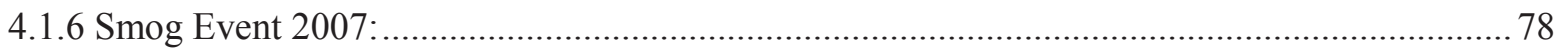

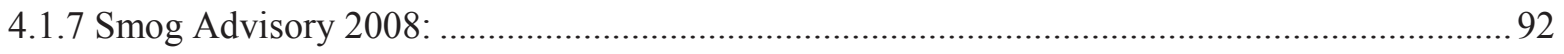

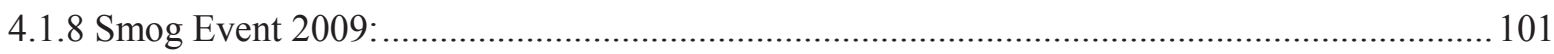

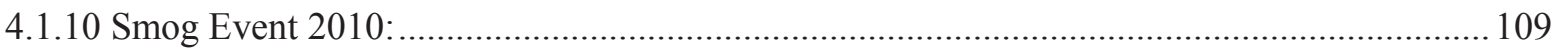

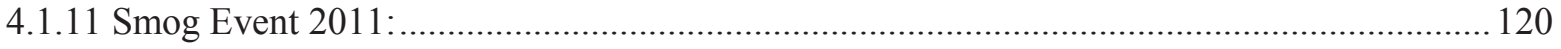

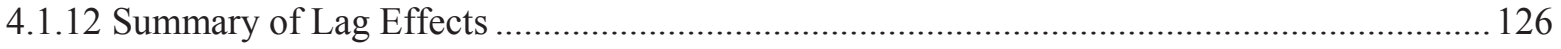

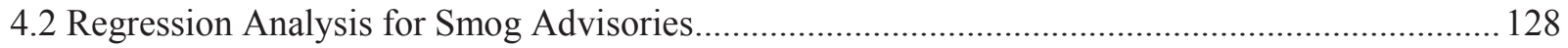

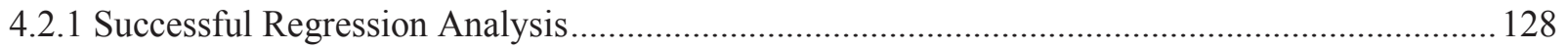

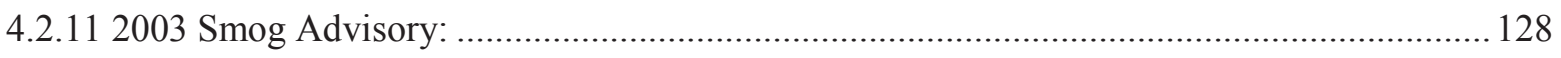

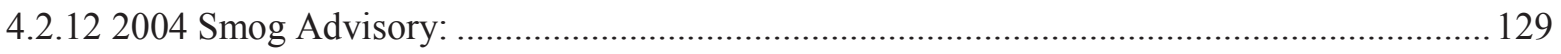

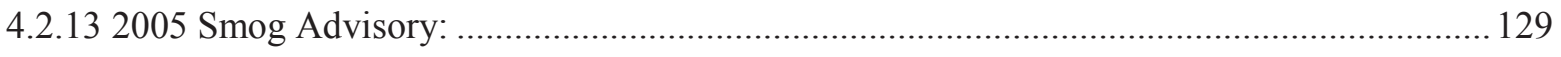

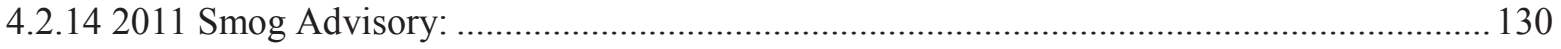


4.2.2 Smog Advisories Unrelated to Illness and Death:

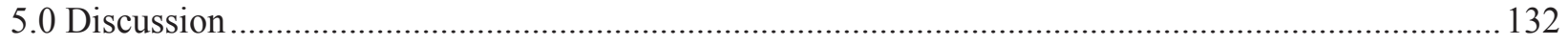

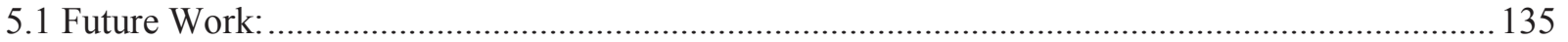

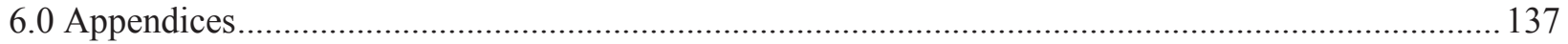

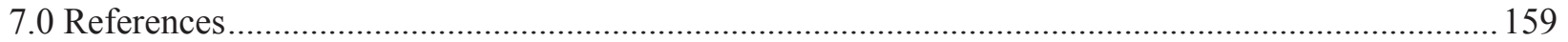




\section{List of Tables}

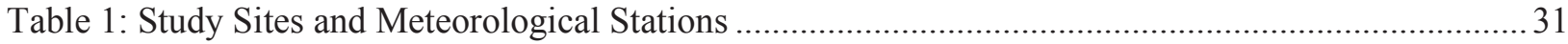

Table 2: Respiratory and Cardiovascular Mortalities during Smog Event Days* .................................. 38

Table 3: Respiratory and Cardiovascular Morbidities during Smog Event Days* ................................... 38

Table 4: Lag effects of death and illness based on wind direction. ..................................................... 127 


\section{List of Figures}

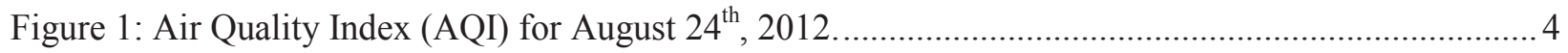

Figure 2: Response to Pollution Levels as adapted from Fig. 8.17, Vallero, 2008................................. 19

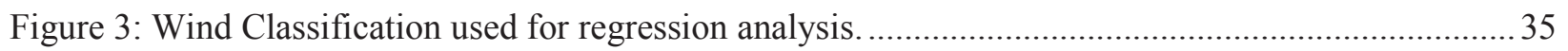

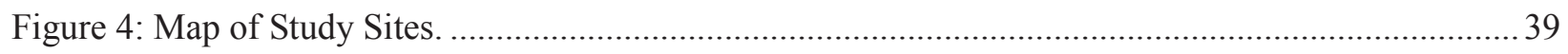

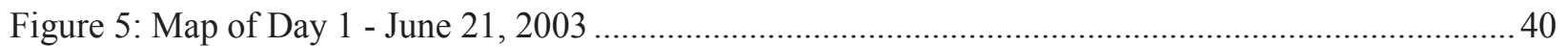

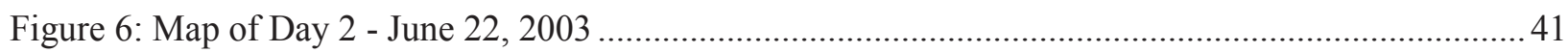

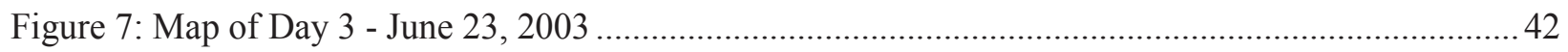

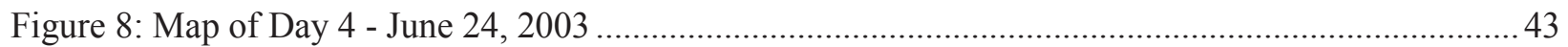

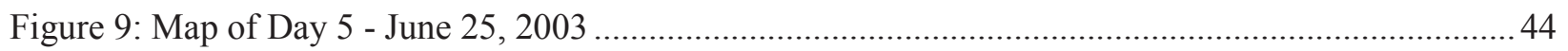

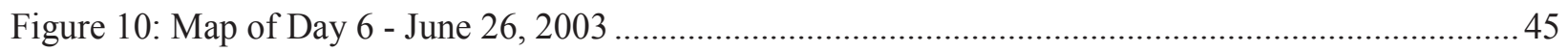

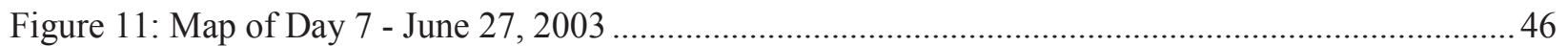

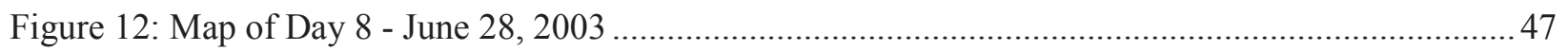

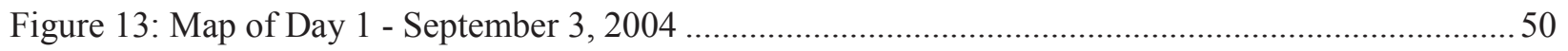

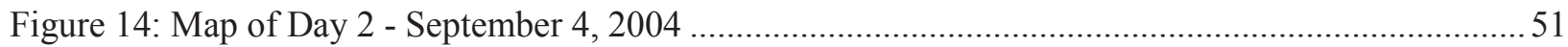

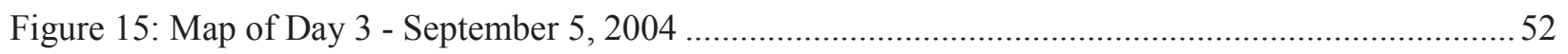

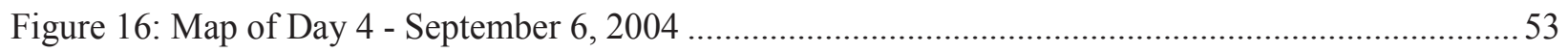

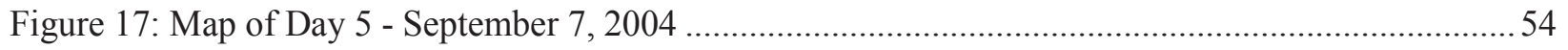

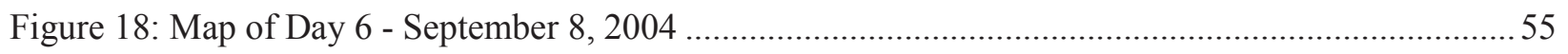

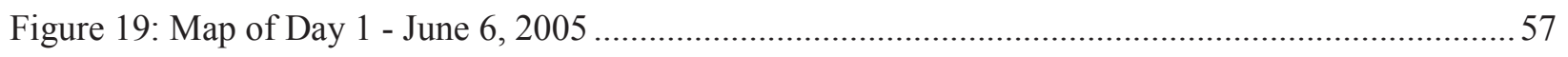

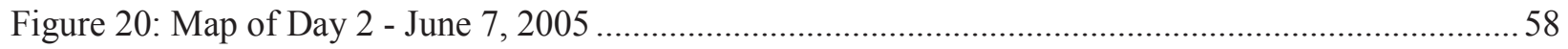

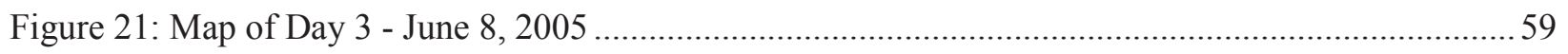

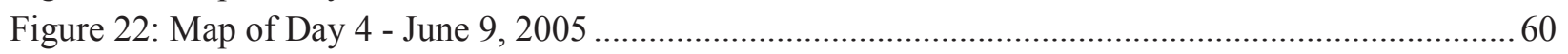

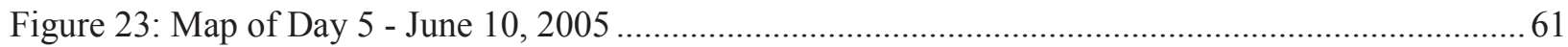

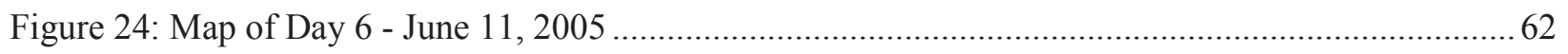

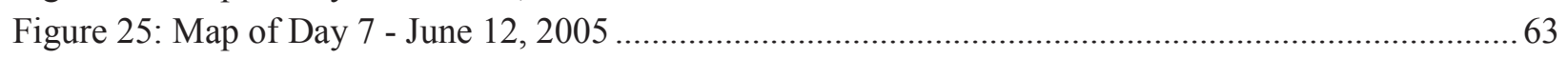

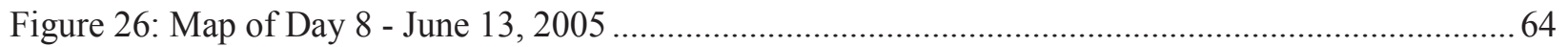

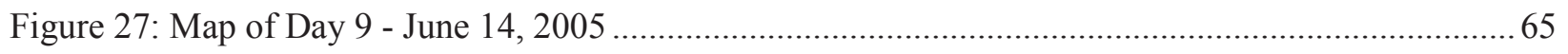

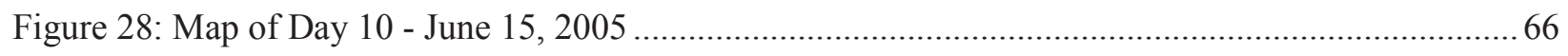

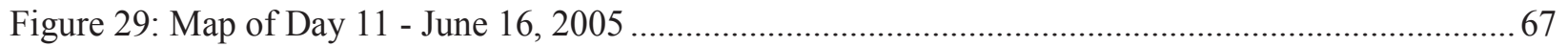

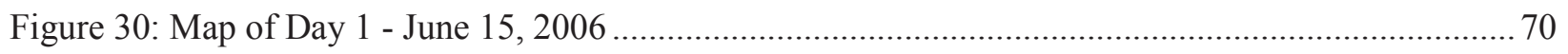

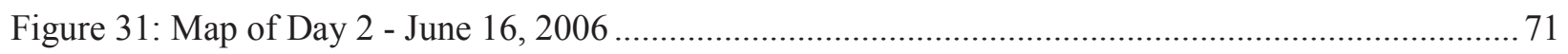

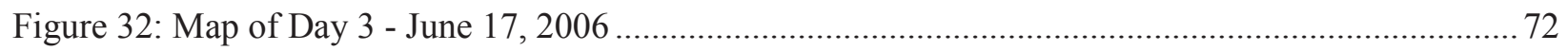

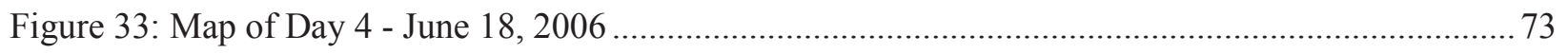

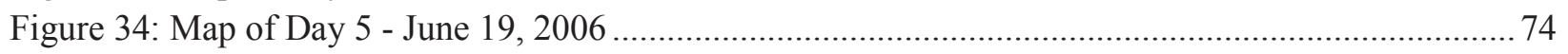

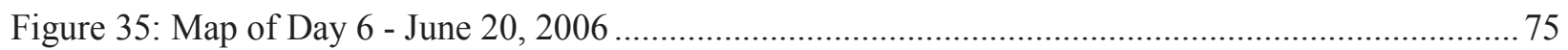

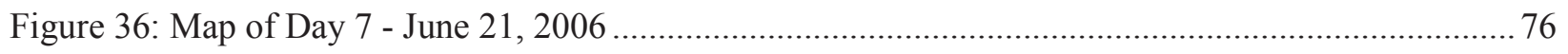

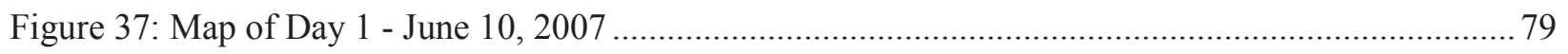

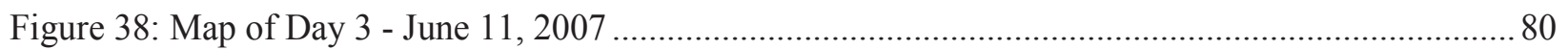

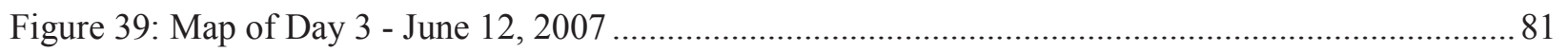

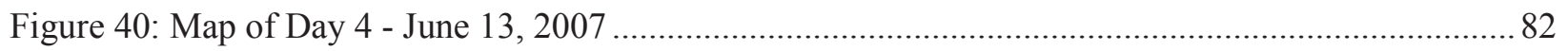

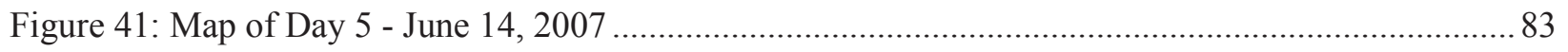

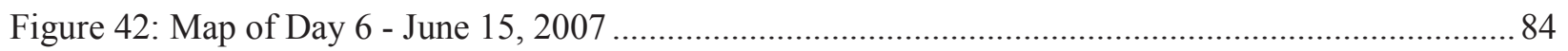




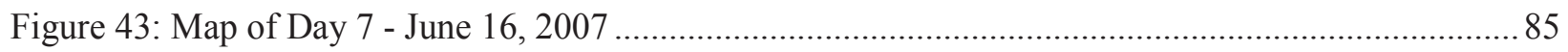

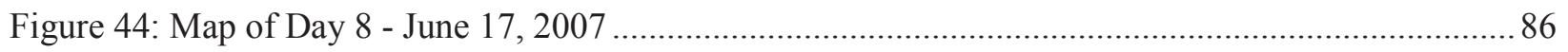

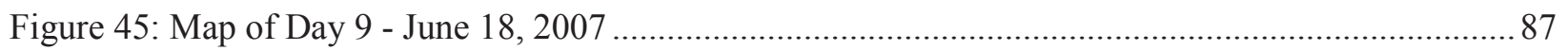

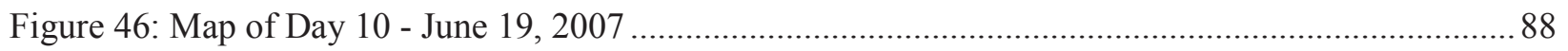

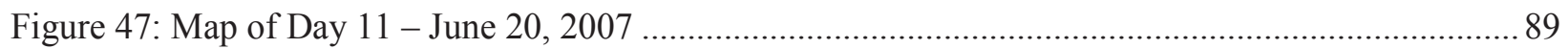

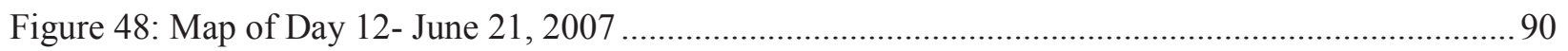

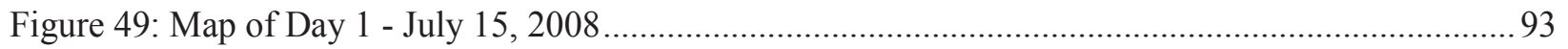

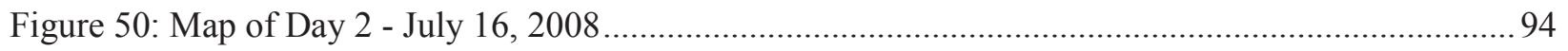

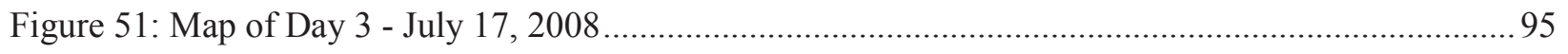

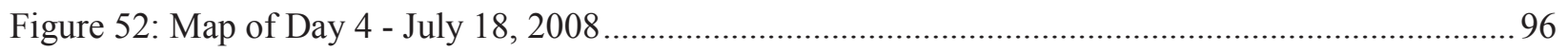

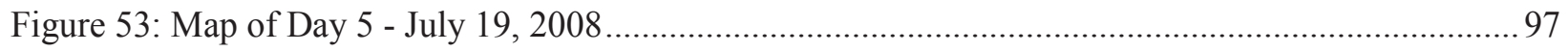

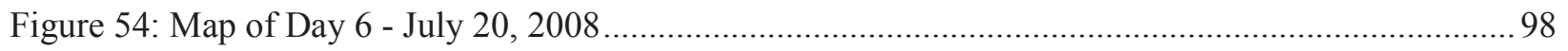

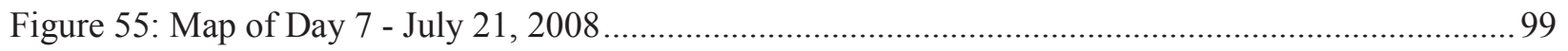

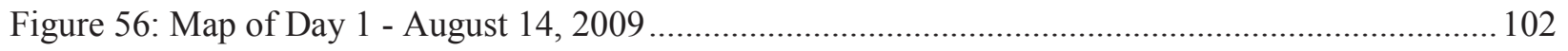

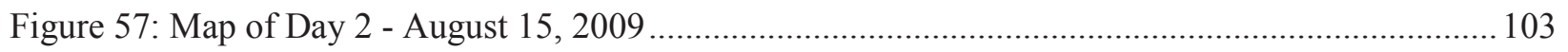

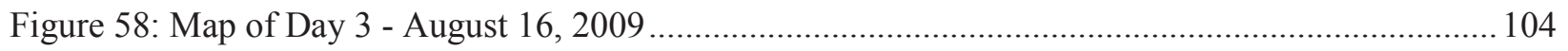

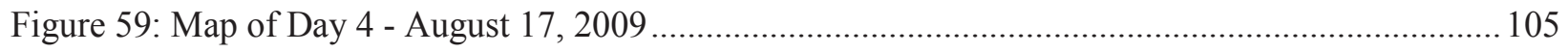

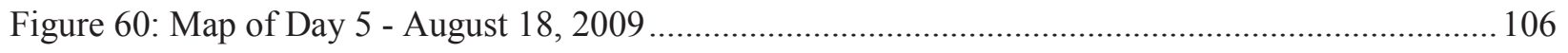

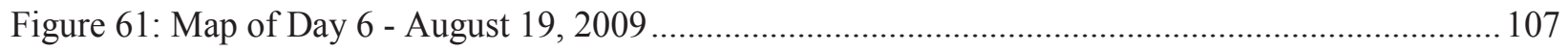

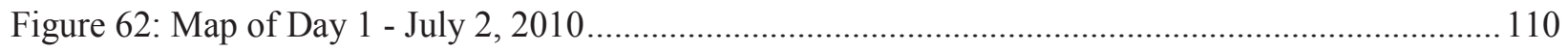

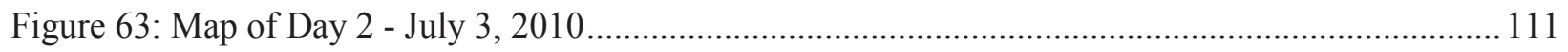

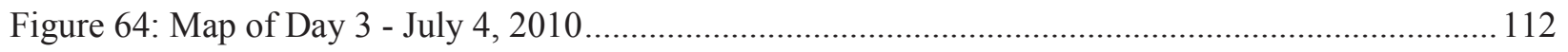

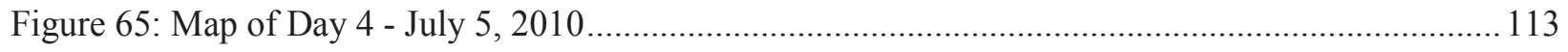

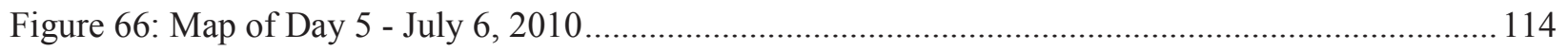

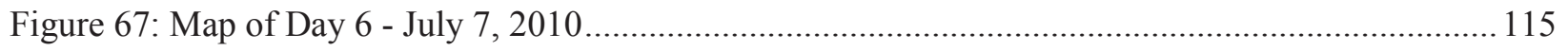

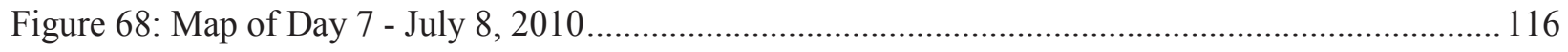

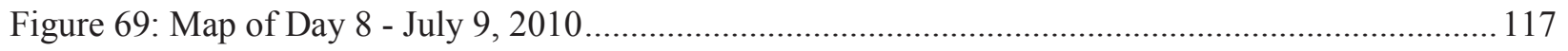

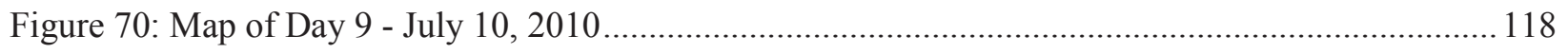

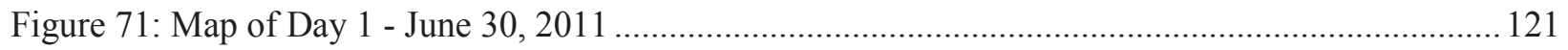

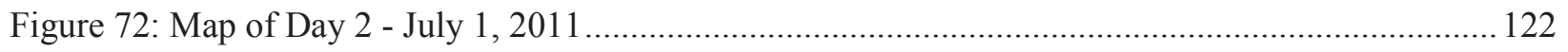

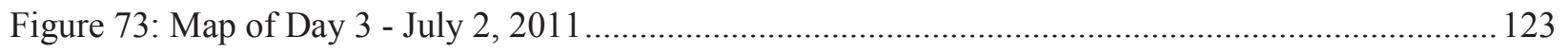

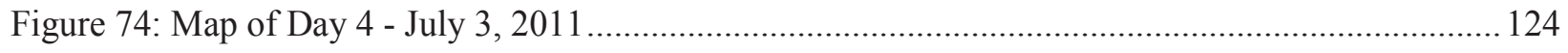

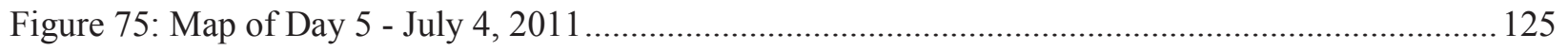

Figure 76: Model Summary from SPSS for 2003 linear regression. .................................................. 128

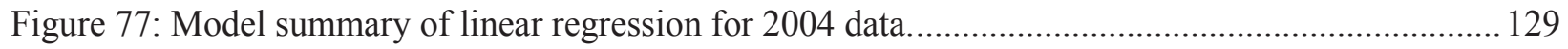

Figure 78: Model summary of linear regression for 2005 data............................................................ 129

Figure 79: Model summary of linear regression for 2011 data.......................................................... 130 


\section{List of Appendices}

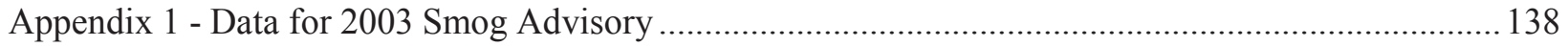

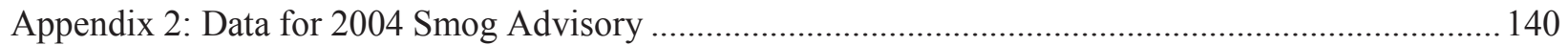

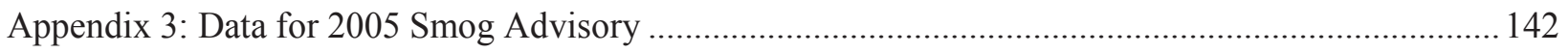

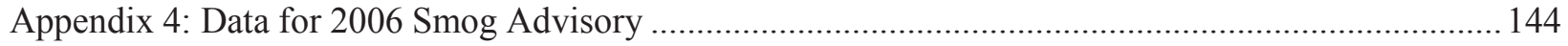

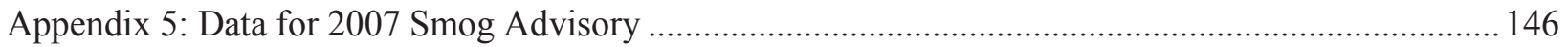

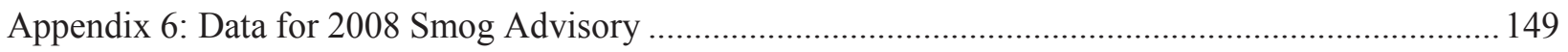

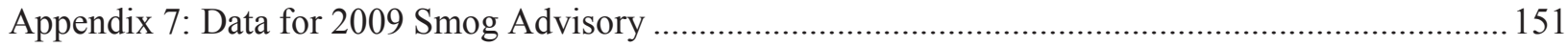

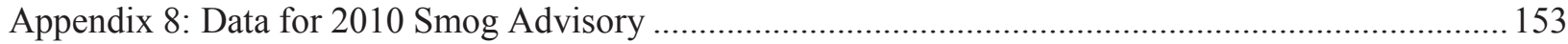

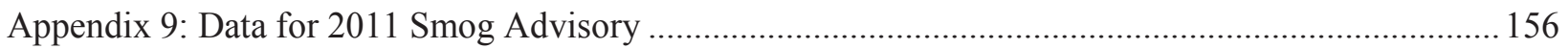

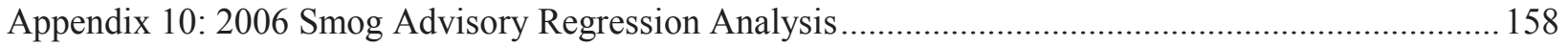

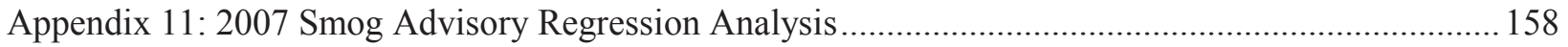

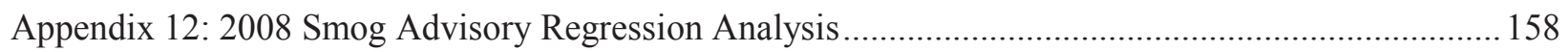

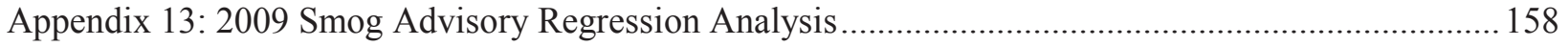

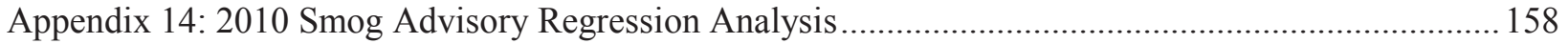




\subsection{Introduction}

Air pollution during summer months in Ontario can cause an increase in illness and death, especially during smog episodes, for those with existing respiratory conditions as well as those with diminished health (Health Canada, 2003). Warmer temperatures result in an increase in concentrations of specific air contaminants such as particulate matter $\left(\mathrm{PM}_{2.5}\right.$ and $\left.\mathrm{PM}_{10}\right)$, ozone $\left(\mathrm{O}_{3}\right)$, nitrogen oxides, sulfur dioxide $\left(\mathrm{SO}_{2}\right)$ and carbon monoxide $(\mathrm{CO})$ (Health Canada, 2003). These specific contaminants at certain levels can cause irritation to lung tissue and the cardiovascular system, which can result in respiratory illness or could potentially cause death if the patient has diminished health conditions. Smog episodes have led to increases in morbidity and mortality which can have an effect on populations and the healthcare systems in cities.

In urban areas, smog advisories are released to the public to ensure that those with preexisting respiratory or diminished health conditions are able to restrict their exposure to air contaminants. In 2005, the Ontario Ministry of Environment (MOE) launched an online program to measure ambient concentrations of air pollutants and to make public an air quality index (AQI) for the cities in Southern Ontario. The AQI is measured from 1 to $100 ; 100$ being the poorest air quality. Areas that record observations in the range of a 50-100 AQI would face potential smog advisories (MOE, 2005). This type of risk management system enables people that may have acute respiratory illnesses or cardiovascular disease to take proper precautions to reduce exposure to high levels of air contaminants.

A study conducted by Toronto Atmospheric Fund (TAF) (2007) discussed the common air pollutants that would be present in a city based on source factors such as industry and vehicles. The most common pollutants are; Sulfur Oxides $\left(\mathrm{SO}_{\mathrm{x}}\right)$, Nitrogen Oxides $\left(\mathrm{NO}_{\mathrm{x}}\right)$, Volatile Organic Compounds (VOCs), Particulate Matter $\left(\mathrm{PM}_{10}\right.$ and $\left.\mathrm{PM}_{2.5}\right)$ and Carbon Monoxide (CO). The 
main contributing source of these pollutants is the burning of fossil fuels. Although there are pollution sources in regions that contribute to their poor air quality, outside sources also pose a threat when considering the mobility of air pollution. Several studies conducted by the MOE $(2000 ; 2002 ; 2006)$ referred to a 50 per cent contribution to the level of air pollution that originates in the United States and enters Canada. Potter (2010) discussed the sources of pollutants that are exchanged between the United States and Canada, due to atmospheric mobility, and has estimated that about 50 per cent of air contaminants in an area such as a city or town can be traced to other sources. This contribution of more than half the air pollutant load from other places makes it difficult to control pollution levels in certain cities. Although the transboundary contribution has only been estimated, this study will focus on the air pollution contributions transported from the Ohio Valley to Southern Ontario, which may have contributed to increased respiratory and cardiovascular illness and death.

The major city centres such as the City of Toronto, make attempts to reduce the amount of emissions that are produced in their urban area. The Toronto Atmospheric Fund (TAF) (2007) study discussed the need to reduce the amounts of NOx, SOx, VOCs, PM, and CO in Toronto by more than 50 per cent. Although this initiative will contribute to increasing the overall air quality of the city, the amount of pollution from sources in the United States that are transported to Ontario by weather systems, makes it difficult to control the levels of these harmful air pollutants. These air pollutants tend to be more harmful when they are concentrated in the summer months; however the levels are also high in the winter months (Rainham et al., 2005). The initiatives made by cities, such as Toronto, to reduce the amounts of air pollutants are mainly related to vehicle emissions but the influence of this 50 per cent contribution may create difficulties, especially when these pollutants negatively affect human health. 
The effects that air pollution can have on human health have been a concern for Health Canada over the last several decades (Health Canada, 2003; 2011). Illness and mortality due to exposure to air pollution during smog days has climbed steadily in Canada, especially in areas with higher populations, where the number of people affected is much greater (Health Canada, 2003). The Ontario Medical Association (OMA) has developed a model that is able to monitor the amount of capital that is lost during smog days, both economic and human capital. This model is known as the Illness Cost of Air Pollution (ICAP), which was created in 2000 by the OMA with help from the Canadian Medical Association (CMA) (Canadian Medical Association, 2008). The ICAP model can measure the extent of mortality and morbidity as well as economic costs and has been implemented throughout 10 provinces in Canada (CMA, 2008). The mortality and morbidity that occurs during a smog episode is an important component of the ICAP model. Not only is it able to estimate the number of illnesses and deaths in a region but can also account for the increase in health care costs in response to smog days. For the purpose of this study, the morbidity outcomes will be the main focus of the research.

The ICAP data reveal the number of visits to a hospital during smog days in a region for a given year (CMA, 2008). Some studies reveal that the effects of air pollutants on human health are temperature-related, but also acknowledge that other weather variables contribute to the amount of pollutants in an area (Rainham and Smoyer-Tomic, 2003). Rainham and SmoyerTomic (2003) and Cheng et al. (2008) have analyzed the connection between the increase in temperatures and air pollution, and human health and have determined that higher temperatures result in greater numbers of illnesses and deaths from air pollution as opposed to lower temperatures. The combination of various air pollutants creates smog (Health Canada, 2003), which can negatively affect those who have pre-existing health problems during a smog episode. 
Studies have identified the correlation between illnesses and premature deaths associated with levels of air pollutants; however, the research that has tried to determine if there is a strong correlation with specific weather events such as prevailing winds and temperature is limited. Lorraine et al. (2008) discussed the importance of policy and risk management measures when informing the public of days when air pollutants are elevated. The AQI identifies the main air pollutants that are present during smog days, which can pose a threat to the elderly and those with pre-existing respiratory illness. The AQI detects areas where the levels of certain pollutants are higher on specific days, utilizing a Google mapping system that shows the location of the monitoring stations or regions along with the numerical value that represents the air quality. The measurement is done on a 1 to 100 scale, with values from 1-49 indicating the AQI is good so the risk of illness may be lessened; meaning areas with a number between 50 and 100 have poor air quality. The following figure, Figure 1 illustrates a typical output of an AQI for August $24^{\text {th }}$ 2012.

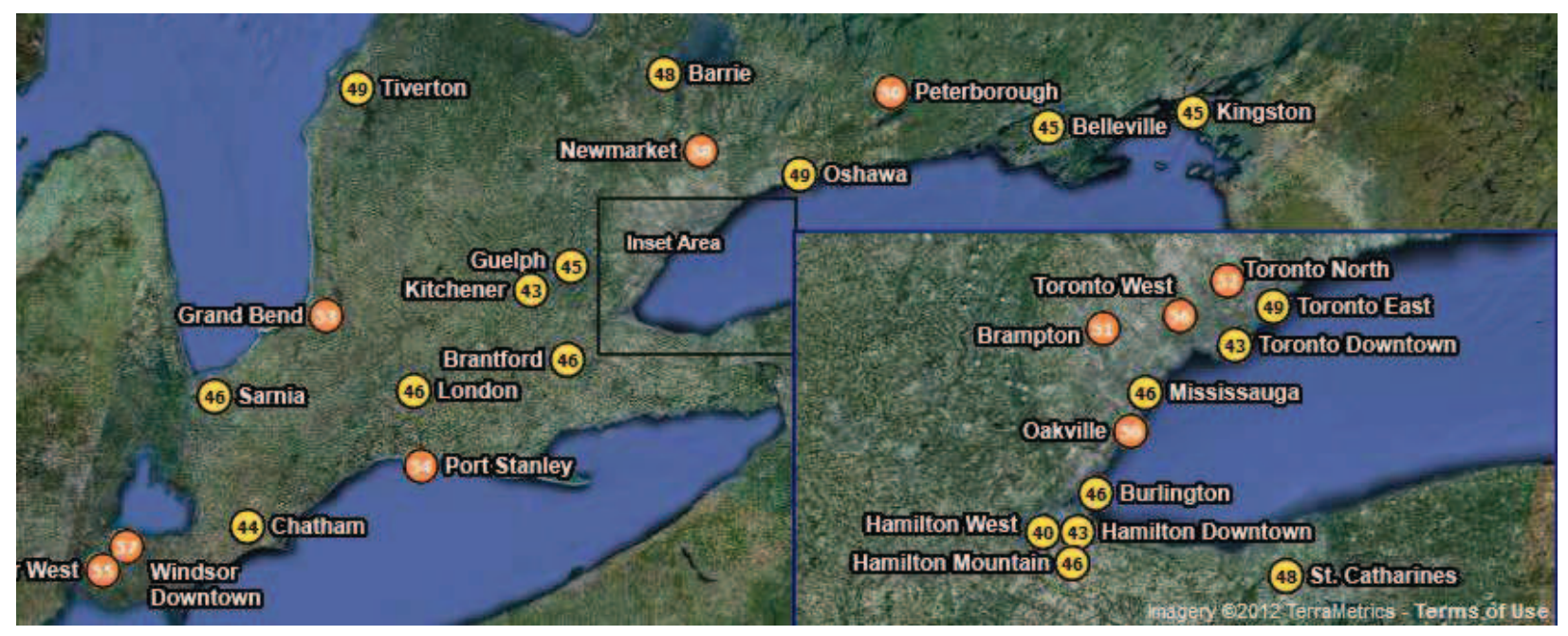

Figure 1: Air Quality Index (AQI) for August 24 $4^{\text {th }}, 2012$.

The AQI assigned for the area is based on the level of particulate matter and ozone in the areas. Although it is understandable that some areas, such as Windsor and Toronto experience high 
levels of air pollutants, areas such as Peterborough, that are not heavily urbanized and do not contain major industries are questionable as to how they receive such high levels of air contaminants.

\subsection{Purpose of Study:}

This study had three main objects:

- To attempt to confirm that 50 per cent of air pollution is sourced from other locations and can affect the levels in an area given prevailing winds,

- To emphasize the lack of spatial sequential investigations of the potential threat smog events have on human health, and

- To show the association of both respiratory and cardiovascular illness with the changes in air quality using Ontario data on morbidity and mortality during selected smog events.

If the transport of pollutants produces a significant effect, it should be detectable in the spatial pattern of illness as prevailing winds transport those contaminants; this is particularly likely if the contribution to local contaminant loads is 50 per cent of the total as estimates suggest. Depending on the location of an urban centre, there are many meteorological variables that can affect pollution conditions in an area, whether due to an increase in temperatures or the effects of onshore lake breezes. Environment Canada (2012) discussed the effects of the mixing and deposition that onshore breezes can have on air pollutants. This phenomenon was also analyzed by Tirabassi (1991) who discussed the circulation of air pollutants between the Alps and the coast in the town of Ravenna, Italy. This would mean that pollution can be transported further and deposited at distant locations depending on where the winds begin to die down and the presence of certain limiting attributes such as waterbodies. If we are to consider Toronto, it is 
located on the North shore of Lake Ontario, which means that the prevailing southwesterly winds move air pollutants across southern Ontario and they can potentially be deposited once the wind dies down. Other major city centres can also have similar effects when outside sources affect an urban centre due to air pollution mobility.

The presence of certain pollutants heightens during smog days, and some human reactions to these pollutants result in either illness or death. Typically, PM and CO have been documented to cause respiratory disease as these are at high levels during a heat wave (Smoyer et al., 2000). During smog days, these types of pollutants seem to be present in higher concentrations due to increased temperatures and potentially because of the effects of prevailing wind patterns. Rainham and Smoyer-Tomic (2003) and Cheng et al. (2008) found that days with dangerously high temperatures and air pollutants have a greater risk of impacting human health. The risk contribution to human health from higher temperatures is roughly 20 per cent and air pollutants account for 80 per cent (Cheng et al., 2008). Both Rainham and Smoyer-Tomic (2003) and Cheng et al. (2008) acknowledge the variable weather conditions that contribute to higher levels of air pollutants; however, they do not focus on specific effects beyond extreme temperatures. What are not taken into account are the prevailing winds that potentially affect the amount of air pollution that can be transported into a region. Given the estimates that 50 per cent of Southern Ontario's contaminants are transboundary contributions, prevailing winds should play a key role in transportation of air contaminants from one location to another.

Prevailing winds play a significant role in the circulation of air in regions which can affect the climate or microclimate of an area. Major cities are believed to be an enormous source of pollutants from the high amount of traffic-related emissions produced by vehicles. Industrial facilities are also a contributor of air contaminants in regions and cities. Generally, industrial 
facilities are built in areas that will not affect surrounding populations in terms of the mobility of air contaminants (Ahrens, 2007); however, looking at the larger picture, wind patterns can move air pollutants from one country or region to another. This means regions in Canada that are experiencing higher amounts of air pollutants could be receiving transboundary contributions from sources in the United States. The amount of air pollution that is transported from the United States to Canada is assumed to be substantial based on the direction of winds and the presence of industrial facilities in the Ohio Valley. In a Masters Project study, Schroeder (2004) acknowledged the Windsor-Quebec corridor as an ideal route for air pollutant transport based on the meteorological and topographic features in a northeast directional pathway. The source of these pollutants would be from the industrial activity in the Ohio Valley which is located southwest of the Windsor-Quebec corridor. In studies by the MOE $(1999 ; 2001)$ it has been estimated that 50 per cent of all air pollutants are from non-local sources. This may imply that prevailing winds have a major contributing factor in the occurrence of smog episodes within Southern Ontario, which could hypothetically be observed in a spatial analysis of smog-related illness events.

A study conducted by Brook et al. (1997) studied, analyzed and tested many cities in Canada and compared the composition of several air contaminants such as $\mathrm{PM}_{10}$ and $\mathrm{PM}_{2.5}$ as well as $\mathrm{SO}_{2}$ and nitrogen compounds that had been deposited on soils due to atmospheric motion. It was found, for all of the contaminants studied, that Ontario received anywhere from 50-60 percent of contaminants whereas other provinces in Canada received 20-45 percent. This study described what was being transported from the United States, specifically the Ohio Valley into Southern Ontario. An annual study conducted by the MOE (2001) referred to research conducted by Fraser and Yap (1997) which monitored and analyzed the amounts of different particle sizes 
of particulate matter; $\mathrm{PM}_{10}$ and $\mathrm{PM}_{2.5}\left(10\right.$ and 2.5 refer to the size in microns, $\left.\mu \mathrm{g} / \mathrm{m}^{3}\right)$, in six urban areas based on prevailing meteorological conditions. It was found that the transport of PM was linked to the surrounding industrial plants. When specifically studying the measurements of PM in Windsor and Hamilton, it was found that levels of PM were much higher in Windsor than Hamilton suggesting a possibility of transferred air contaminants from another location. The MOE (2001) then concluded that the reason PM levels were lower in Hamilton was due to the presence of the Niagara Escarpment and its influence on local atmospheric conditions.

In Ontario, the prevailing direction of wind movement is south west to north east. Based on the knowledge that winds transport air pollutants to other locations, the major effects of illness and death in a region attributed to smog do not necessarily mean that the source is found in the town or local region that is experiencing the smog event. This external source of air pollutants can also play a major role in determining who will be greatly affected by air pollution or where. In order to determine who is greatly affected, mapping the spatial distribution of populations that are experiencing illness or death attributed to smog days is required to gain a better understanding of the effects of prevailing wind patterns. Therefore, this research will examine major city centres in Southern Ontario along the Windsor-Quebec corridor as well as investigating other areas that are located outside this pathway to determine if the movements of air contaminants are revealed in the spatial patterns of smog events and air pollution-related illnesses. The plan of study would attempt to prove that during a smog event the incidences of air pollution-related morbidity and mortality lead to determining an association between those effects and prevailing winds. There is uncertainty in the literature and research about this 50 per cent figure; however, based on the levels of smog that are experienced in Southern Ontario, 
perhaps this could be acknowledged as the contribution of the Ohio Valley's air pollution that is mobilized and transported through Ontario based on weather systems.

\subsection{Sources of Air Pollution:}

Since the industrial revolution, air pollution has caused some health stresses on the population due to the burning of fossil fuels for steam engines (Vallero, 2008). Although the air pollutants of concern then were smoke and ash, as we move forward in the $20^{\text {th }}$ and $21^{\text {st }}$ century, there began to be a shift in the types of air pollutants common in city dwellings. The shift in machinery which required materials such as coal, oil and gas, caused smoke and industrial fog in cities, creating health issues for their citizens (Vallero, 2008). The introduction of personal automobiles also played a large role in the increase of air pollution in cities; however, there were other forces such as home heating that led to higher levels of industrial fog. Larger cities, such as New York City and Los Angeles experienced significant levels of air pollution which blanketed the city in the form of smog (Vallero, 2008). Smog describes the yellowish-brown fog or haze that is low lying and is particularly noticeable during rush hour traffic and throughout the day along a city skyline. Smog is generally more noticeable during the summer months when temperatures are very high. Smog is created when there is an exposure to sunlight, in the presence of water vapour and high temperatures, to these existing compounds in the atmosphere. Due to high temperatures in the summer months as well as high solar radiation reaching the earth's surface, environmental conditions favour the production of specific types of air pollutants that interact to form smog (Health Canada, 2003; Vallero, 2008). Smog event are defined by heightened levels of air pollutants and reduced air quality resulting in rising levels of morbidity and mortality for those who suffer from respiratory or cardiovascular illnesses. By reducing the risk for those with pre-existing illnesses, there may be a reduction in the health care costs of 
government spending that is a result of elevated air contaminants. Levels of air pollutants are also heightened during smog episodes as opposed to levels during non-smog days, resulting in low air quality thus creating health issues for the population that is affected. Sources of air pollution vary and cities are only able to control the pollution that is produced in their city limits.

\subsection{Traffic and Other Sources of Pollution:}

Transportation vehicles are the largest source for air pollution in cities (Health Canada, 2011). Based on the population of Ontario, there are many vehicles, trucks for transport and buses on the roads that lead to elevated levels of air contaminants in the province. The Toronto Atmospheric Fund (TAF) as well as programs such as Drive Clean helped reduce the amounts of vehicle emissions within Ontario; however, there is an the additional burden of transboundary air pollution. Although the attempts to reduce the emissions produced in Ontario could help reduce illnesses and death, the external sources of air contaminants may add to the air quality problem in cities.

The MOE (2005) assessed the production of PM in the industrialized area of the Ohio Valley as being 28 times greater than the PM levels created in Ontario. This would mean that when weather and wind conditions are ideal, this PM would be transported to Ontario. The result of this pollutant transport is elevated levels, especially during smog episodes, which would lead to illnesses and deaths. In the summer of 1998, the MOE (2005) conducted research that required modeling ground level $\mathrm{O}_{3}$ in Ontario. It was determined that Ontario only contributed 16 per cent of $\mathrm{O}_{3}$ emissions, which meant the source of $\mathrm{O}_{3}$, would be mainly from external sources. For PM emissions, it was found that the GTA contributes more than 50 per cent of the PM produced in Ontario. Although this contradicts the 50 per cent figure of emissions from the Ohio Valley, this could explain the smog events that occur outside the Golden Horseshoe, in areas such as 
Peterborough. In places like Windsor, London and Waterloo, the effects of winds blowing from the Southwest could transport the elevated levels of PM from the United States into Southern Ontario. The effects prevailing winds could possibly have on the transport of air pollution could change the way research in conducted on morbidity and mortality by addressing external sources as well as local sources of air contaminants.

Many studies such as TAF, 2007, Jerret et al., 2009, Health Canada, 2011, look at trafficrelated mortality in Ontario; however, there are more contributing factors than just vehicle emissions in an urban setting. Particulate matter (PM) is a major contributor to illness due to its respirable properties and its ability to travel long and short distances (Kampa \& Castanas, 2007). This is the reason why many studies have been conducted regarding the health effects of PM for its ability to remain in local surroundings but also to travel to other locations. Although PM is an important contaminant in this study, the acknowledgement of the other air contaminants present during smog events will be considered as smog is comprised of many air contaminants. Because this study does not use any actual measurements of the levels of $\mathrm{PM}_{2.5}, \mathrm{O}_{3}, \mathrm{SO}_{\mathrm{x}}$ and $\mathrm{NO}_{\mathrm{x}}$ in the spatial analysis, it will be assumed that during a smog event the levels and combinations of all of these air toxins cause respiratory and cardiovascular morbidity and mortality. Vallero (2008) details the composition of the ground level atmosphere which would generally contain hydrocarbons, $\mathrm{NO}_{\mathrm{x}}, \mathrm{SO}_{\mathrm{x}}$, oxygenated hydrocarbons, $\mathrm{O}_{3}$ and free radicals. Although these compounds generally explain the presence of a hazy brownish fog, industry as well as vehicles adds more contaminants to the atmosphere. Although all air contaminants contribute to poor health, I will be specifically analyzing the effects of $\mathrm{PM}_{2.5}$ and $\mathrm{O}_{3}$, since they seem to be the main air pollutants creating the majority of health problems. It is the objective for analysis especially, for those who suffer from pre-existing respiratory or cardiovascular illness. 


\subsection{Meteorology and Air Quality:}

Flemming (1996) emphasized the important role that meteorology plays in air quality, and that neither weather nor contaminant loads can be discussed separately when explaining health effects related to air quality. The atmosphere plays a vital role in determining the air quality of a region; therefore, when explaining the changes in air quality the weather must be considered as well as any anthropogenic influences (Flemming, 1996; Rainham et al., 2005). The Ontario MOE AQI serves as a warning system when air quality is reduced in cities; however, it must be considered that the temperature also plays an important role with the weather system that may be present during an AQI alert. It has been established that temperatures show a strong correlation with air pollution and human health during an extreme weather event; therefore, more deaths occur during extremely cold or extremely warm temperature conditions (Katsouyanni et al., 1993; 2003; Smoyer et al., 2000; Rainham et al., 2005). However, temperature is not the only factor that plays a role in the concentration of air pollutants within cities or regions.

Rainham et al. (2005) examined the levels of pollutants during specific weather systems, acknowledging the strong connection between meteorological effects and air quality in a region. The effect of a high pressure system compared to a low pressure system was substantial. Due to the lack of ventilation during a high pressure system, air contaminants are not transported through the system and tend to remain concentrated in the area or region. During low pressure systems, the air contaminants are circulated more effectively and do not tend to settle. Samet et al. (1998) also discussed the strong correlation between mortality and air pollution levels under the influence of weather systems in Philadelphia. The modeling attempted to show the differences between air-pollution mortality and synoptic weather patterns but had not revealed any substantial outcome; however, Samet et al. (1998) made it clear that more research was required to show that there is a correlation. During pollutant event conditions, wind direction and 
speed play an equally important role, especially when considering the mobility of air contaminants within regions, provinces, or between two countries.

Although studies have attempted to analyze the meteorological effects of an area, prevailing winds could potentially be the reason this 50 per cent figure exists and might explain why areas have measured levels of air contaminants that are not produced in their locales. Prevailing winds move air contaminants from one area to another depending on the speed and direction the wind is traveling. The effects of the circulation of air contaminants within Southern Ontario may be indicative of the role the Ohio Valley contaminants play and given the direction the wind blows the majority of the time.

\subsection{Policies and Legislation for Controlling Air Pollution:}

Health Canada (2006) discussed the National Ambient Air Quality Objectives

(NAAQOs) that require at a national, provincial and regional levels to remain under the standards set by federal regulations. Due to the effects of air pollution on the human and natural environments, both Canada and it's provinces created policies in an attempt to reduce the risks and hazards that were faced when being exposed to polluted air. The Canadian Environmental Action Plan (CEPA) is one of the main environmental protection plans used in order to regulate and reduce pollutants that are created and released into our human and natural environments. The levels of certain air contaminants are important when maintaining a safe environment for populations living close to a pollution source; therefore, Canada-Wide Standards (CWS) were set for certain air contaminants that pose a threat to human health. These standards are easily set for industrial effluents; however, when considering the levels of air contaminants that are released from vehicles, it is difficult to put limits on the output of $\mathrm{PM}$ and $\mathrm{O}_{3}$. Even though there are 
regulations in place to reduce local air contaminants, it is impossible to regulate transboundary contributions.

The difficulty with regulating air pollution is solely based on the particle's ability to be transported easily through the atmosphere to other areas in a country, continent and the world. In a large area such as North America, it is difficult to control what air pollutants are entering into Canada from the United States and vice versa. Lorraine et al. (2008) discussed the difficulties of policy makers and risk managers when faced with the transboundary and intercontinental issues of air movements in local and regional settings. The main issue was the effort in controlling the emissions of certain industries; however, weighing the costs of impacts to public health against implementation of specific air pollution reduction mechanisms is difficult to do. The control of the mobility of air pollutants is also difficult to manage without considering the options of reducing emissions, resulting in further conflicts in the battle between industry and public wellbeing. Although industry is a producer of air pollution in human and natural environments, vehicles also compromise the air quality in towns and cities (Lorraine et al., 2008). Regulating and maintaining safe levels of air contaminants may reduce the number of illnesses and deaths that occur each year during smog events.

\subsection{Air Quality and Human Risk:}

Declining air quality in urban centres has led to numerous health concerns, creating additional economic strain on the provinces' healthcare system. Since Ontario has the largest portion of Canada's population, the study of human response to air pollutants is especially important. As was mentioned earlier, the effluents from the United States can be transported into Canada and specifically Ontario. As the majority of Canadians live in Southern Ontario and southern Quebec, a study to determine how humans react to the input of additional atmospheric 
contaminants transported the Ohio Valley can have an effect on the health of the population. When a smog event is issued, this generally indicates that the levels of air contaminants are much higher than on an average day. Although we would associate the highest risk humans living in large urban centres, some of those living in rural communities may also be affected. The Toronto Atmospheric Fund (TAF) attempts to reduce levels of air pollutants that may be caused from neighbouring industry and vehicle use in the city. Although the City of Toronto has methods to reduce pollutants produced in its own boundaries, the contributing factors like long distant transport located outside of the city cannot be reduced.

Many studies (Samet et al., 1998; 2000; Peng et al., 2005; 2009; Smoyer-Tomic 2000; Lippman, 2006) discuss the relationship between air pollution and mortality in cities; however, these studies only discuss the presence of PM. Health effects could go beyond just one singular air contaminant. Lippman (2006) for example, acknowledged the connection between fine PM, specifically looking at ambient air concentration of nickel and its effects on the cardiovascular system; however, this study will not take into account specific particulates, rather consider all forms of PM to have an effect on human health based on exposure. By studying morbidity and mortality during smog events, perhaps, the numbers of humans that are affected could be better understood, aiding in the knowledge that several air contaminants could affect people, not just one. The OMA and CMA have revealed the number of deaths that occur during summer months, but to examine the deaths that occur during smog events issued by the MOE, another pattern may emerge to the human response when air quality is reduced throughout the duration of a smog event. The human response to smog events which as described by Vallero (2008) would be considered an intermediate term of air quality since a smog event only lasts hours to days, rather than long-term which are months to years. This type of response can be seen in Figure 2. The 
resulting response would be respiratory disease; however, it has been shown that high levels of air pollutants can also attribute to cardiovascular disease. Therefore, those who are affected during a smog event would suffer from acute respiratory disease rather than chronic diseases.

\subsection{Spatial Analysis of Air Pollution and Health Effects:}

There have been several studies (Dominici et al., 2002; Jerret et al., 2005; Rainham et al., 2005) that discuss the spatial variation between mortality and air pollutions; however, they only document mortality and do not look in morbidity in areas that were studied. Rainham et al. (2005) looked at various meteorological factors that affect air pollution and mortality rates in the Greater Toronto Area (GTA) in winter and summer months. Although this study does examine the possibility of a variation between mortality outcomes during the winter and summer months, the reader may gain more knowledge if there was an analysis that shows the spatial variation between regions in Toronto. Having more variety in meteorological sources may also help differentiate the effects felt in various regions around the GTA, Rainham et al. (2005) only had the option to collect meteorological data from one source; however, by using various study sites and their corresponding meteorological stations, a difference in human health effects may be observed based on the region they live in. The study by Rainham et al. (2005) assists in determining the ideal scenario in which more deaths would be experienced. The hottest air masses during the summer months resulted in a greater number of deaths; however, the air pollutant levels were relatively moderate. Since the main focus of this research is determining the effects prevailing winds have on air pollution and sub sequentially morbidity and mortality during smog events in the summer, Rainham's results could help further the understandings of why certain concentrations of air contaminants may affect the populations differently. In contrast, Rainham et al. 2005 only discussed the GTA; perhaps a better understanding of how 
Southern Ontario is being affected can be gained by examining the occurrences of illness and death during extreme summer temperatures and smog advisories.

\subsection{Thesis Statement:}

Since high levels of harmful air pollutants are associated with specific weather events, the collection of the areas that experience smog episodes will be reflected in the higher numbers of respiratory and cardiovascular illnesses and deaths for those who are prone to or have preexisting illnesses. Based on the notion that Southern Ontario's prevailing winds blow from southwest to northeast and that Ontario is located northeast of a contamination source, the large industrial complex in the Ohio Valley, just southwest of Windsor, levels of air pollutants are expected to be sequentially higher from west to east as smog events continue, resulting in an increase in the numbers of illnesses or deaths during a smog episode. Due to prevailing winds, the smog events that occur in one area can be expected to occur later in time in other areas in the northeast direction, resulting in a spatial sequence of smog events in Southern Ontario. Although research has shown a correlation between air pollutants and human health during summer months, the spatial analysis of a pattern of specific smog episodes associated with illnesses and deaths has not been examined for Ontario. During the extent of a smog event there should be a correlation between the days that a smog event occurs and the number of illnesses and deaths; therefore, the longer the smog event, the more deaths and illnesses are expected to occur. This study will spatially depict the number of illnesses and deaths that are associated with smog events in the 8 selected regions in Southern Ontario, and the spatial analysis is expected to reveal a pattern that occurs across the regions with exposure to high levels of air pollutants that are related to smog episodes. The following diagram (Figure 2) reveals a pattern that is expected 
during a smog advisory based on meteorological conditions of the wind speed and wind direction.

Another pattern that is expected is that during the smog event, the number of illnesses and deaths will increase around 2 to 3 days after a smog event, based on studies by Wyzga (1978) and Pope et al. (1995) that revealed a lagged effect for high levels of air pollutants. The increase in morbidity and mortality is an expected response to the high levels of air pollutants that reduce the health of those who have respiratory or cardiovascular illnesses over time. Since smog advisories are issued when there are significant levels of air pollutants (MOE, 2010), it is assumed, that air pollutants are at a dangerous level for the health of the population that is experiencing the smog event. The mobility of the air contaminants is believed to be the main reason why areas experience high levels of air pollutants even though they may not produce them. The contribution of a substantial portion of the contaminated load from the south west should be revealed in the spatial progression of air pollution related illnesses from west to east along the Windsor-Quebec corridor. Figure 2 illustrates the human response to high concentrations to air contaminants, adapted from Vallero (2008). The green cross would indicate the expected reaction based on the level of pollutants that would occur during a smog event. As smog events can last anywhere from 1 hour to 1 day or more the level of exposure would be expect to result in those who suffer from respiratory disease would feel, for example, an asthma attack. The level of pollution is also illustrated in this figure, suggesting that levels that are moderate to high would occur during an intermediate (smog) event. The visibility indicated on the left side of the graph, could also be applied to a smog advisory, as during summer months, in some areas; smog can be highly visible, resulting in low visibility of the surrounding area. 


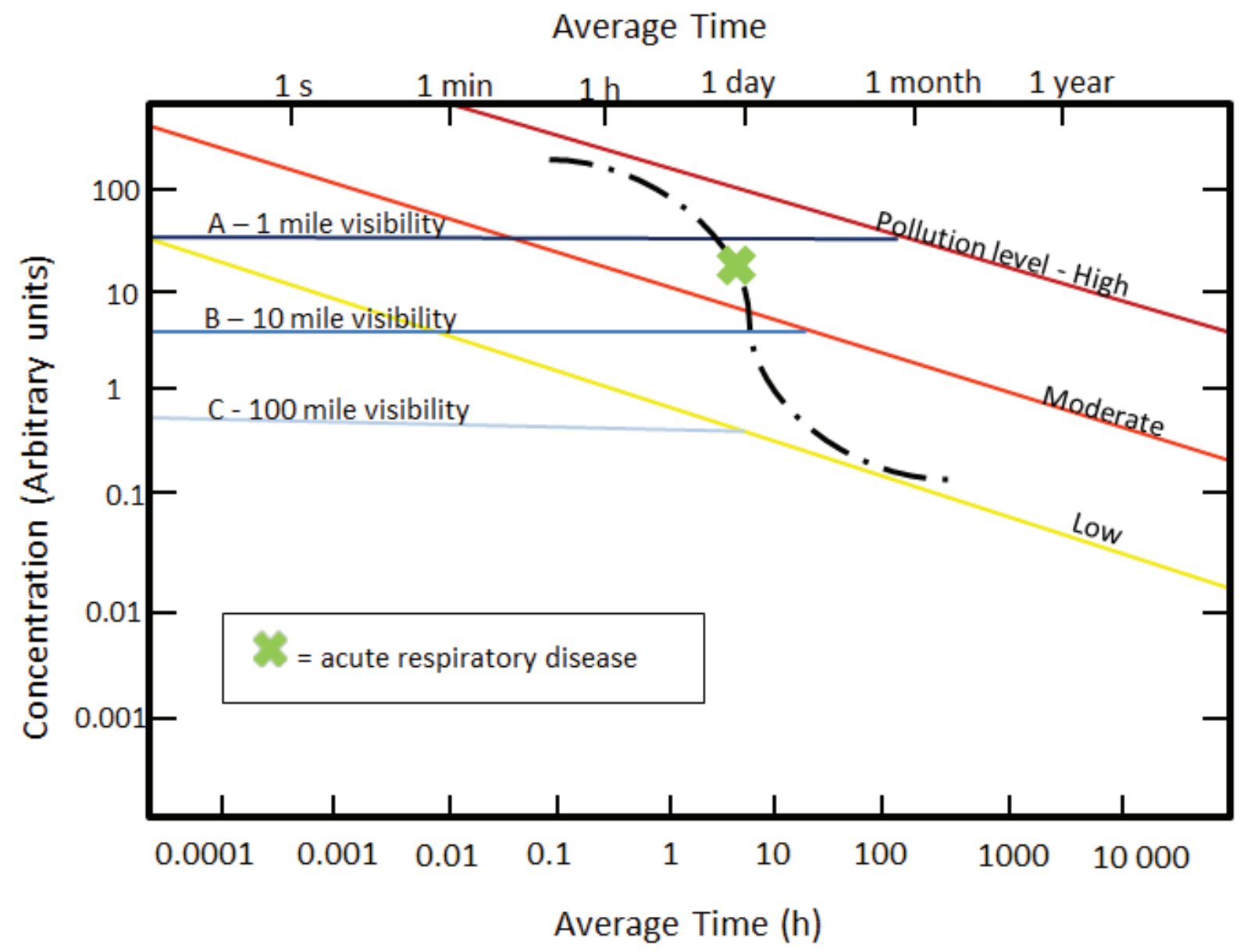

Figure 2: Response to Pollution Levels as adapted from Fig. 8.17, Vallero, 2008.

Hypothesis: The human response to exposures of high levels of air pollutants during a smog event will show increased morbidity and mortality when the source of pollutants is moving in the direction towards the study sites; therefore, if the wind is moving in a northeast direction, there should be a sequential increase in illnesses and deaths due to the contribution of air contaminants from the southwest. 


\subsection{Literature Review}

Although the association between air quality and human health in cities has been a concern since the industrial revolution, it wasn't until the London Fog event, that the relationship between poor air quality and increased deaths was discovered. In the late 1830 s to 1840 s, William Farr discovered the correlation between cold weather and deaths in London and Wales; however the numbers of deaths were never collected daily (Ellis, 1972). It was not until the 1950s that the collection of daily deaths was important in determining what could cause increases in mortality rates. The relationship between air quality and mortality became very clear during the 1950s when areas experienced an increase in temperatures resulting in an excessive rise in deaths due to respiratory disease (U.A., 1954; Boyd, 1960; Schenker, 1993). U.A. (1954), Boyd (1960) and Schenker (1993) discussed the events of 1952 when the United States and other European countries had brought attention to this correlation between air quality and deaths and created measures to help prevent the reoccurring smog that is present in urban areas. A similar study was conducted by Boyd (1960) in which he investigated the negative correlation between winter temperatures and number of deaths that occurred in London with data from 1952. The data collection for mortality then was done by a weekly basis, since data collection is now done in an efficient manner that collects all hospital admissions on a daily basis. Boyd (1960) illustrates an analysis for determining deaths and air quality before a time when data was collected in a more precise manner. Samet et al. (2000) discussed many studies that account for the number of deaths and illnesses, due to cardiovascular and respiratory complications, not solely from particulate matter, but are attributed by other pollutants that are present as well as the meteorological factors that tend to push these pollutants in areas.

Studies linking specific air pollution levels to the severity of illness and death have also been a common topic in several research papers. Martin (1964), Samet et al. (2000), Leikauf 
(2002), Lipfert and Morris (2002) and Nafsted et al. (2003) discuss similar cases while studying specific air contaminants and their known effects on lung functionality. Leikauf (2002) discussed the term hazardous air pollutants (HAPs) which consist of several compounds that lead to illness and death, while other studies focus on a few specific air pollutants that could cause respiratory or cardiovascular illnesses depending on length of exposures. Lipfert and Morris (2002) collected and analyzed data from 1960-1997 to revealed effects of specific air contaminants on human health. They took into account the general demographics and regional patterns within the United States, in order to determine who was at risk of exposure to a range of specific air contaminants. Nafsted et al. (2003) studied the effects due to exposure to $\mathrm{SO}_{\mathrm{x}}$ and $\mathrm{NO}_{\mathrm{x}}$. The effects air pollution in urban centres focused mainly on acute respiratory disease while chronic health effects due to long-term exposure of these air contaminants was also important (Nafsted et al., 2003). Nafsted et al. (2003) conducted a long-term study in Norway to determine effects of carcinogenic air contaminants on lung tissue. They found that many people who have been exposed to high levels of air pollutants can experience high levels of lung cancer. Hales et al. (2000), Samet et al. (2000), Chauhan and Johnston (2003), and Samet et al. (2008) examined the health effects associated with particulate matter (PM) as a main contributor to increases in respiratory illness during events that have elevated levels of PM. Wolf-Benning et al. (2012) studied areas that had a classification of urban and rural roads, by looking at the number of vehicles that would release PM into the area and measured levels to determine the potential hazards each settlement (urban vs. rural) may pose to the surrounding populations health. Although Samet et al. (2008), Peng et al. $(2005 ; 2009)$ discussed the effects of fine PM, WolfBenning et al. (2012) measured fine, coarse and giant PM that is released from vehicle traffic 
which urged all types of PM can affect human health negatively due to the uncertain distribution of PM of all diametres present in the atmosphere.

The Illness Costs of Air Pollution (ICAP) model was developed to determine the number of people that are affected by poor air quality in terms of illness and deaths in a specific region. The Ontario Medical Association (OMA) (2000) calculated the overall increased economic costs on the health care system for Ontario to be around 1 billion dollars. The Canadian Medical Association (CMA), in the next few years, had joined with the OMA to determine the costs for the entire country. The acknowledgement of how air pollution burdens our health system has created concerns at all levels of government. Federal and Provincial governments have taken measures to help reduce the amount of air pollution in the country as well as at a municipal level where the city of Toronto through the TAF has made many efforts in reducing the levels of traffic pollution to better protect its citizens.

The association between specific meteorological events and levels of air pollutants has resulted in numerous studies that have examined the variables that contribute to higher levels of air pollutants (Ellis, 1972; Samet et al, 1998; Salmond et al., 2000; Samet et al, 2000; Samet et al., 2008). There have been a number of studies, such as Peng et al. $(2005 ; 2009)$ and Cheng et al. (2008) that examine the meteorological effects and air pollution; however most studies only focus on extreme weather conditions (Smoyer-Tomic and Rainham, 2001; Semenza et al., 2008). The extreme weather conditions studied generally occurred during the summer and winter months, when various meteorological events occur such as high pressure systems. Cheng et al. (2008) look at the extreme temperatures and the levels of air pollutants during that time, analyzing the impacts to human health during these extreme temperature events but associated with the level of air pollutants that cause respiratory illness. Rainham et al. (2005) conducted a 
study that specifically identified the different air masses that resulted in increased levels of mortality in the Greater Toronto Area (GTA). They studied both the winter and summer air masses experienced in the City of Toronto. Using a meteorological station location at Pearson International Airport, the data provided by one station was assumed to be representative for the whole of the Toronto Area, which does not take in account the varying microclimates that occur in any region, especially larger areas such as the GTA.

Although there are studies that explained the impacts of air quality in urban centres, many studies failed to examine areas that were not defined by high traffic and dense populations. An area of concern would be the Peterborough Region. This area consists of low density housing and is located in a cottage country area. During the summer months, this region experiences high AQI readings which would imply poor air quality for the region. Kim (2001) discussed a specific event that occurred in June 2001 in which the MOE had urged people to carpool or take public transit to not add to the current air pollution burden the region was facing.

The notion of smog and air pollutants being transported from other locations is a common discussion in certain regions of Ontario (MOE, 2000; Kim, 2001; Lindgren, 2001; Ladurantaye, 2002). Lindgren (2001) discussed the idea that Southern Ontario cannot escape from high pollutant concentrations found in the urban city centres because these countryside areas are also experiencing smog transported and poor air quality. Ladurantaye (2002) conferred that in order to get fresh air; one would have to leave the Georgian Bay-Lake Huron area in order to have a smog free environment. The occurrence of smog days throughout Southern Ontario seems to be creating harmful environments, even for those who may not live in a heavily urbanized area.

A study conducted by Smoyer, Rainham and Hewko (2000) uses a similar study site comparison of the number of heat related deaths among the elderly along a similar corridor; 
however, it does not take into account the specific number of deaths and illnesses that occur during a specific smog event. Smoyer et al. (2000) take in account the number of deaths that occur during the duration of a summer in 5 study sites in Southern Ontario along the same corridor. Although the findings show that a relationship exists between deaths and the number of extreme temperature days, it fails to show a sequential spatial pattern with respect to a specific event, instead it shows the effects in the entirety of a summer. Smoyer et al. (2000) also only acknowledge the elderly population, not taking in account any other age group or sensitive persons. Smoyer et al. (2000) also acknowledge that some deaths may be associated with air pollution and acknowledge that some studies should include air pollution data for heat-wave days. A similar study by McGeehin and Mirabelli (2001) examined heat-related mortalities and morbidities in the United States; however, they acknowledge the elderly and younger children, who tend to be more susceptible to illnesses or death during the event of a heat-wave and are vulnerable. Although heat-related deaths are significant in the United States, the number of deaths that occur in the winter months is substantially higher, insinuating that weather is not the only factor that affects the number of deaths (McGeehin \& Mirabelli, 2001). McGeehin and Mirabelli (2001) point out the key gaps in the research such as a lack of information regarding specific weather variables that affect those who are susceptible as well as the weather-related risk factor for heat-related illness and deaths. Even though this study will focus on air pollutionrelated deaths, the studies conducted for heat-waves and heat vulnerability will be used as an indication in determining behaviour that occurs during high temperatures.

Studies such as Samet et al. (2000), Nel (2005), Jerret et al. (2009) and Wolf-Benning (2012), discuss the increasing morbidity and mortality numbers due to the presence of particulate matter. Samet et al. (2000) monitored the level of PM and the number of deaths that occurred in 
cities in the United States. They acknowledged the association between deaths and high levels of hospital admissions due to the presence of high levels of PM. The focus of this study was to monitor smaller particles of PM in several cities and treat them individually based on the presence of emissions by manufacturers located in the study areas. This study, however, only examined at the hospitalization of those 65 years and older, because they were assumed to be more readily affected by PM than the other age groups. Nel (2005) discussed the importance of monitoring $\mathrm{PM}_{10}$ and $\mathrm{PM}_{2.5}$; however, they examined the effects of the smaller particles that are not monitored and cause more harmful respiratory illness and deaths (Nel, 2005). Nel (2005) and Jerret et al. (2009) also explain that ultrafine particles are created from vehicle emissions. These particles have the ability to reach deep in the lung tissues causing severe damage, and potentially death (Nel, 2005). Wolf-Benning et al. (2012) measures the levels of air contaminants in major city centres where there are high levels of air pollutants. Although the transboundary contributions are discussed as a main contributor to the air pollution being experienced in Southern Ontario, perhaps this explains the low air quality experienced in Peterborough, Ontario. Since the GTA is close to the Peterborough region, the vehicle emissions from the GTA may be affecting the air quality and smog event occurrences in Peterborough. Jerret et al. (2009) used a methodology that required the identification of almost 2,500 Toronto patients who had visited a physician for respiratory illness using their Ontario Health Insurance Plan (OHIP). This study used the postal codes of these patients; however, it took into account factors such as age, height, weight, smoking status so forth, whereas this thesis will focus on all patients in the study sites that have visited ambulatory care using their OHIP. As age seems to be a key factor in the number of deaths and illnesses that occur during smog events, this research will look at the distribution of age in the same manner as the OMA used in the ICAP model. The only other 
important data being used will be the date as well as their location by Forward Sortation Area (FSA) which is the first three characters of a postal code to indicate the area they live in.

There are several studies (Samet et al., 2005; 2008; Peng et al.,2005; 2009) that examine the number of deaths that occur during a given summer; however, these studies fail to take in account the number of illnesses and deaths that are reported for a given smog event. Smog events can last anywhere from a 1 day to a week or longer and lag effects can also be experienced during these times. Hales et al. (2000) attempted to show a correlation between meteorological variables and daily deaths associated with air pollutants for Christchurch, New Zealand; however, they failed to find a correlation between levels of specific air pollutants and wind speed and direction. The point of this research is to establish the role of transported air contaminants within an area that is downwind from a specific pollution source. The research shows meteorological effects that play a role during low air quality days; however, do not take into account the direct effects wind direction and speed could have on different areas. A study conducted by Tirabassi (1991) investigated at the spectrum of air pollutants in an industrial region in Ravenna, Italy and the interaction with the microclimate that occurs between the Alps and the coast with the surrounding petroleum plants. Tirabassi (1991) measured the wind speed and the levels of air pollutants during the day to determine the peak concentrations during specific conditions, such as high or low wind speeds and the dilution of air contaminants. The wind direction was also taken into account. He determined that the wind direction played a role on the time of dilution, inferring the concentrations may remain high if the source of emissions were moving in a specific direction which did not promote the dilution of contaminants in the atmosphere. This mainly was an effect of the onshore breeze phenomenon that occurred in Italy, however is common in any country or region that are located on a shoreline. This study would be 
useful in determining the characteristics of the study sites since they are sandwiched between the Great Lakes and may have some of the same characteristics since there is a definitive source of emissions from the Ohio Valley located southwest of the study sites. Although Tirabassi (1991) evaluated the meteorological effects occurring in a heavily industrial area, this study still may aid in the understanding of shoreline circulation of air contaminants and how wind plays a crucial role.

It is well known that the prevailing winds in Southern Ontario move in a northeastern direction, which could mean that based on specific meteorological variables, such as wind speed, a smog event that is observed first in Windsor, could be experienced in Toronto in a given day or a number of days based on the transport of air pollution from the Ohio Valley to regions in Southern Ontario. It was observed by the OMA that the morbidity and mortality in Southern Ontario during a smog event rises greatly which was determined through the use of ICAP; however, there are no visual aids to help determine the overall risk of poor air quality in Ontario. By creating a time series and map sequence of a smog event could help provide more information regarding the number of illnesses and deaths that could be experienced as well as which region is at the greatest risk of the effects of poor air quality.

Jerret et al. (2005) studied and analyzed air pollutants in Los Angeles to show the level of particulate matter around Los Angeles. They used a spatial analysis technique to show which zip codes contained the highest levels of PM and then applied those levels to the number of cancer related mortalities that occurred in the zip code areas. Although Jerret et al. (2005) will be useful in the aiding a spatial analysis study, the way they projected the number of deaths will not be applied to Southern Ontario. Jerret et al. (2005) used an average population per zip code, which can be done in a highly populated urban area such as LA, especially when the zip codes are 
located closely together; however, since I will be using several study sites with varying populations, I will not be able to use this same method. Although the methods are slightly different, and I will be looking at different variables, this study will be useful to help conduct a spatial analysis of morbidity and mortality with the selected meteorological variables. Anderson (2009) discussed the different types of epidemiological studies when considering human effect and air pollution. There are two different types of studies; short-term and long-term. Long-term studies look into spatial variability of air pollution at different concentrations, while the shortterm studies which include specific smog episodes which are known as temporal variability studies. Although, technically speaking this study would be considered a short-term analysis based on the length of each smog event, since I will be analyzing several events over the course of 8 years, then it could also be considered a long-term study analysis. A spatial analysis of the contribution of the air pollution from the Ohio Valley will reveal the effects of smog events along the Windsor-Quebec corridor during specific wind direction conditions. 


\subsection{Methodology}

The methodology for this thesis involved the use of previous research as well as other methods that have not been used to investigate the spatial analysis of deaths and illnesses during smog events. This study took into account many factors that influence respiratory and cardiovascular illnesses and deaths such as levels of pollutants and extreme temperatures. Although this research entailed the use of diverse methods to analyze the progression of morbidity and mortality during a smog event, many assumptions were made to conduct this analysis.

This study used 9 smog events from the years 2003-2011 which were selected based on the length of the event for 8 regions that are along the Windsor-Quebec corridor. For each study site, population data was recorded as a means of comparison. The data collection process also involved the use of historical meteorological data including; max, temperature, average temperature, average wind speed and average wind direction. Cardiovascular and respiratory morbidity and mortality data were obtain from the Canadian Institute for Health Information (CIHI) which involved manipulation of certain variables such as the date of admission, FSA and age of patient. The FSAs were then sorted into the 8 regions. Average air pollution levels of PM and $\mathrm{O}_{3}$ were calculated per day from the MOE historical pollution data source and used as a measure of the intensity of a smog day.

Many assumptions were made in this study, based on previous research, in order to collect the number of deaths and illnesses that occurred during smog events. The data collected for respiratory and cardiovascular illness and death were assumed to be due to the presence of high amounts of $\mathrm{PM}$ and $\mathrm{O}_{3}$ during a smog event. Another assumption was that the number of deaths and illnesses occurring at the beginning of the smog event was representative of a baseline level of morbidity and mortality. There were also limitations to the study such as the 
hospital data used was also only tied spatially to the forward sortation areas (FSAs) that were within the study regions, so those who had travelled from other locations to the study sites were not able to be detected, therefore were not used in this study. Another limitation to this study was the use of averages for the meteorological data which could not be representative of a section during the day in which levels could have been moderately high. A third limitation would be the use of only one smog event per year, several smog events are documented; however, only one was used and since each smog event is different, this may not represent the overall outcome of deaths and illnesses that could occur, especially if smog events overlap.

The data used were obtained from various sources; some were publicly available, while 2 data sets were acquired from the Canadian Institute for Health Information (CIHI). Weather Data were obtained from Environment Canada's Weather Office archives. Smog advisory days were obtained from the Ontario Ministry of Environment (MOE) air quality index (AQI) records from 2003 to 2011. The means of measuring a smog event was done by monitoring levels of air contaminants, if elevated levels of air contaminants are expected, a smog advisory would be issued at least 24 hours before. The advisory ended when air contaminant levels decreased to a relative baseline. The levels of PM and $\mathrm{O} 3$ were also collected from the historical air pollution database on the AQI website which were used for the regression analysis to test against morbidity and mortality.

Population data for each region were obtained from the Canadian Census 2006. This allowed for a comparison to each study site during a smog event. The data collected and sorted for cardiovascular and respiratory deaths and illnesses during smog advisories took into account the lag effect that is generally experienced during episodes of high levels of pollutants, therefore, the study site with the longest smog advisory was used and the day before the advisory was taken 
to provide a baseline and show a progression level of deaths and illnesses. The two days after the smog advisory were also included in the data collected to ensure that any possible lag effects that may be felt by the population experiencing the smog advisory were captured. Studies such as Swartz (2001) and Sahsuvaroglu and Jerret (2007) acknowledge this lag time, which is why it is important to consider in the data collection portion of the methodology.

\subsection{Data Collection}

Based on the availability of meteorological data, specific regions in Southern Ontario were chosen. Many cities also required the use of a couple meteorological stations due to the decommissioning of some stations. The following table, Table 1 shows the cities chosen in the Windsor-Quebec corridor.

Table 1: Study Sites and Meteorological Stations

\begin{tabular}{|c|c|c|}
\hline Regions & $\begin{array}{c}\text { Population } \\
\text { (Census 2006) }\end{array}$ & $\begin{array}{c}\text { Meteorological Station } \\
\text { (Environment Canada) }\end{array}$ \\
\hline Windsor-Essex & 393,402 & Windsor A \\
\hline London-Middlesex & 422,333 & London Int'l \\
\hline Waterloo & 478,121 & $\begin{array}{c}\text { Kitchener/Waterloo and Region of Waterloo Int'1 } \\
\text { Airport }\end{array}$ \\
\hline Peel-Halton & $1,598,661$ & Pearson Int'l \\
\hline York-Durham & $1,453,970$ & Pearson Int'l \\
\hline City of Toronto & $2,503,281$ & Toronto City Centre + Toronto Island \\
\hline $\begin{array}{c}\text { Peterborough-Kawartha } \\
\text { Lakes }\end{array}$ & 207,641 & $\begin{array}{c}\text { Peterborough Trent U + Peterborough A + } \\
\text { Peterborough AWOS }\end{array}$ \\
\hline Niagara Peninsula & 427,421 & Vineland Station \\
\hline
\end{tabular}

The meteorological data were obtained for each study site based on the longest smog advisory that occurred for that event. Data for one day before the longest smog advisory were collected and labeled as a pre-day, some regions did experience more than one pre-day due to the lesser 
number of smog advisory days. The purpose of the collection of a pre-day was to determine a baseline cardiovascular and respiratory morbidity and mortality rate that occurred in each region during a non-smog advisory day, since that information is not readily available based on regional differences in Ontario. Data were also collected for two days after the smog event, labeled as post-days, the purpose of collecting that information allowed to capture potential lag effects that would have occurred. A post-day would indicate that the region is no longer is a smog advisory; however, based on lag effects, those regions could still experience high levels of morbidity and mortality, therefore making it an essential portion of the data.

Hospital admissions were obtained from the CIHI National Ambulatory Care Response Systems (NACRS) while the mortality data were obtained from the Hospital Mortality Database (HMDB). The diseases that were of interest were indicated by the International Code of Diseases, $10^{\text {th }}$ revision, Canada which captured those cases that suffered from respiratory and cardiovascular illnesses. These included diseases of the circulatory system file code numbers; ICD-I10, ICD-I1 1-13, ICD-I21, and ICD-I23 as well as diseases of the respiratory system file code numbers;

ICD-J45, ICD-J95, and ICD-J98

It also has to be assumed that those who suffered from respiratory or cardiovascular illness were taken to the closest hospital to their home. Based on this assumption, those who came in contact with the same air contaminants were expected to show a wave-like progression revealed in the map series using the FSAs in the 8 study sites. Since this could not be shown, as smog advisories are not issued for areas in a town or city, a larger scale wave-like progression is expected to be seen from Windsor-Essex to Peterborough-Kawartha lakes. For the data collected and sorted, there were several patients that did not have an FSA from Ontario included 
individuals who were diagnosed for respiratory or cardiovascular illnesses, they were not used since the area they lived in during the smog event and therefore were omitted. The FSAs were then condensed into the regions displayed in Table 1 by sorting through each FSA and assigning it to the selected regions along the corridor. The data collected can be seen in Appendices 1-9 which involve the study site, the date of the smog event, the progress day of the smog event, raw deaths and illnesses, population, normalized deaths and illnesses, maximum and average temperature, wind direction, wind speed and levels of $\mathrm{PM}$ and $\mathrm{O}_{3}$.

\subsection{Spatial Model}

These tabular data in Appendices 1-9 were joined with the spatial representation of the assigned regions indicated in Table 1 to create a map series of each smog event by day. The maps illustrate the specific day of the smog event whether it was a pre-day, smog day (numbered) or a post-day. The maps also show the number of deaths and illnesses that have occurred during each day and in each region represented by graduated circles on the map. Since each region has a different population, in order to compare regions, the number of deaths and illnesses observed was normalized. Normalization was done by taking the population of the area and dividing it by 100,000 to show the number of people per 100,000 that were affected by smog related illness that day. The resulting number was then used as a denominator and the raw number of deaths or illnesses in that area was divided by that. An example can be seen in Equation 1 (Eq.1).

$$
\text { normalized population }=\frac{\text { total population of Region }}{100,000}
$$

Example of normalized population:

$$
\text { City of Toronto }=\frac{2,503,281}{100,000}=25.03281
$$

Example of normalized death for the City of Toronto: 


$$
\begin{aligned}
& \text { Normalized no. }=\frac{\text { Raw deaths/illnesses }}{\text { normalized population }} \\
& \text { June 23, } 2003=\frac{89}{25.03281}=3.6 \text { per } 100,000 \text { population }
\end{aligned}
$$

The deaths and illnesses were separated into 5 classes which each graduated circle represents a specific number for the particular smog day. The larger the circle represents the highest range of morbidity and mortality. Since each smog day results in a different number of illnesses and deaths, the size of the circles for each day represents a different class range. This can be confusing for the reader, however, the acknowledgement of the large circle representing the larger number of morbidity and mortality that occurred is assumed. The arrows on the map series indicate the average direction of wind for each area for that particular day. This was set using a rotational setting, which required the arrows to be pointed in the direction of the compass (in degrees) that were indicated in Appendices 1-9. The wind direction is measured in degrees and in the direction the wind is coming from is indicated by the arrow, which is why the arrows are pointed opposite to the direction that the wind is moving across Southern Ontario. The arrow direction can be confusing to the reader; however it is based on the way the wind data are collected.

The Canadian Smog Science Assessment (2012) noted the City of Toronto conducted an analysis of air pollution related deaths and illnesses during smog days and found that the majority of deaths and illnesses that have occurred, happened during days classified by the MOE AQI as "good" days, this is assumed to be indicative of the lag effects felt during or after a smog event. Even though the AQI is an important aspect to consider for this study, it only started to be collected in 2007, making it difficult to compare to the 2003-2011 data that were collected for smog advisories; therefore it is going to be assumed that during a smog event, the air quality tends to be moderate or poor. This may show that the highest number of deaths that have 
occurred, occur during the lag effect that has been felt days after a smog event. Pope et al. (1995) discuss the phenomena of a lag effect after there have been many days of poor air quality. Although several lag times were studied, the numbers varied anywhere between 2-5 days to 5 weeks. With this knowledge, the 2-5 day lagged association observed by Pope and Dockery (1992); Pope et al. (1995) will be used for this study.

A qualitative analysis was conducted for the spatial sequence of smog events by the changes in deaths and illnesses as well as wind direction for each day. The direction of the arrow should indicate a high number of deaths or illnesses if it is pointing in the southwest direction during a smog event. By examining each region's death and illnesses as well as the direction of wind, each region may reveal a different pattern.

\subsection{Regression Analysis}

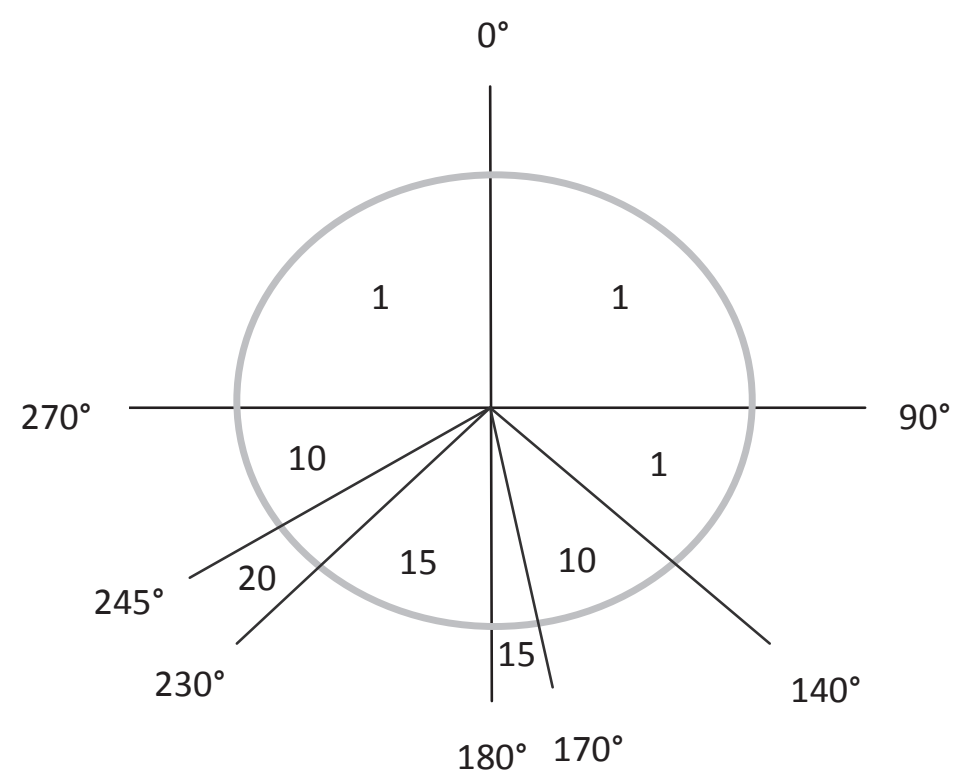

Figure 3: Wind Classification used for regression analysis.

A linear regression was conducted to determine the strength of each variable in correspondence to the effects of wind using SPSS statistical package. 


$$
y=a+b x_{1}+b x_{2}+b x_{3} \ldots b x_{n}
$$

In which;

$y=$ Wind Classification * Max Temperature

$x_{1}=$ Raw Deaths

$x_{2}=$ Raw Illnesses

$x_{3}=$ Normalized Deaths

$X_{4}=$ Normalized Illnesses

$x_{5}=$ Max Temperature

$x_{6}=\mathrm{PM}_{2.5}$ Level

$x_{7}=03$ Level

The dependent variable used was a variable constructed of a wind direction classification multiplied to maximum temperature and the variables tested against that were raw deaths and illnesses, normalized deaths and illnesses, max temperature and the average level of $\mathrm{PM}_{2.5}$ and $\mathrm{O}_{3}$. The reason for creating a variable for wind direction is based on the way wind direction data are collected and were not treated by SPSS on direction rather based on high or low values. It is collected in the form of compass degrees from 0 to 360, 0 and 360 both being representative of North. Based on the contribution of air pollutants from the United States, a classification was created and assigned a number established on the direction (in degrees) the wind was blowing from. Figure 3 shows the classification method used. The wind classification was decided based on the air pollution effect that was experienced from wind direction, as well as the chance of the wind direction. The chance of the wind moving within the southern direction is quite high, therefore it was assigned a value of 10-20, since the prevailing winds in Southern Ontario are southwesterly, the highest value is assigned to the degrees in that particular direction $\left(230-245^{\circ}\right)$. 
The greater the direction of wind concluded with southwest, the higher the value it was assigned. The classification also is assigned on the level of air contamination that would be sourced from the location of air pollution producers in the Ohio Valley, which is southwest of Southern Ontario, resulting in the highest classification or value. The value of one was assigned to the direction that is believed to be of least occurrence, since the prevailing winds in Southern Ontario are in the southwesterly direction, it is assumed that the other directions will not play a significant role, especially if the wind is moving from the east, north, northeast or northwest direction. Also due to the impact that other industrial areas in the US may have on Southern Ontario, a 10 or 15 value was assigned representing the potential risk of air pollution from Detroit and Buffalo. This wind rose was centred on the Windsor-Essex region and all the other study sites used the specific wind classification measurements based on that specific location.

In order to capture the changes in deaths and illnesses that occur during a smog event, the day before and two days after the smog event were also used for each event. Since the occurrence of smog events during each year was quite high, only one smog advisory per year was analyzed. The selection of each event was based on the length of the event. The longest smog event was used to show the association with the lag effects felt days after the smog advisory was issued. Table 2a show the total number of cardiovascular and respiratory-related mortalities that occurred for all study sites during the smog events. These numbers in raw format have not been normalized and represent all 8 regions that are used in this study. Table $2 \mathrm{~b}$ illustrates the total number of cardiovascular and respiratory morbidities that occurred during the smog events for each region. Although these numbers will not be used in the analysis these numbers are to indicate the large number of people affected during a single smog event over the course of 9 years. 
Table 2: Respiratory and Cardiovascular Mortalities during Smog Event Days*

\begin{tabular}{|l|l|l|l|l|l|l|l|l|l|}
\hline $\begin{array}{l}\text { Age } \\
\text { Group }\end{array}$ & 2003 & 2004 & 2005 & 2006 & 2007 & 2008 & 2009 & 2010 & 2011 \\
\hline $0-4$ & 43 & 28 & 53 & 19 & 26 & 12 & 13 & 24 & 12 \\
\hline $5-19$ & 51 & 33 & 88 & 40 & 74 & 26 & 32 & 49 & 20 \\
\hline $20-64$ & 508 & 374 & 856 & 509 & 880 & 507 & 438 & 795 & 359 \\
\hline $65+$ & 1071 & 791 & 1672 & 1155 & 1936 & 1144 & 944 & 1718 & 940 \\
\hline Total & $\mathbf{1 6 7 3}$ & $\mathbf{1 2 2 7}$ & $\mathbf{2 2 6 9}$ & $\mathbf{1 7 2 3}$ & $\mathbf{2 9 1 9}$ & $\mathbf{1 6 8 9}$ & $\mathbf{1 4 7 7}$ & $\mathbf{2 5 8 6}$ & $\mathbf{1 3 3 1}$ \\
\hline
\end{tabular}

This includes the one day before and two days after the longest smog event that occurred in the study sites*

Table 3: Respiratory and Cardiovascular Morbidities during Smog Event Days*

\begin{tabular}{|l|l|l|l|l|l|l|l|l|l|}
\hline $\begin{array}{l}\text { Age } \\
\text { Group }\end{array}$ & 2003 & 2004 & 2005 & 2006 & 2007 & 2008 & 2009 & 2010 & 2011 \\
\hline $0-4$ & 111 & 99 & 174 & 105 & 145 & 52 & 50 & 132 & 56 \\
\hline $5-19$ & 232 & 157 & 418 & 215 & 395 & 160 & 113 & 287 & 133 \\
\hline $20-64$ & 530 & 467 & 837 & 506 & 937 & 542 & 473 & 821 & 518 \\
\hline $65+$ & 244 & 234 & 454 & 342 & 652 & 387 & 397 & 699 & 512 \\
\hline Total & $\mathbf{1 1 2 0}$ & $\mathbf{9 6 0}$ & $\mathbf{1 8 8 3}$ & $\mathbf{1 1 7 1}$ & $\mathbf{2 1 3 2}$ & $\mathbf{1 1 4 4}$ & $\mathbf{1 0 3 6}$ & $\mathbf{1 9 4 2}$ & $\mathbf{1 2 2 2}$ \\
\hline
\end{tabular}

This includes the one day before and two days after the longest smog event that occurred in the study sites*

\subsection{Results}

After compiling data into map series, qualitative observations were made for each smog event which specifies the areas that were experiencing the highest deaths, illnesses and the associated wind direction. Other observations that were made for the smog events were the overall effects which included; the areas that experienced the highest and lowest deaths, highest and lowest illnesses during specific days in each smog episode. Maximum temperature for those days was also considered to perhaps verify why regions had lower number of deaths or illnesses due to a lower temperature. Table 4 illustrates the areas with the highest death and illness rates along with the direction of wind 2 to 3 days prior to the smog day, which can be found at the end of this section. 


\subsection{Smog Advisory Spatial Analysis:}

Study Sites in Southern, Ontario, Canada

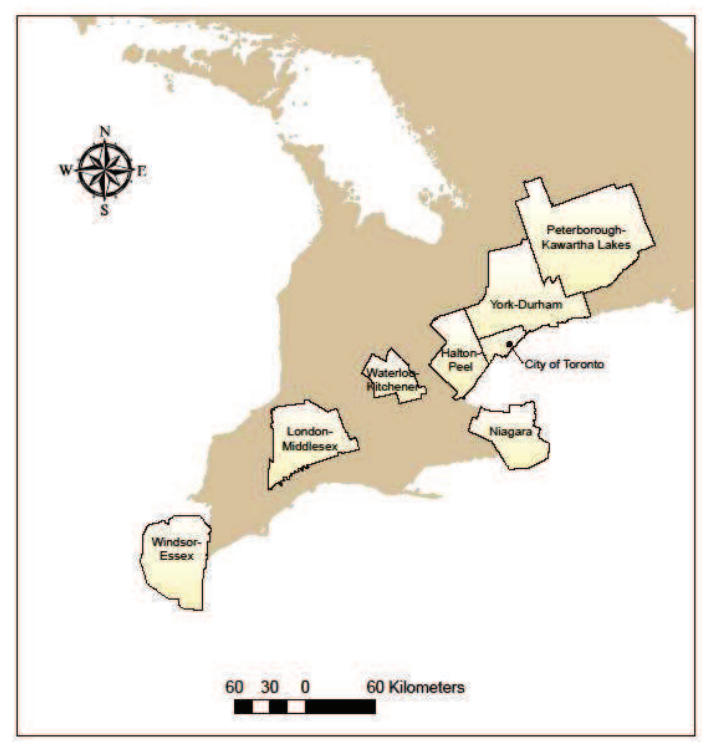

Figure 4: Map of Study Sites.

\subsubsection{Smog event 2003:}

In 2003 there was an average of 5 smog advisories for the chosen regions, Windsor consisted of 6 smog advisories. The selected smog advisory was the first smog event of 2003 and affected all study sites along the corridor. During this smog event, the average number of smog days was 4, with the exception of Windsor, which had 5 smog days. Since the longest smog event was used to determine the days of data collection, the London-Middlesex, WaterlooKitchener, Halton-Peel, Niagara, City of Toronto, York-Durham and Peterborough-Kawartha Lakes regions had 2 pre-days. All sites smog advisories ended on the same day (June $26^{\text {th }}$ ), resulting in the same two post-days after the event. From visual interpretation, the following observations were made: 
Day 1 - June 21, 2003 - During the first day of observations, all regions are in a pre-day of a smog advisory. During a pre-day observation, the highest number of deaths occurred in WindsorEssex at 4.6 deaths per 100,000 with wind blowing from the southeast. The second highest deaths occurred in Niagara Region at 4 deaths per 100,000 with winds blowing from the southwest direction. Niagara also had the highest number of illnesses on pre-day 1, with 4 illnesses per 100,000 people.
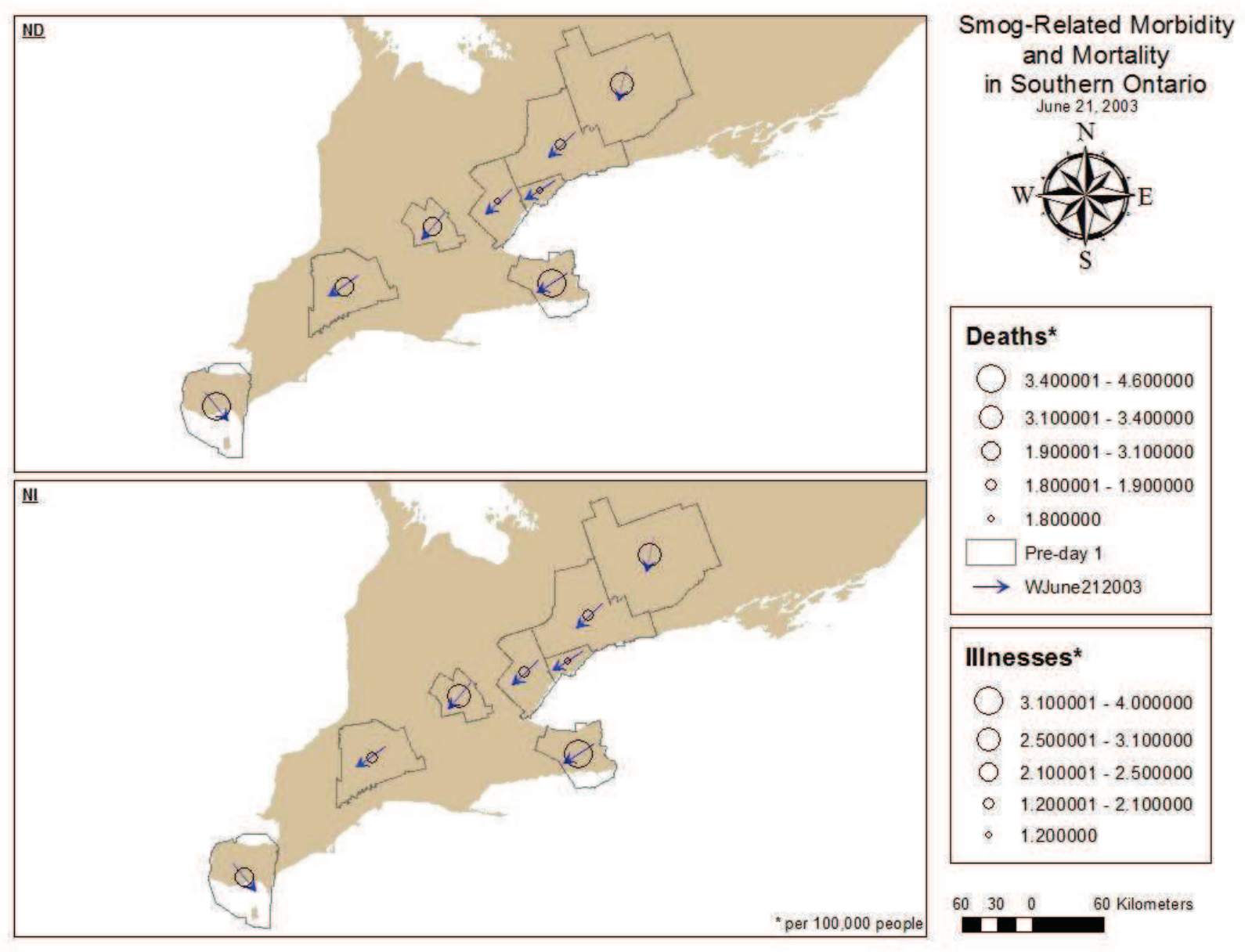

IIInesses*

( $3.100001-4.000000$

( $2.500001-3.100000$

O $2.100001-2.500000$

- $1.200001-2.100000$

- 1.200000

$\begin{array}{lll}60 & 30 & 0\end{array}$

$\begin{array}{rrr}30 & 0 & 60 \text { Kilometers }\end{array}$

Figure 5: Map of Day 1 - June 21, 2003 
Day 2 - June 22, 2003 - In Windsor- Essex, a smog event was issued; however, the other study sites were still in a non-smog episode. The highest number of deaths on this day occurred in Windsor-Essex and Peterborough-Kawartha Lakes regions. Although the Windsor-Essex area was in a smog advisory, the number of deaths was lower at 3.8 per 100,000 compared to 3.9 per 100,000 in Peterborough-Kawartha Lakes region. The wind direction for Windsor area was in the south-southwest origin while the Peterborough region had a west-southwest direction. The area that contained the highest number of illnesses was in Niagara with at 4.9 per 100,000 people with a wind direction from the southwest.
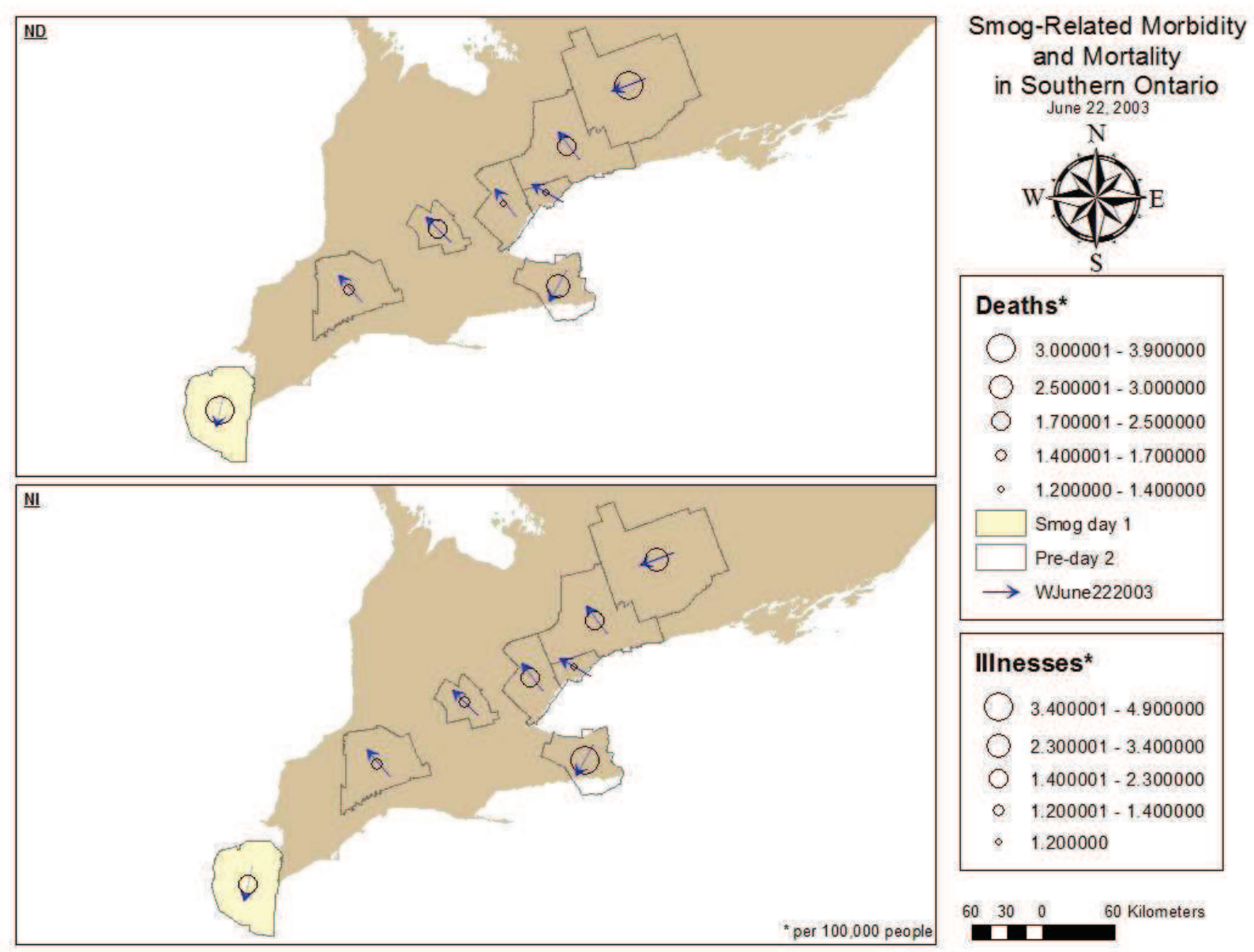

Figure 6: Map of Day 2 - June 22, 2003 
Day 3 - June 23, 2003 - During the third day, all areas are in a smog advisory, with WindsorEssex being in its second smog day. The area that contained the highest number of cardiovascular and respiratory deaths was Windsor-Essex and Niagara. The number of deaths for the Windsor area was 6.7 per 100,000 people with wind coming from the west and Niagara had 6.3 deaths per 100,000 people with winds from the southwest. The highest number of illnesses occurred in Peterborough accounting for 6.3 deaths per 100,000 people with wind direction from the west.
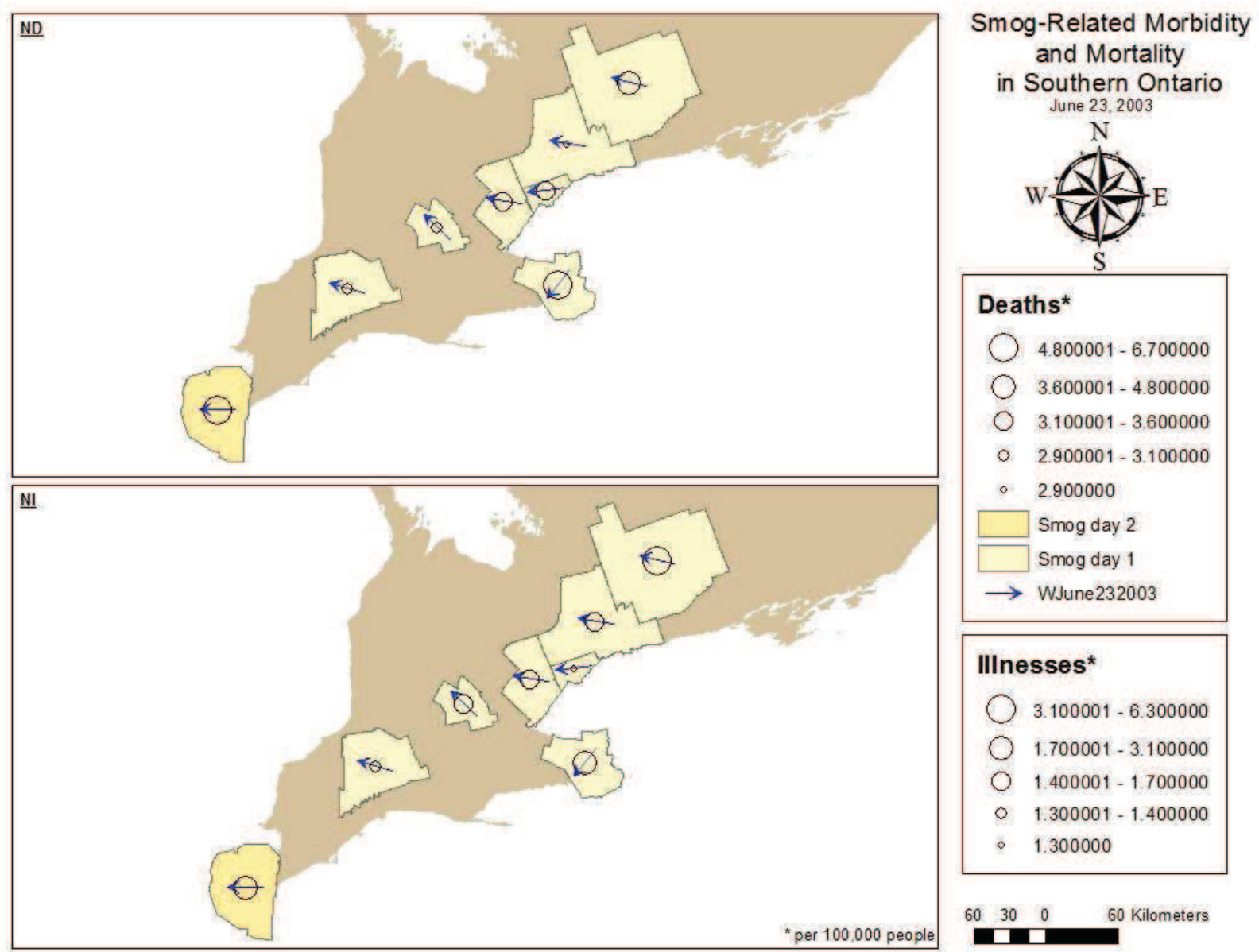

Figure 7: Map of Day 3 - June 23, 2003 
Day 4 - June 24, 2003 - The highest numbers of deaths occurred in the Windsor area with 6.6 deaths per 100,000 people. Peterborough resulted in the highest number of deaths at 6.7 deaths per 100,000 people and Niagara had 4.2 mortalities per 100,000 people. For each of these regions, the wind direction was from the southwest, supporting the research hypothesis. The highest illnesses also occurred in Peterborough and Niagara regions with 6.6 per 100,000 people and 5.2 per 100,000 people. The reasoning for the Peterborough area resulting in high morbidity and mortality could be due to the impact of air pollution from the Greater Toronto Area (GTA).
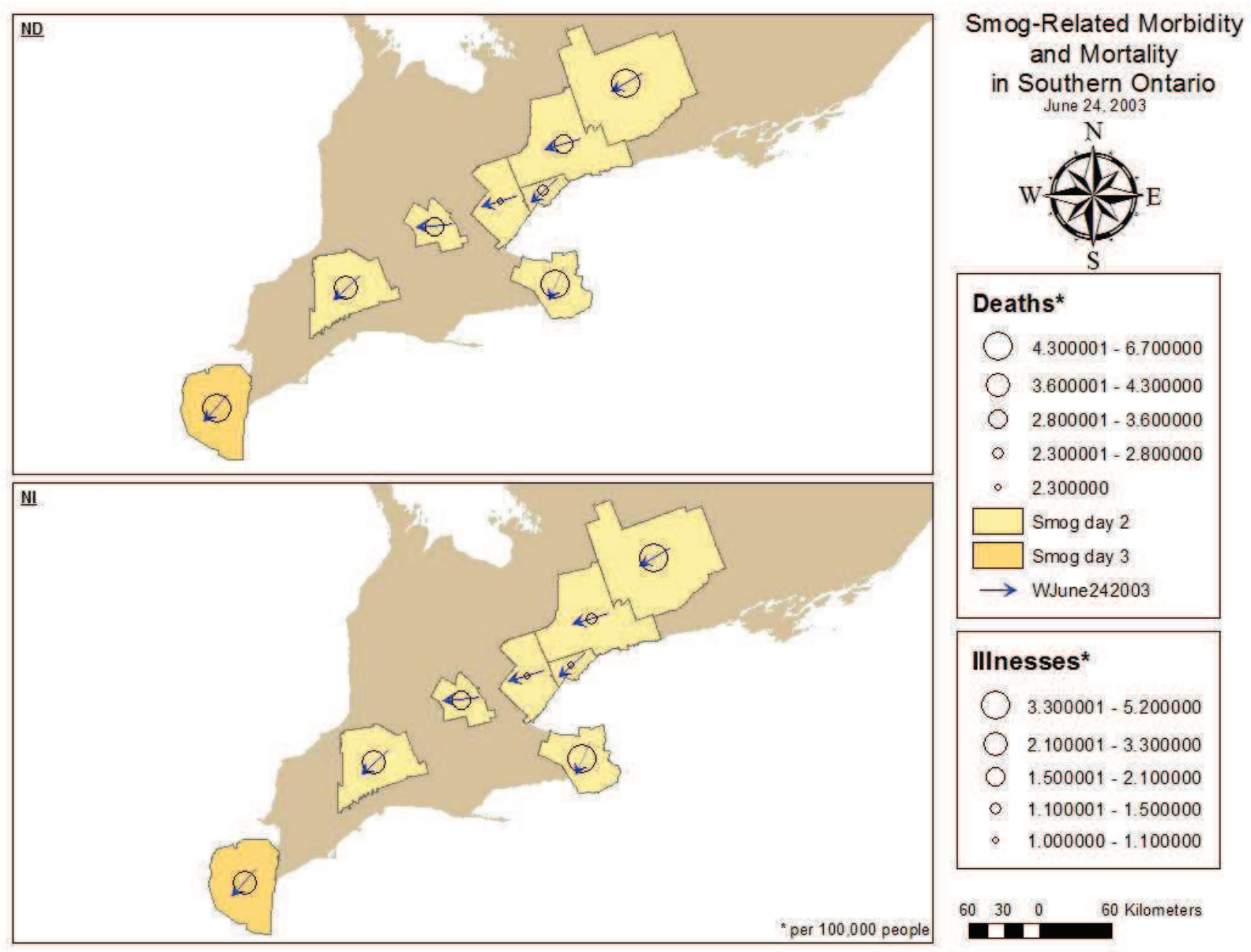

Figure 8: Map of Day 4 - June 24, 2003 
Day 5 - June 25, 2003 - During the fifth day of observation, Windsor-Essex is in its $4^{\text {th }}$ smog day while all other study sites are in the $3^{\text {rd }}$ smog day. The highest number of deaths experienced during the fifth was in Windsor with 7.4 per 100,000 people which accounts for a 2-3 day lag effect that could explain the higher number of deaths that occurred in Windsor. The highest number of illnesses that occurred was observed in Windsor and Peterborough with 4.3 in Windsor and 4.8 per 100,000 people in the Peterborough area. For both of these regions, the wind was moving from the southwest.
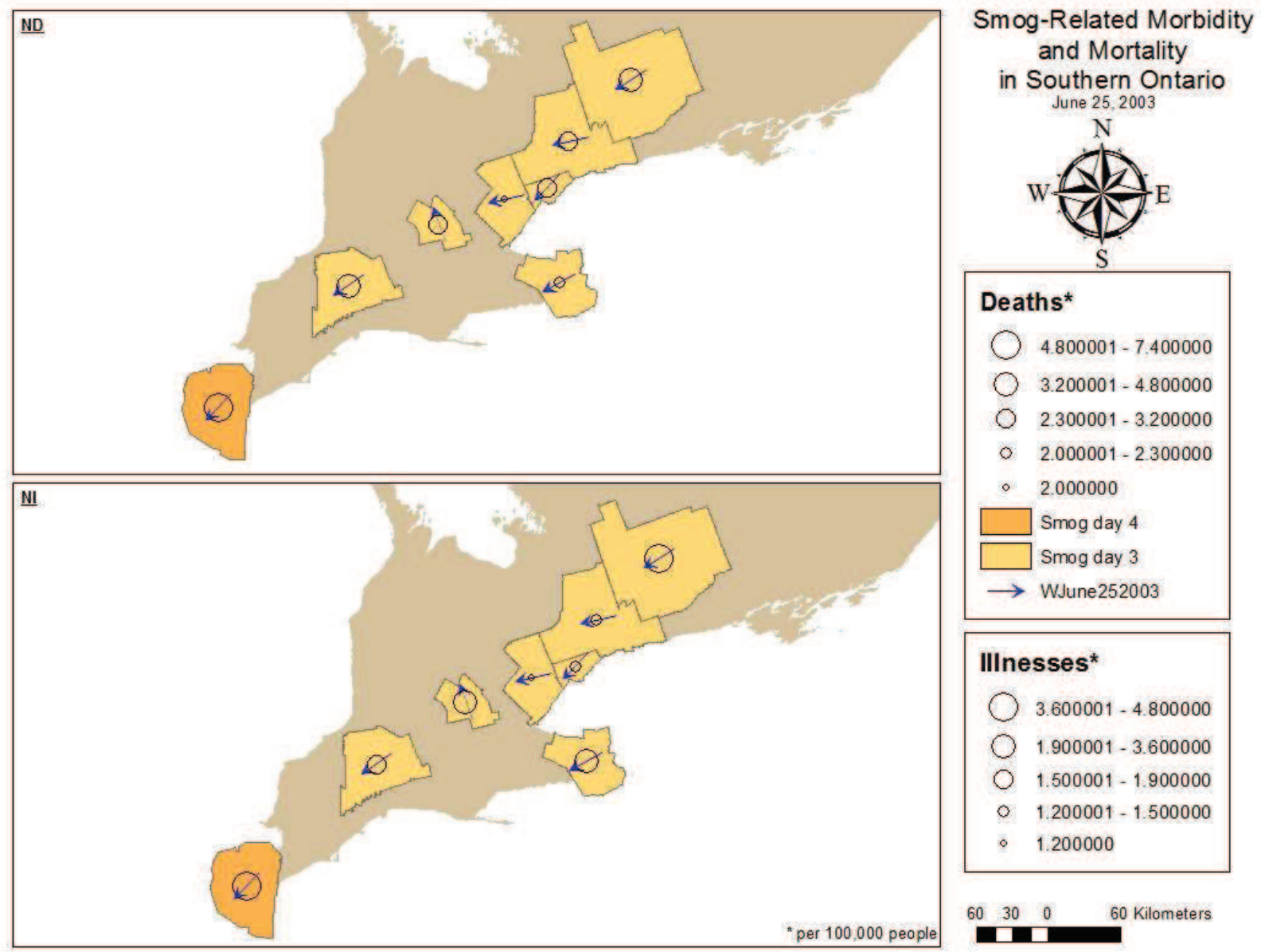

Figure 9: Map of Day 5 - June 25, 2003 
Day 6 - June 26, 2003 - On the last smog day for all regions, Peterborough experienced the highest number of deaths and illnesses. There were 6.7 mortalities and 3.4 morbidities per 100,000 people. The wind direction for Peterborough during the $4^{\text {th }}$ smog day was southwest.
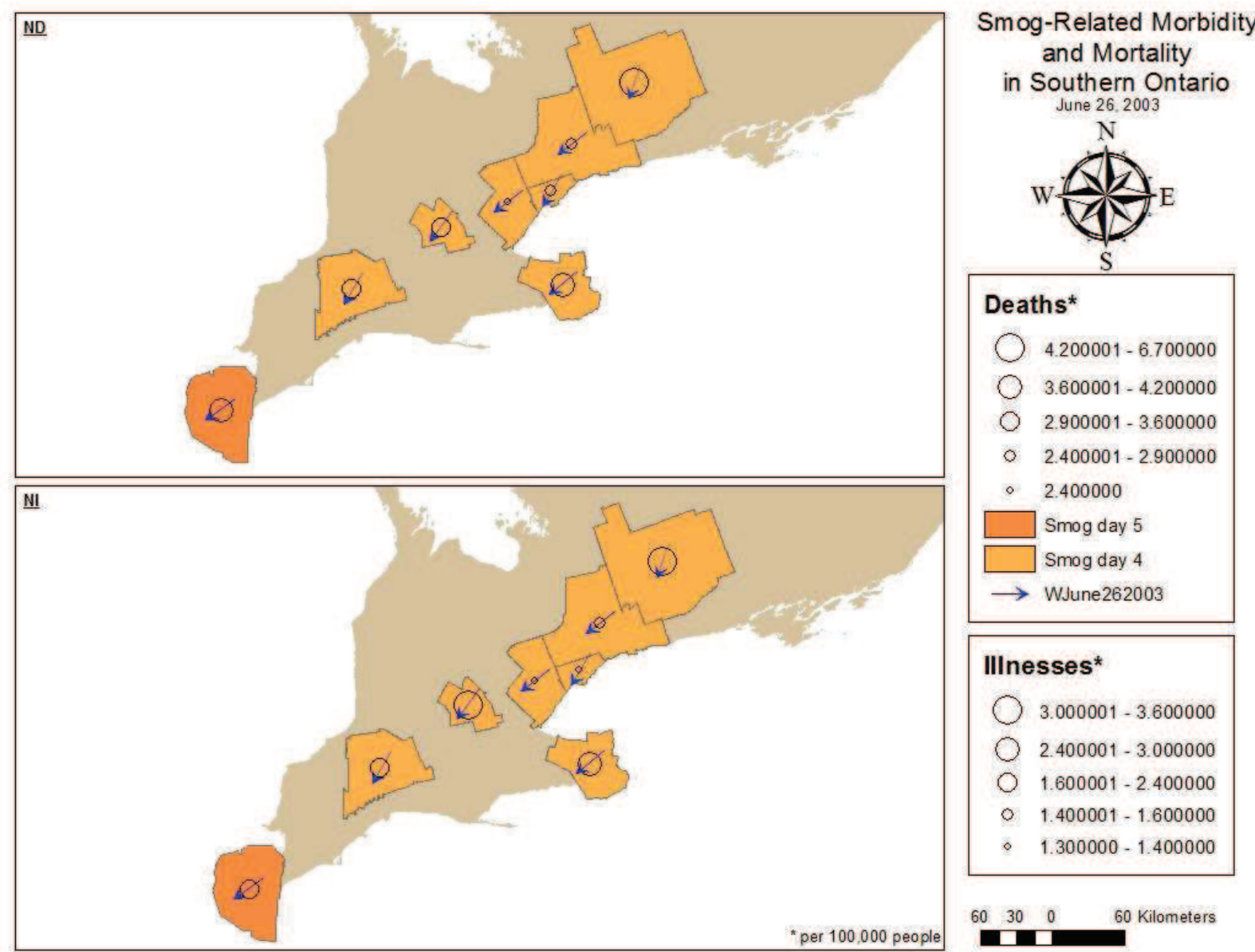

\section{IIInesses*}

( $3.000001-3.600000$

() $2.400001-3.000000$

( $1.600001-2.400000$

- $1.400001-1.600000$

- $1.300000-1.400000$ 
Day 7 - June 27, 2003 - The first post-day after the smog event still yielded a number of cardiovascular and respiratory morbidity and mortality cases due to lag effects of high levels of air contaminants. London-Middlesex region yielded the highest number of deaths at 5.2 per 100,000 people with winds moving from the southwesterly direction. Niagara and Peterborough had the highest number of illnesses with 3.7 and 3.4 per 100,000 people.

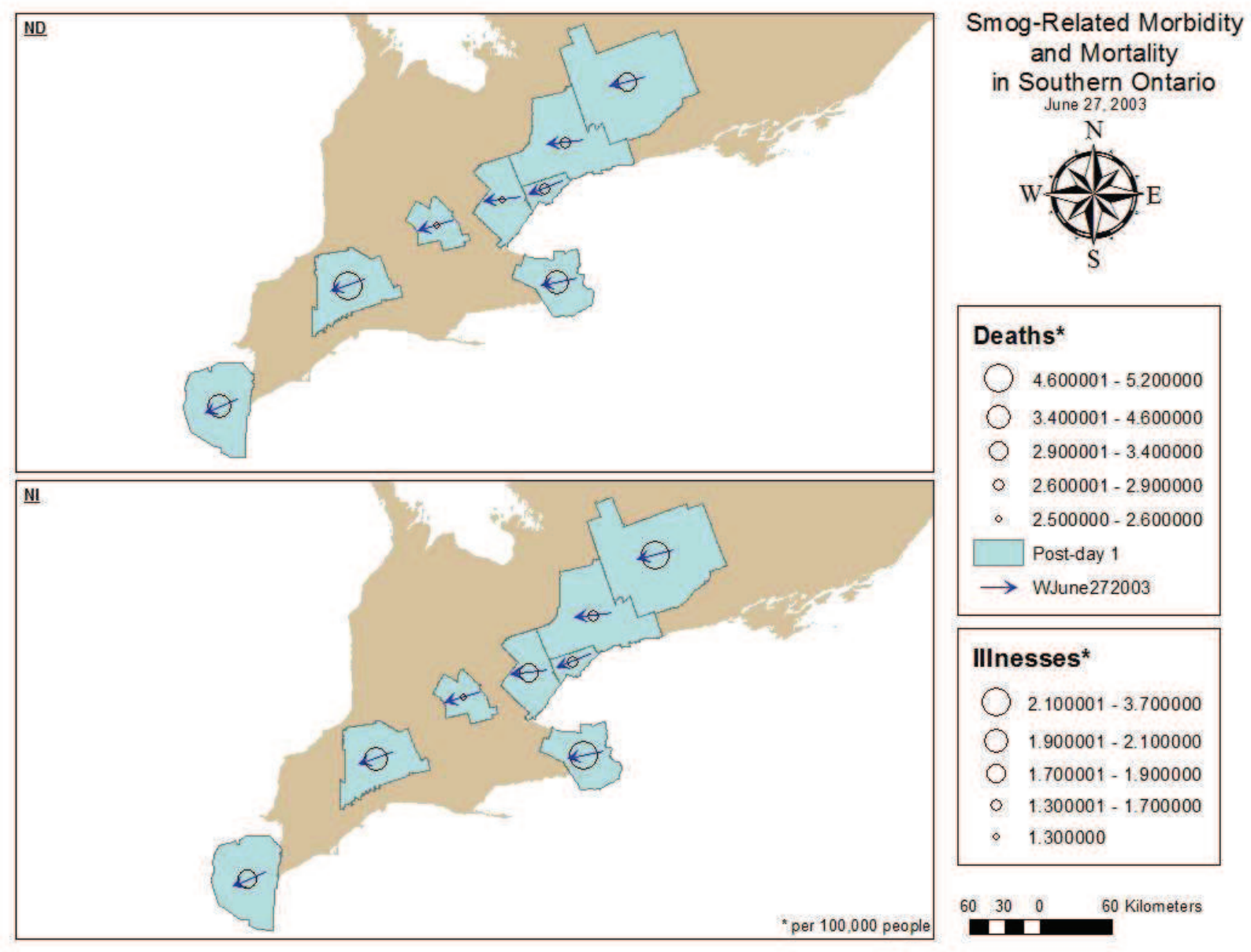

Figure 11: Map of Day 7 - June 27, 2003 
Day 8 - June 28, 2003 - The second post day should also yield numbers of deaths and illness. The area with the highest deaths was Peterborough-Kawartha lakes region with 7.2 deaths per 100,000 people and 3.9 illnesses per 100,000 while the average wind direction moving from the southwest. The regions with the highest levels of illnesses are the Niagara region with 4.2 illnesses per 100,000 with wind direction also from the southwest.
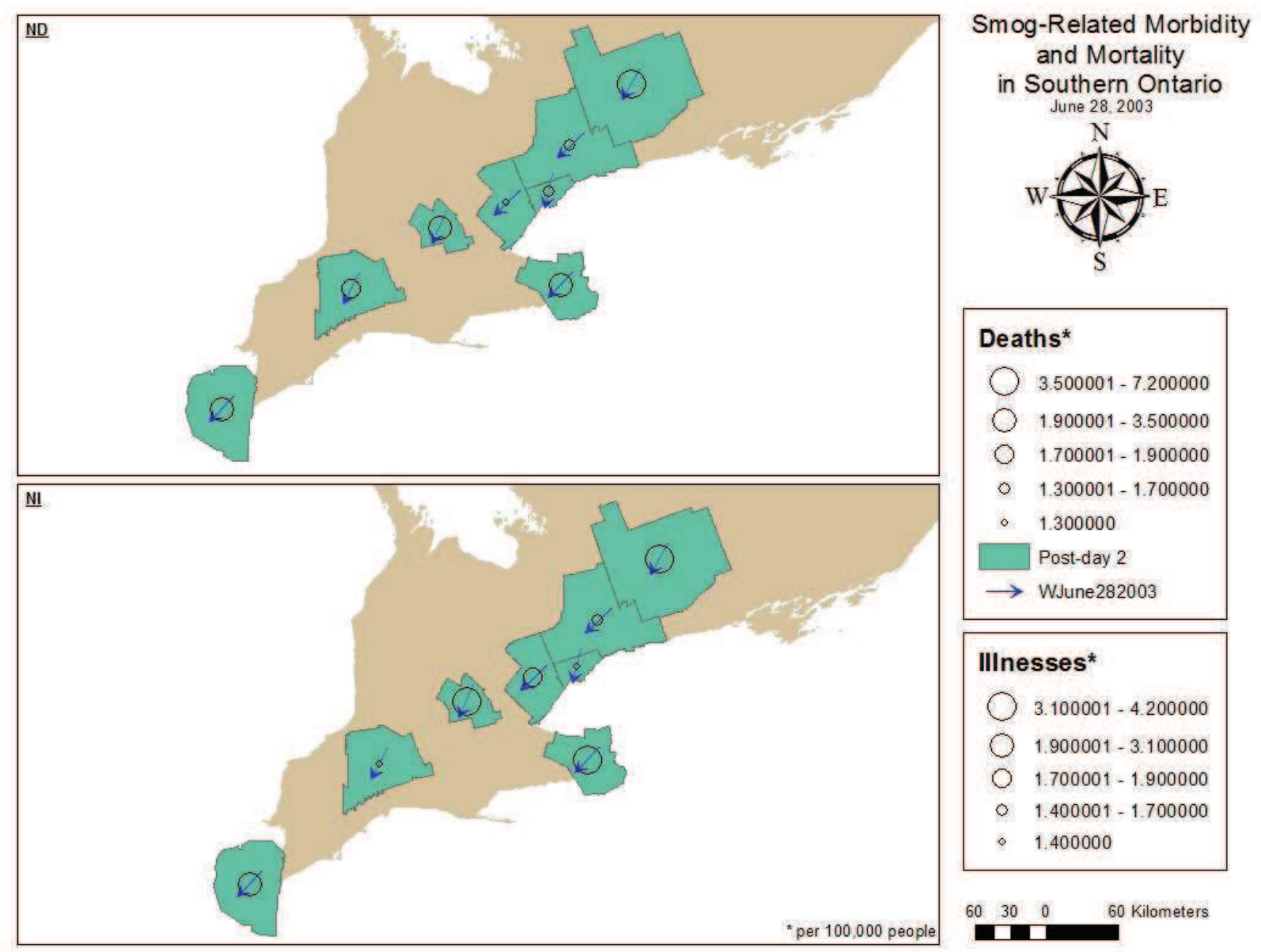

IIInesses*

( $3.100001-4.200000$

( $1.900001-3.100000$

C $1.700001-1.900000$

- $1.400001-1.700000$

- 1.400000

Figure 12: Map of Day 8 - June 28, 2003 


\section{Summary of Smog Event 2003:}

The overall observations from the 2003 smog advisory resulted in the highest number of deaths in Windsor-Essex during the $4^{\text {th }}$ smog day with 7.4 deaths per 100,000 people. During this day, the average temperature in Windsor was 27 degrees Celsius with southwest winds. The lowest deaths that occurred during the smog event happened in the City of Toronto during the second pre-day at 1.2 per 100,000 people. The average temperature was 22.8 degrees Celsius with winds moving from the northwest-north. The illnesses rates during the smog event were the highest in Peterborough at 6.3 per 100,000 with an average temperature of 22.6 degrees Celsius with winds from the northwest-north. The lowest illness rate during the smog event was in the City of Toronto on smog day 2 with 1 person per 100,000 people. The average winds were moving from the southwest during second smog day in Toronto.

The Peterborough-Kawartha Lakes region could be experiencing high levels of illness and death due to the contribution of two sources; the transboundary contribution as well as air pollution created in the GTA. Based on the location of Peterborough in conjunction to the GTA which consists of the three largest regions in this study; Halton-Peel, City of Toronto and YorkDurham, it would be assumed that Peterborough would experience these high levels of morbidity and mortality from the two contributing pollution sources as well as the role of wind direction as it moves across Southern Ontario. 


\subsubsection{Smog Event 2004:}

During 2004, an average of 6 smog advisories were experienced in the study sites which the exception of Niagara and Waterloo-Kitchener which experienced 5 smog advisories. The 5 advisory consisted of an average of 3 smog days and was selected not solely based on length but also on meteorological data availability since the Niagara region was missing data in a later smog advisory. Another motive for choosing this specific advisory was based on the length of the smog advisories for all regions. An earlier smog advisory could have been selected for observations, however, the average smog days were 2 .

All regions with the exception of Peterborough had a 3 day length smog advisory. The Peterborough-Kawartha Lakes smog advisory lasted 2 days and ended on September $5^{\text {th }}$. This means that this region had 3 post-days occur from the $6^{\text {th }}$ of September to the $8^{\text {th }}$ while all other regions had 2 post-days. From visual interpretation, the following observations were made: 
Day 1 - September 3, 2004 - The pre-day of this smog event revealed the highest number of deaths and illnesses in Peterborough-Kawartha Lakes region with the wind direction moving from the southwest. There were 5.8 deaths and illnesses per 100,000 people.
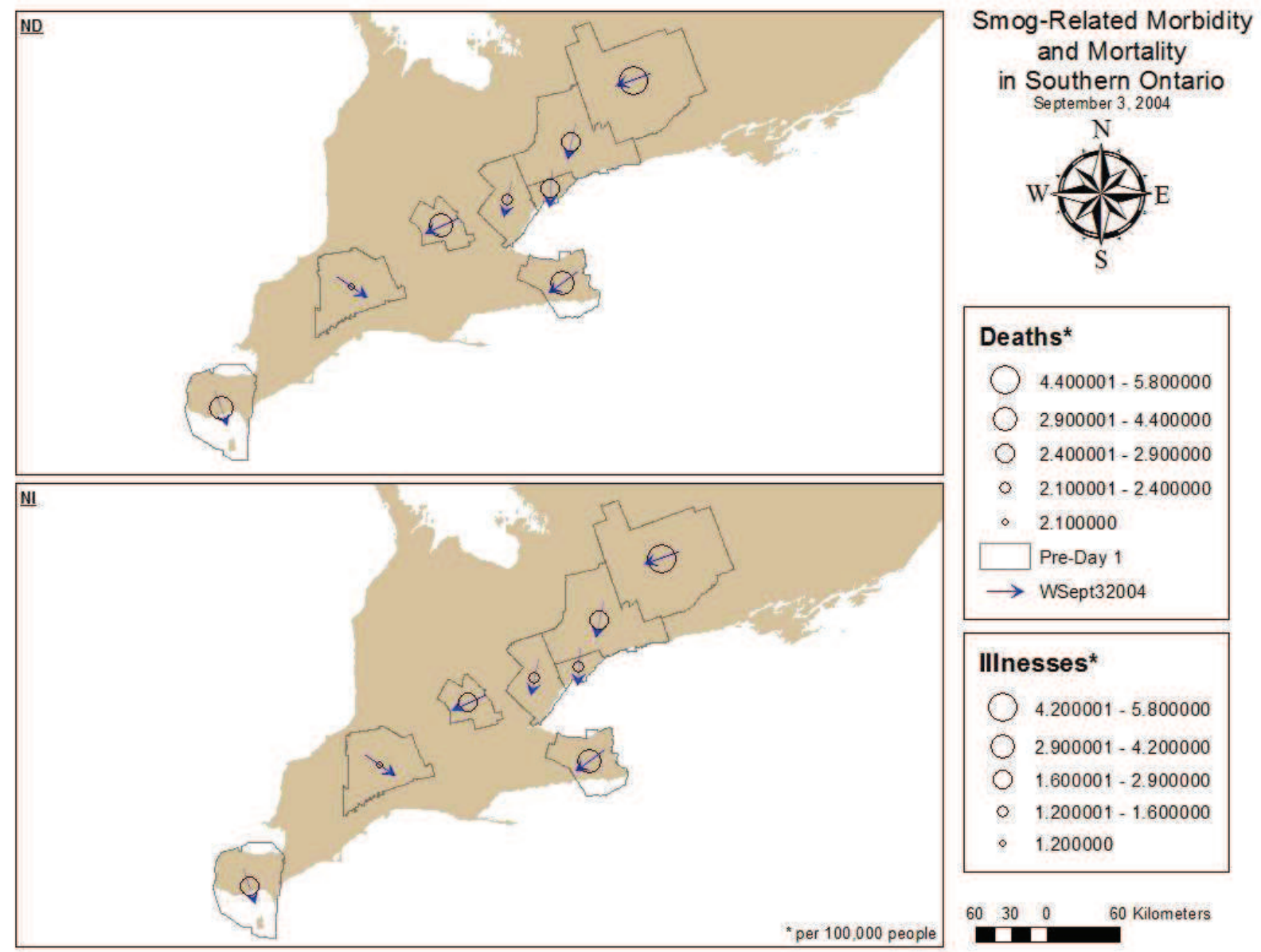

IIInesses*

( $4.200001-5.800000$

() $2.900001-4.200000$

( $1.600001-2.900000$

- $1.200001-1.600000$

- 1.200000

Figure 13: Map of Day 1 - September 3, 2004 
Day 2 - September 4, 2004 - For the first smog day, Peterborough region had the highest number of deaths with 4.3 deaths per 100,000 people with winds moving in from the southeast. The highest number of illnesses occurred in the Niagara region with 3.3 illnesses per 100,000 and Windsor-Essex with 3.1 illnesses. The wind direction for both these regions was also from a southeastern path.
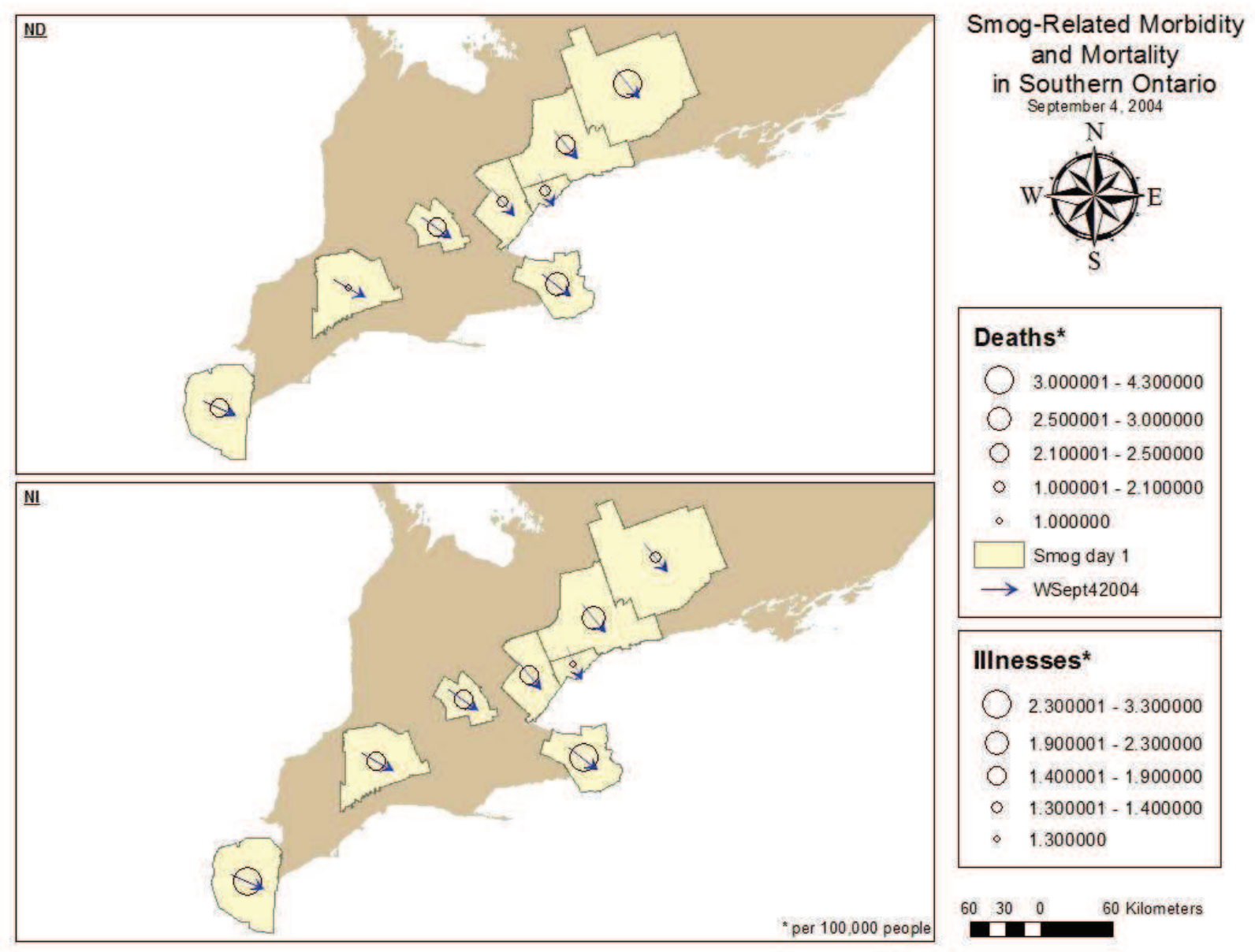

\section{Deaths*}

( $3.000001-4.300000$

$2.500001-3.000000$

$2.100001-2.500000$

$1.000001-2.100000$

- 1.000000

Smog day 1

WSept42004

\section{IIInesses*}

$2.300001-3.300000$

( $1.900001-2.300000$

O $1.400001-1.900000$

- $1.300001-1.400000$

- 1.300000

Figure 14: Map of Day 2 - September 4, 2004 
Day 3 - September 5, 2004 - During the second smog day, the wind direction for the regions experiencing the highest level of deaths and illnesses was from the southeasterly direction. Windsor-Essex experienced 3.1 deaths per 100,000 people and the Peterborough-Kawartha Lakes had 3.4 deaths and 3.9 illnesses per 100,000 people. The Niagara region also had the second highest illness rate at 3.3 per 100,000 people.

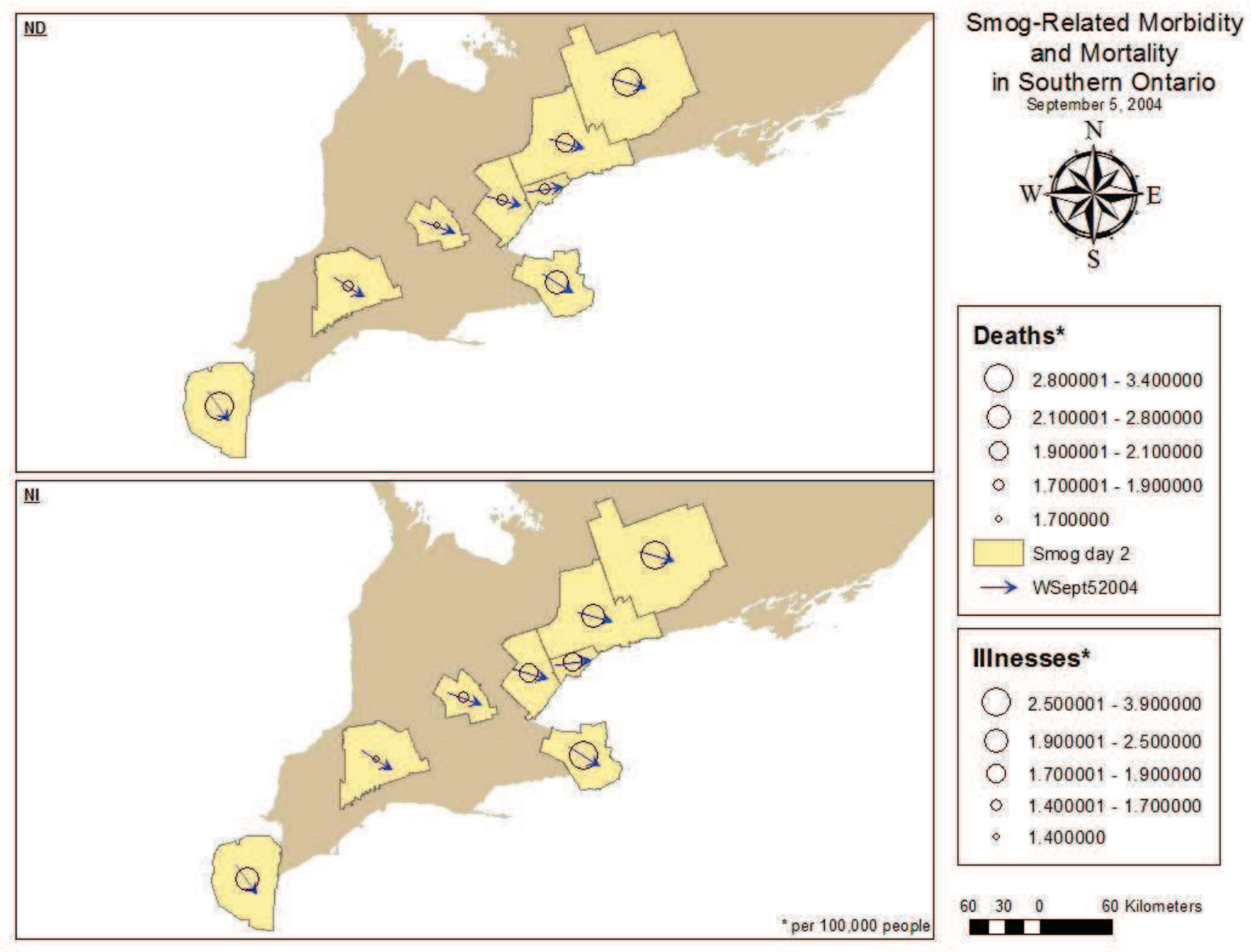

Figure 15: Map of Day 3 - September 5, 2004 
Day 4 - September 6, 2004 - All regions, except for the Peterborough Kawartha Lakes had a 3 day smog advisory. During the third smog day, Windsor-Essex and Niagara Region experience the highest level of deaths with Windsor at 4.8 deaths and Niagara 4.7 per 100,000 people. The direction of wind for Windsor was from the south while the Niagara region experienced southwesterly winds. The Peterborough Kawartha Lakes region was in post-day 1 and experienced the highest level of illnesses at 6.7 per 100,000 people with winds moving from the southeast, showing potential lag effects from the previous 2 to 3 days.
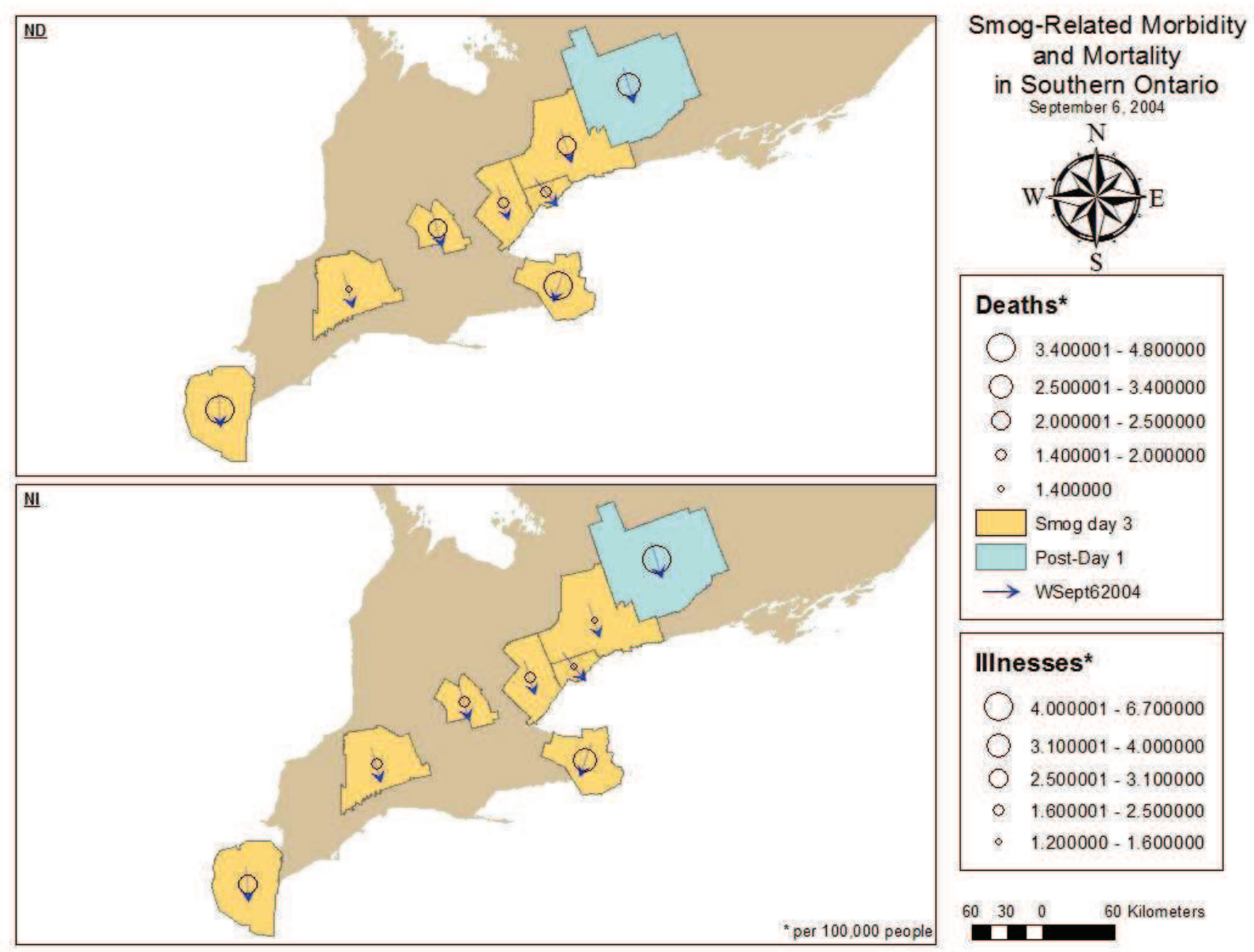

Figure 16: Map of Day 4 - September 6, 2004 
Day 5 - September 7, 2004 - All regions were in post-days, with the majority being in the first post-day while Peterborough-Kawartha Lakes was in its second post-day. The highest death rates were in the Windsor-Essex region with 6.4 cardiovascular and respiratory mortalities and the Peterborough region had 6.3 deaths per 100,000 people. The wind direction for Windsor region was moving from the south and the Peterborough region had westerly winds. The higher death rate could also be indicative of the lag effects that occur from high levels of air contaminants.
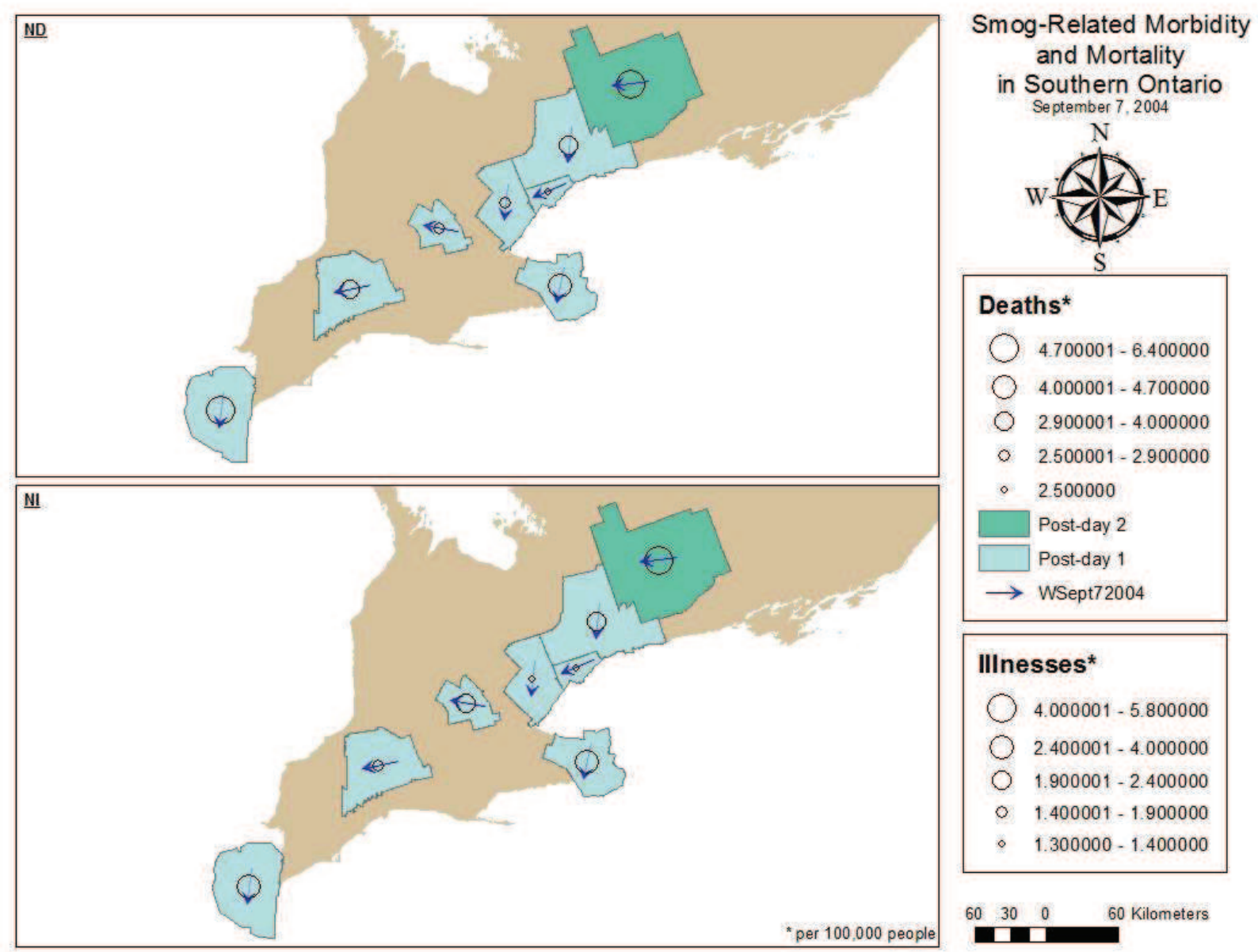

Figure 17: Map of Day 5 - September 7, 2004 
Day 6 - September 8, 2004 - The third post-day for Peterborough- Kawartha Lakes had 5.6 deaths and 8.2 illnesses per 100,000 people with winds from the east. During the second post-day for the Windsor region, there were 5.1 deaths per 100,000 people with a northeasterly wind direction.
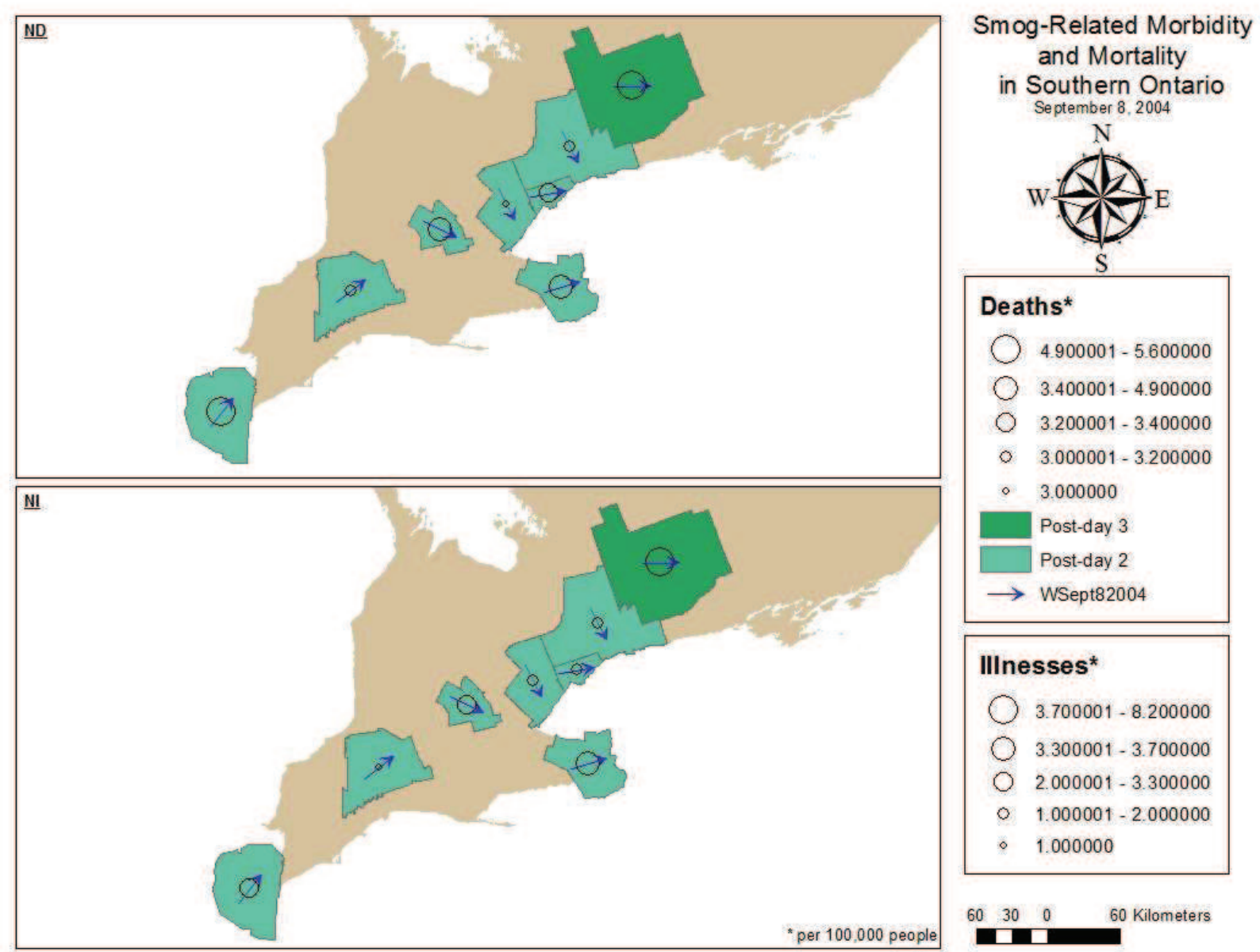

\section{IIInesses*}

$3.700001-8.200000$

() $3.300001-3.700000$

O $2.000001-3.300000$

- $1.000001-2.000000$

- 1.000000

Figure 18: Map of Day 6 - September 8, 2004 


\section{Summary of Smog Event 2004:}

The overall effects of mortality and morbidity in Southern Ontario during the longest 2004 smog advisory resulted in the highest death rate in Windsor at 6.4 per 100,000 persons during post-day 1 with an average temperature for that region at 27.4 degrees Celsius with southerly winds. The lowest deaths were in the London-Middlesex area with 1 death per 100,000 people that occurred during the first smog day. The average temperature for the London region was 21 degree Celsius with east-southeasterly winds. The illness rates were highest in the Peterborough region during the third post-day with 8.2 illnesses per 100,000 people. The average temperature for that particular day was 15.7 degrees Celsius with easterly winds. The reason for this high level of illnesses that occurred days after the smog advisory is likely due to the lag effects following the first or second smog day in Peterborough. The lowest illness numbers were also found in the London-Middlesex area with 1 illness per 100,000 people during the second post-day. The average temperature for that day was 16.5 degree Celsius from the northeastern direction.

\subsubsection{Smog Event 2005:}

In 2005, there was an average of 13 smog advisories issued in the 8 study sites. The longest smog advisory chosen had an average of 7 smog days. The areas with the longest smog advisories were Windsor-Essex and London-Middlesex with 8 smog days. The PeterboroughKawartha Lakes region experienced the shortest smog event of 6 days which began on June $9^{\text {th }}$. All smog advisories end on June $14^{\text {th }}$ and each region had 2 post-days after the last smog day. From visual interpretation, the following observations were made:

Day 1 - June 6, 2005 - During the pre-smog event day, the highest number of deaths and illnesses were experienced in the Peterborough- Kawartha Lakes region with 7.7 deaths and 5.3 illnesses per 100,000 people with winds from the southwest direction. The reason the death and 
illness rate was so high in Peterborough could be due to lag effects since the Peterborough region also had a short smog advisory on June $3^{\text {rd }}$ to the $4^{\text {th }}$ which could account for a 2-3 day lag time.
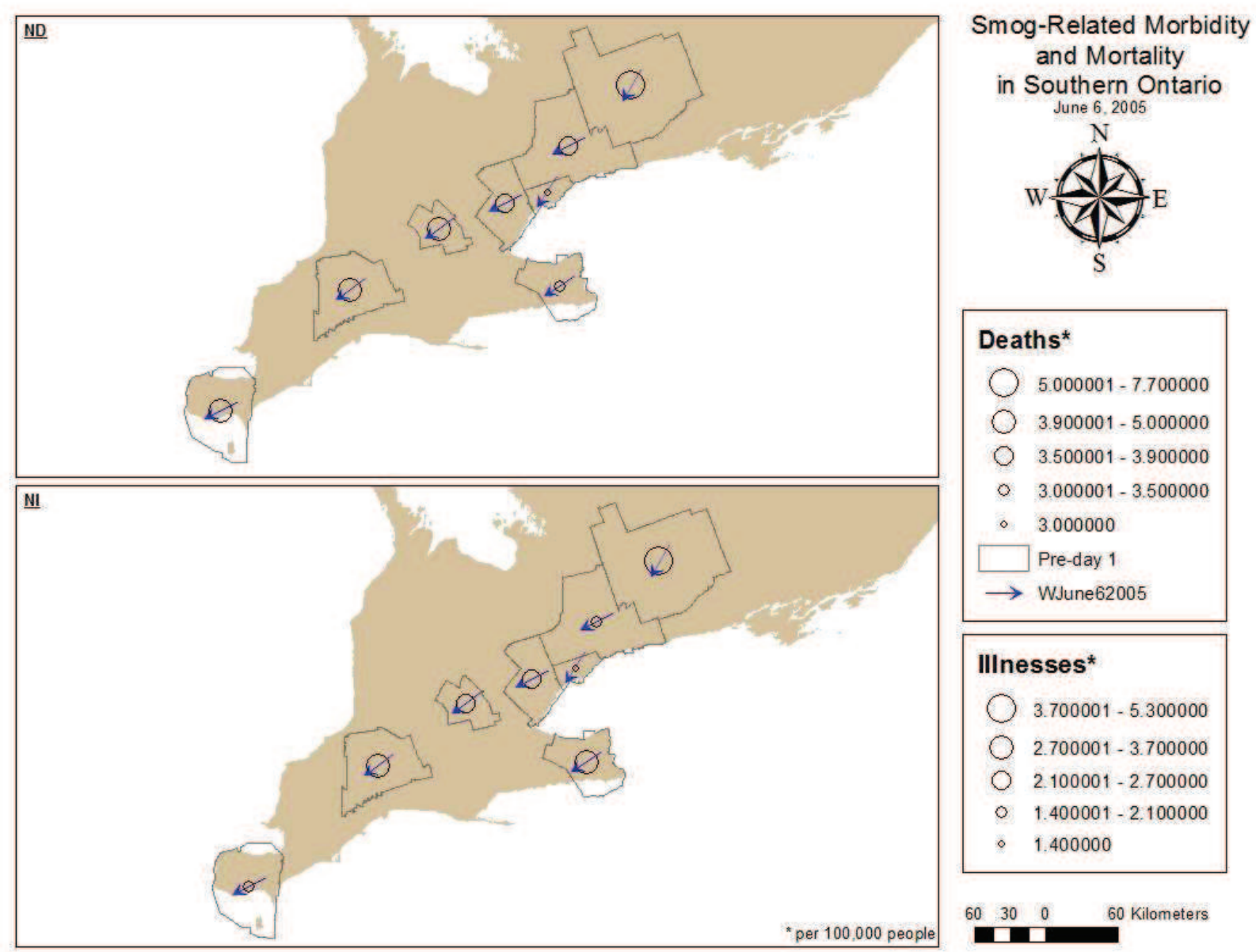

IIInesses*

( $3.700001-5.300000$

() $2.700001-3.700000$

( $2.100001-2.700000$

- $1.400001-2.100000$

- 1.400000

Figure 19: Map of Day 1 - June 6, 2005 
Day 2 - June 7, 2005 - The only two regions that were in the first day of a smog advisory are Windsor-Essex and London-Middlesex. The highest number of deaths occurred during the first smog day in the Windsor-Essex area, with 4.6 deaths per 100,000 people, with winds moving from the southwest. The highest number of illnesses occurred in Peterborough-Kawartha Lakes region during the second pre-day of the smog advisory with 5.8 illnesses, followed by Windsor region with 5.1 illnesses per 100,000 people. The average wind direction in the Peterborough region was moving from the west.
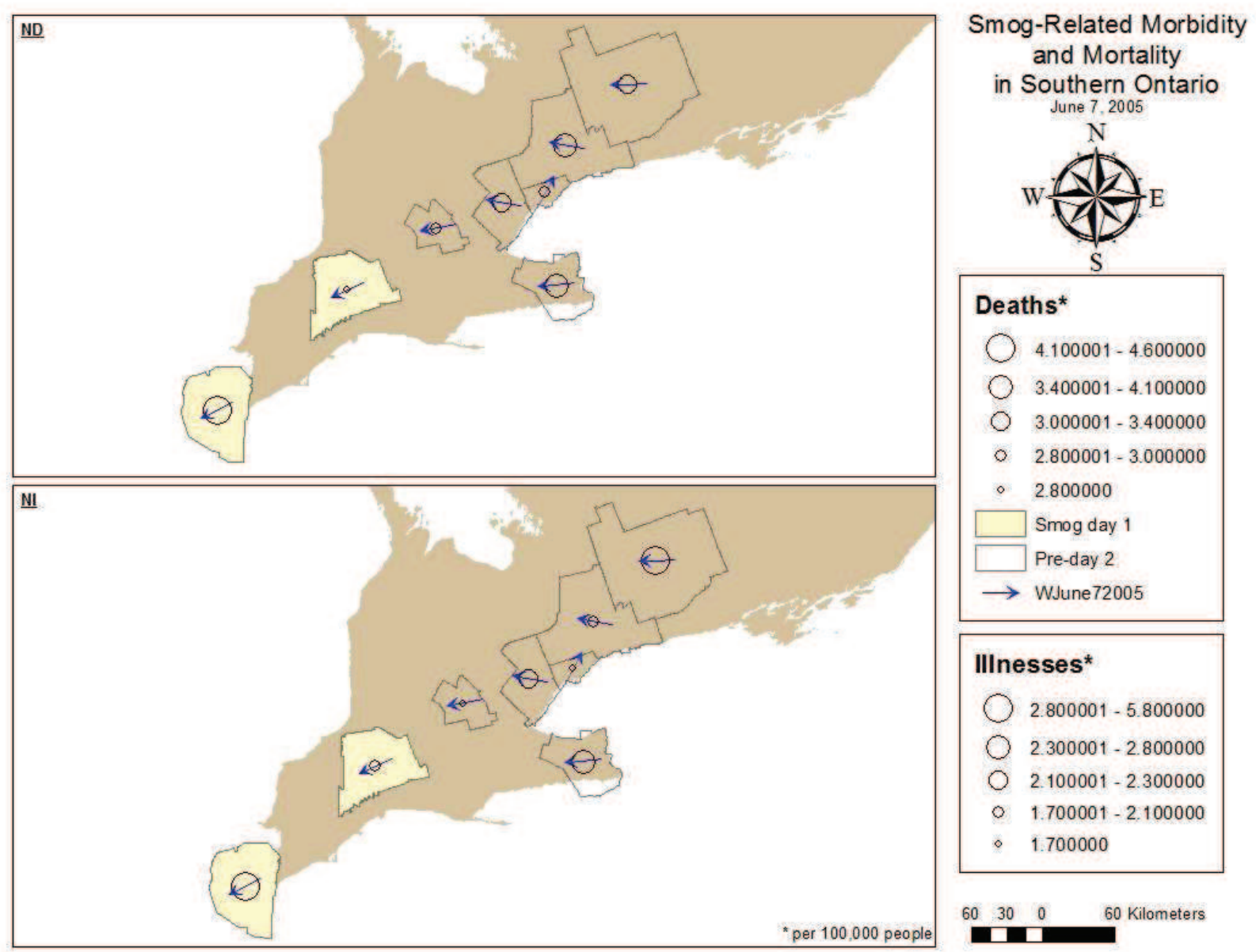

Figure 20: Map of Day 2 - June 7, 2005 
Day 3 - June 8, 2005 - All study sites are in a smog advisory with the exception of the Peterborough-Kawartha Lakes region. The highest death rate was in the Windsor area during its second smog day at 6.4 deaths per 100,000 with winds moving from the southwest. The region with the highest illness rate was the Peterborough region with 5.8 illnesses per 100,000 people with winds moving from the southeast. The second highest illness rate occurred during the first smog day for the Niagara region at 5.2 morbidities per 100,000 people while average wind direction was blowing from the southwest.
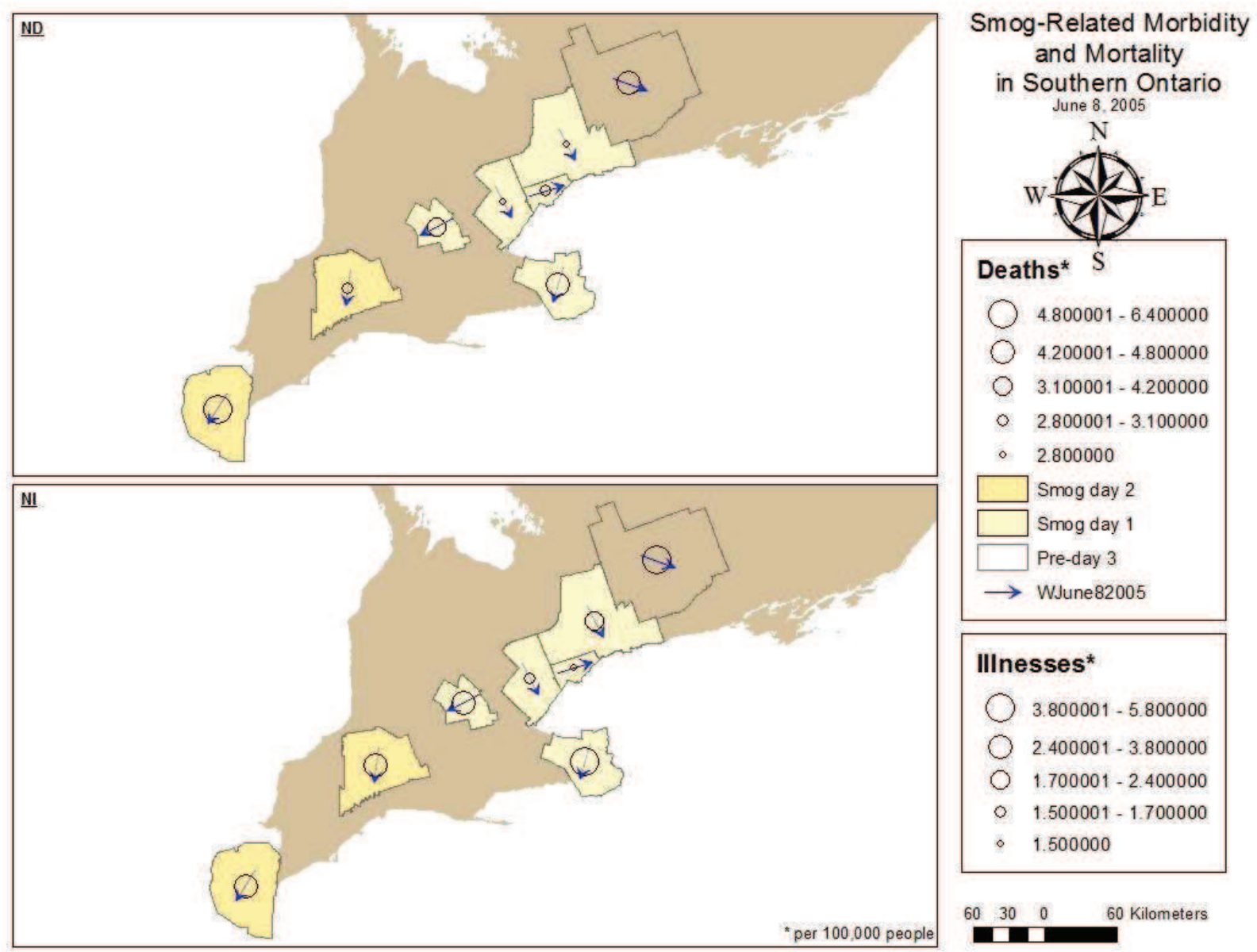

Figure 21: Map of Day 3 - June 8, 2005 
Day 4 - June 9, 2005 - All regions are in a smog advisory, with Windsor-Essex, Niagara, and Peterborough-Kawartha Lakes with the highest morbidity and mortality rates out of all study sites. Each region was in a different day of the smog episode. Niagara, in the second smog day, and Peterborough, in the first smog day, both had the same death rate at 6.3 per 100,000 people and southeasterly winds. Windsor-Essex was in the third smog day and had 6.1 deaths per 100,000 people with south winds. Illnesses in Windsor and Peterborough were the same at 3.8 per 100,000 people, with Niagara region having a rate at 3.1 per 100,000 people.
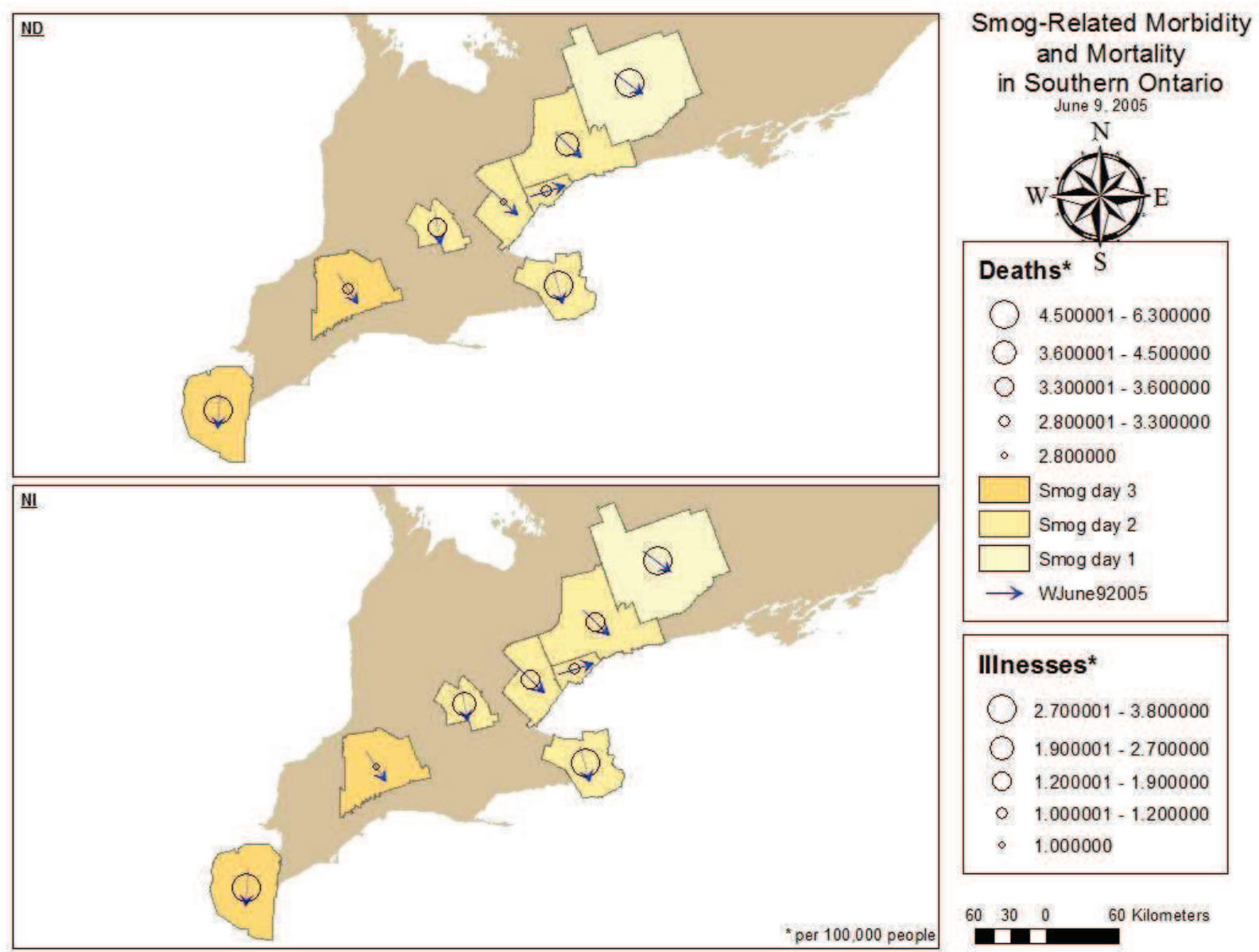

Figure 22: Map of Day 4 - June 9, 2005 
Day 5 - June 10, 2005 - The highest death rates for the fifth day of observation occurred during the fourth smog day in Windsor-Essex and second smog day Peterborough-Kawartha Lakes regions. Peterborough region had 7.2 deaths per 100,000 people with winds moving from a southerly direction. The high level of 7.2 could be lag effects. Windsor region had 6.1 deaths and also had the second highest illness rate at 4.3 illnesses per 100,000 with winds moving from the southwest. The highest rate of illness occurred in the London-Middlesex region during its fourth smog day with 4.5 illnesses per 100,000 with winds moving from the south.
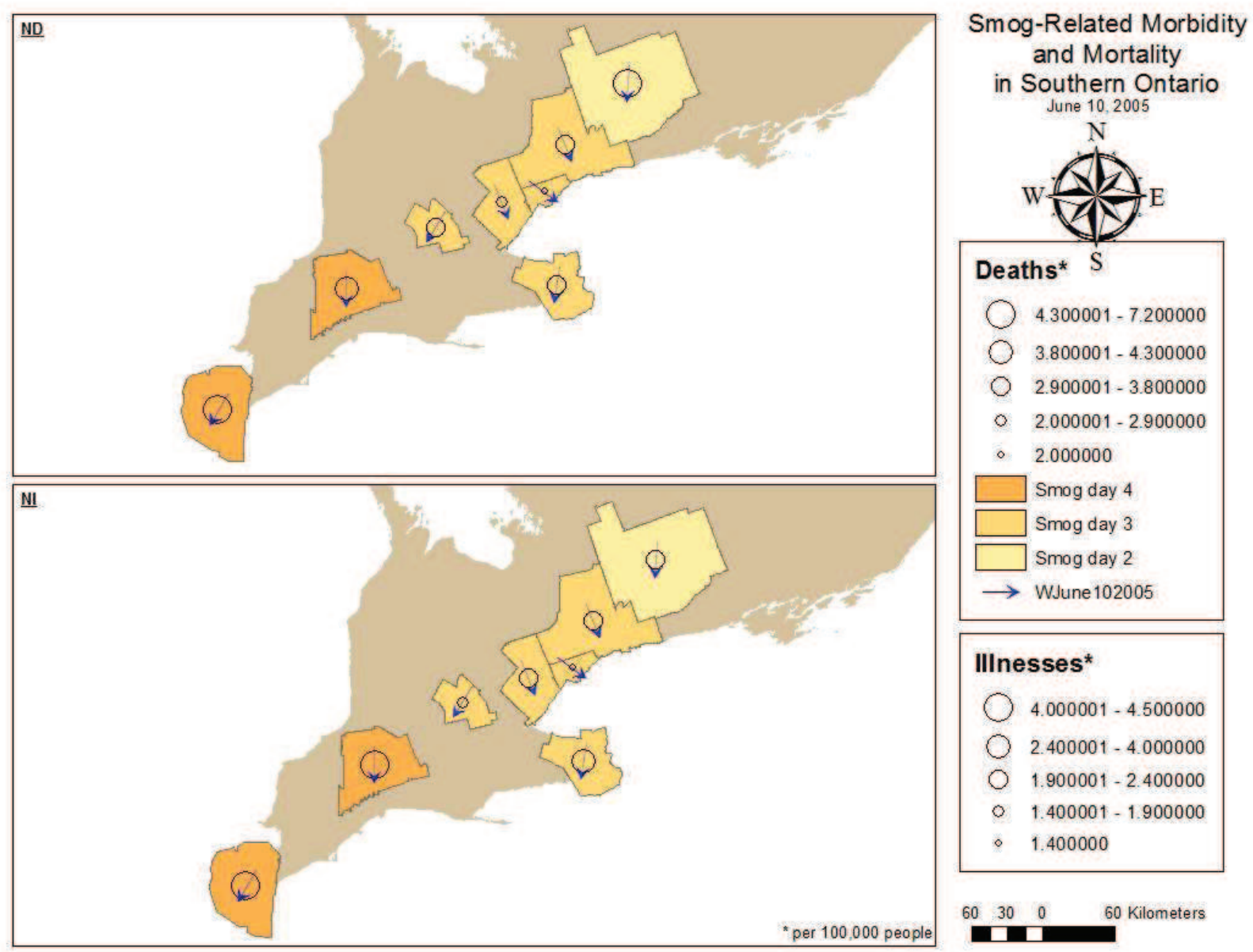

Figure 23: Map of Day 5 - June 10, 2005 
Day 6 - June 11, 2005 - The highest death rates during the $6^{\text {th }}$ day were in the Windsor and Peterborough regions. Peterborough also had the highest illness rate during this day with 6.3 deaths and 8.7 illnesses per 100,000 people. The wind direction for Peterborough was blowing from the south-southeast. Windsor had the second highest deaths with 4.8 deaths per 100,000 people along with winds from the southwest.
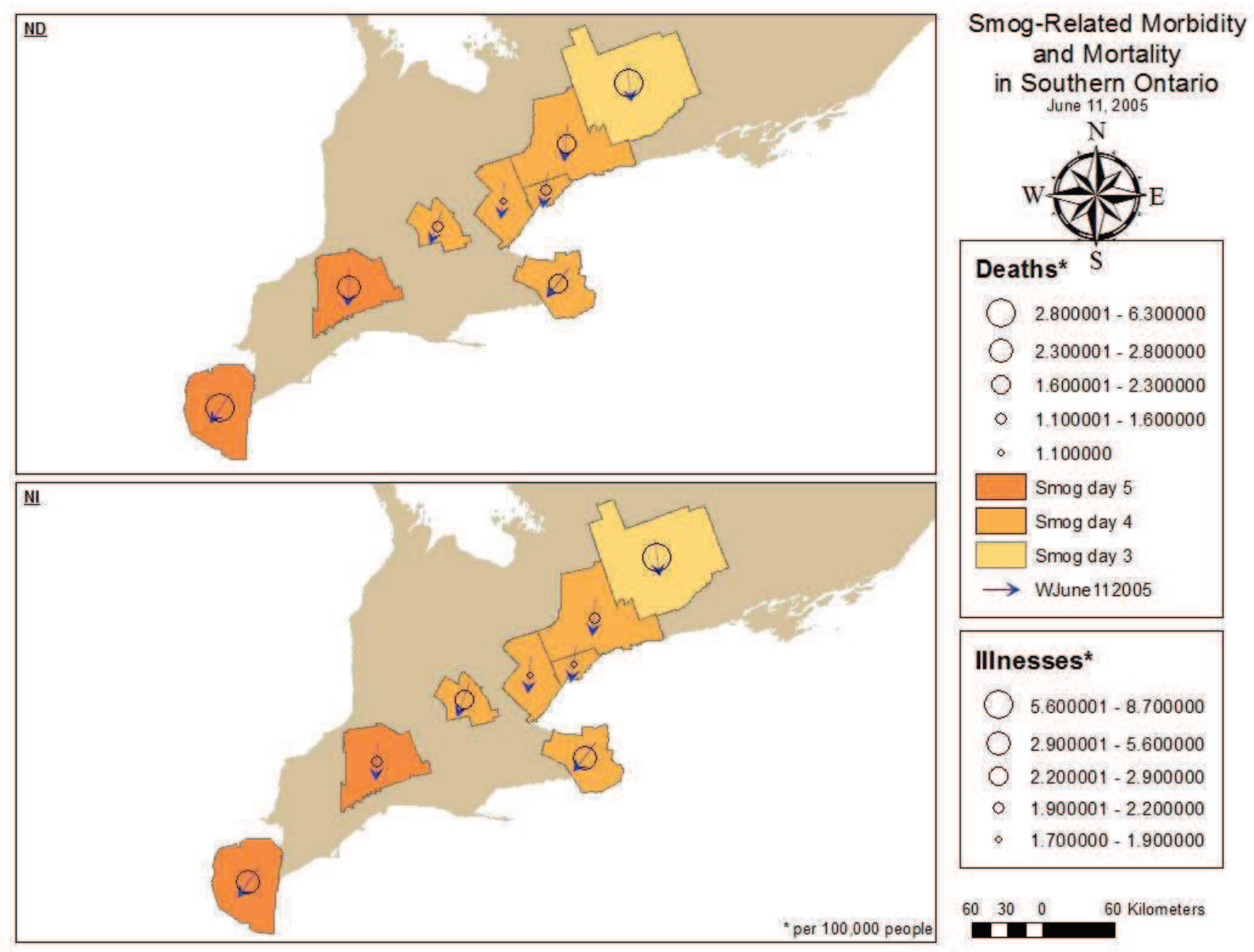

Figure 24: Map of Day 6 - June 11, 2005 
Day 7 - June 12, 2005 - The sixth smog day in Windsor-Essex resulted in 5.3 deaths per 100,000 people, the highest level for all regions. Peterborough-Kawartha Lakes had the highest illness level at 6.7 per 100,000 people. Both regions had southwesterly winds, which could support the hypothesis; however, some areas that experienced low deaths and illnesses did have prevailing winds from the southwest direction.
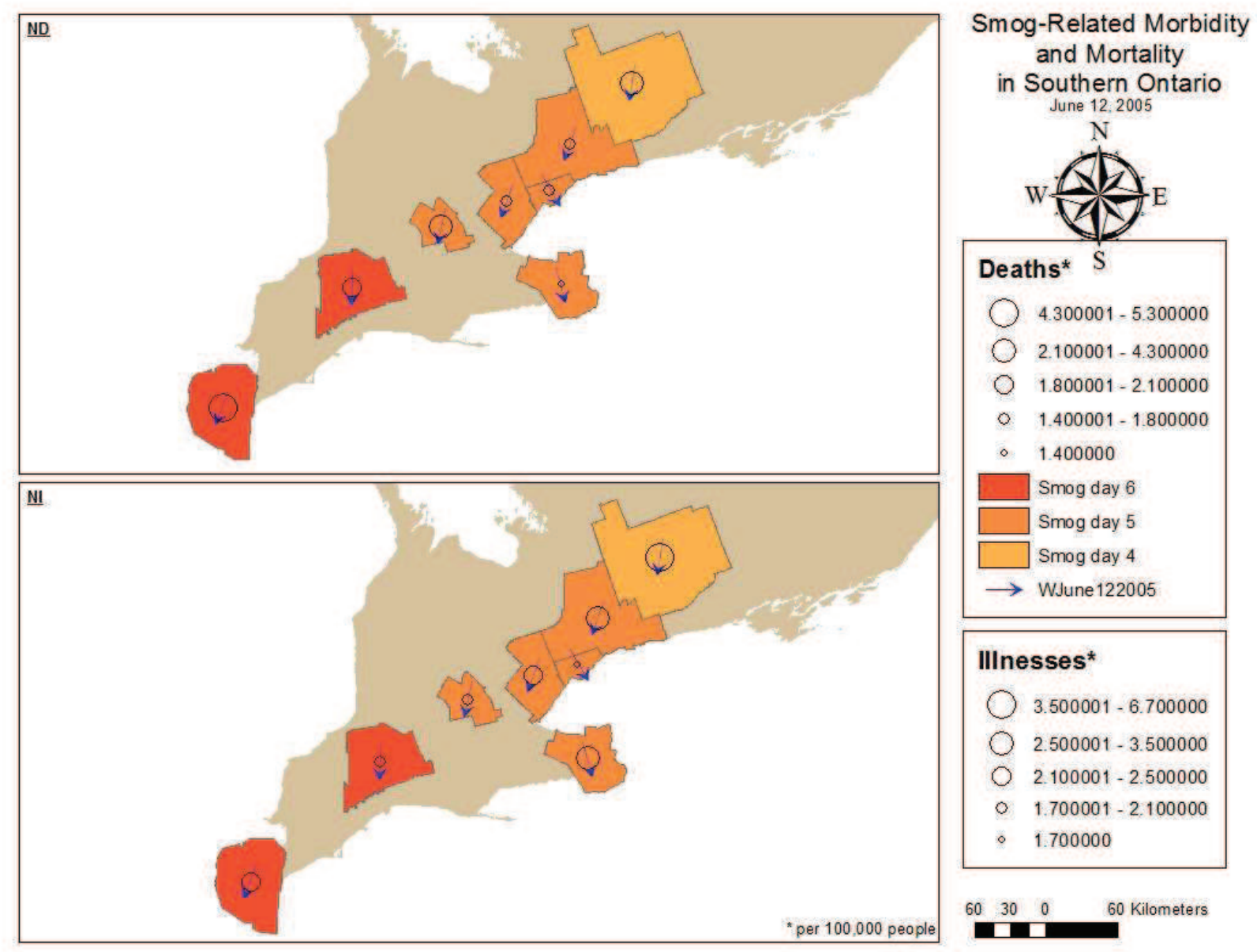

Figure 25: Map of Day 7 - June 12, 2005 
Day 8 - June 13, 2005 - Peterborough- Kawartha Lakes region experienced the highest level of deaths and illnesses out of all the study sites during its $5^{\text {th }}$ smog day. There were 8.2 deaths and 6.3 illnesses per 100,000 people with winds moving from the southeast.
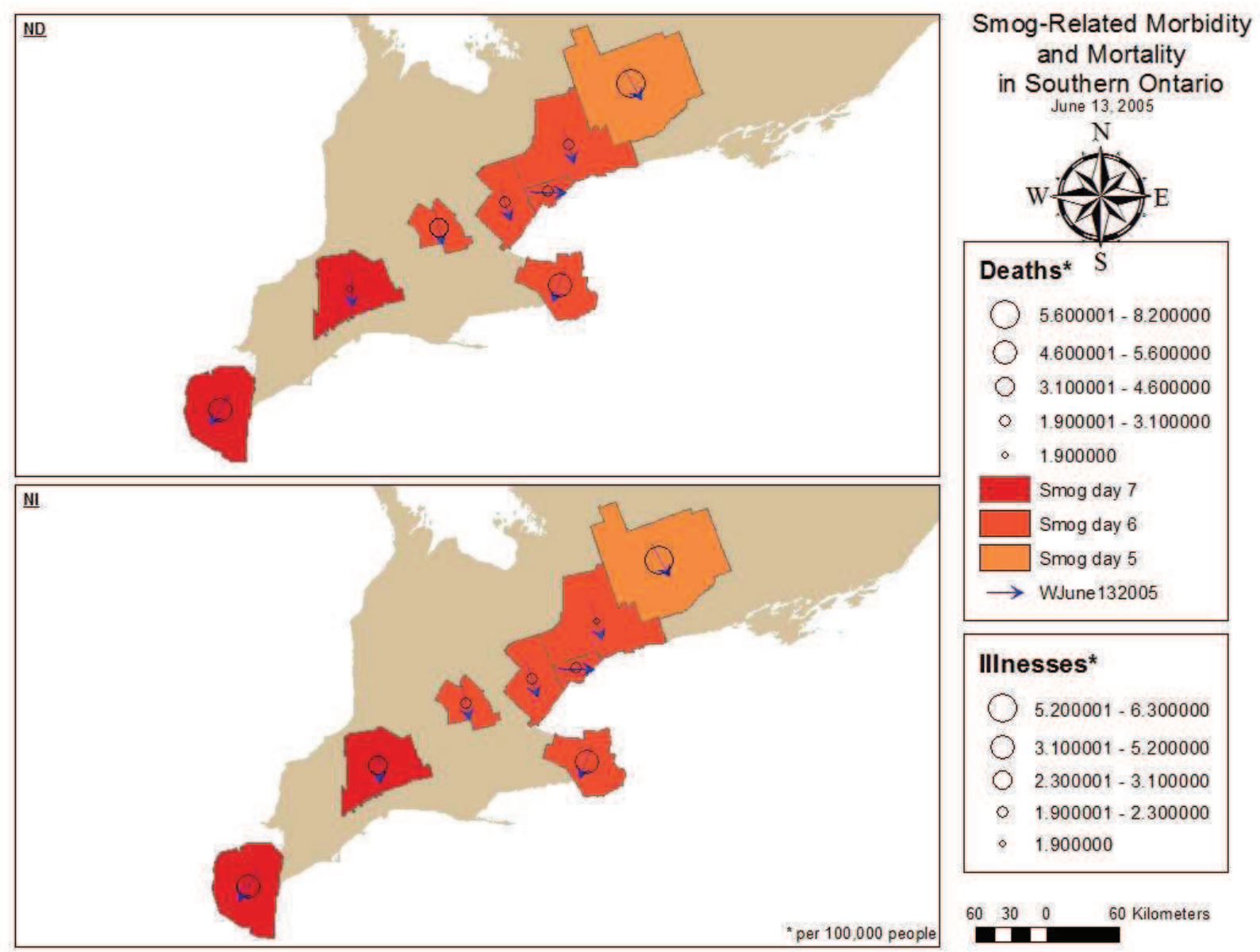

IIInesses*

( $5.200001-6.300000$

() $3.100001-5.200000$

( $2.300001-3.100000$

- $1.900001-2.300000$

- 1.900000

Figure 26: Map of Day 8 - June 13, 2005 
Day 9 - June 14, 2005 - During the final smog day for all regions, the majority of the study sites had a southwesterly wind direction; however, the area with the highest deaths was PeterboroughKawartha Lakes region with a more west-southwest direction. The highest number of deaths for all of the study sites was 6.7 deaths per 100,000 people in the Peterborough region. The second highest level was in the Niagara region during its $7^{\text {th }}$ smog day with 5.4 deaths and it also had the highest illnesses at 3.7 per 100,000 people.
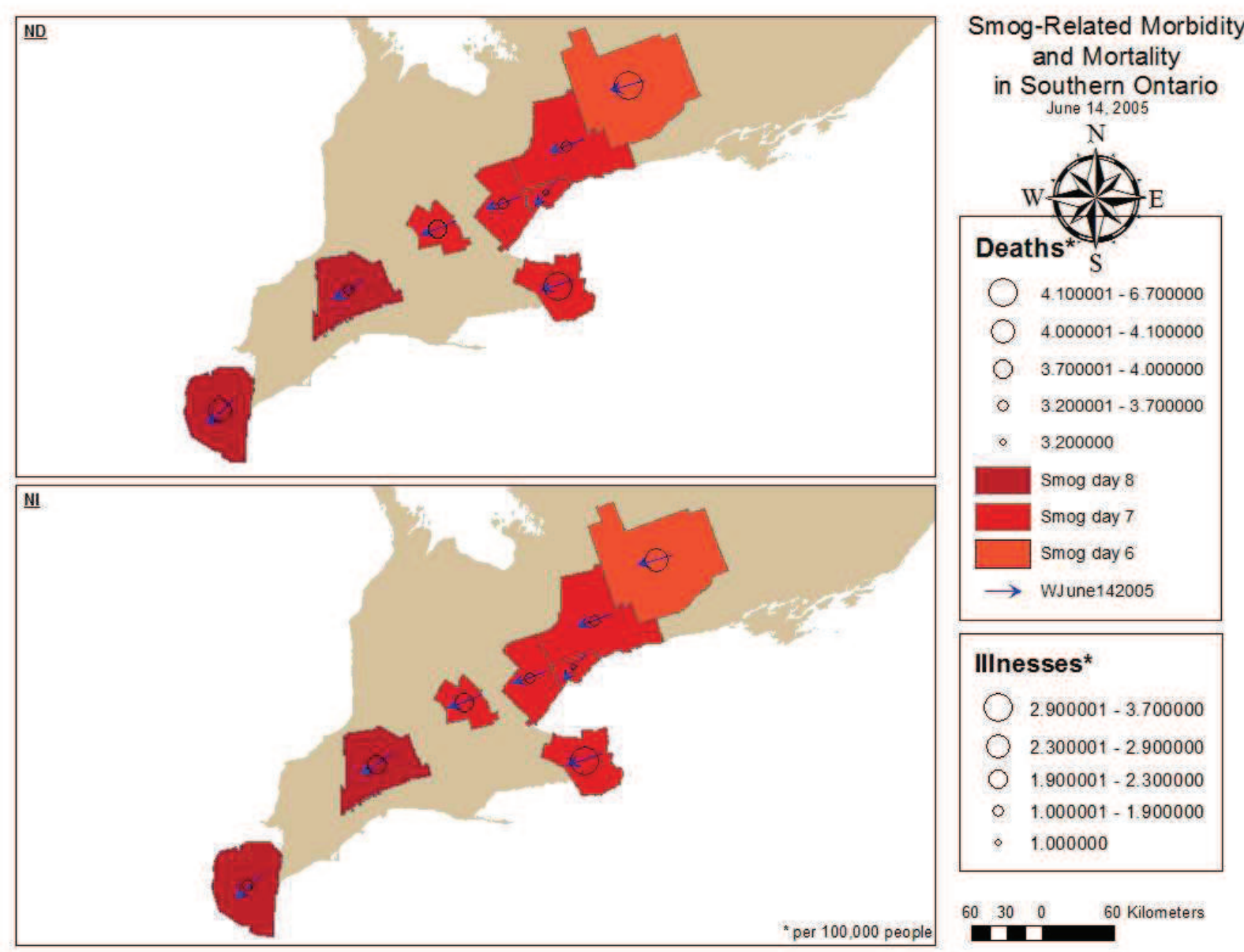

Figure 27: Map of Day 9 - June 14, 2005 
Day 10 - June 15, 2005 - During the first post-day of the smog advisory, Peterborough-

Kawartha Lakes region had the highest level of deaths at 10.1 per 100,000 people and illnesses of 5.3 per 100,000 people with winds moving from the southwest. The second highest illness rate was in the London-Middlesex region that experienced 4.3 illnesses per 100,000 with winds moving from the westerly direction.
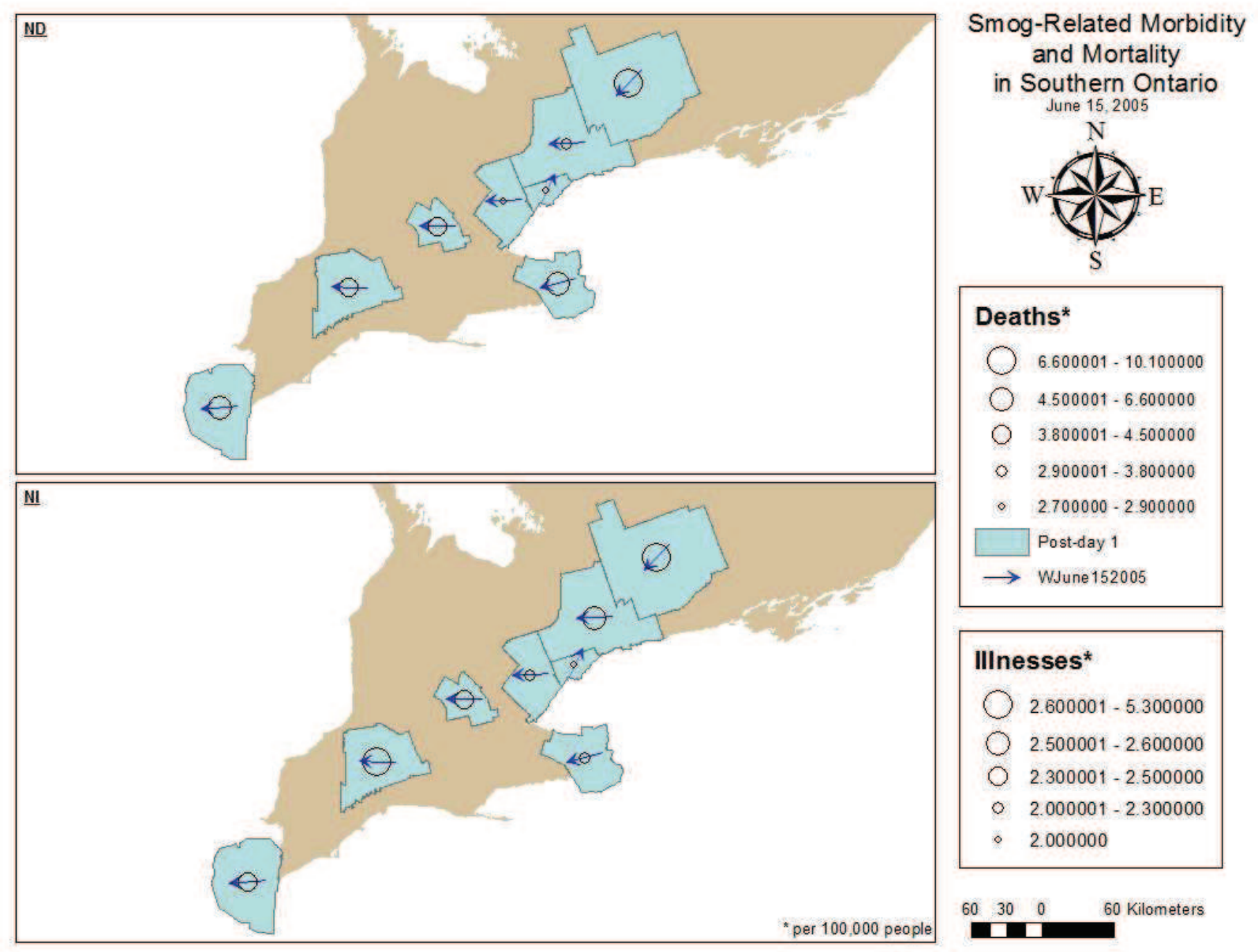

\section{IIInesses*}

( $2.600001-5.300000$

(1) $2.500001-2.600000$

( $2.300001-2.500000$

- $2.000001-2.300000$

- 2.000000

Figure 28: Map of Day 10 - June 15, 2005 
Day 11 - June 16, 2005 - During the second post-day, the highest number of deaths occurred in the Windsor-Essex region with 6.4 deaths per 100,000 people with winds blowing from the northwest. Peterborough region had the second highest death rate and the highest illness rate with 6.3 deaths and 5.3 illnesses per 100,000 people with winds also from the northwest.
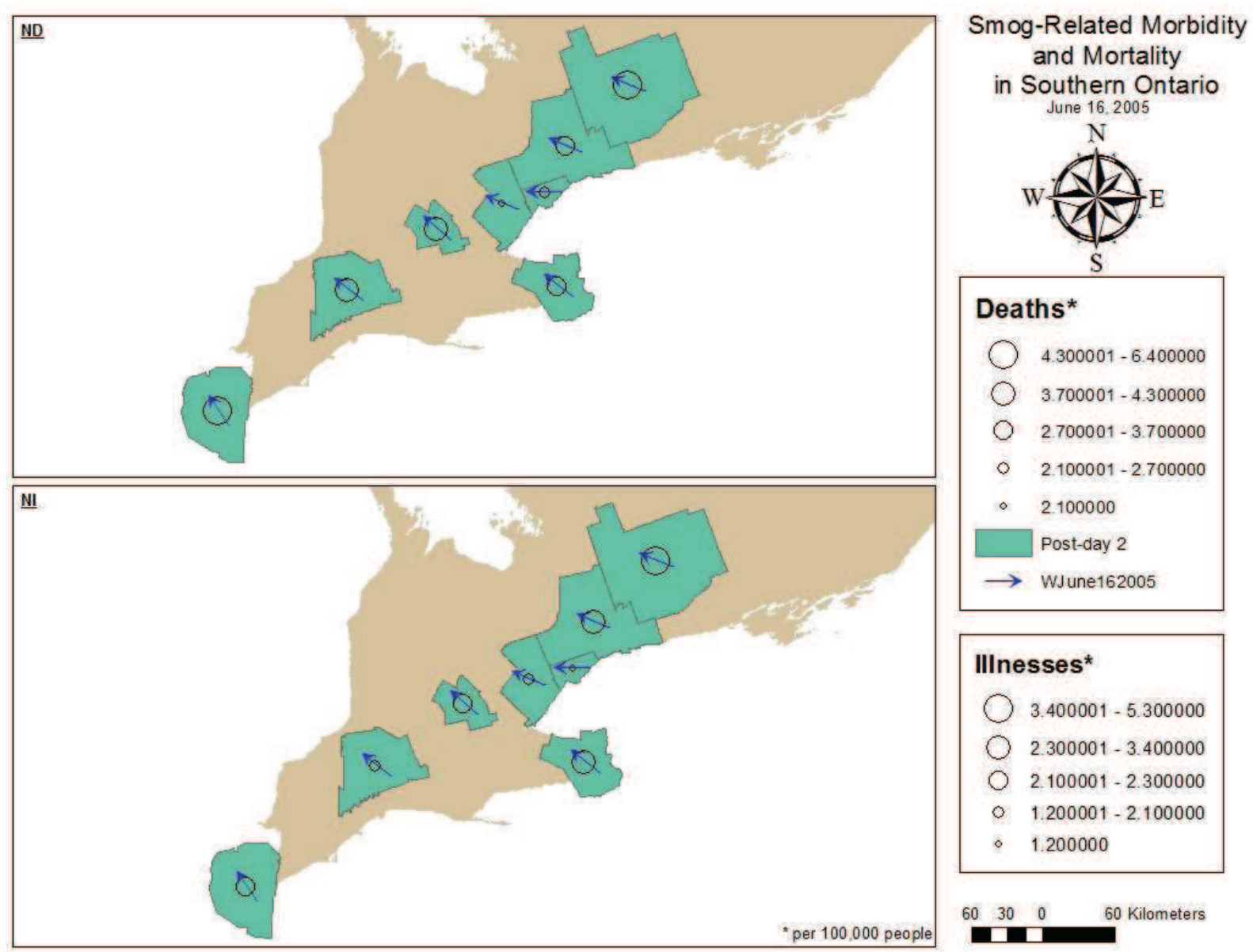

\section{IIInesses*}

C $3.400001-5.300000$

() $2.300001-3.400000$

O $2.100001-2.300000$

- $1.200001-2.100000$

- 1.200000

Figure 29: Map of Day 11 - June 16, 2005 


\section{Summary of Smog Event 2005:}

The overall highest death rate occurred in the Peterborough-Kawartha Lakes region during the first post-day with 10.1 deaths per 100,000 people. The average temperature for that day was 19.4 degrees Celsius which is not substantially high, meaning heat sensitivity would not be the major contributor to such a high rate. The winds were blowing from the southwest, which could potentially be a reason for the high death rate. The lowest death rate was in the Halton-Peel region during its fourth smog day with 1.1 deaths per 100,000 people. The average temperature for that area was 27.2 degrees Celsius with winds blowing from the south. Since it is assumed that the major contributor of transboundary air contaminants is the United States, this would raise questions about the hypothesis. The highest level of illnesses also occurred in the Peterborough region during the third smog day at 8.7 illnesses per 100,000 people. The average temperature for that day was 25.5 degrees Celsius with winds blowing from the southsoutheasterly direction. The area that had the lowest number of illnesses during the smog event was the City of Toronto during the seventh smog day with 1 illness per 100,000 people. The average temperature for that day was 24 degrees Celsius with winds moving from the southwest which also raises questions about the hypothesis regarding the relationship between air pollution and temperature causing high numbers of morbidity and mortality.

Although Windsor did experience high levels of deaths and illnesses on smog days, it was expected that both Windsor and London would have higher rates of morbidity and mortality since they had the longest smog events. However, the Peterborough-Kawartha Lakes region experienced the highest level of cardiovascular and respiratory deaths and illnesses with the shortest smog event of all regions; however, the average wind direction was from the southwesterly to southeast path. 
It should also be discussed that the possible outcomes for the Niagara region for smog event days when Niagara revealed the highest number of deaths and illnesses; this could be due to the presence of the Nanticoke Coal Plant located on the shores of Lake Erie. In some instances, the wind direction is pointed from the area that it is located. Since this plant was running during the time of analysis, this could have affected those who are susceptible to respiratory or cardiovascular illness in the Niagara region.

\subsubsection{Smog Event 2006:}

In 2006, the average number of smog events was 5 for all regions. The second smog advisory was chosen based since it was the longest event that occurred during the summer months. The number of smog days for each region was 3 with the exception of the WindsorEssex Region which had 4 smog days during the advisory. All regions smog advisory ended June $19^{\text {th }}$ resulting in 2 post-days for each study site. Since the previous smog advisory for this year was at the end of May, it is assumed that it will not be affecting the number of deaths and illnesses that occur during the observed smog event. From visual interpretation, the following observations were made: 
Day 1 - June 15, 2006 - During the pre-day of all regions, Windsor-Essex experienced the highest level of deaths at 5.3 per 100,000 people with winds moving from the southeast. The area that experienced the highest level of illnesses was the Peterborough-Kawartha Lakes region with 7.7 illnesses per 100,000 people with winds moving from the southwesterly direction.
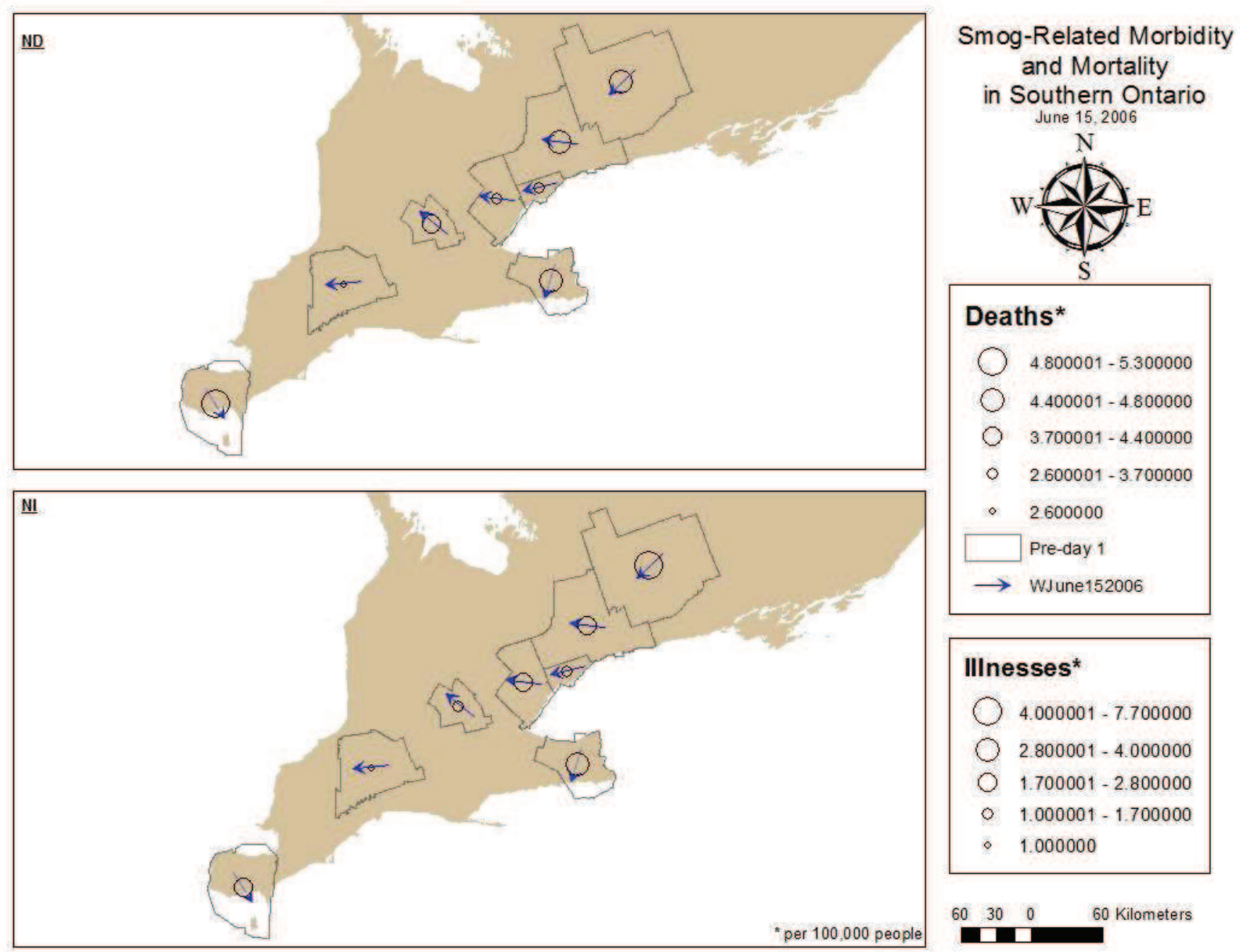

Figure 30: Map of Day 1 - June 15, 2006 
Day 2 - June 16, 2006 - All regions are in a second pre-day except for Windsor-Essex which had its first smog advisory day. The highest level of deaths occurred in the Waterloo-Kitchener region with 5.4 deaths per 100,000 people. The area with the highest illness rate was the Niagara region with 3 illnesses followed by Windsor-Essex and London-Middlesex with 2.8 illnesses per 100,000 people. All regions had wind flowing from roughly a southwest direction with WindsorEssex a south-southwest direction.
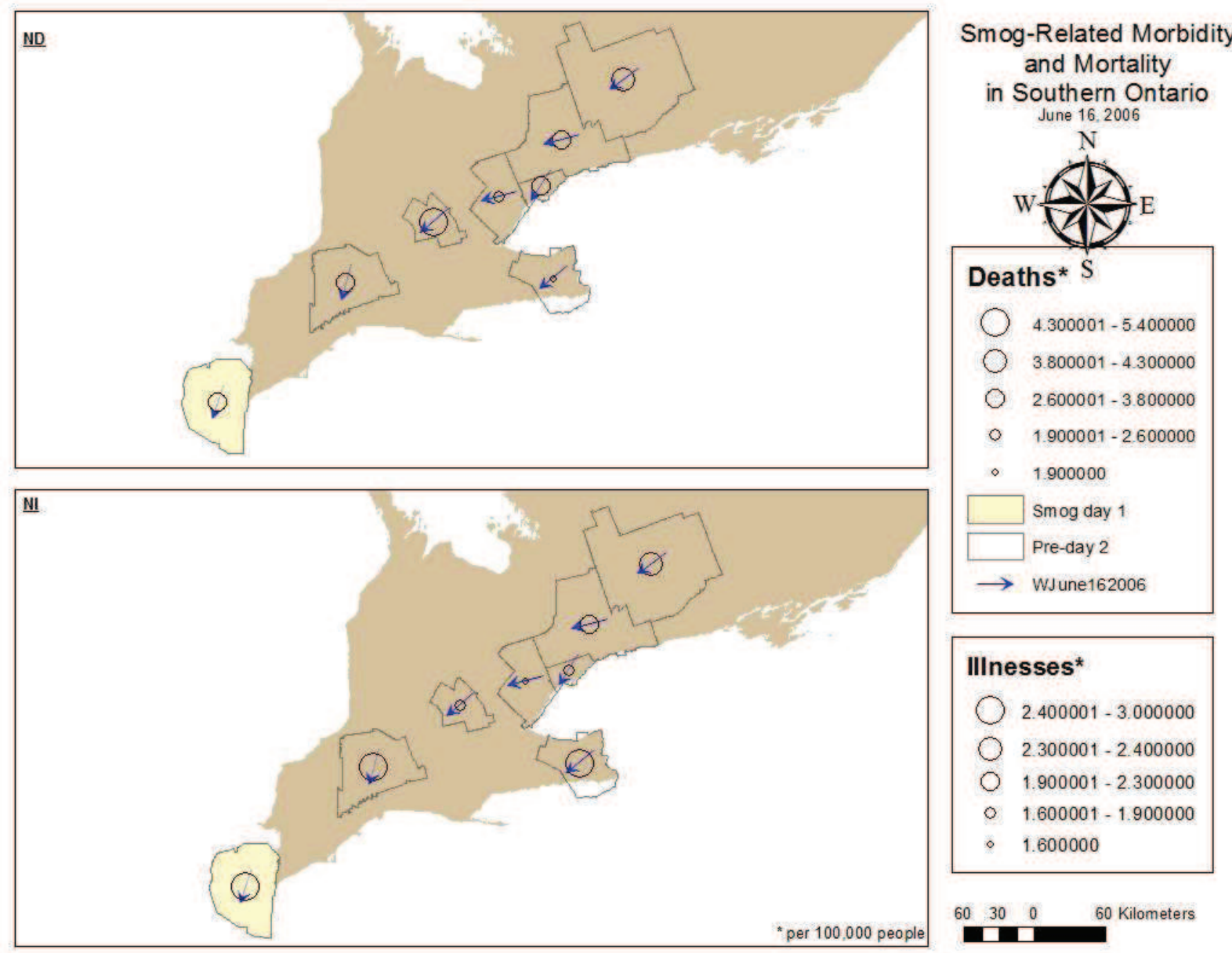

Figure 31: Map of Day 2 - June 16, 2006 
Day 3 - June 17, 2006 - All regions are in a smog advisory with Waterloo-Kitchener having the highest deaths on its first smog day of 3.3 deaths per 100,000 people with winds from the southwest. Peterborough-Kawartha Lakes had the highest illnesses for this day, smog day 1, with 4.3 illnesses per 100,000 people also with southwesterly winds.
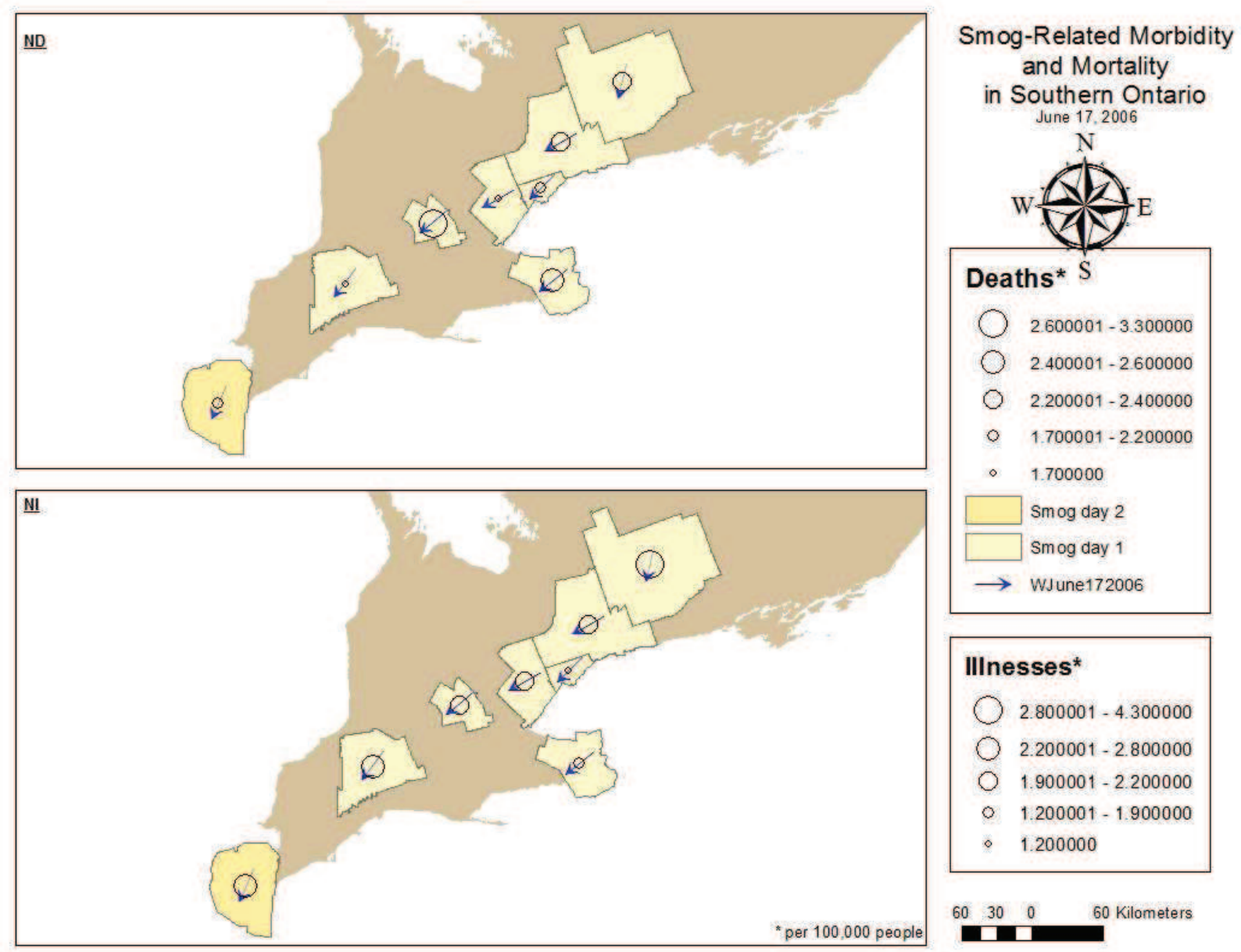

Figure 32: Map of Day 3 - June 17, 2006 
Day 4 - June 18, 2006 - During the fourth day of observations, all regions experiencing the high levels of deaths and illnesses had wind coming from the southwest. London-Middlesex had the highest deaths at 3.8 deaths followed by Niagara with 3.5 deaths per 100,000 people. Areas that had the highest level of cardiovascular and respiratory illnesses were the Peterborough region with 3.9 illnesses and the Windsor region with 3.6 illnesses per 100,000 people.
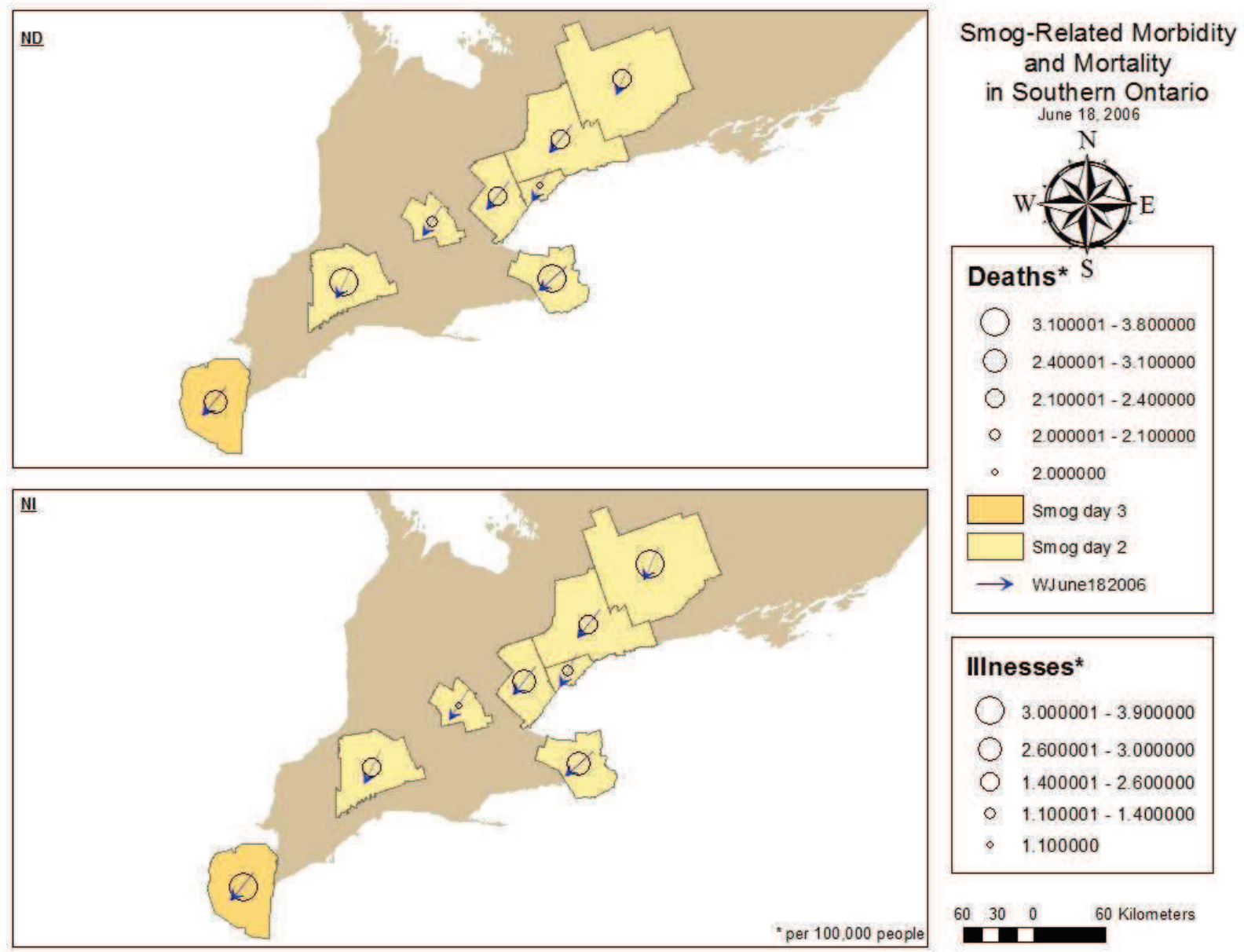

\section{IIInesses*}

( $3.000001-3.900000$

() $2.600001-3.000000$

C $1.400001-2.600000$

o $1.100001-1.400000$

- 1.100000

Figure 33: Map of Day 4 - June 18, 2006 
Day 5 - June 19, 2006 - The fifth day of observations had the highest levels of deaths from regions with southwesterly winds, while the area with the highest level of illnesses had wind blowing from the northwest. The York-Durham region experienced 5.5 deaths followed by Windsor-Essex with 4.6 deaths per 100,000 people. Peterborough-Kawartha Lakes region had 4.3 illnesses per 100,000 people during its third smog day.
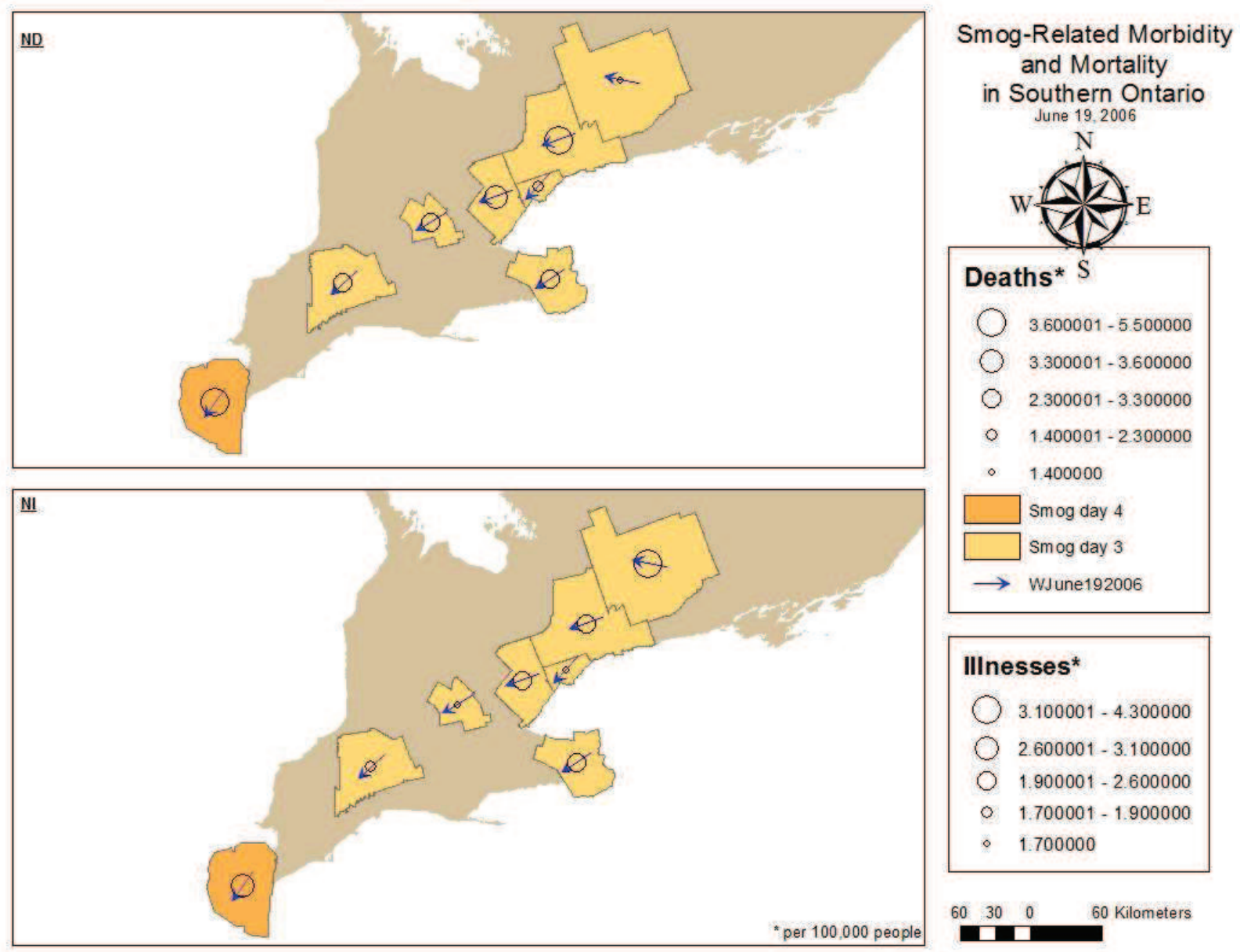

\section{IIInesses*}

( $3.100001-4.300000$

() $2.600001-3.100000$

C $1.900001-2.600000$

- $1.700001-1.900000$

- 1.700000

Figure 34: Map of Day 5 - June 19, 2006 
Day 6 - June 20, 2006 - During the first post-day, both areas that experienced the highest level of deaths, also experienced the highest levels of illnesses with winds blowing from the south. Peterborough-Kawartha Lakes had 7.2 deaths and 6.3 illnesses per 100,000 people followed by Windsor-Essex region with 6.6 deaths and 5.3 illnesses per 100,000 people.
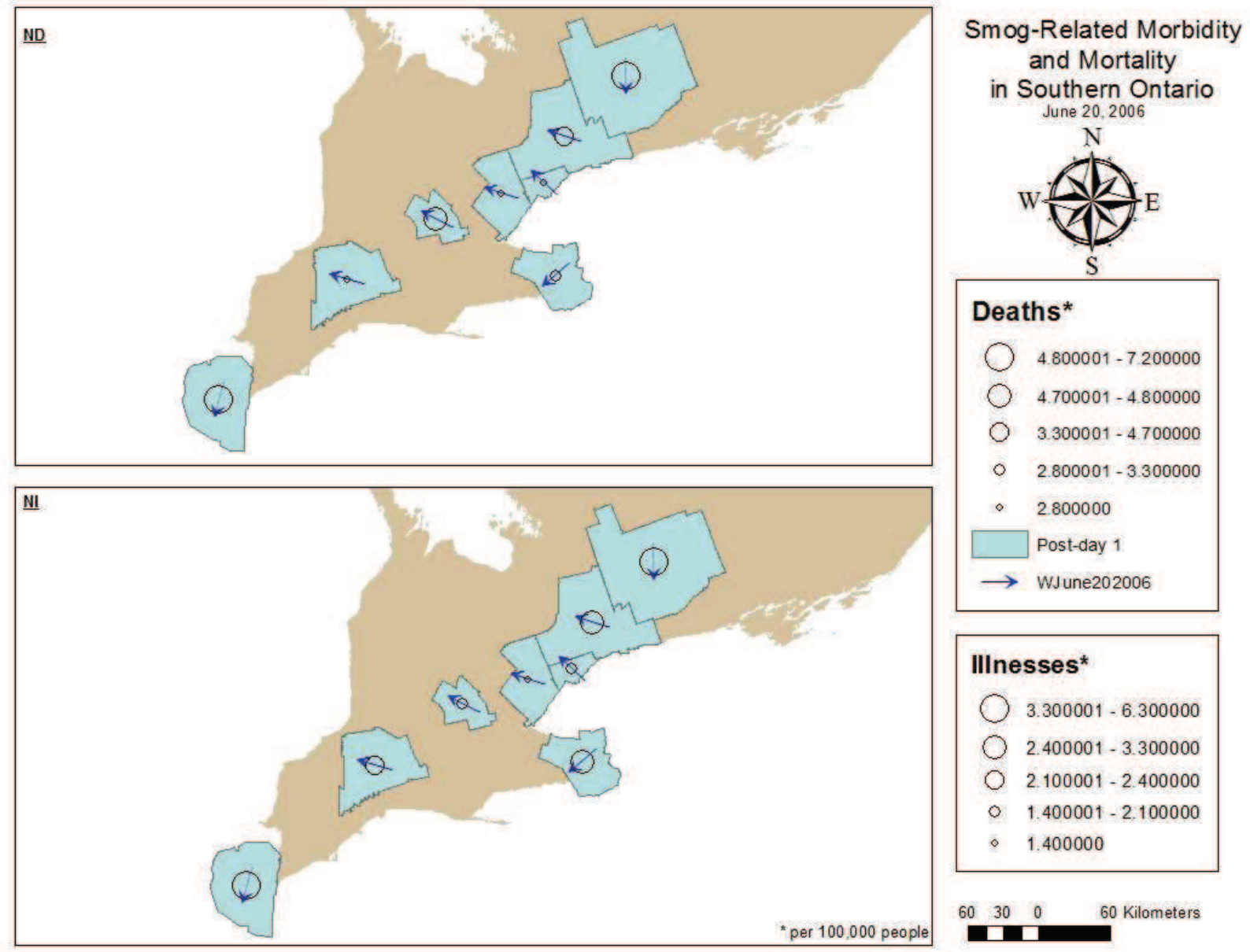

Figure 35: Map of Day 6 - June 20, 2006 
Day 7 - June 21, 2006 - During the second post-day after the smog advisory, Niagara region had the highest level of deaths at 6.8 per 100,000 people with winds moving from the southwest. Windsor experienced the second highest death rate with 6.6 deaths per 100,000 people and winds blowing from the south. Peterborough-Kawartha Lakes region had the highest level of illnesses at 5.3 illnesses per 100,000 people with southwesterly winds. Windsor had the second highest morbidity rate at 4.8 illnesses per 100,000 people.
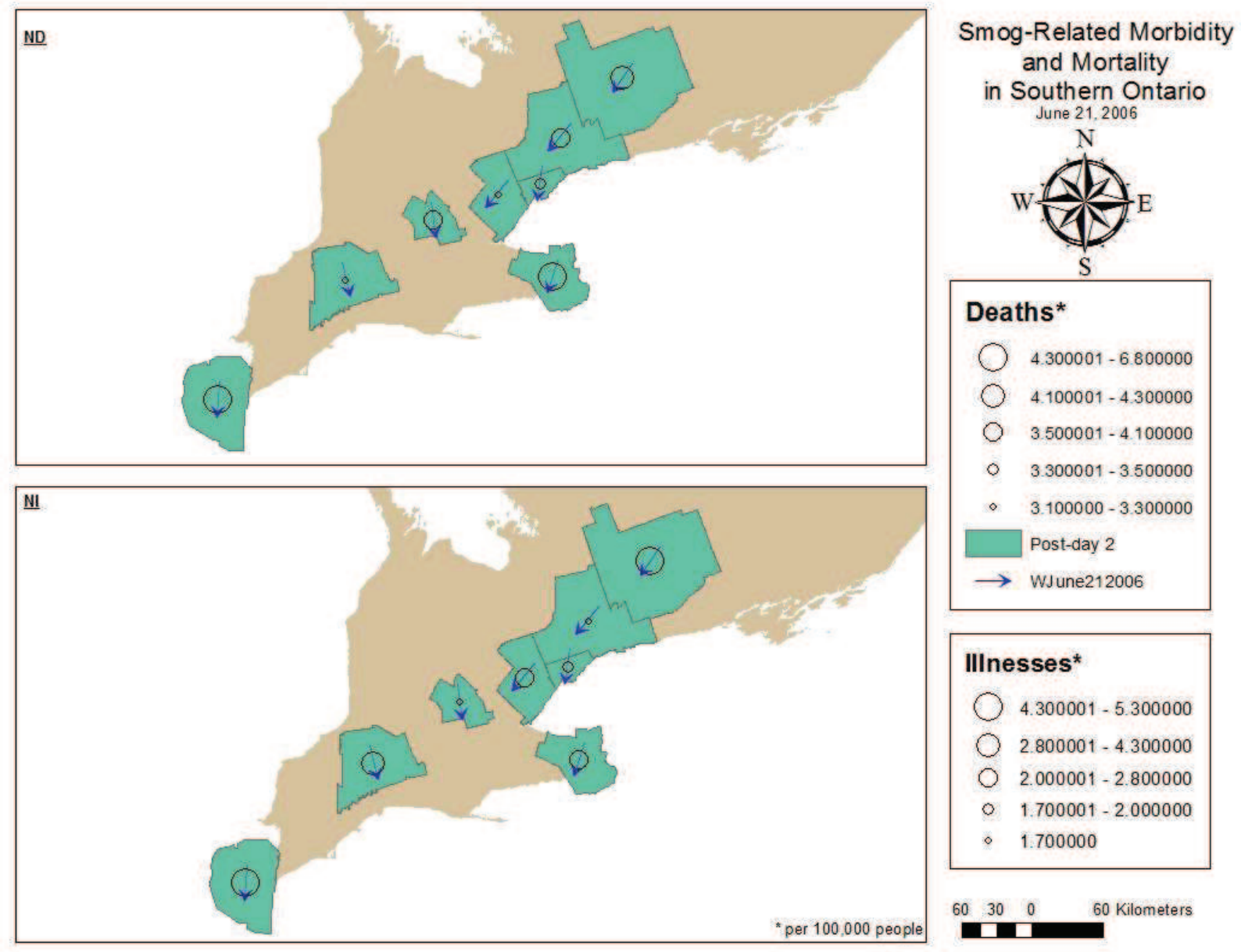

Figure 36: Map of Day 7 - June 21, 2006 


\section{Summary of Smog Event 2006:}

The highest level of deaths for the entire smog event occurs in the PeterboroughKawartha Lakes region on post-day 1 with 7.2 deaths per 100,000 people, a modest average temperature of 16.9 degrees Celsius with average wind direction for that day from the south. the lowest death rate was also in the Peterborough region which occurred during smog day 3 with 1.4 mortalities per 100,000 people. The average temperature for that day was 18.2 degrees Celsius and west-northwesterly winds. This would indicate that other factors are playing a role besides temperature and wind direction resulting in high or low death rates.

The highest illness rate occurs during the pre-day for the Peterborough region, indicating that other factors are playing a role in the heightened level of cardiovascular and respiratory illnesses. The level for that day was 7.7 illnesses per 100,000 people, which an average temperature of 20.3 and southwesterly winds. The region that experienced the lowest level of illnesses was the London-Middlesex region during the first pre-day, which 1 illness per 100,000 occurred during a daily average temperature of 19.3 and average wind direction from the west. 


\subsubsection{Smog Event 2007:}

In 2007, all regions selected had anywhere from 8-13 smog advisories. The WindsorEssex region had the highest number of smog advisories and Peterborough-Kawartha Lakes region had the lowest. During this year smog advisories began in early May, and continued throughout the month of May and June. The longest advisory selected was the $6^{\text {th }}$ smog advisory that year. Each region fluctuated in start and end dates of the smog event. The Windsor-Essex region had 9 smog days. Beginning two days later, the Waterloo-Kitchener, Halton-Peel and Niagara regions had 7 smog days during the event followed by York-Durham and City of Toronto with 5 smog days occurring in the middle of the event. London-Middlesex had 2 smog days at the end of the event. The Peterborough Kawartha Lakes region had not been issued a smog advisory, therefore it would be assumed that it would not have as great of an impact as an area in a smog advisory. From visual interpretation, the following observations were made: 
Day 1 - June 10, 2007 - During the pre-day of the smog advisory, Windsor-Essex region experienced the highest level of deaths at 4.1 deaths per 100,000 people with winds from the southwest. The area with the highest illnesses was the Peterborough-Kawartha Lakes region with 7.2 illnesses per 100,000 people with winds also from the southwest. This area; however, was not in a smog advisory, indicating that other factors are attributing to the high number of cardiovascular and respiratory morbidity and mortalities.
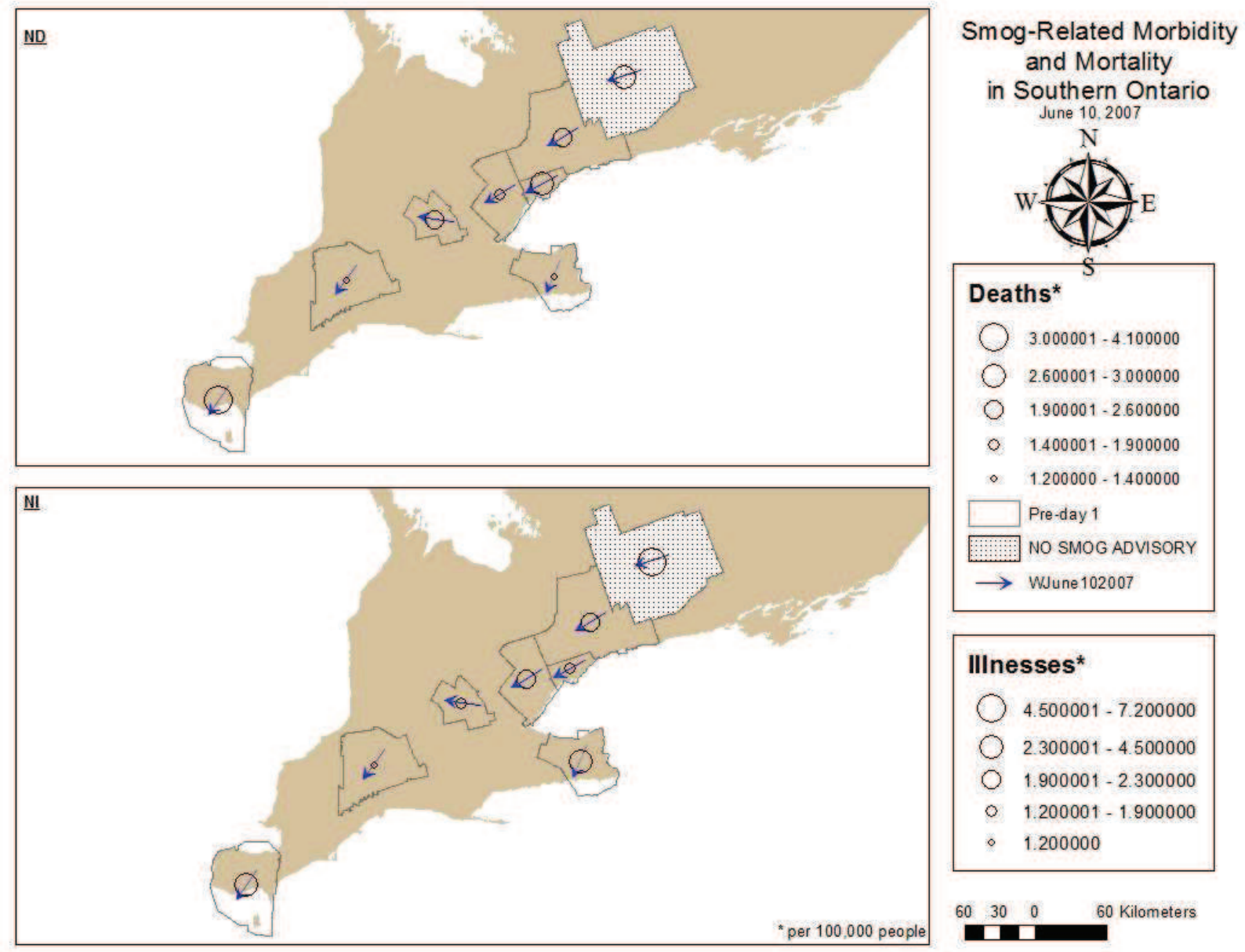

Figure 37: Map of Day 1 - June 10, 2007 
Day 2 - June 11, 2007 - The area with the highest level of deaths was the Peterborough region, with 10.6 deaths per 100,000 people and winds from the south. The highest illnesses that occurred were also in an area with no smog advisory. The London-Middlesex area during a preday had 5.7 cardiovascular or respiratory illnesses with winds from the south-southwest, while Peterborough had 5.3 illnesses per 100,000 people also in a non-smog advisory.
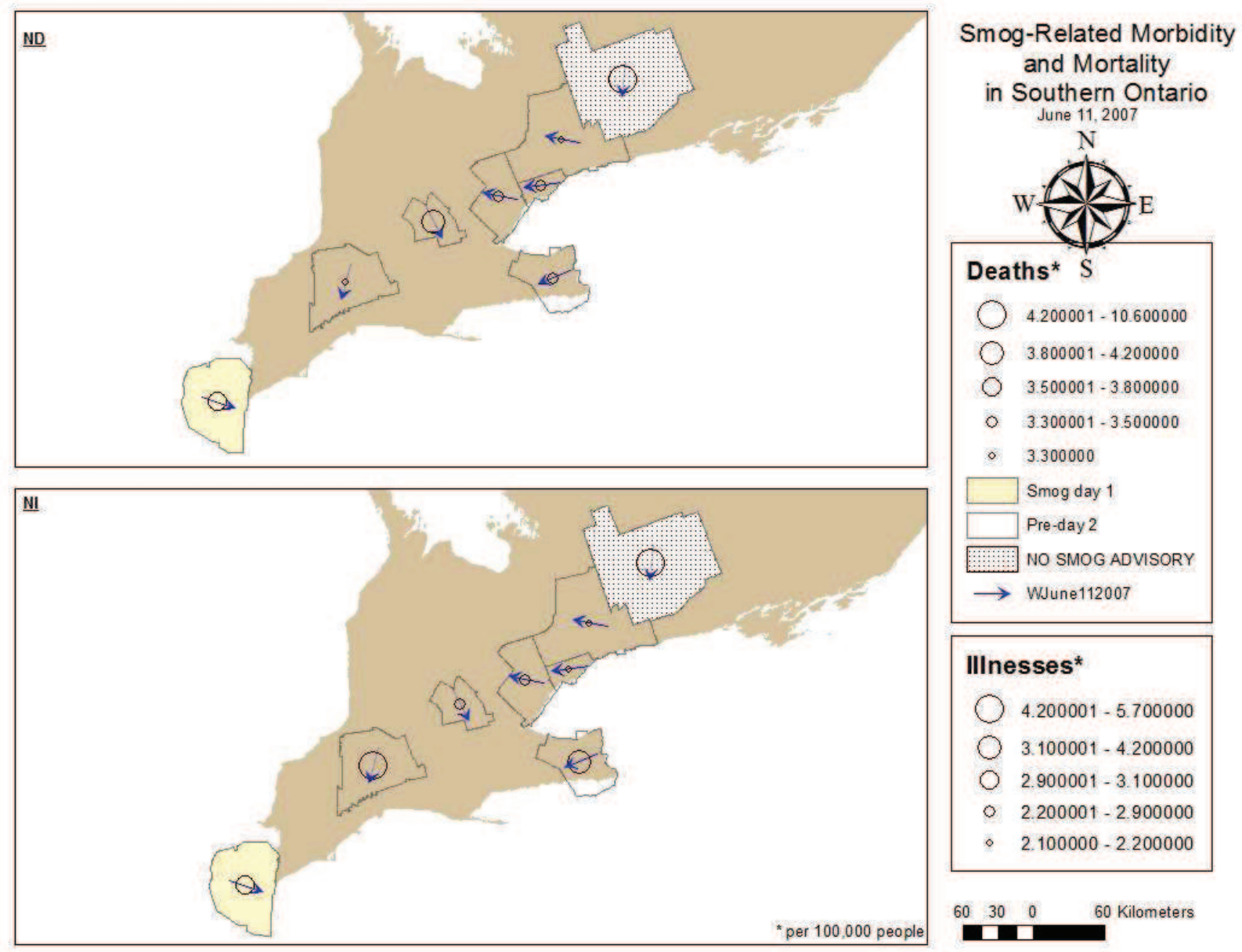

Figure 38: Map of Day 3 - June 11, 2007 
Day 3- June 12, 2007 - During Windsor-Essex second smog day, the region experienced the second highest level of deaths at 5.3 per 100,000; however, Peterborough-Kawartha Lake region had the highest deaths at 5.8 per 100,000. Again, on the third observation day, Peterborough region had the highest illness rate at 6.7 per 100,000 people. The wind direction for WindsorEssex was from the east and the Peterborough-Kawartha Lakes region had winds from the southeast.
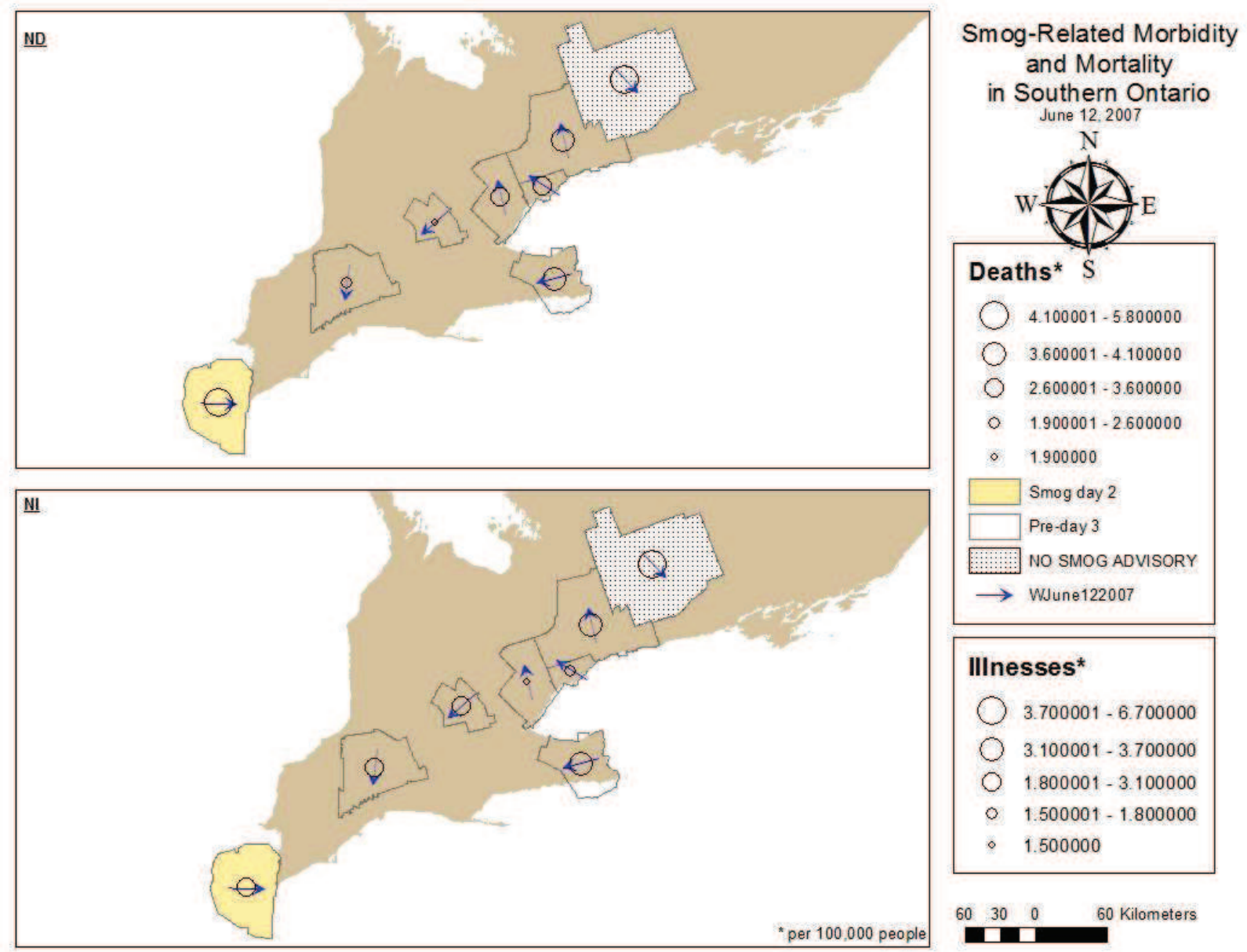
IIInesses*
$3.700001-6.700000$
( $3.100001-3.700000$
( $1.800001-3.100000$
- $1.500001-1.800000$
- 1.500000 
Day 4 - June 13, 2007 - On the third smog day, the Windsor-Essex region had the highest level of mortality and morbidity at 6.7 deaths and 5.1 illnesses per 100,000 with winds from the southeasterly direction. Progressing through the smog event, the Windsor regions death rate seems to be increasing steadily as the smog event persists, an indicator of lag effects from human response to high levels of air pollutants.
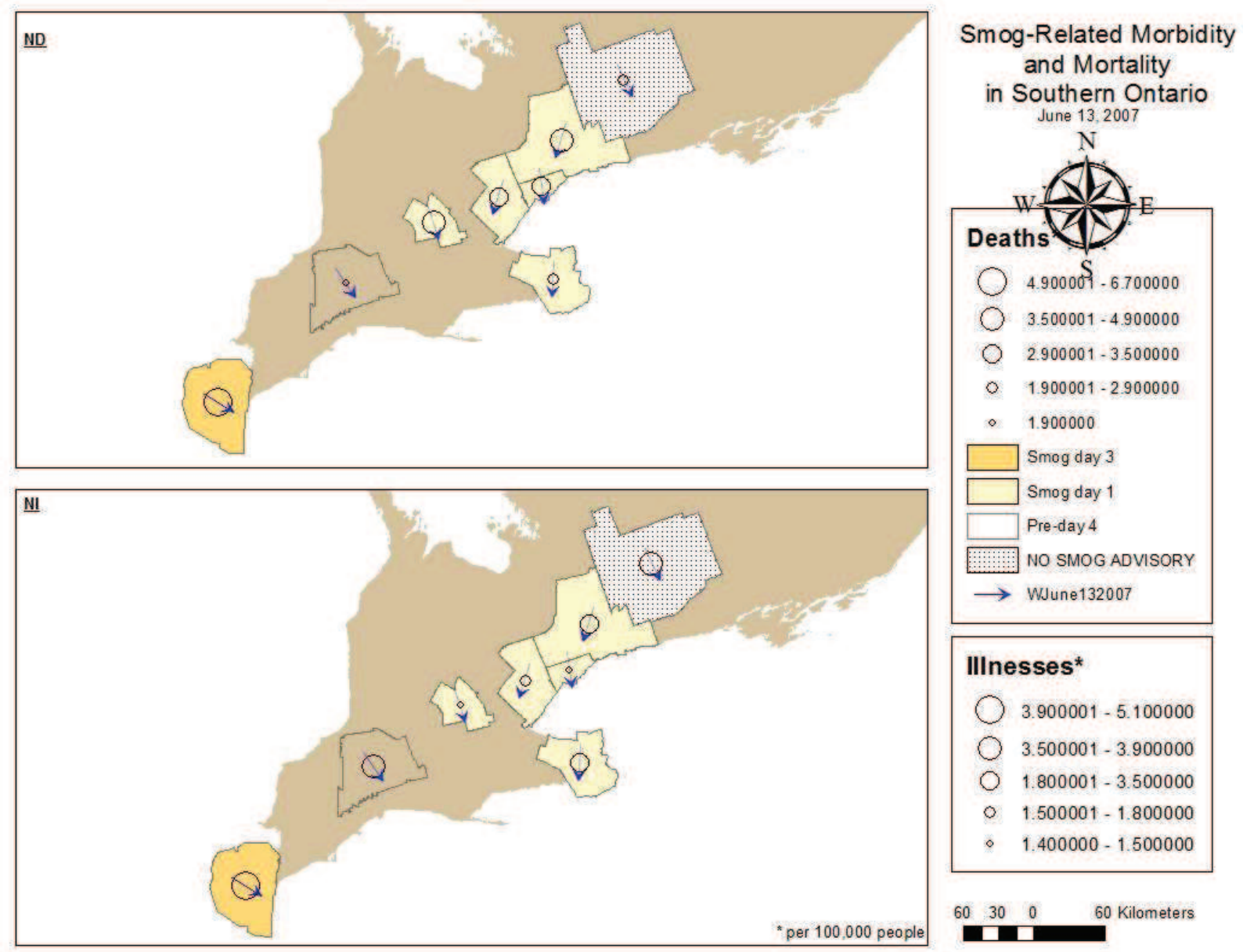

Figure 40: Map of Day 4 - June 13, 2007 
Day 5 - June 14, 2007 - On the second smog day, the Waterloo-Kitchener region experienced the highest level of deaths and illnesses out of all the study sites at 5 deaths and 3.3 illnesses per 100,000 . Peterborough region experienced the second highest death rate at 4.8 per 100,000 people. Both regions had winds blowing form the southeast.
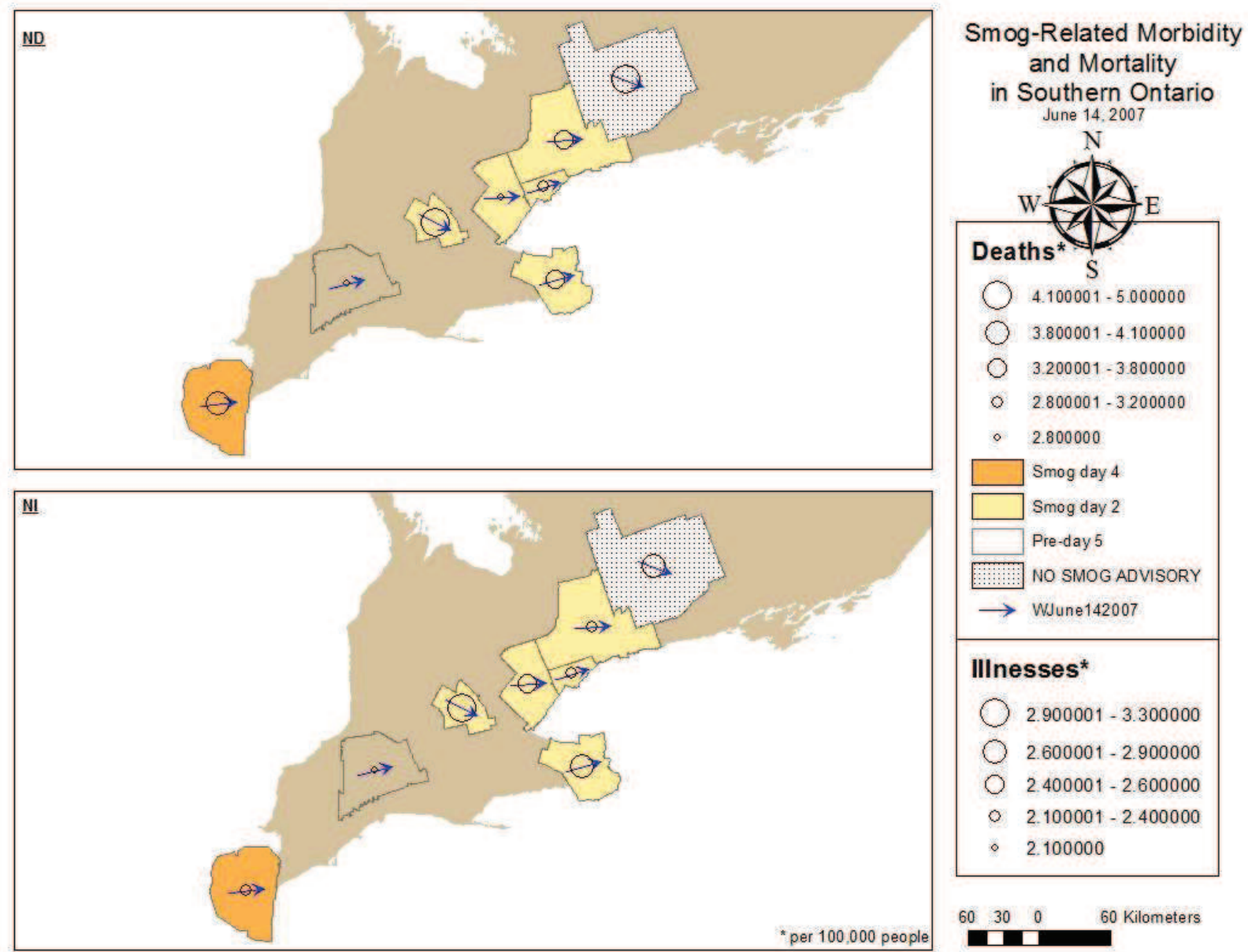

Figure 41: Map of Day 5 - June 14, 2007 
Day 6 - June 15, 2007 - On the third smog day for the Waterloo area, it had the highest death rate at 4.8 per 100,000 and the Peterborough region had the highest illness rate at 4.3 per 100,000 people. Both areas again had wind from the southeast direction.

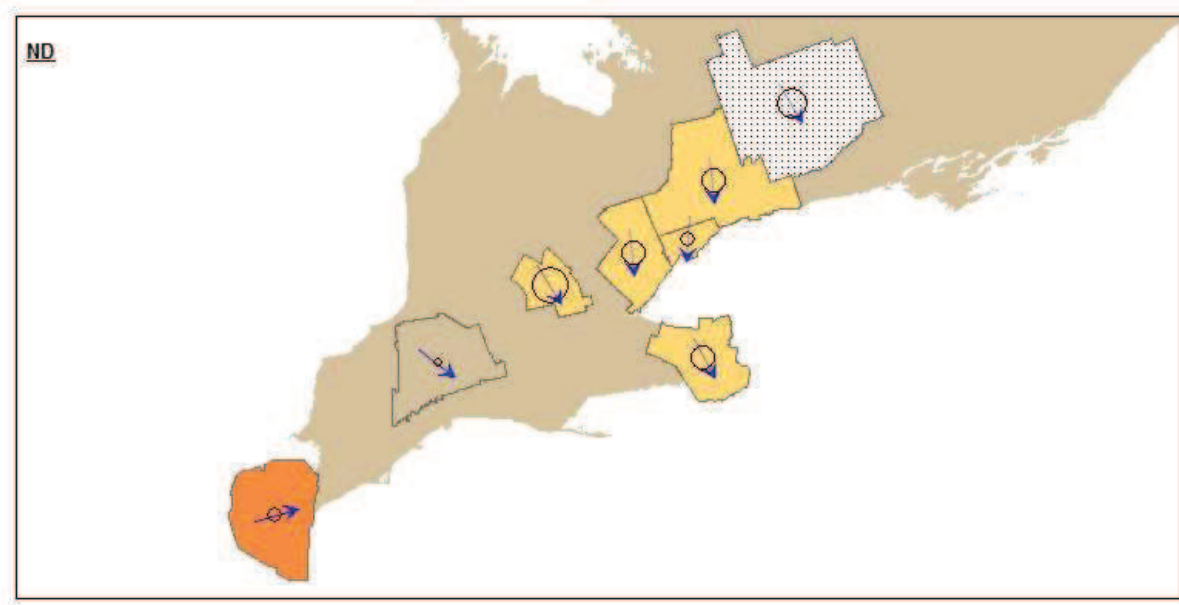

\section{Smog-Related Morbidity and Mortality} in Southern Ontario June 15,2007

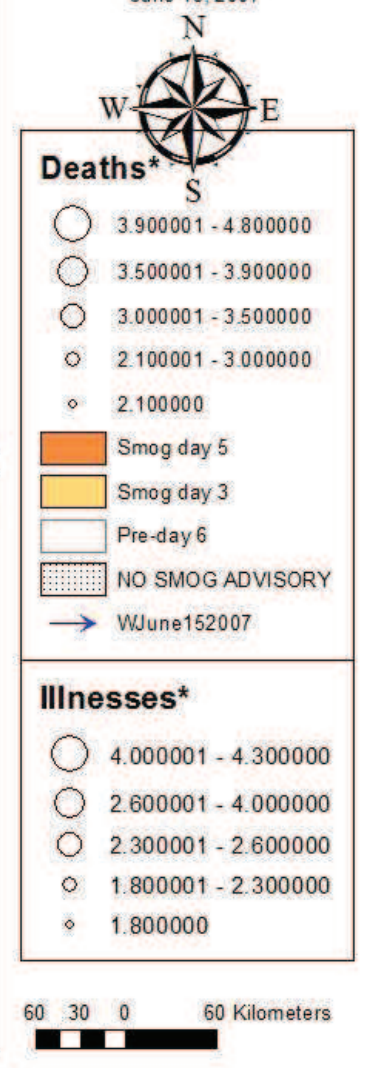

Figure 42: Map of Day 6 - June 15, 2007 
Day 7 - June 16, 2007 - During Windsor-Essex's sixth smog day, the highest death rate was 3.6 out of 100,000 people with wind from the south-southwest. The Waterloo region had the second highest rate at 3.4 deaths per 100,000 people with influencing winds from the west. The highest illness rate was also in the Windsor region at 6.4 per 100,000 people. This rate would support the hypothesis that the longer the smog advisory, the higher the deaths and illnesses along with the prevailing wind contribution.
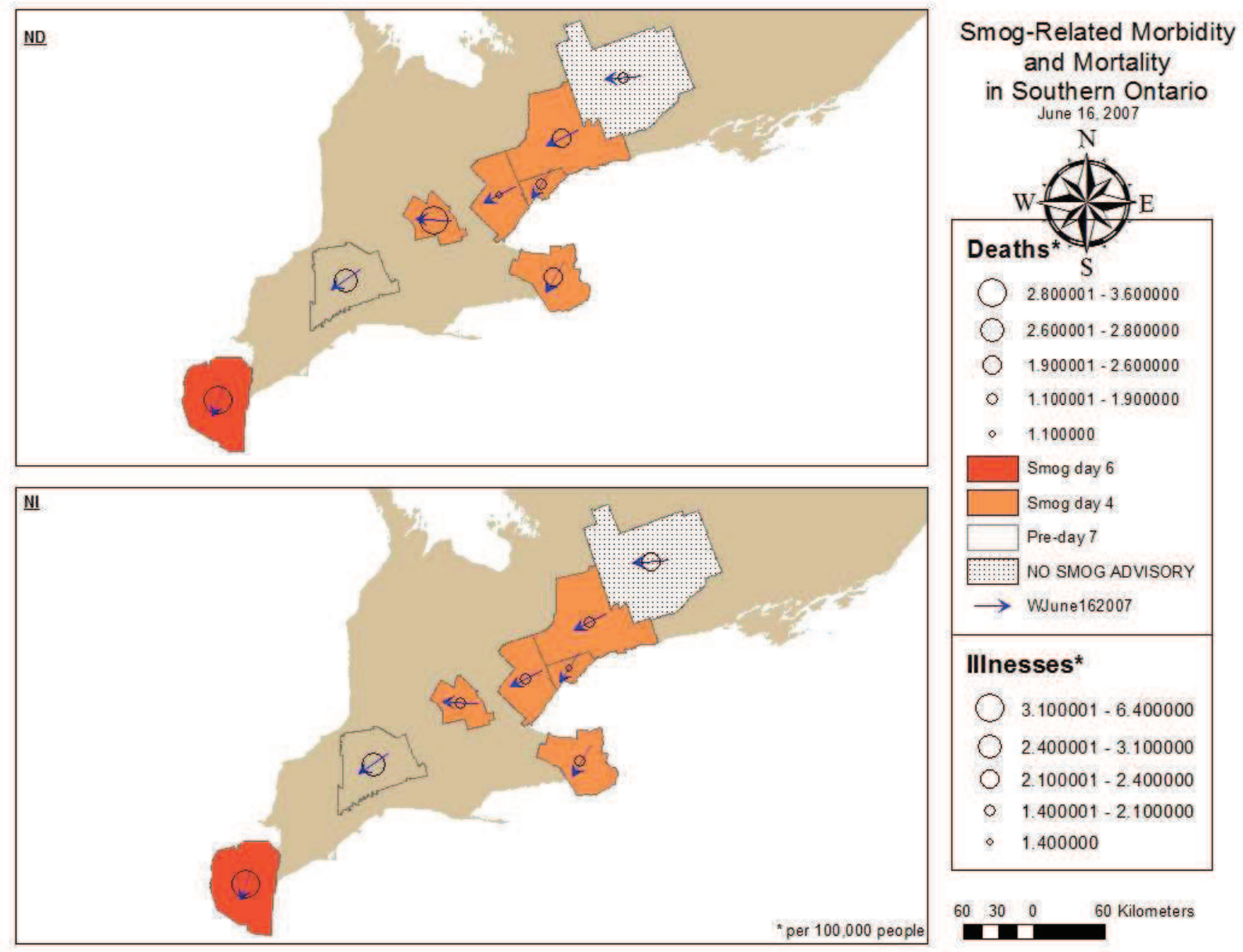

Figure 43: Map of Day 7 - June 16, 2007 
Day 8 - June 17, 2007 - The Windsor-Essex region had the highest death rate during its seventh smog day at 4.6 deaths per 100,000 with southeasterly winds. The second highest rate was in the Waterloo area at 2.1 deaths per 100,000 people and northwesterly winds. The PeterboroughKawartha Lakes region experienced the highest rate of illness during day 8 with 4.3 morbidities per 100,000 and northwesterly winds. Windsor also had a high level of illness at 4.1 per 100,000 people.
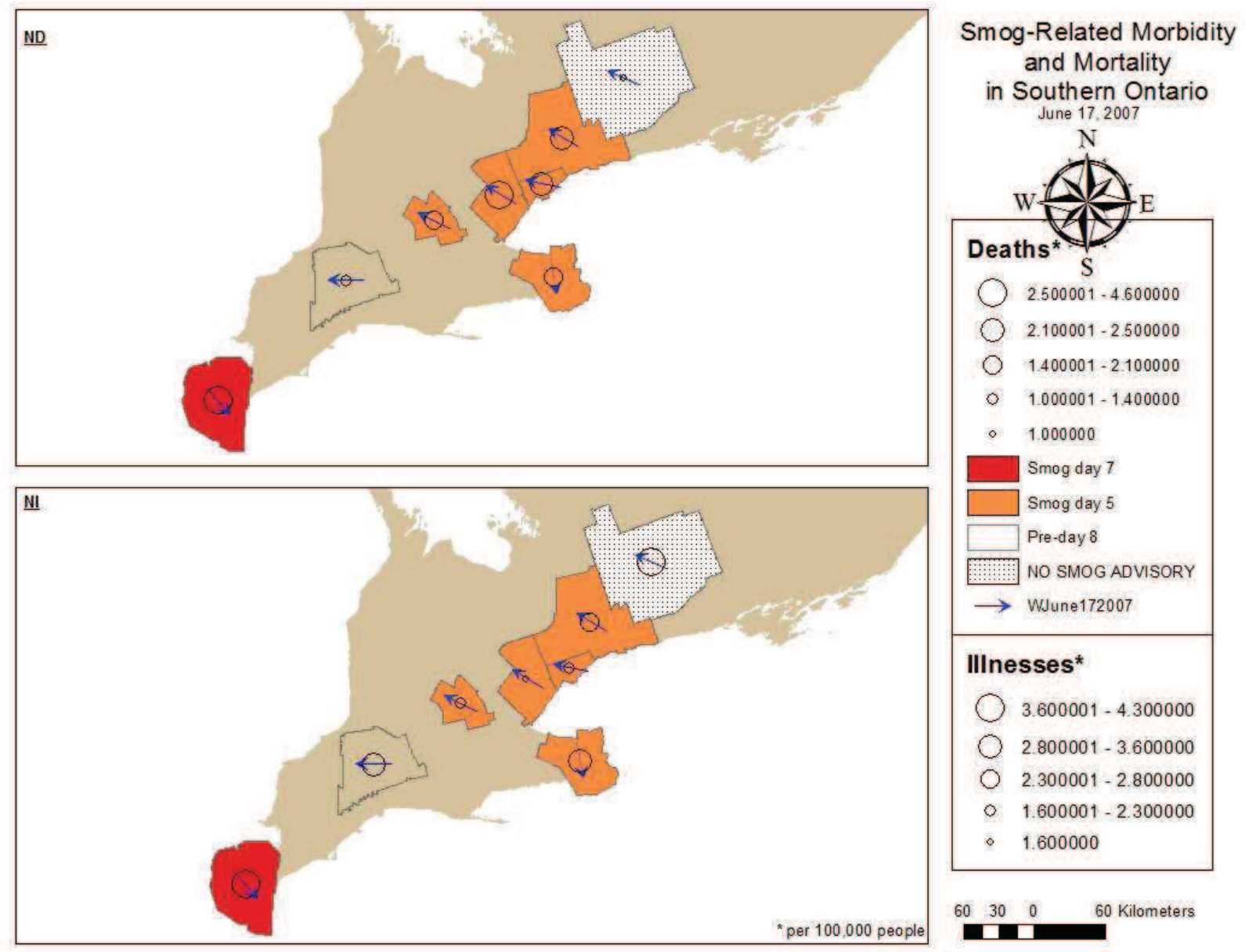

Figure 44: Map of Day 8 - June 17, 2007 
Day 9 - June 18, 2007 - The Waterloo area experienced the highest death rate at 5 deaths per 100,000 people with winds from the south-southwest. York-Durham also experienced high rates of 4.8 mortalities per 100,000 people with south-southeasterly winds. The area with the greatest rate of morbidity was the Peterborough-Kawartha Lakes area, experiencing 10.1 illnesses per 100,000 people and winds from the south.

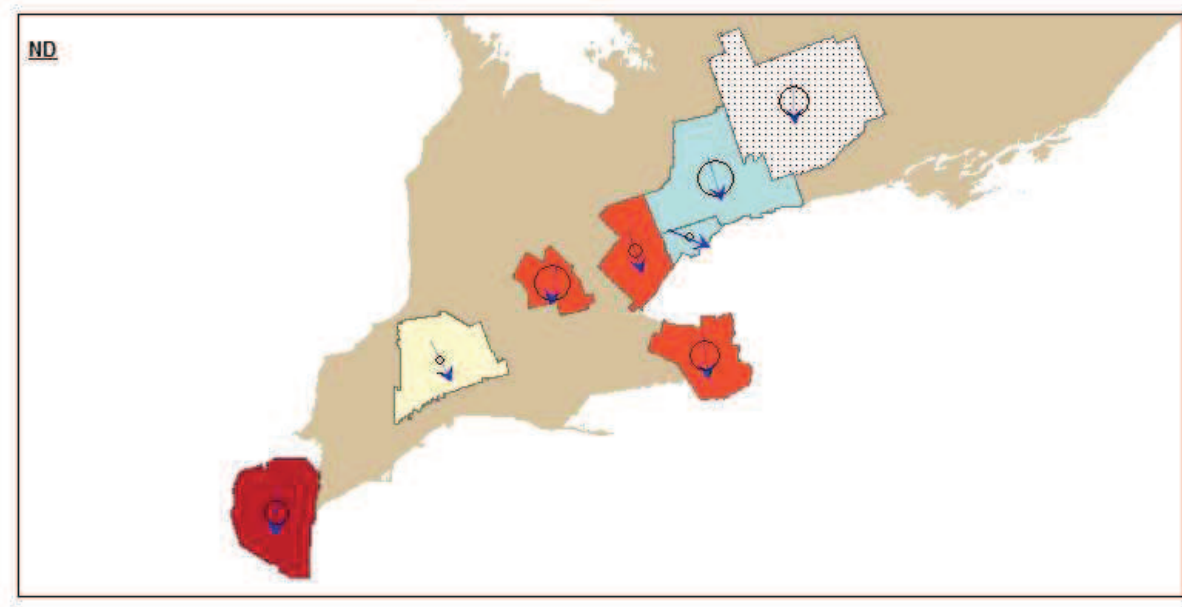

\section{Smog-Related Morbidity} and Mortality in Southern Ontario June 18,2007
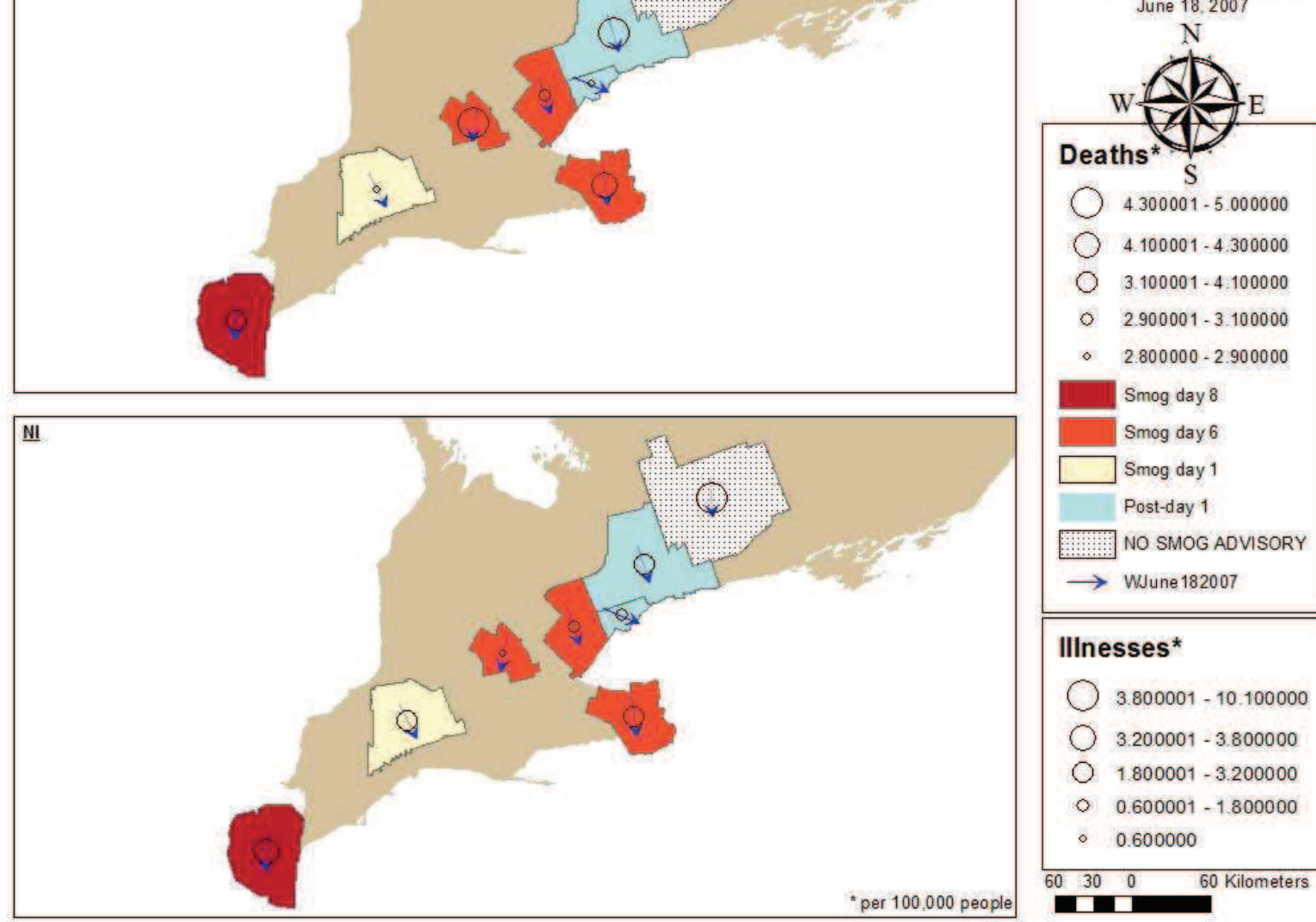

\section{IIInesses*}

( $3.800001-10.100000$

() $3.200001-3.800000$

( $1.800001-3.200000$

- $0.600001-1.800000$

- 0.600000 
Day 10 - June 19, 2007 - The highest level of deaths occurred during the Windsor region's ninth smog day with 6.4 mortalities per 100,000 people. Dominant winds were from the westsouthwest. The Niagara region also experienced high levels of illness during its seventh smog day at 4.9 morbidities per 100,000 with average wind direction from the southwest.
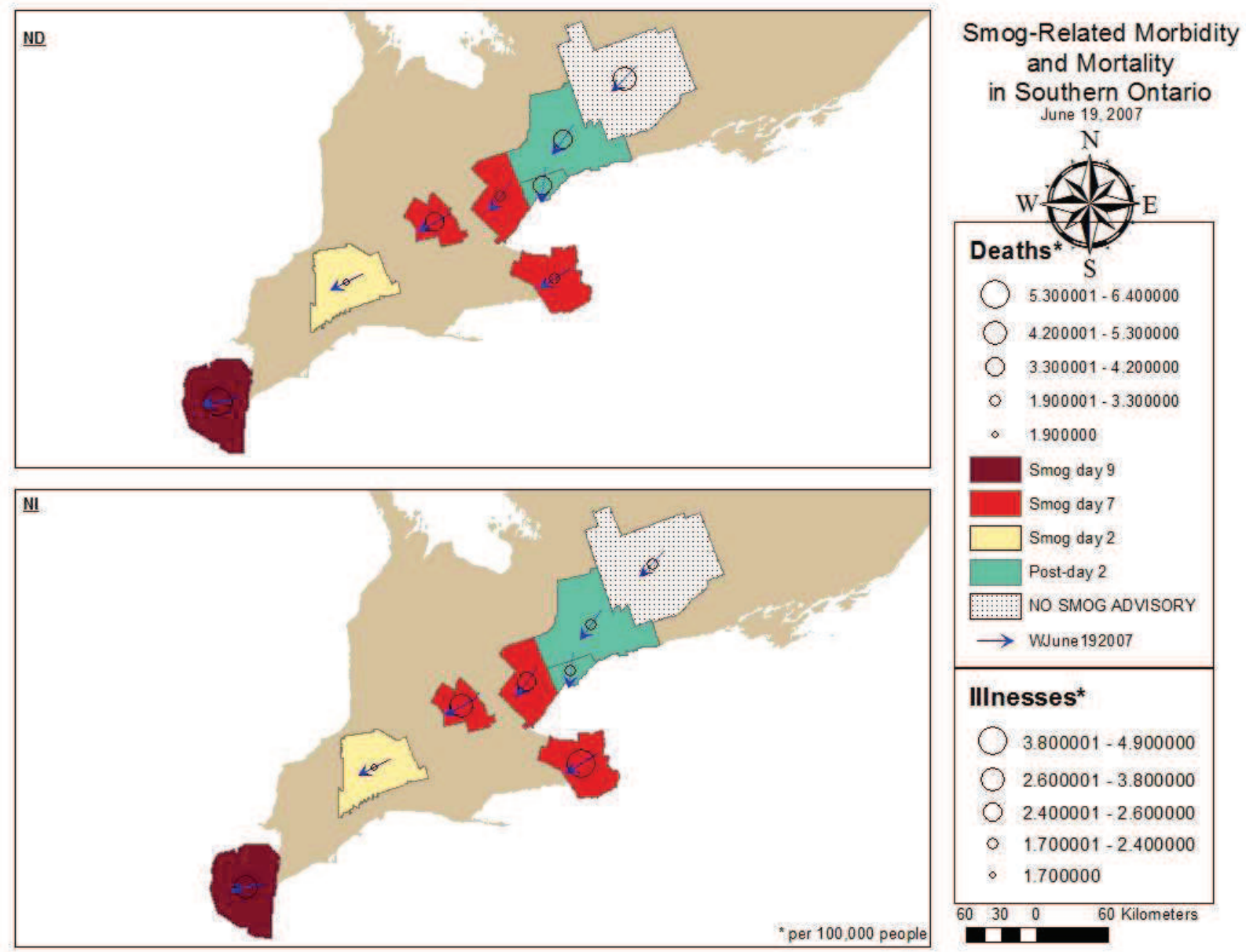

Figure 46: Map of Day 10 - June 19, 2007 
Day 11 - June 20, 2007 - The highest level of deaths during the eleventh day of observation occurred in the Peterborough region at 5.3 deaths per 100,000 with west-northwesterly winds. The second highest death rate occurred during the first post-day in the Windsor area at 5.1 deaths per 100,000 with dominant westerly winds. The Niagara region had the highest illness rate at 4.4 per 100,000 people with west-northwesterly winds.

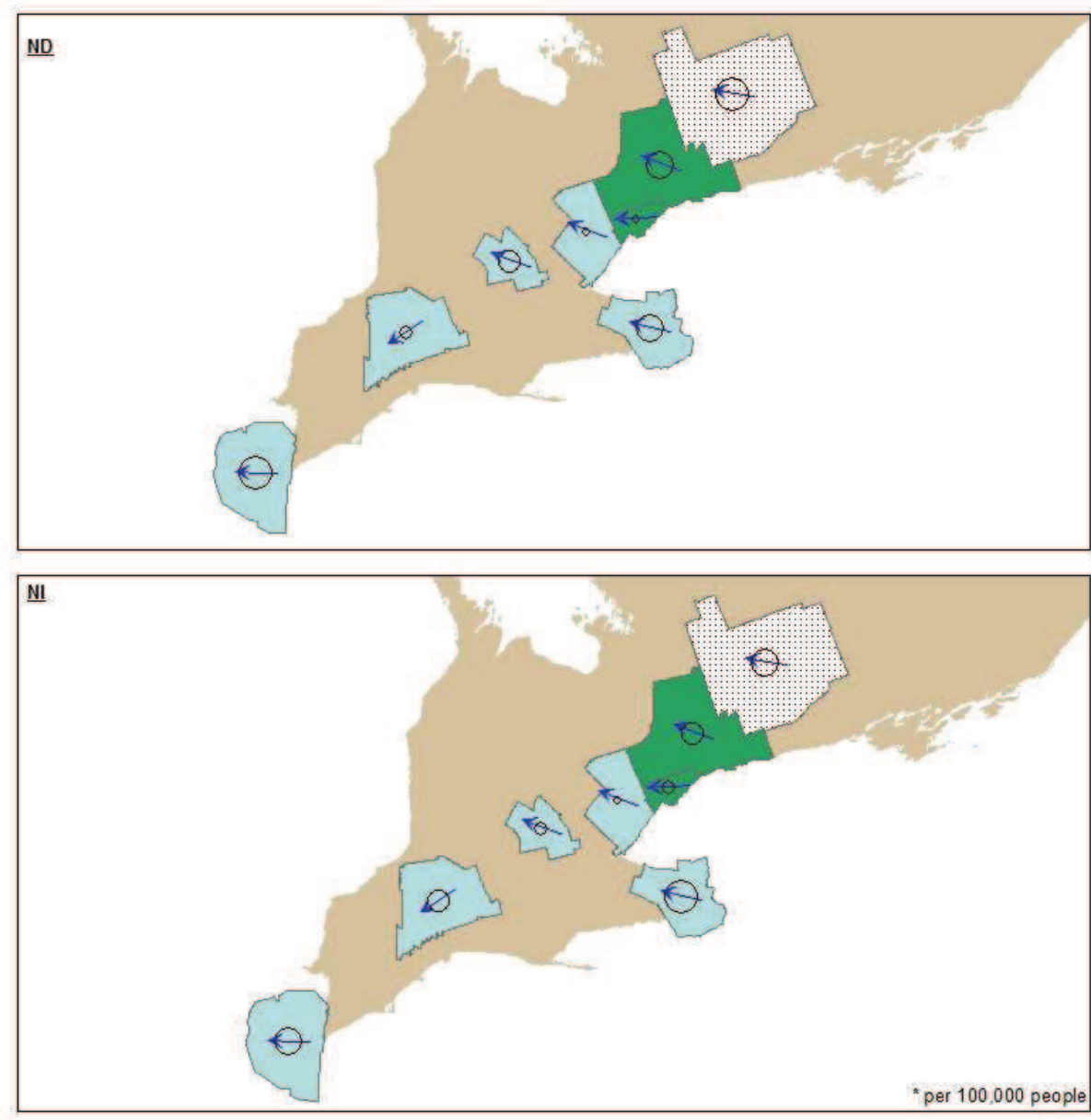

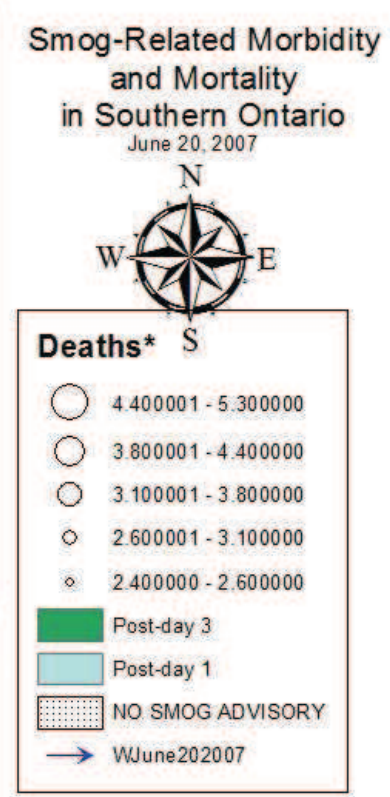

IIInesses*

(3) $3.800001-4.400000$

( $2.800001-3.800000$

( $2.100001-2.800000$

o $1.400001-2.100000$

- 1.400000

$\begin{array}{lll}60 & 30 & 0\end{array}$

Figure 47: Map of Day 11 - June 20, 2007 
Day 12 - June 21, 2007 - During the second post-day the Windsor-Essex region experienced the highest death rate for cardiovascular and respiratory problems at 6.1 deaths per 100,000 with winds from the southwest. The Peterborough region had the highest morbidity rate at 5.6 illnesses per 100,000 people with winds from the west-northwest.
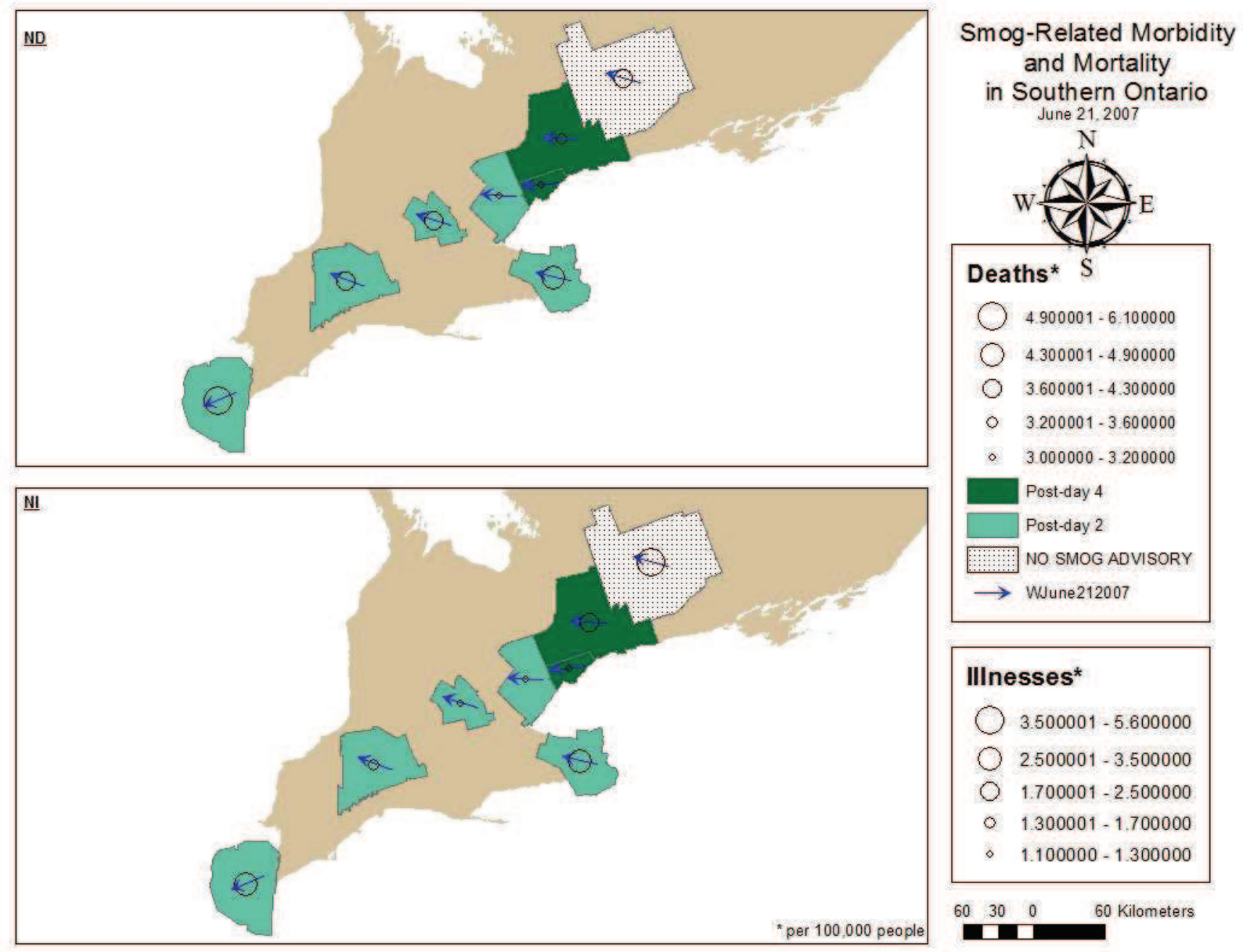
IIInesses*
$3.500001-5.600000$
( $2.500001-3.500000$
O $1.700001-2.500000$
- $1.300001-1.700000$
- $1.100000-1.300000$

Figure 48: Map of Day 12- June 21, 2007 


\section{Summary of Smog Event 2007:}

Although Peterborough did not experience a smog event during this time, it still had a significant number of deaths and illnesses out of the rest of the regions. The highest rate was during a non-smog advisory at 10.6 deaths per 100,000 people with an average temperature of 19.9 degrees Celsius and a southerly wind direction. This could suggest other influences on cardiovascular and respiratory morbidity and mortality. The area with the lowest death rate was also in Peterborough at 1 death per 100,000 with an average temperature on that day at 21.9 with west northwesterly winds. The highest illness occurred in Peterborough as well with a rate of 10.1 per 100,000 people, during this day the average temperature was 19.2 degrees Celsius and the wind direction was from the south. The area with the lowest illness rate was in the WaterlooKitchener area on smog day 6 with a rate of 0.6 morbidities per 100,000 people. The average temperature for that day was 23.5 degrees Celsius, much warmer than the Peterborough region, with wind from the south-southwest.

The effects experienced by the Peterborough-Kawartha Lakes region during a non-smog advisory could again be due to the effects of the GTA. Another potential reason could be the way pollution data is collected, perhaps the level that it is collected is not representative of where people are affected. Since the major meteorological station is located outside of the downtown centre in the Peterborough region, this could not represent what is occurring at the hospitals. The monitoring station for pollution levels stands at 226 metres potentially does not represent the ground levels of air contaminants. 


\subsubsection{Smog Advisory 2008:}

In 2008, the number of smog advisories varied from 3 to 6 for the study sites. The Halton-Peel and City of Toronto areas experienced 6 smog events while the PeterboroughKawartha Lakes and Waterloo-Kitchener regions had the least smog events with a total of 3 for each area. The longest advisory chosen was the $4^{\text {th }}$ advisory that year which occurred in midJuly. Not all regions were in a smog advisory. Peterborough-Kawartha Lakes, WaterlooKitchener and York-Durham were in a non-smog advisory during this event. The longest smog days were 4 and experienced in Windsor-Essex, Halton-Peel, Niagara and City of Toronto. The shortest smog advisory occurred in London-Middlesex with 2 smog days which occurred at the end of the smog event.

All regions in a smog advisory with the exception of London-Middlesex had 1 pre-day. The London-Middlesex region had 3 pre-days before beginning the smog event. All regions in a smog event had finished on July $19^{\text {th }}$ and had 2 post-days. Since 3 of the regions did not experience a smog event, it would be assumed that they would have the least number of morbidity and mortality. The areas with the longest smog event are expected to have the highest number of morbidity and mortality. From visual interpretation, the following observations were made: 
Day 1 - July 15, 2008 - The longest smog event for this year did not include all study sites, Peterborough-Kawartha Lakes, York-Durham and Waterloo-Kitchener regions did not have a smog advisory issued. During the first day of observations, the area with the highest death rates was the Waterloo region with 11 deaths per 100,000 people with winds moving from the southsouthwest direction. The area with the highest illnesses was also not in a smog advisory, the Peterborough region experienced 4.8 illnesses per 100,000 people with winds blowing from the southwest. The second highest illness level was in the Niagara region with 3.7 illnesses per 100,000 with winds from the south-southwest.
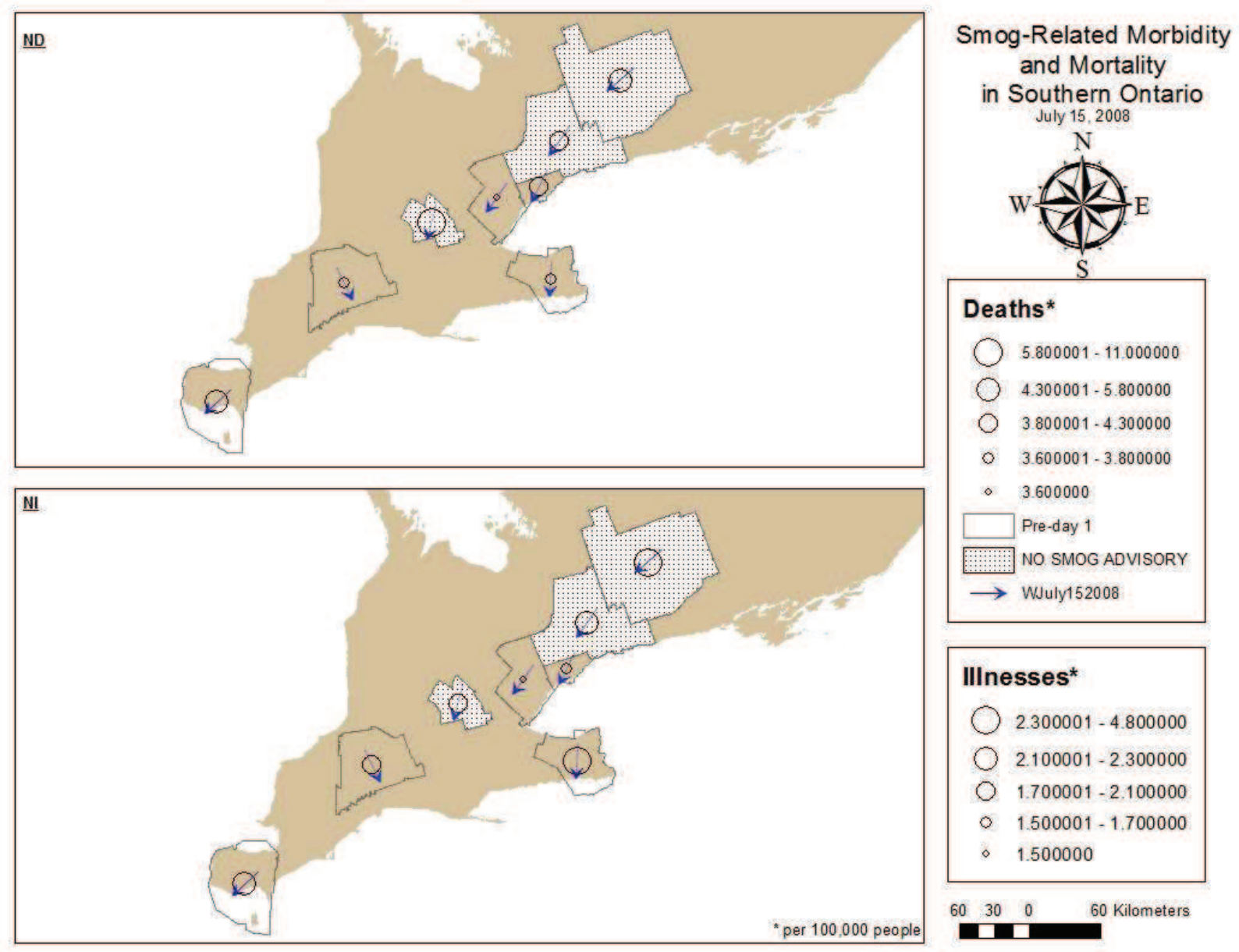

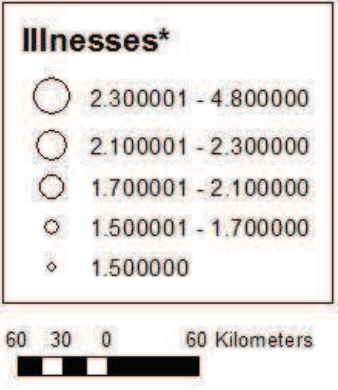

Figure 49: Map of Day 1 - July 15, 2008 
Day 2 - July 16, 2008 - During the second day of observations, the Waterloo region had the high death rate with 7.7 mortalities per 100,000 followed by Windsor-Essex region during the first smog day with 7.4 deaths per 100,000. Both areas had a wind direction of southwest.

Windsor also had the highest morbidity rate with 3.3 illnesses per 100,000.
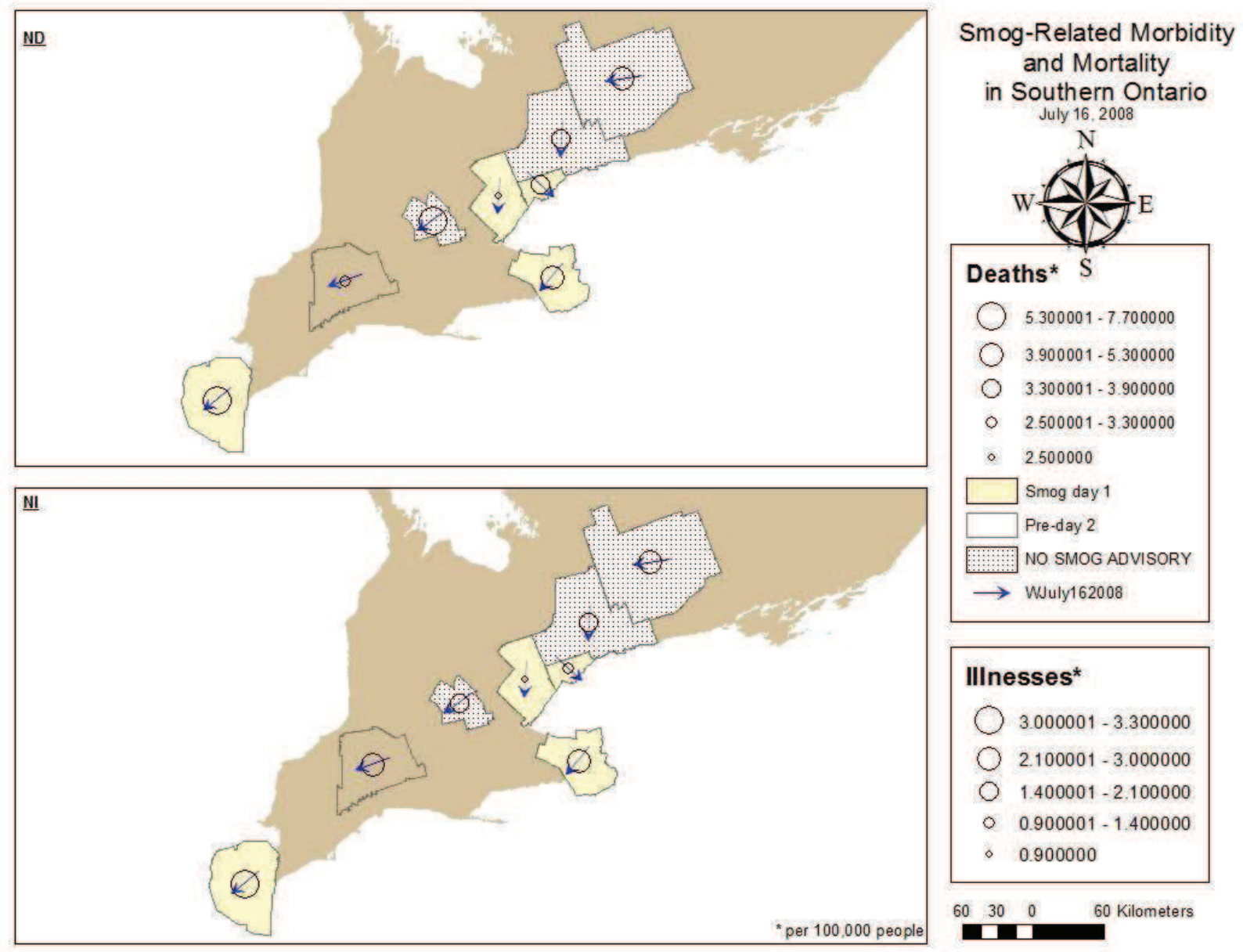
IIInesses*
( $3.000001-3.300000$
( $2.100001-3.000000$
O $1.400001-2.100000$
$0.900001-1.400000$
- 0.900000

Figure 50: Map of Day 2 - July 16, 2008 
Day 3 - July 17, 2008 - On the third day of observations, the Waterloo area had the highest number of deaths at 8.7 mortalities per 100,000 people. The Windsor-Essex region had the highest number of illnesses during the second smog day of the smog event, with 4.3 morbidities per 100,000 people. Both regions had winds from the southwest.
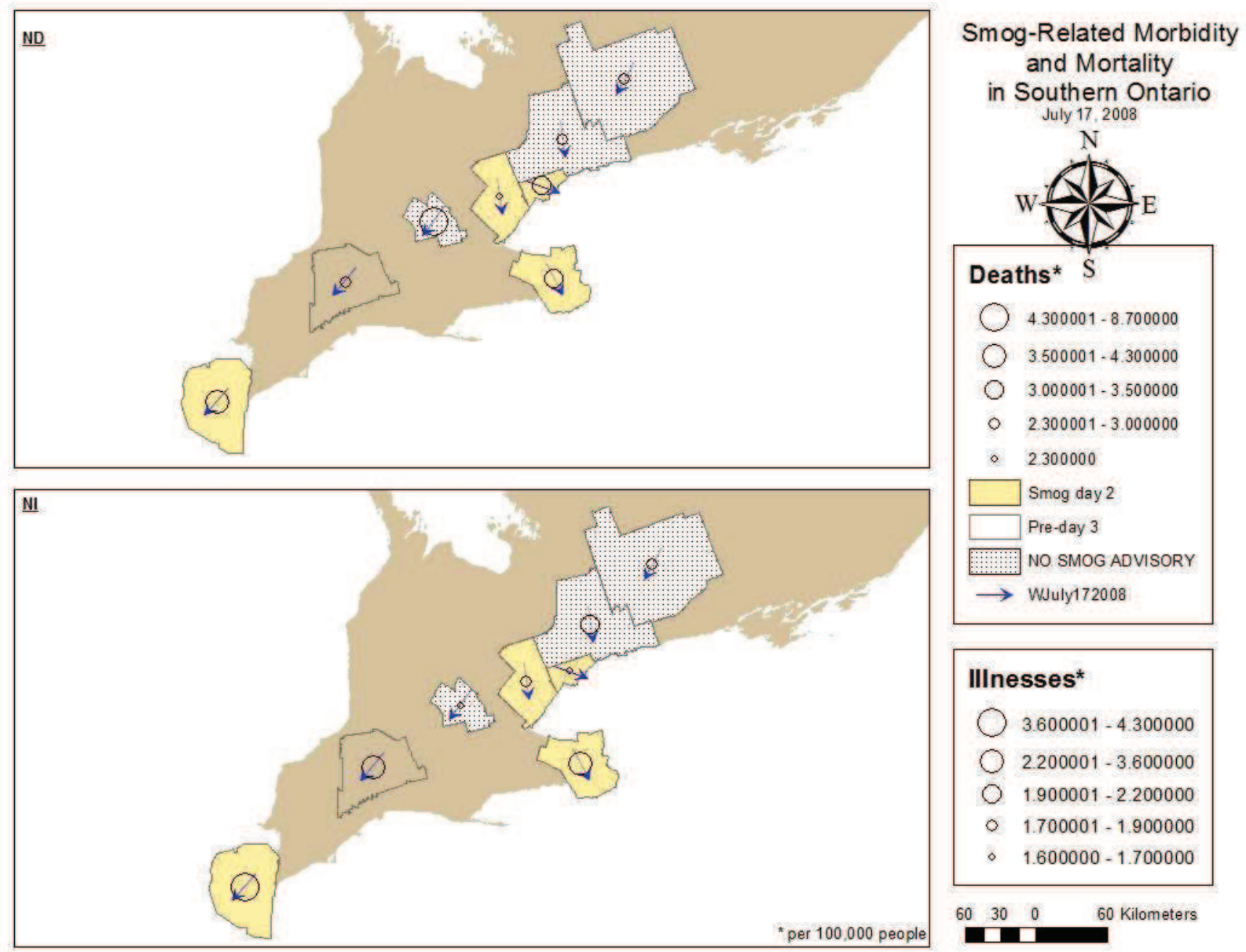

Figure 51: Map of Day 3 - July 17, 2008 
Day 4 - July 18, 2008 - Waterloo-Kitchener death rate stayed the same with 8.7 deaths per 100,000 people. Peterborough and Niagara had the highest illness rate with 4.3 illnesses during a non-smog day in the Peterborough area followed by 4.2 illnesses per 100,000 people in the Niagara region. All three regions had a southwesterly wind direction.
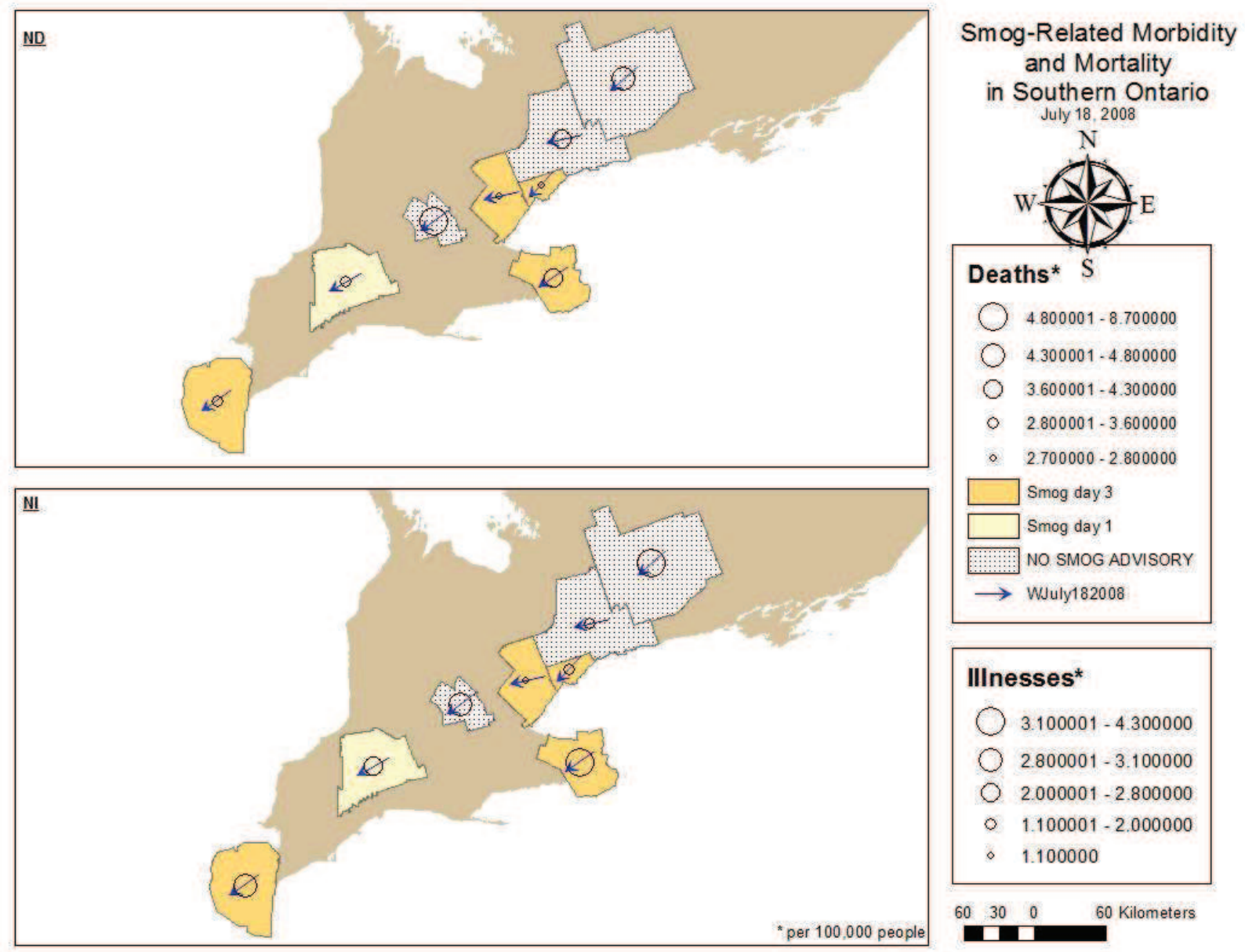

\section{IIInesses* \\ $3.100001-4.300000$ \\ ( $2.800001-3.100000$ \\ ( $2.000001-2.800000$ \\ - $1.100001-2.000000$ \\ - 1.100000

Figure 52: Map of Day 4 - July 18, 2008 
Day 5 - July 19, 2008 - Waterloo-Kitchener had the highest death rate with 5.3 deaths per 100,000 people occurring during the fifth day of observation. Wind was moving from the southwesterly direction. The London-Middlesex and Niagara region had the same illness rate at 4 illnesses per 100,000 people. London was in its second smog day with influencing winds from the south. The Niagara region was in its fourth smog day during the episode with winds blowing from the southwest.
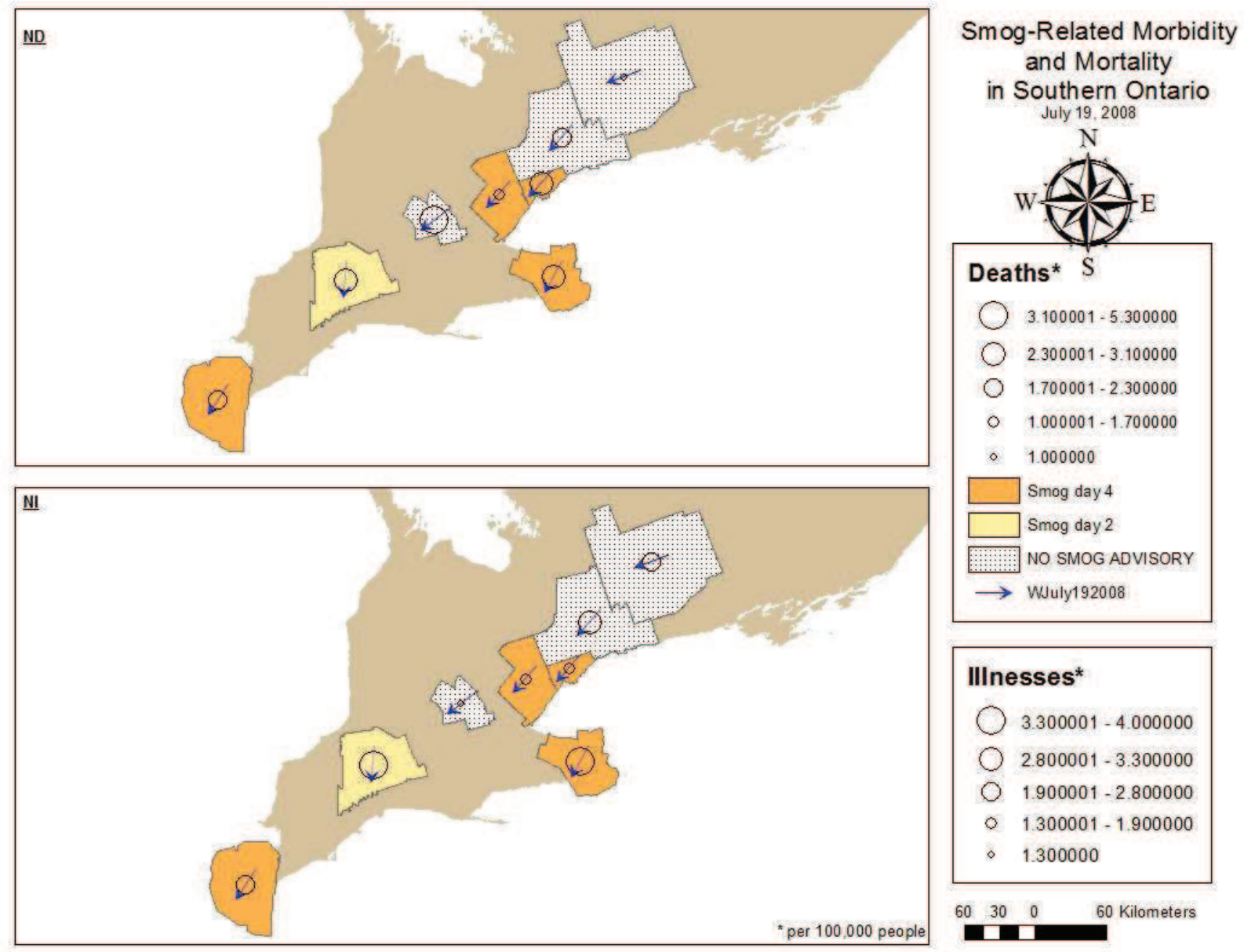
IIInesses*
( $3.300001-4.000000$
() $2.800001-3.300000$
( $1.900001-2.800000$
- $1.300001-1.900000$
- 1.300000 
Day 6 - July 20, 2008 - The Waterloo region had 3.9 deaths per 100,000 people on the sixth day of the non-smog advisory with southeasterly winds. Niagara region had the highest illness rate during its first post-day at 4.7 illnesses per 100,000 people with southern winds. This could indicate lag effects felt in Niagara as the illness rate had increased from the previous day. The second highest illness rate was in London-Middlesex region during the first post-day of a 2 day smog event, with 4.5 morbidities per 100,000 people and winds from the southwest.
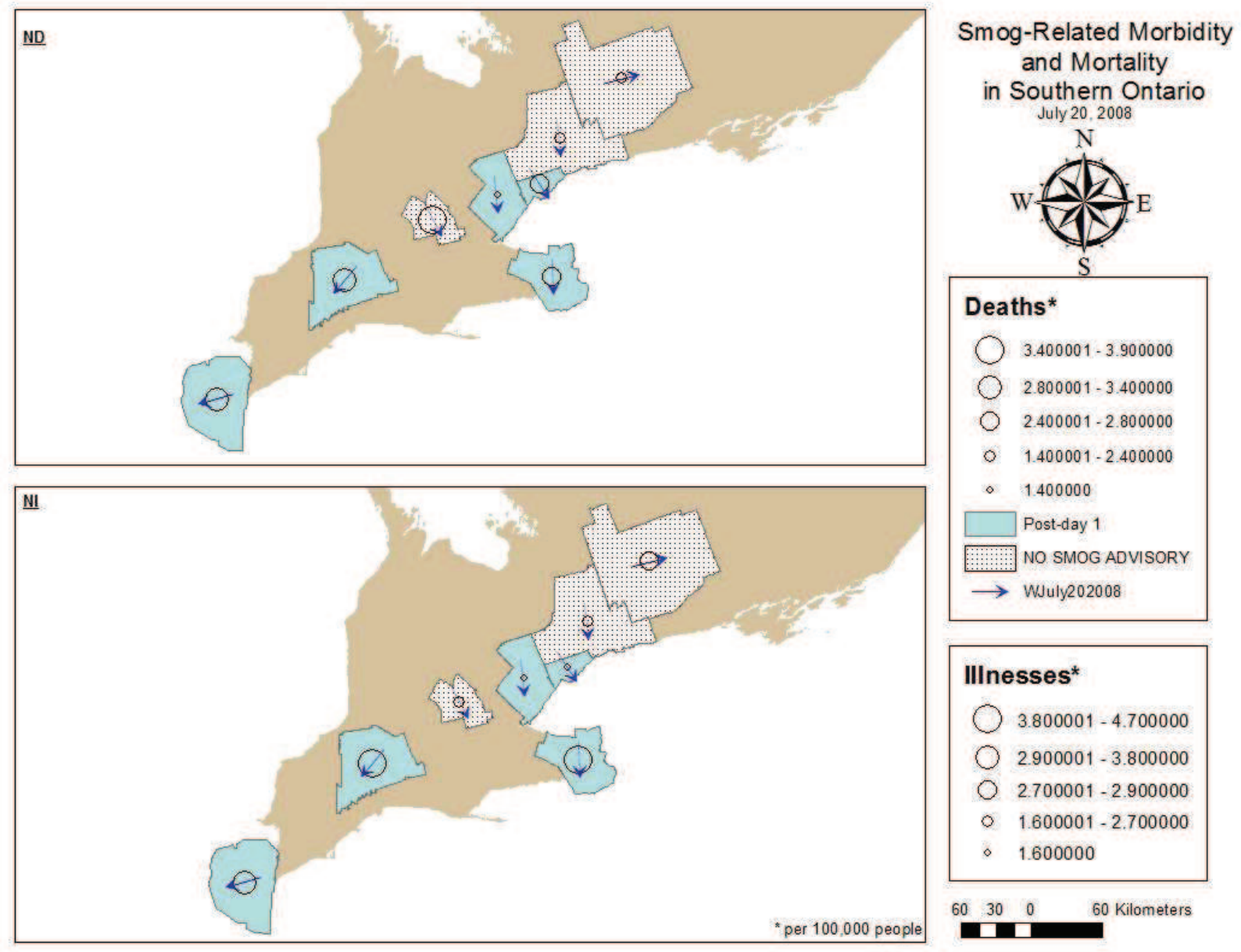

Figure 54: Map of Day 6 - July 20, 2008 
Day 7 - July 21, 2008 - On the last day of observation the Waterloo region had the highest death rate again with 10.1 deaths per 100,000 people with wind from the southeast. The reason for an increase in cardiovascular and respiratory deaths is difficult to determine since the average temperature for that day was 19.7 degrees Celsius and since the area is not in a smog event, it is assumed that air contaminant levels are low. The Peterborough-Kawartha Lakes area had an illness rate of 4.8 illnesses of 100,000 with winds from the south-east. The London-Middlesex region had the second highest illness rate at 4.5 illnesses per 100,000 people with winds from the west-northwest.
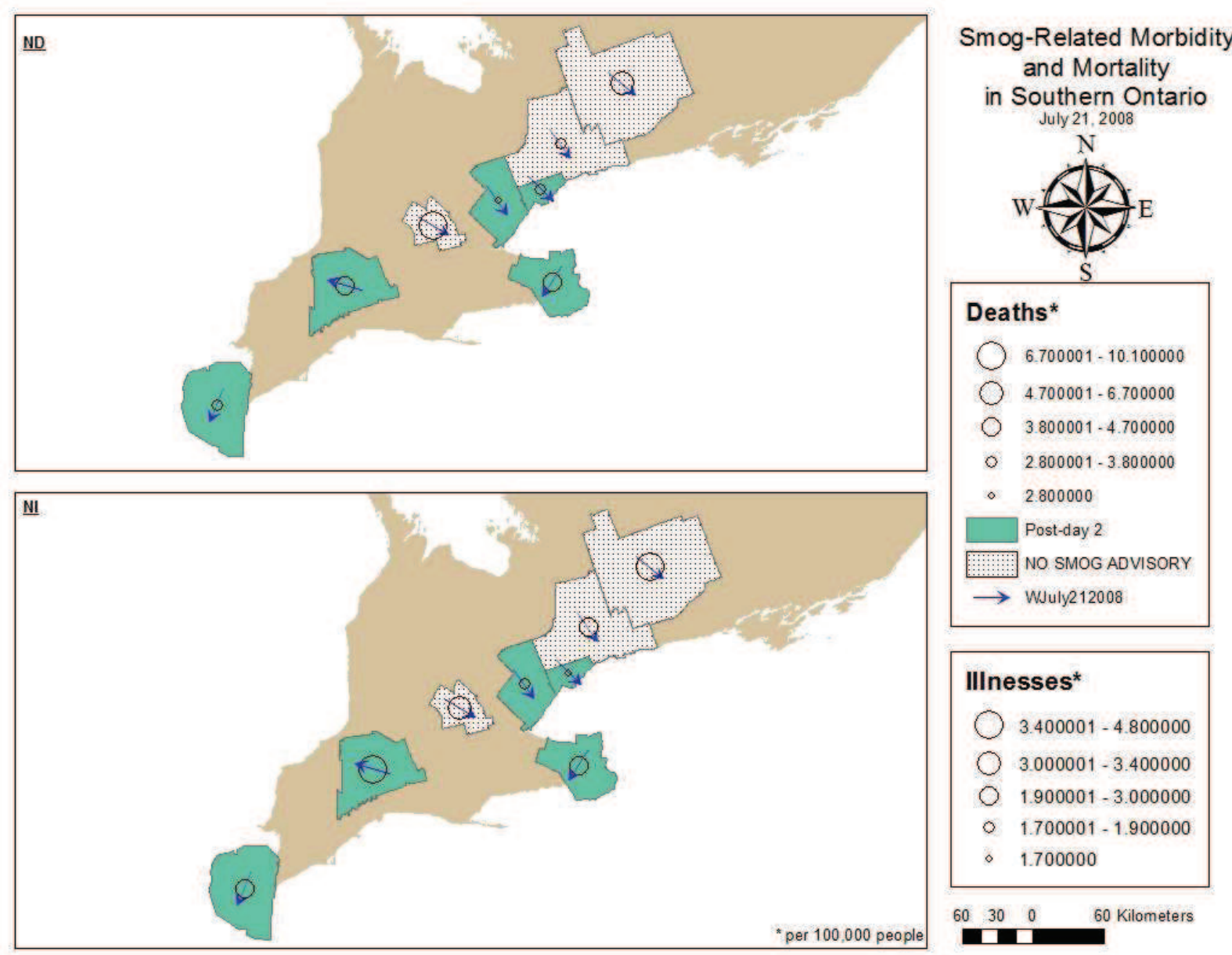

\begin{tabular}{|c|c|}
\hline \multicolumn{2}{|c|}{ Illnesses* } \\
\hline & $3.400001-4.800000$ \\
\hline & $3.000001-3.400000$ \\
\hline & $1.900001-3.000000$ \\
\hline 0 & $1.700001-1.900000$ \\
\hline$\circ$ & 1.700000 \\
\hline 30 & 60 Kilometers \\
\hline
\end{tabular}

Figure 55: Map of Day 7 - July 21, 2008 


\section{Summary of Smog Event 2008:}

During the smog advisory, the area with the highest deaths occurred in the WaterlooKitchener region during a non-smog day with 11 deaths per 100,000 people during that day, the average temperature was 19 degrees Celsius with winds from south-southwest. The area with the lowest deaths was in the Peterborough region at 1 death per 100,000 people with an average temperature of 23.3 degrees Celsius with winds from the west-southwest. Peterborough also had the highest level of illnesses at 4.8 morbidities per 100,000 people with the average temperature of 19 degrees Celsius and winds coming from the southeast. The lowest illness rate occurred in the Halton-Peel region during its first smog day at 0.9 illnesses with an average temperature of 24.7 degrees Celsius with southerly winds. The majority of the highest deaths and illnesses occurred in regions that did not have a smog advisory which could indicate that other factors are affecting cardiovascular and respiratory morbidity and mortality. Since the average temperatures for the areas with high rates was not significantly high, which could indicate other factors are playing a role in the number of deaths and illnesses. 


\subsubsection{Smog Event 2009:}

In 2009, the average number of smog advisories were 2 which the exception of the Windsor-Essex region that had 3 smog advisories. The longest advisory selection was the last one that occurred in Mid-August which was 3 days in length. Since there were no advisories previous to the selected one, it would be assumed that there would not be a substantial amount of deaths and illnesses to occur. All regions had 3 smog days which began and finished on the same days. Since all regions have the same smog event, a wave-like progression would not be assumed, rather as each day passed, the number of deaths in each region is expected to increase. After the second or third day, the number of deaths and illnesses was expected to be at its highest. From visual interpretation, the following observations were made: 
Day 1 - August 14, 2009 - During the pre-day of the smog event, the regions with the highest death rate were Niagara and Windsor-Essex. The death rate in Niagara was 4.7 mortalities per 100,000 with winds from the southeast. The Windsor region had a slightly lower death rate from Niagara, at 4.6 mortalities per 100,000 people with south-southeasterly winds. The area with the highest illness rate was London-Middlesex with 4 morbidities per 100,000 and winds blowing from the $\mathrm{S}$.
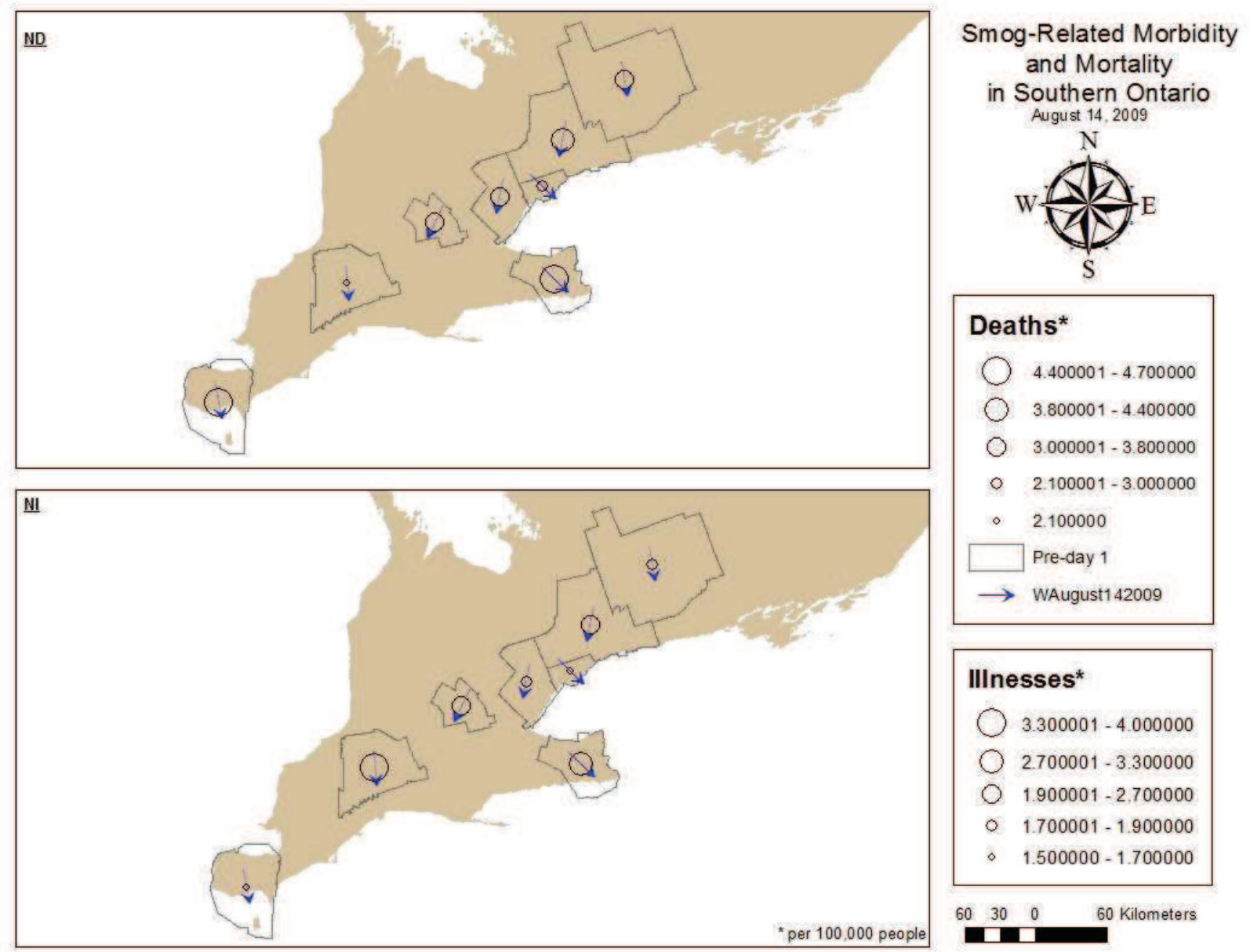
IIInesses*
( $3.300001-4.000000$
( $2.700001-3.300000$
O $1.900001-2.700000$
- $1.700001-1.900000$
- $1.500000-1.700000$
$\begin{array}{lll}60 & 30 & 0\end{array}$
60 Kilometers

Figure 56: Map of Day 1 - August 14, 2009 
Day 2 - August 15, 2009 - All regions are in a smog advisory, the highest deaths occurred in the York-Durham region with 3.9 deaths per 100,000 people and winds from the southwest. The regions with the highest illness rates were Peterborough-Kawartha Lakes region with 4.3 illnesses and Niagara with 3.5 illnesses per 100,000 people. The wind direction for the Peterborough area was from the south-southwest while the Niagara wind direction was the southsoutheast.
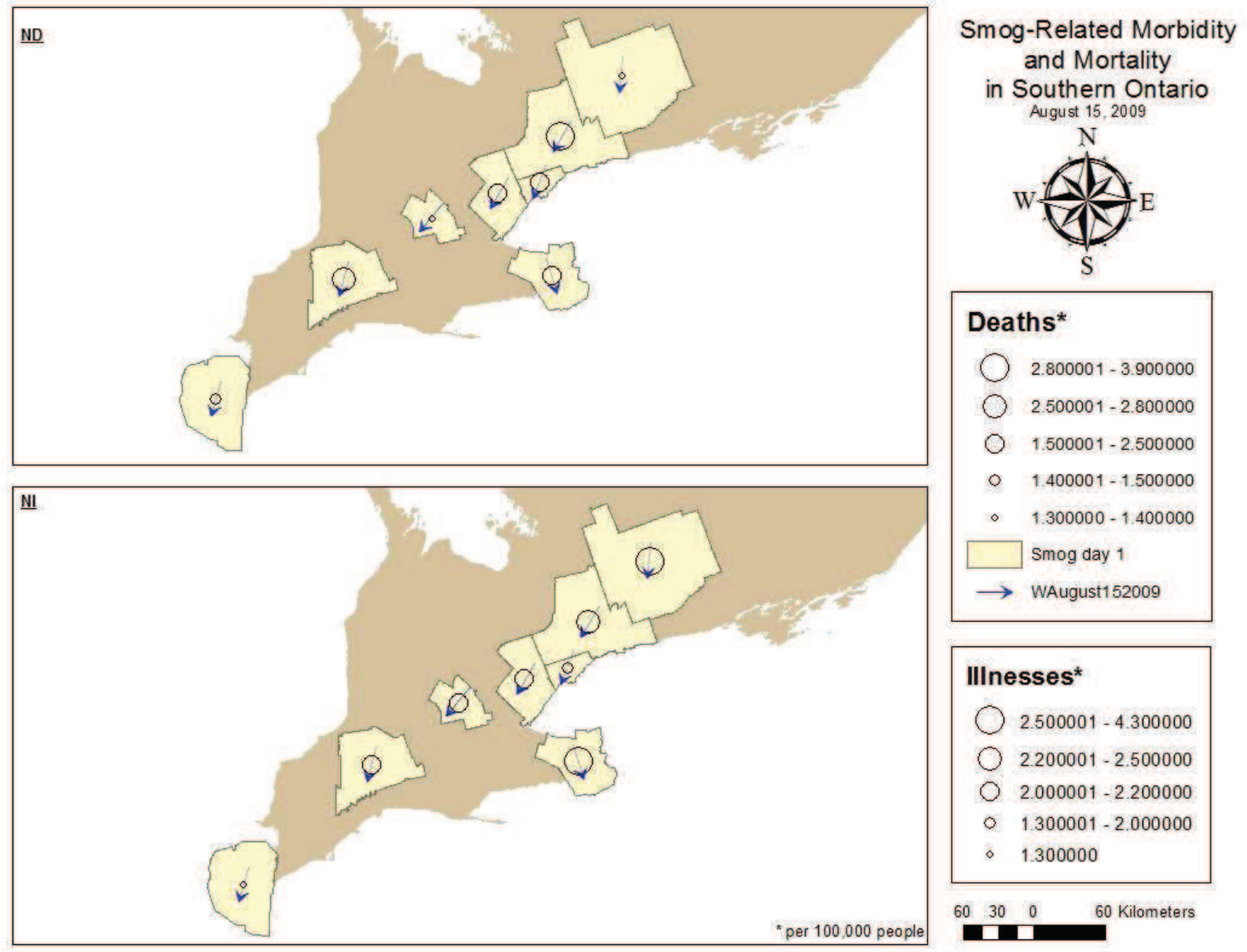
IIInesses*
( $2.500001-4.300000$
( $2.200001-2.500000$
O $2.000001-2.200000$
- $1.300001-2.000000$
- 1.300000
$\begin{array}{lll}60 & 30 & 0\end{array}$
$\begin{array}{lll}30 & 0 & 60 \text { Kilometers }\end{array}$

Figure 57: Map of Day 2 - August 15, 2009 
Day 3 - August 16, 2009 - During the second day of the smog advisory, the region with the highest death rate was the York-Durham region, with 2.8 deaths per 100,000 people, this is quite low, indicating that the effects of the first smog day have not been felt. The wind direction for this area was from the southeast. The region with the highest level of illnesses was the Niagara region with 4.9 morbidities per 100,000 people that occurred when winds were from the southwest.
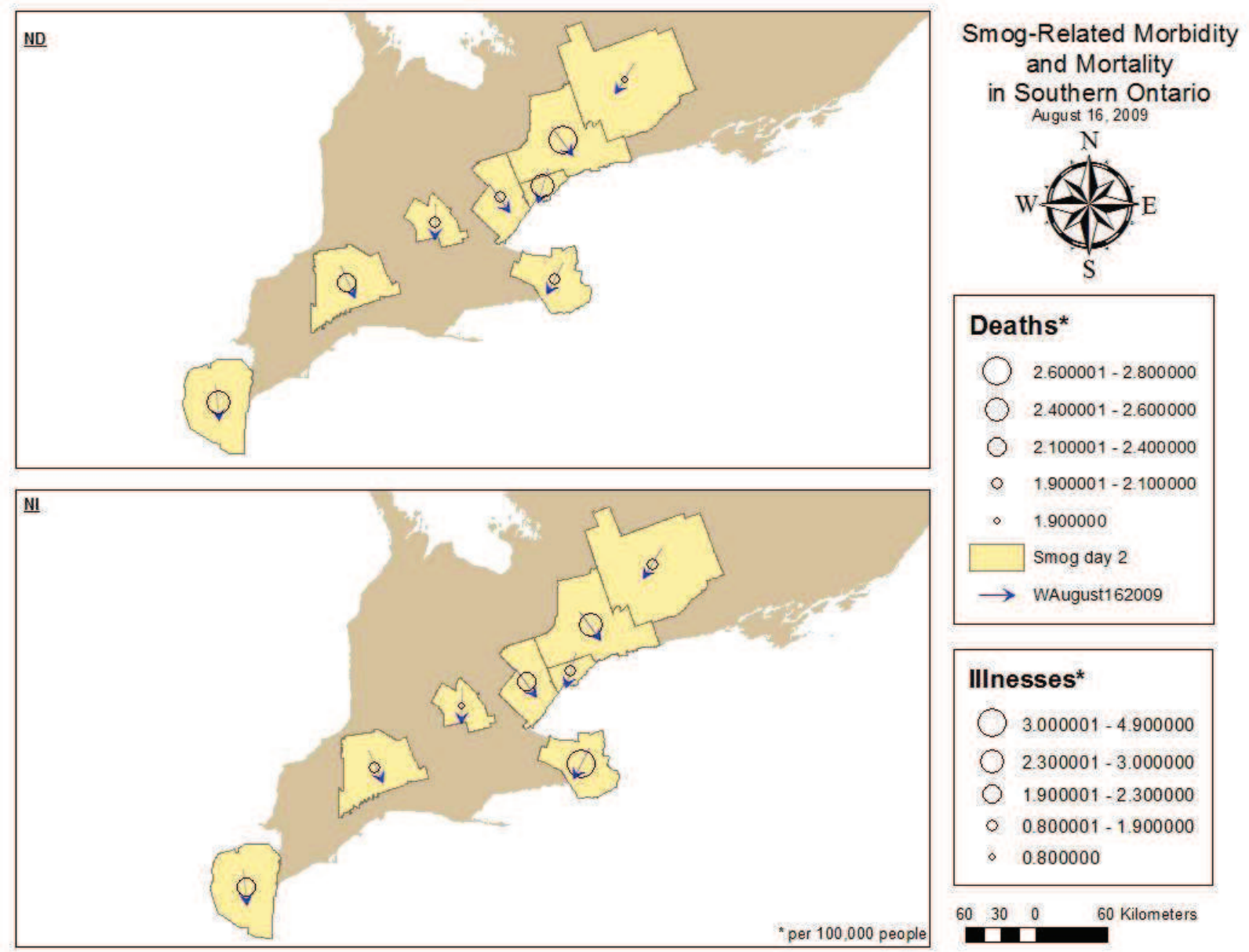

\section{IIInesses*}

(3.000001-4.900000

( 2.300001-3.000000

( $1.900001-2.300000$

o $0.800001-1.900000$

- 0.800000 
Day 4 - August 17, 2009 - During the third smog day of the episode, the areas that had the highest mortality and morbidity rates also had winds from the southwest. The Windsor-Essex region had 5.1 deaths per 100,000 , this increase in deaths indicate that human health is responding to the lag effects of high levels of air pollutants. The Waterloo-Kitchener region had the highest illness level with 5.4 illnesses per 100,000 people, also indicated a rise in respiratory and cardiovascular disease after 2 smog days.
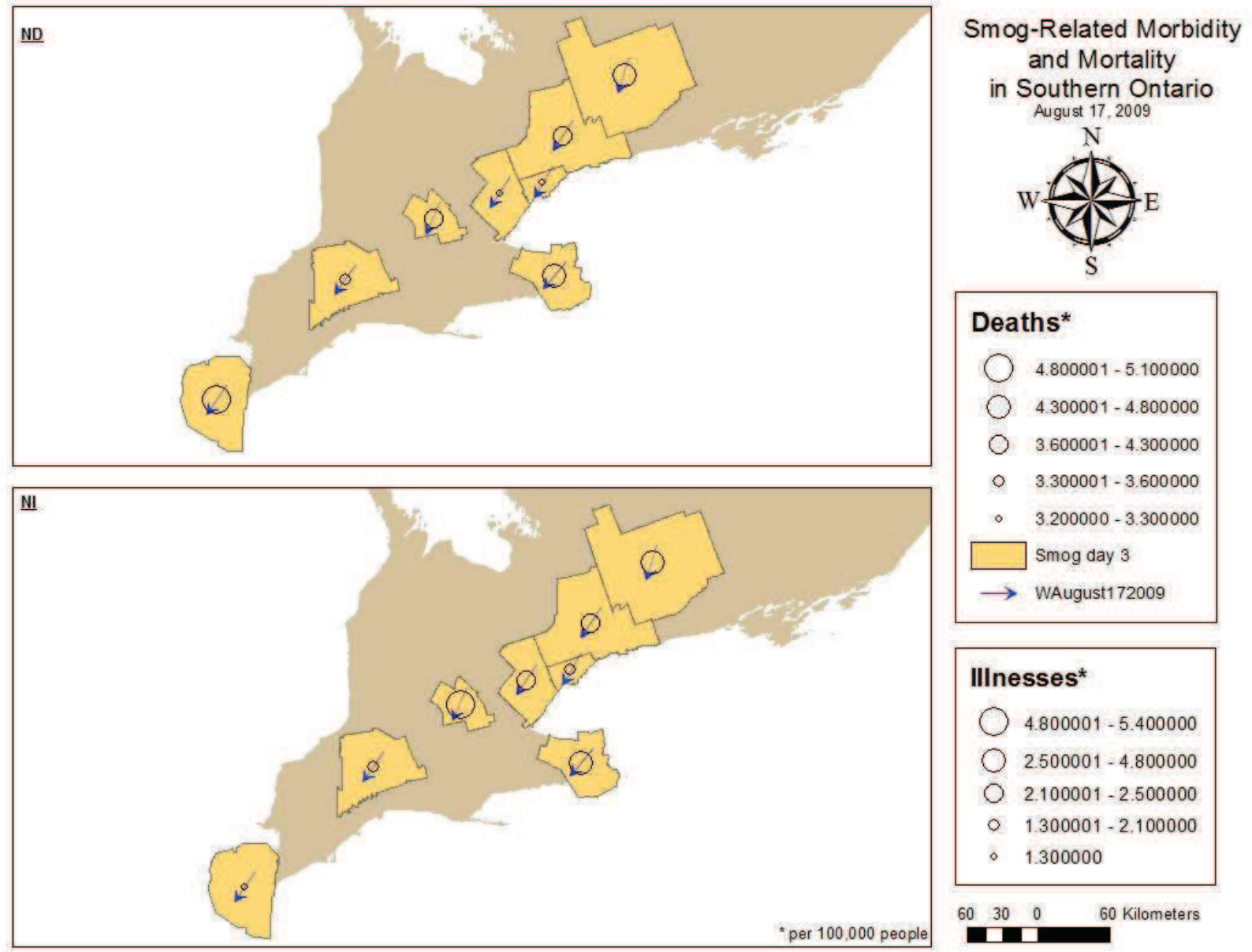

\section{Deaths* \\ ( $4.800001-5.100000$ \\ () $4.300001-4.800000$ \\ O $3.600001-4.300000$ \\ - $3.300001-3.600000$ \\ - $3.200000-3.300000$ \\ Smog day 3 \\ $\rightarrow$ WAugust172009}

\section{IIInesses*}

( $4.800001-5.400000$

( $2.500001-4.800000$

O $2.100001-2.500000$

- $1.300001-2.100000$

- 1.300000 
Day 5 - August 18, 2009 - On the first post-day after the smog advisory, the Niagara region experienced the highest death rate out of all the study sites at 5.4 deaths per 100,000 people, slightly increasing the rate from the previous day. The illness rate also increased, the Peterborough region showed a 7.2 illness rate per 100,000 people. Both regions had winds from the southwesterly direction. This would indicate the lag effects played a major role in the increase of deaths on the first post-day.
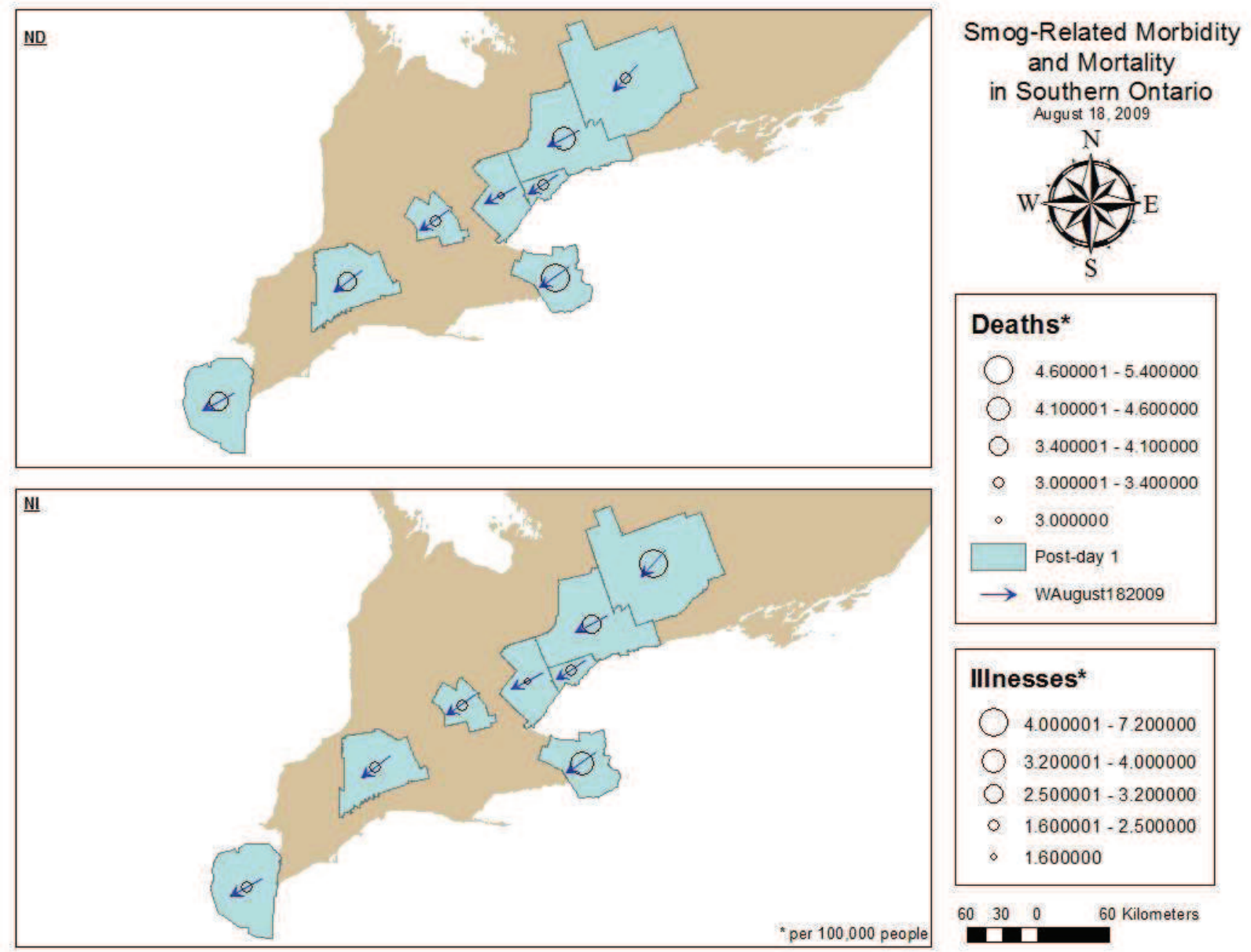

\section{IIInesses*}

( $4.000001-7200000$

( $3200001-4.000000$

( $2.500001-3.200000$

- $1.600001-2.500000$

- 1.600000 
Day 6 - August 18, 2009 - The second post-day after the smog event showed a substantial increase in the death rate in the Peterborough region with 7.7 deaths per 100,000 people with winds from the west. Peterborough also had the highest illness rate at 3.4 illnesses per 100,000 people, followed by the York-Durham region with the second highest illness rate at 2.8 illnesses per 100,000 people with a southwesterly wind.
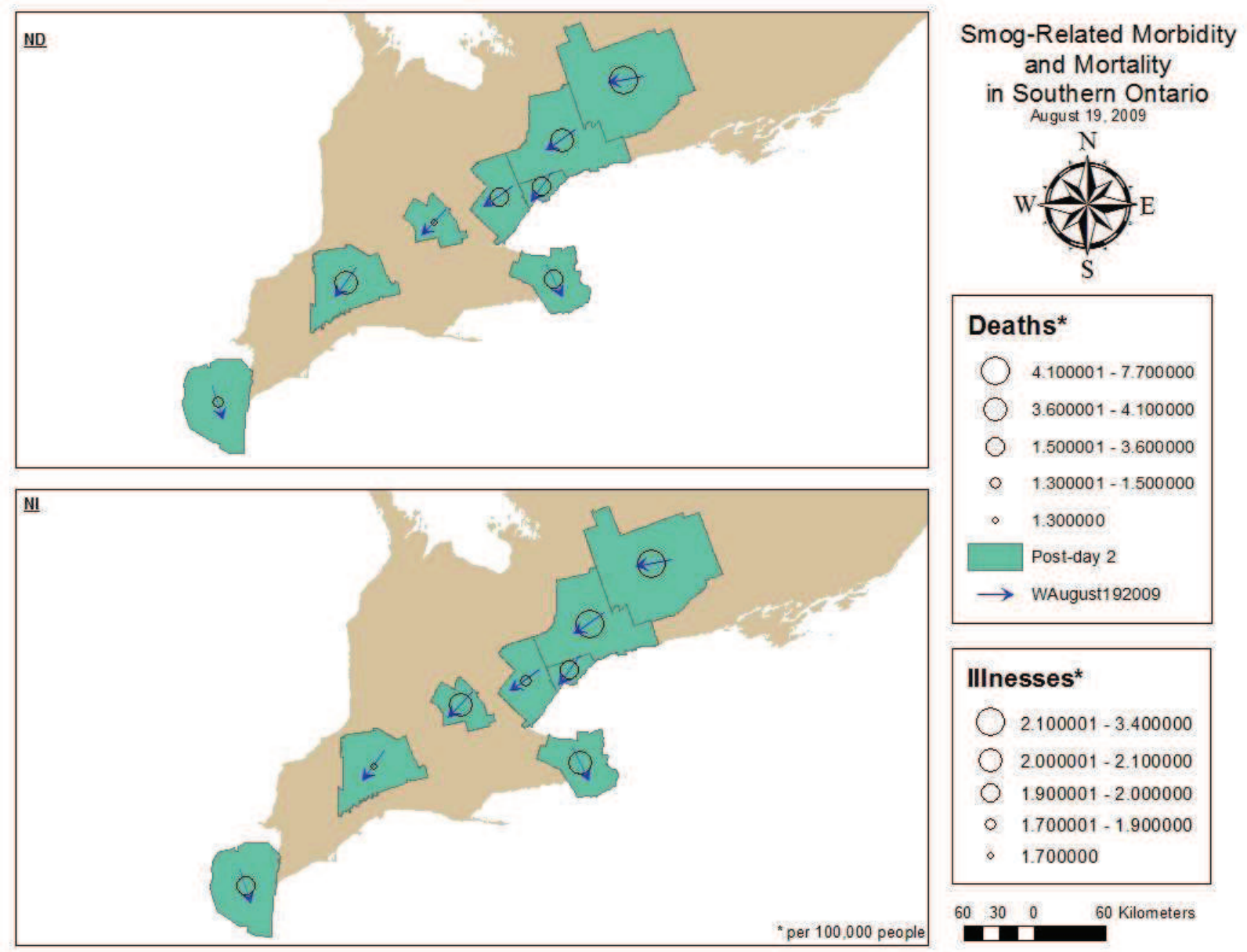

\section{IIInesses*}

$2.100001-3.400000$

( $2.000001-2.100000$

○ $1.900001-2.000000$

o $1.700001-1.900000$

- 1.700000

60 Kilometers

Figure 61: Map of Day 6 - August 19, 2009 


\section{Summary of Smog Event 2009:}

The highest death rate for the entire smog event was in the second post-day in the Peterborough region, with 7.7 deaths per 100,000 people. During this day, the average temperature was 19.8 degrees Celsius with wind blowing from the west-southwest. Since the temperature was not at a dangerous level, it is very likely the high rate is attributed to the lag effects. The lowest death rate also occurred on the second post-day in the Waterloo-Kitchener region with 1.3 deaths per 100,000 people, the average temperature was 20.4 degrees Celsius with southwesterly winds. This region did not experience the same lag effects as Peterborough, rather the heighten death rate in this region occurred on the fourth smog day, indicating other factors are influencing each region in Southern Ontario. The same regions that experienced the highest and lowest death rates also experienced the highest and lowest illness rate. The Peterborough region had the highest illness rate during the first post-day with 7.2 illnesses per 100,000 people, the average temperature was 23.1 degrees Celsius and winds were from the southwest. This could be an indicator for a lag effect felt the following day in which the death rate increased substantially, it is possible a number of those who were emitted to hospital with cardiovascular or respiratory illness could have succumbed to the exposure. The lowest illness rate occurred in the Waterloo region during the second smog day with 0.8 illnesses per 100,000 people. The average temperature for that day was 22.5 degrees Celsius and southerly winds. The following day, smog day 4, the illness rate in Waterloo-Kitchener rose to 5.4 illnesses per 100,000 people, which could also indicate a lag effect. 


\subsubsection{Smog Event 2010:}

In 2010, all study sites experienced a total of 2 smog events during this month. The longest smog event which was selected occurred in early-July. Since there was no smog event previous to this one, it would be assumed that the pre-days deaths and illnesses would be lower. The length of the smog event; however, could result in high morbidity and mortality numbers after the first 2 to 3 days of the events. The areas with the longest smog event were WindsorEssex and London-Middlesex with 6 smog days. All other regions experienced 5 smog days and 2 pre-days. All regions' smog advisories ended on July $8^{\text {th }}$ and were followed by 2 post-days. From visual interpretation, the following observations were made: 
Day 1- July 2, 2010 - During the first pre-day, the area that had the highest illness rate was the Windsor-Essex region with 8.1 deaths per 100,000 people and winds blowing from the south. The York-Durham region had the highest level of illnesses with 4.6 illnesses per 100,000 people and with southwesterly winds.
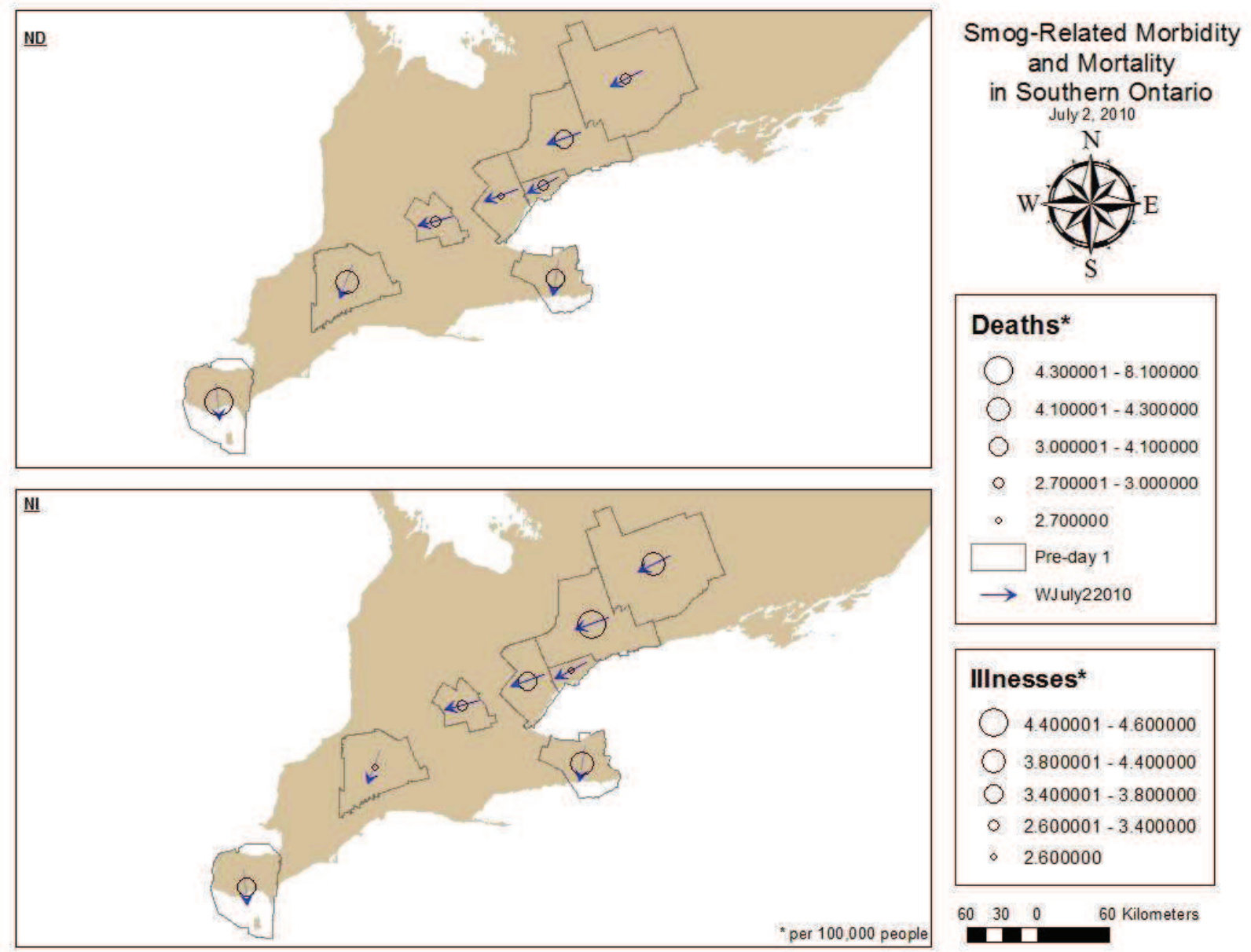

\section{IIInesses*}

( $4.400001-4.600000$

( $3.800001-4.400000$

O $3.400001-3.800000$

- $2.600001-3.400000$

- 2.600000

Figure 62: Map of Day 1 - July 2, 2010 
Day 2 - July 3, 2010 - During the second observation day, Windsor-Essex and LondonMiddlesex had entered into a smog advisory, however the rest of the study sites were experiencing non-smog days. The area with the highest death rate was the Peterborough region with 3.9 deaths per 100,000 people. The Niagara region had the highest illness rate with 4.4 illnesses per 100,000 people. Neither of these sites was in a smog advisory but yielded the highest numbers of cardiovascular and respiratory mortality and morbidity cases. Both of these regions experienced wind directions from the southwest. A potential reason why Niagara is experiencing high levels of illnesses could be due to the influence of the coal plant located to the west.
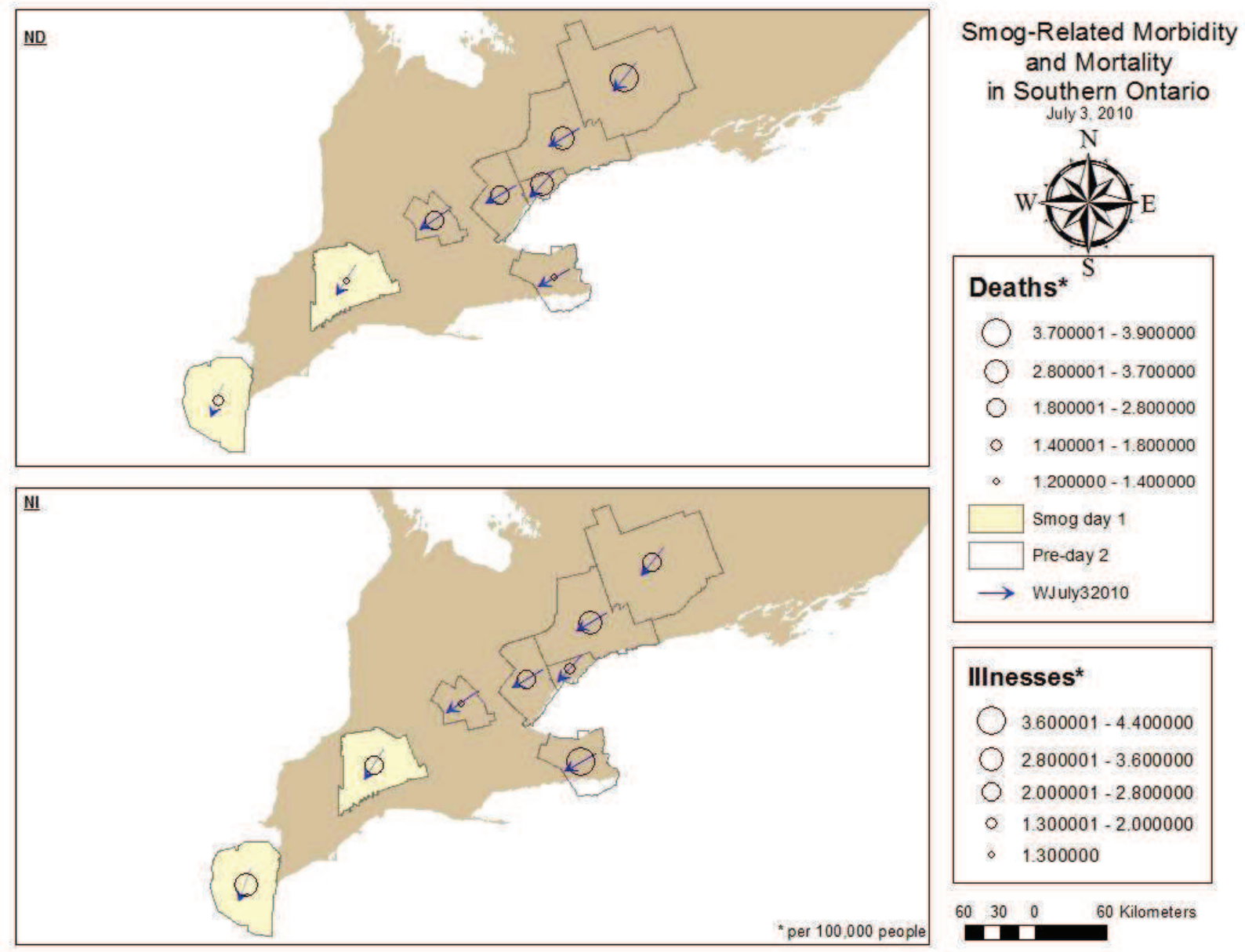
IIInesses*
$3.600001-4.400000$
$2.800001-3.600000$
( $2.000001-2.800000$
- $1.300001-2.000000$
- 1.300000

Figure 63: Map of Day 2 - July 3, 2010 
Day 3 - July 4, 2010 - On the third day of observations, all regions were in a smog advisory.

Windsor-Essex was in its second day of a smog advisory and had the highest number of deaths in the region with 3.8 deaths per 100,000 people. The Peterborough region was in its first smog day with 6.3 illnesses per 100,000 people. Both areas had influencing winds from the southwest.
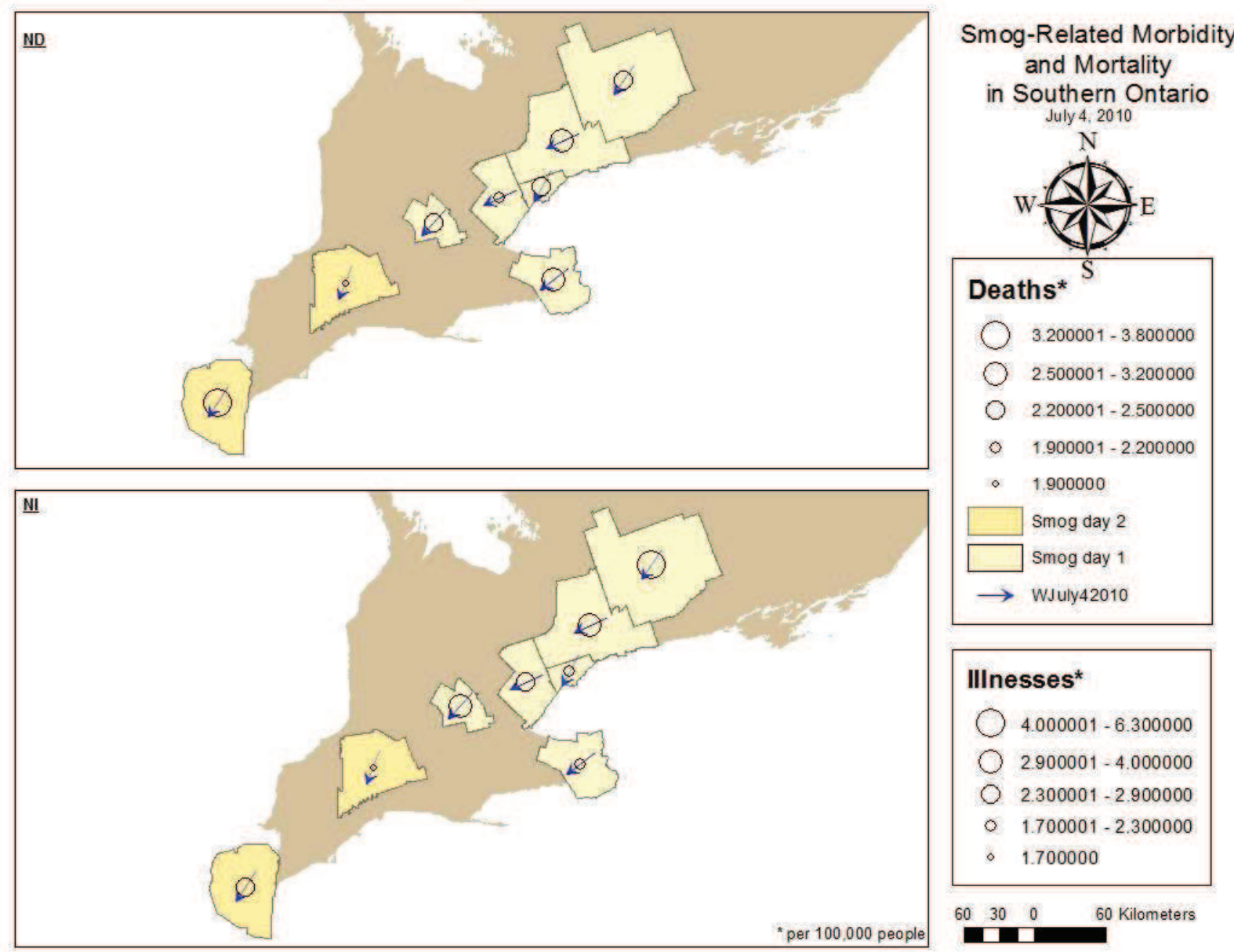

\section{IIInesses*}

( $4.000001-6.300000$

( $2.900001-4.000000$

O 2.300001-2.900000

- $1.700001-2.300000$

- 1.700000

$\begin{array}{llll}60 & 30 & 0 & 60 \text { Kilometers }\end{array}$

Figure 64: Map of Day 3 - July 4, 2010 
Day 4 - July 5, 2010 - On the fourth day of observations, the number of deaths in southwesterly wind conditions had doubled with 7.6 deaths per 100,000 people on the third smog day. The Niagara region had the second highest death rate at 6.3 deaths per 100,000 people, again almost doubling from the previous day. The areas with the highest illness rates were the Peterborough area with 7.2 illnesses per 100,000 people followed by the Waterloo-Kitchener region with 5.7 illnesses per 100,000 people. All regions had winds from the southwest direction.
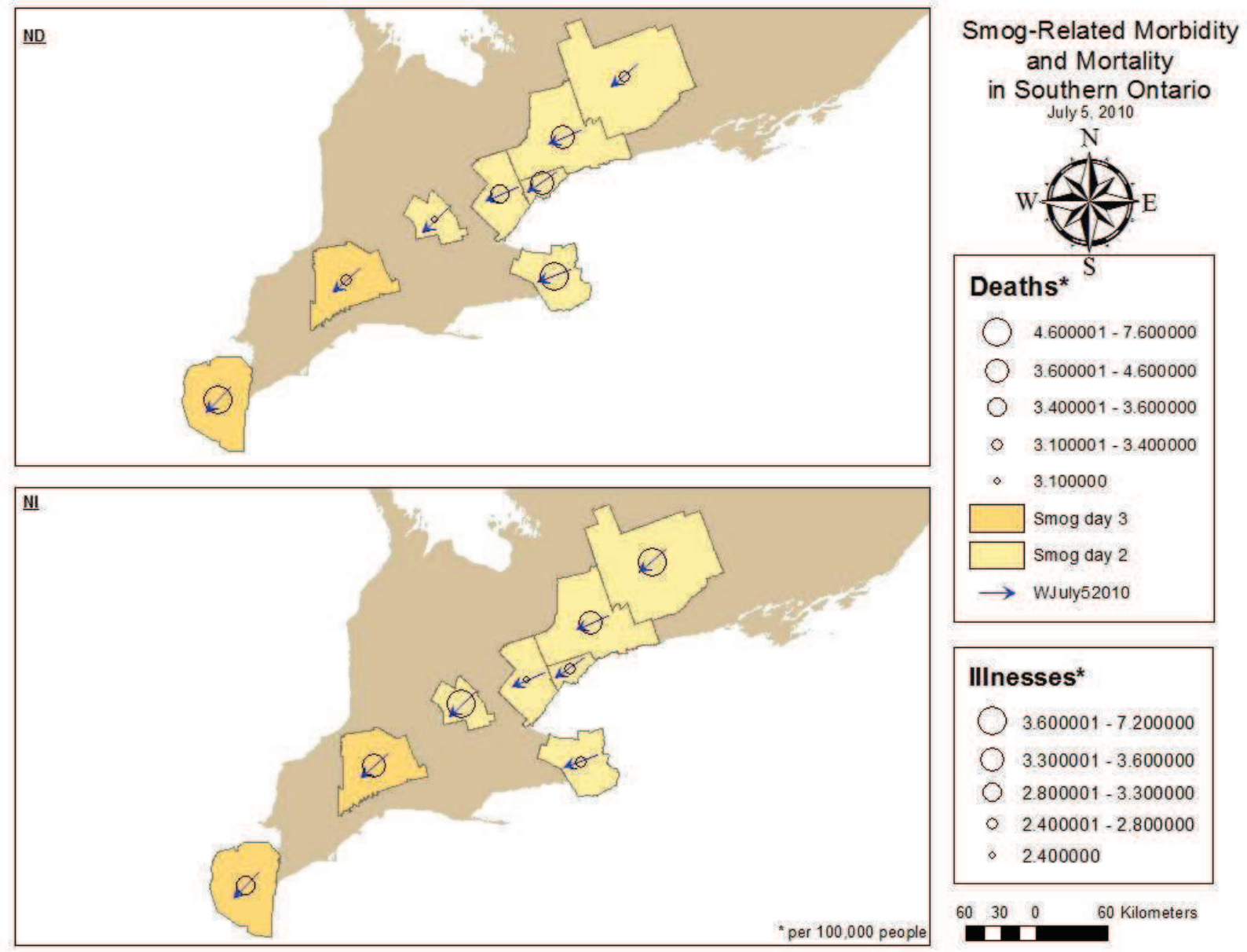

Figure 65: Map of Day 4 - July 5, 2010 
Day 5 - July 6, 2010 - During the third and fourth smog days, the Windsor area had the highest death rate of 6.9 per 100,000 people, followed by York-Durham and Peterborough-Kawartha lakes regions with 6.3 deaths per 100,000 people. The Niagara region experienced the highest illness level with 5.6 morbidities per 100,000 people. Three out of the four regions had southwesterly winds, whereas the York-Durham region had westerly winds.
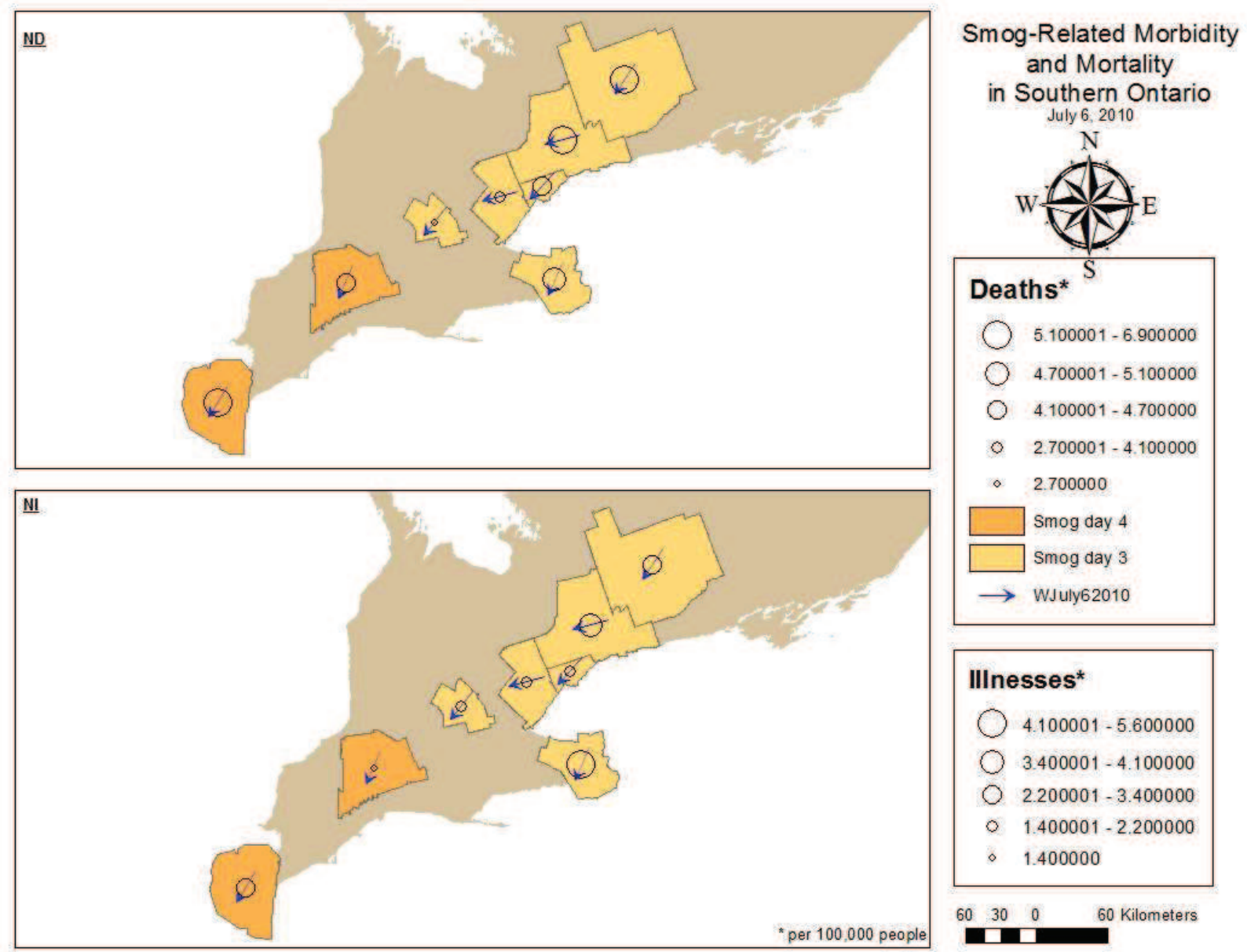

\section{IIInesses*}

$4.100001-5.600000$

O $3.400001-4.100000$

O $2.200001-3.400000$

- $1.400001-2.200000$

- 1.400000

60 Kilometers

Figure 66: Map of Day 5 - July 6, 2010 
Day 6 - July 7, 2010 - During the fifth smog day, the Windsor region had a high death rate of 8.6 per 100,000 people and Niagara had the highest illness level of 4.7 per 100,000 people which was slightly lower than the previous day. Both regions had southwesterly winds.
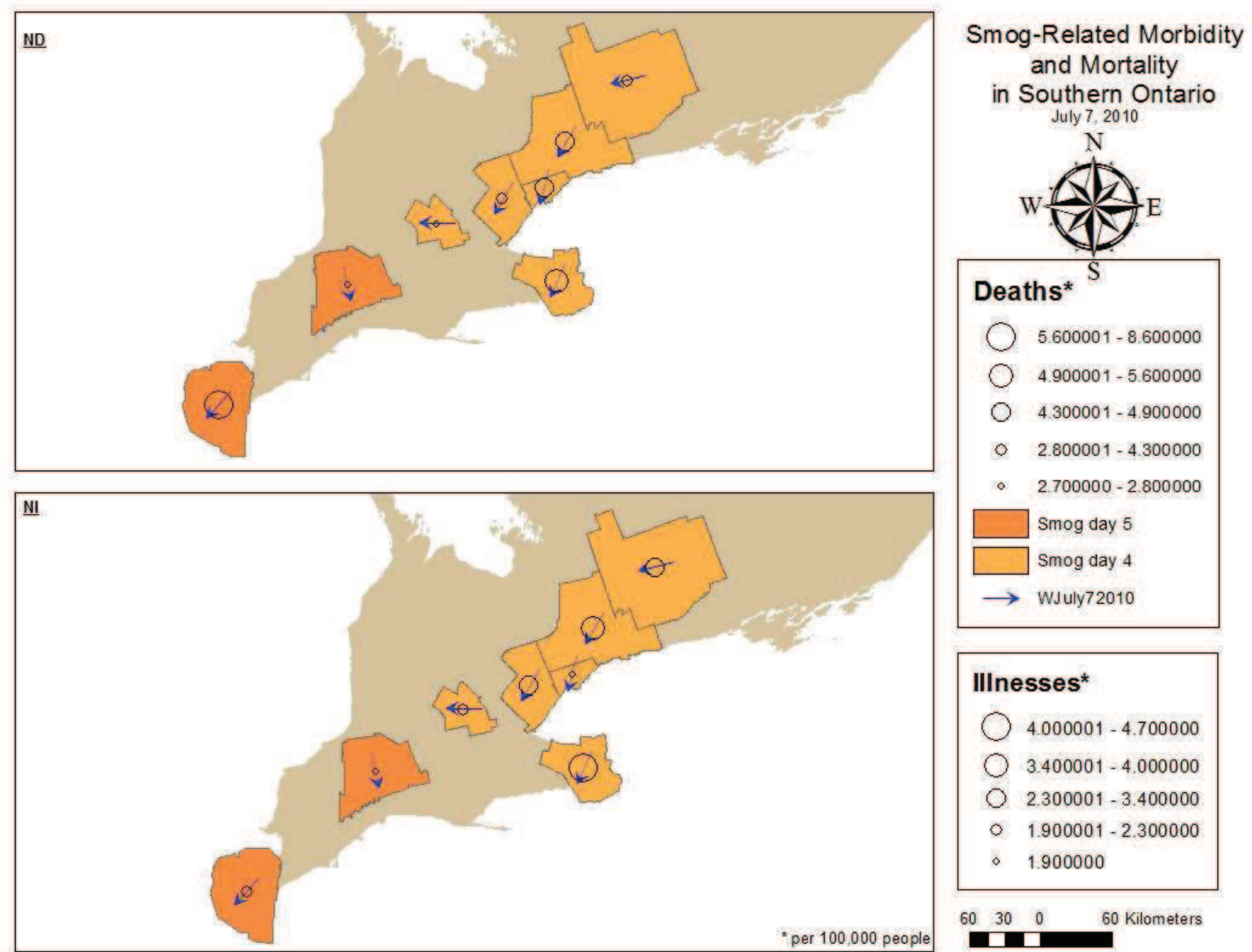

\begin{tabular}{|c|c|}
\hline \\
\hline \multicolumn{2}{|c|}{$\begin{array}{l}\text { Illnesses }{ }^{*} \\
4.000001-4.700000\end{array}$} \\
\hline & $3.400001-4.000000$ \\
\hline 0 & $2.300001-3.400000$ \\
\hline 0 & $1.900001-2.300000$ \\
\hline 8 & 1.900000 \\
\hline
\end{tabular}

Figure 67: Map of Day 6 - July 7, 2010 
Day 7- July 8, 2010 - On the sixth smog day, Windsor-Essex again had the highest death rate of 9.2 deaths per 100,000 people. The area with the highest illness level was the Waterloo-

Kitchener region with 5.7 illnesses per 100,000 people. The wind direction for both these regions was from the southwest.
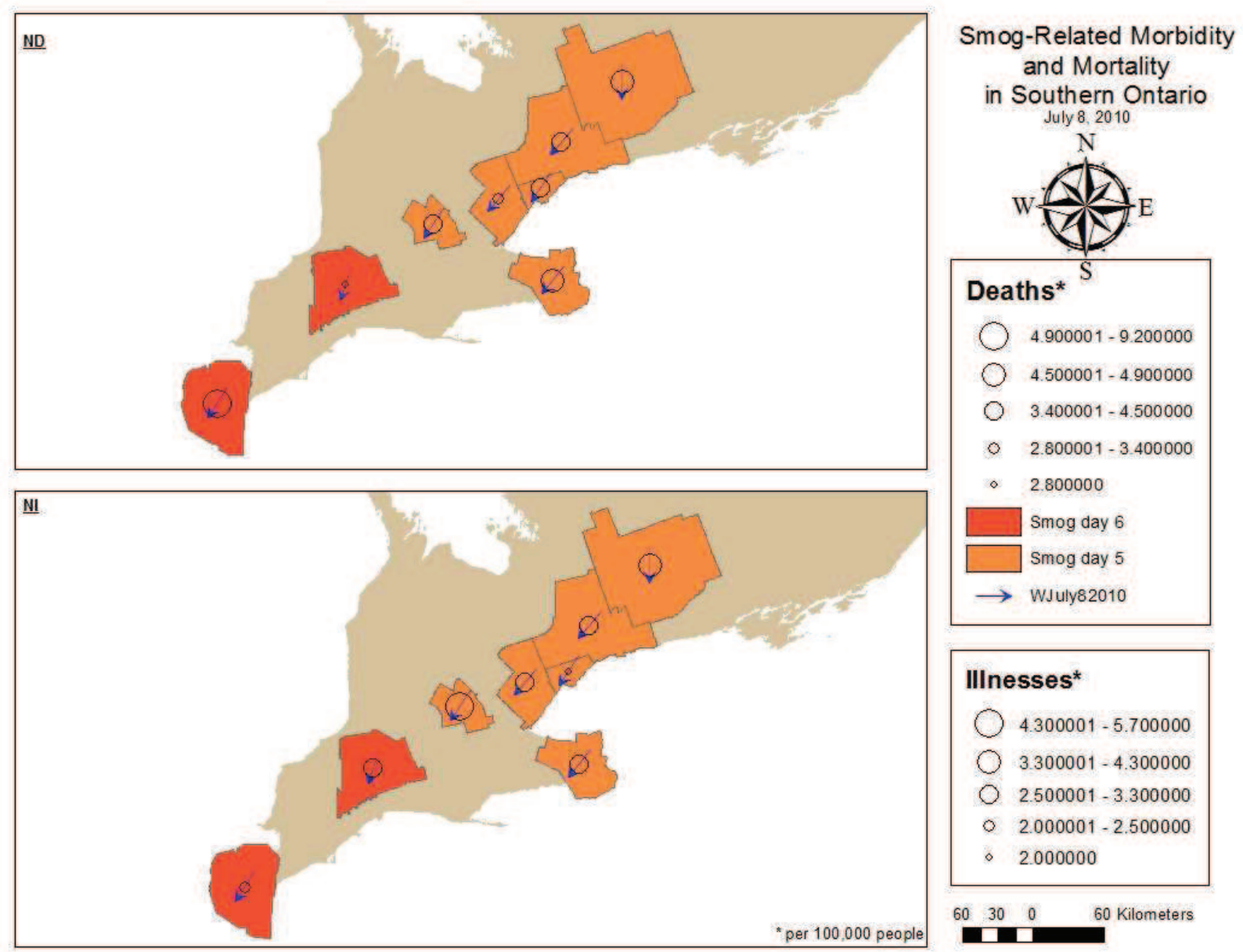

\section{IIInesses* \\ ( $4.300001-5.700000$ \\ O $3.300001-4.300000$ \\ ○ $2.500001-3.300000$ \\ - $2.000001-2.500000$ \\ - 2.000000

Figure 68: Map of Day 7 - July 8, 2010 
Day 8 - July 9, 2010 - During the first post-day, the death and illness rate decreased from the previous day. The Windsor-Essex region had a death rate of 7.1 per 100,000 and an illness rate of 4.3 per 100,000 . The region had wind blowing from the southeast.
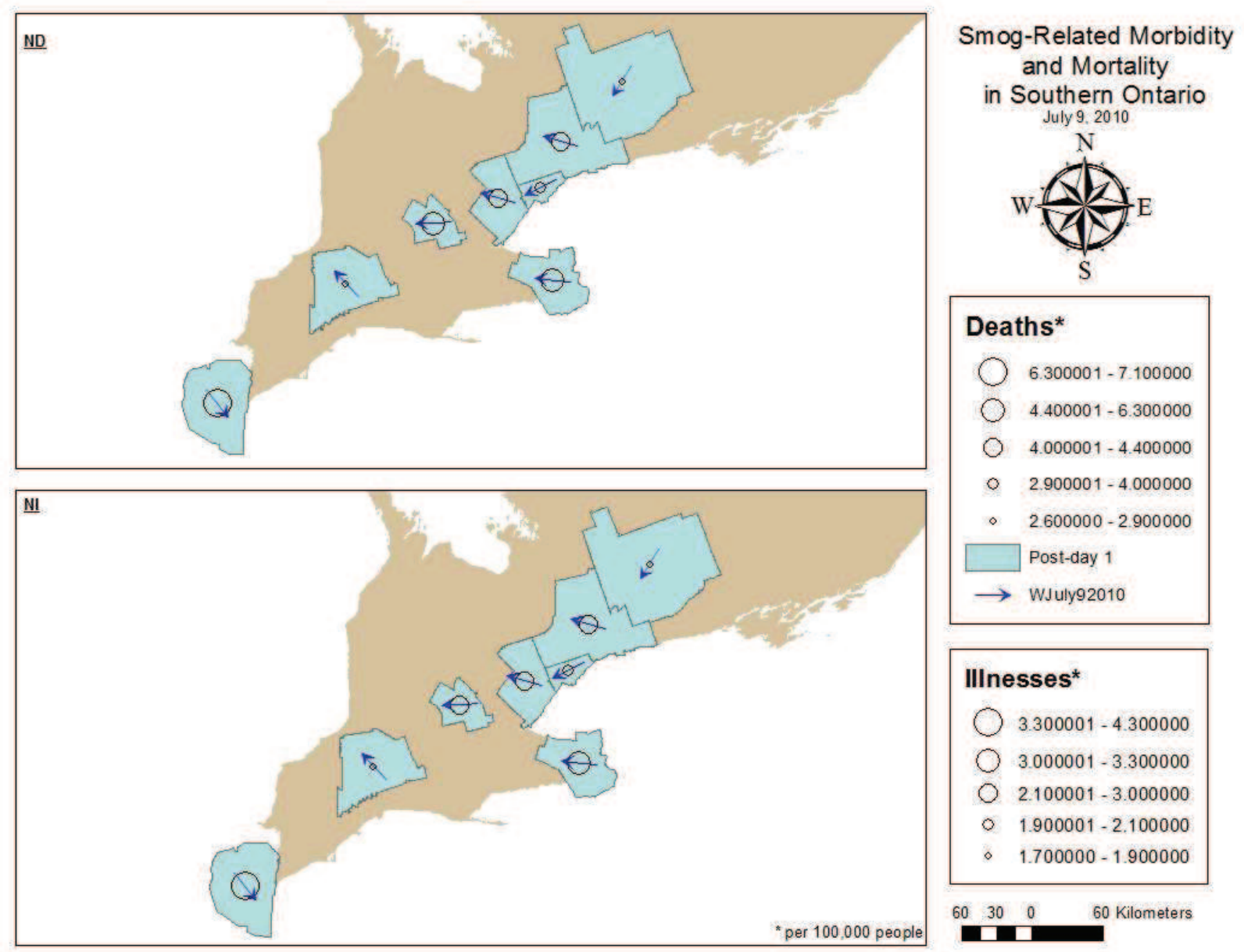

\begin{tabular}{|c|c|}
\hline Dea & ths* \\
\hline & $6.300001-7.100000$ \\
\hline$\checkmark$ & $4.400001-6.300000$ \\
\hline 0 & $4.000001-4.400000$ \\
\hline$\circ$ & $2.900001-4.000000$ \\
\hline 。 & $2.600000-2.900000$ \\
\hline & Post-day 1 \\
\hline$\rightarrow$ & WJuly92010 \\
\hline
\end{tabular}

\section{IIInesses*}

$3.300001-4.300000$

( $3.000001-3.300000$

○ $2.100001-3.000000$

o $1.900001-2.100000$

- $1.700000-1.900000$

$\begin{array}{llll}60 & 30 & 0 & 60 \text { Kilometers }\end{array}$

Figure 69: Map of Day 8 - July 9, 2010 
Day 9 - July 10, 2010 - On the second post-day, the death level decreased drastically. The Windsor-Essex and York-Durham regions had the highest death rate of 3.8 per 100,000 people. The illness rate in Waterloo region was the highest of all regions at 4.2 per 100,000 people followed by Windsor with 3.8 illnesses per 100,000 people. The wind direction for Windsor had changed and was from the southeast, whereas York-Durham's was from the west and Waterloo's from the northwest.
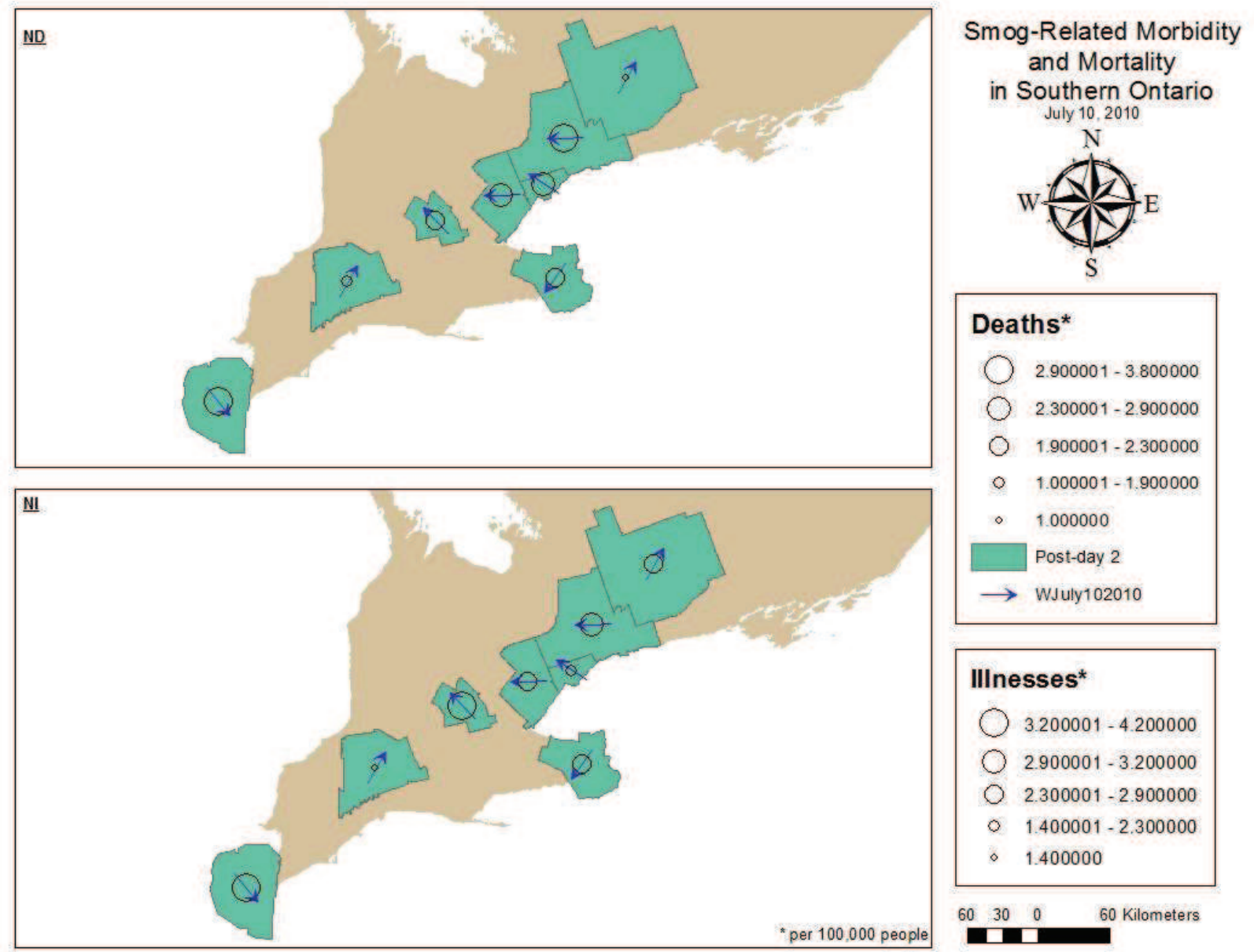

\section{Deaths* \\ ( $2.900001-3.800000$ \\ O $2.300001-2.900000$ \\ O $1.900001-2.300000$ \\ - $1.000001-1.900000$ \\ - 1.000000 \\ Post-day 2 \\ $\rightarrow$ WJuly102010}

\section{IIInesses*}

$3.200001-4.200000$

( 2.900001-3.200000

O 2.300001-2.900000

- $1.400001-2.300000$

- 1.400000 


\section{Summary of Smog Event 2010:}

The overall effects of the smog event could be seen during observation day 7 of WindsorEssex's sixth smog day on which the death rate was at its highest. The average temperature for that day was 23.6 degrees Celsius with southwesterly winds. This elevated number could be due to the effects of the first 5 days of the smog event when exposure was at its highest, resulting in an increase in deaths. The area with the lowest death rate was the Peterborough region during the second post-day with 1 death per 100,000 people with an average temperature of 22.4 degrees Celsius and winds from the north-northeast. This low illness rate is expected to occur days after the smog event since the air quality was expected to be better on non-smog days.

The Peterborough area had the highest illness rate during the second smog day at 7.2 illnesses per 100,000 people. During this day, the average temperature was 26 degrees Celsius and the winds were moving from the southwest. This would support the hypothesis that areas with southwesterly prevailing winds would experience the highest number of illnesses in sequence. The area with the lowest illness rate was the Waterloo region during the second preday with 1.3 illnesses per 100,000 people. During this day, the average temperature was 21.3 degrees Celsius with southwesterly winds, contrary to the expected results. 


\subsubsection{Smog Event 2011:}

In 2011, all regions except for Peterborough-Kawartha Lakes and Windsor-Essex experienced 1 smog advisory. Peterborough-Kawartha Lakes did not experience a single smog advisory that year. Windsor-Essex was the only region that had 4 smog advisories which were each 2 days long. The second smog advisory in Ontario was chosen and occurred at the beginning of July. All regions in a smog event had one smog day, except for Windsor-Essex which had 2 days. It would be expected that since Windsor-Essex had the longest smog advisory it would experience the highest numbers of deaths and illnesses. From visual interpretation, the following observations were made: 
Day 1 - June 30, 2011 - During the pre-day before the smog advisory, the area with the highest death rate was the York-Durham region with 5.2 per 100,000 people and wind blowing from the west-northwest. The second highest death rate was in the Niagara region at 5.1 per 100,000 people with wind from the SW. The Halton-Peel area had the highest illness rate with 4.2 illnesses per 100,000 people and the wind direction was also from the west-northwest.

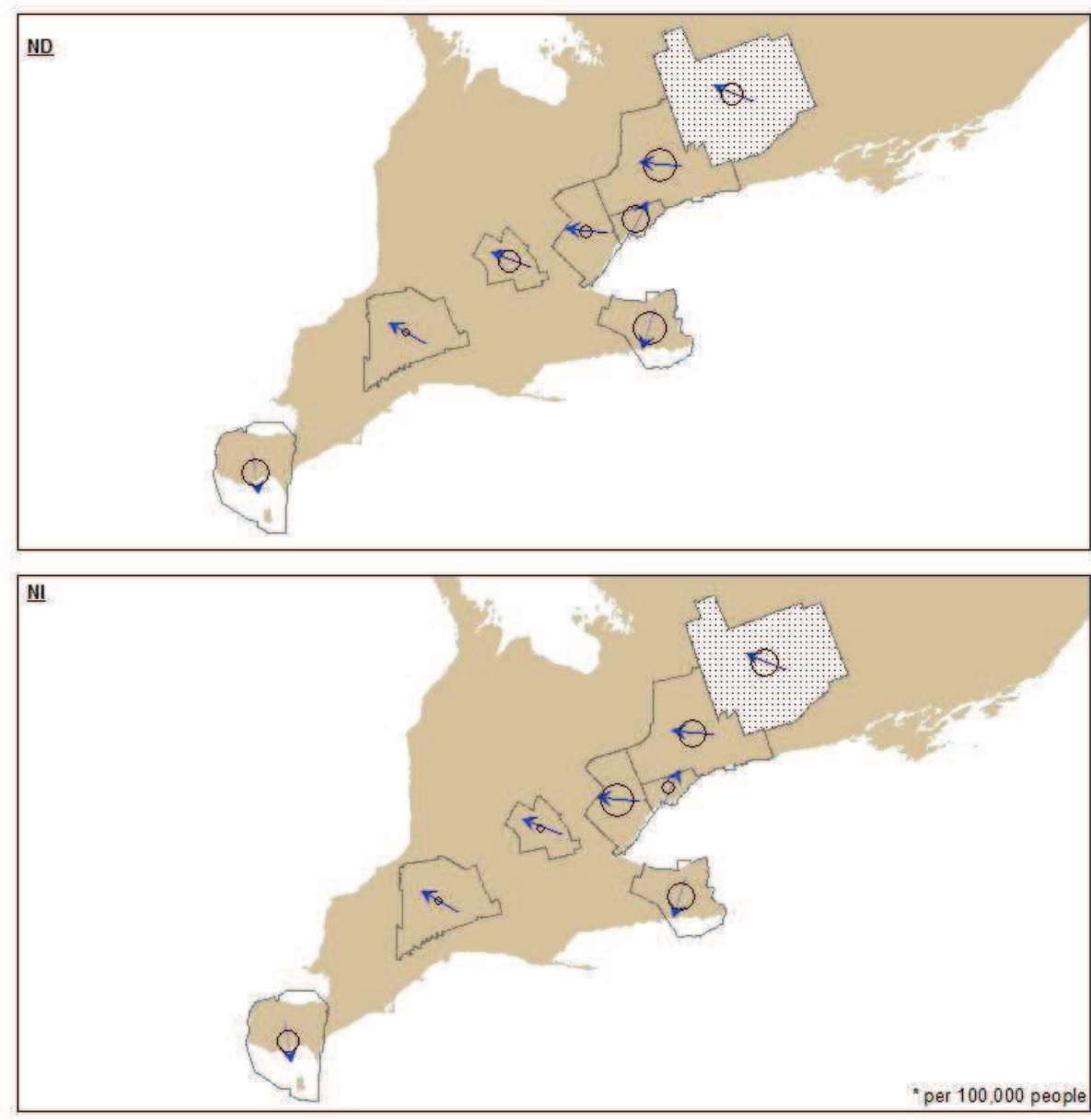

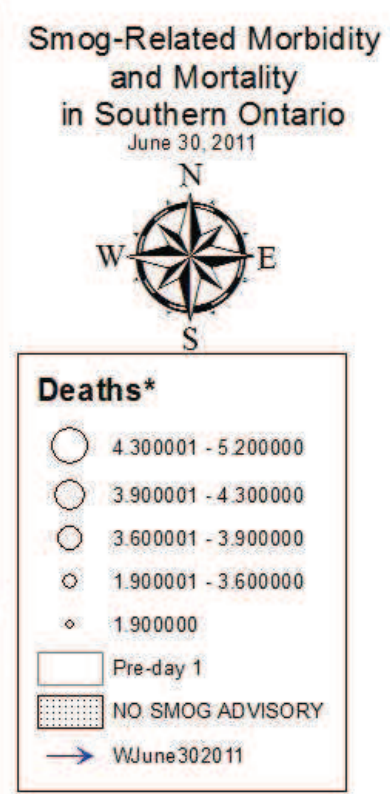

IIInesses*

$3.700001-4.200000$

C $3.100001-3.700000$

- $2.900001-3.100000$

- $2.100001-2.900000$

- $1.900000-2.100000$

$\begin{array}{lll}60 & 30 & 0\end{array}$

60 Kilometers

Figure 71: Map of Day 1 - June 30, 2011 
Day 2 - July 1, 2011 - During the first smog day, London-Middlesex had the highest death rate with 4.5 deaths per 100,000 people, followed by Windsor-Essex with 4.1 deaths and YorkDurham with 4 deaths per 100,000 people. The wind direction for London-Middlesex was from the south-southeast, the Windsor-Essex region was southeast and the York-Durham region had wind blowing from the south-southwest. The highest illnesses were recorded in the Windsor and York regions with 4.3 illnesses per 100,000 people, followed by Niagara with 4.2 illnesses per 100,000 people whiling experiencing a south-southeasterly wind direction.
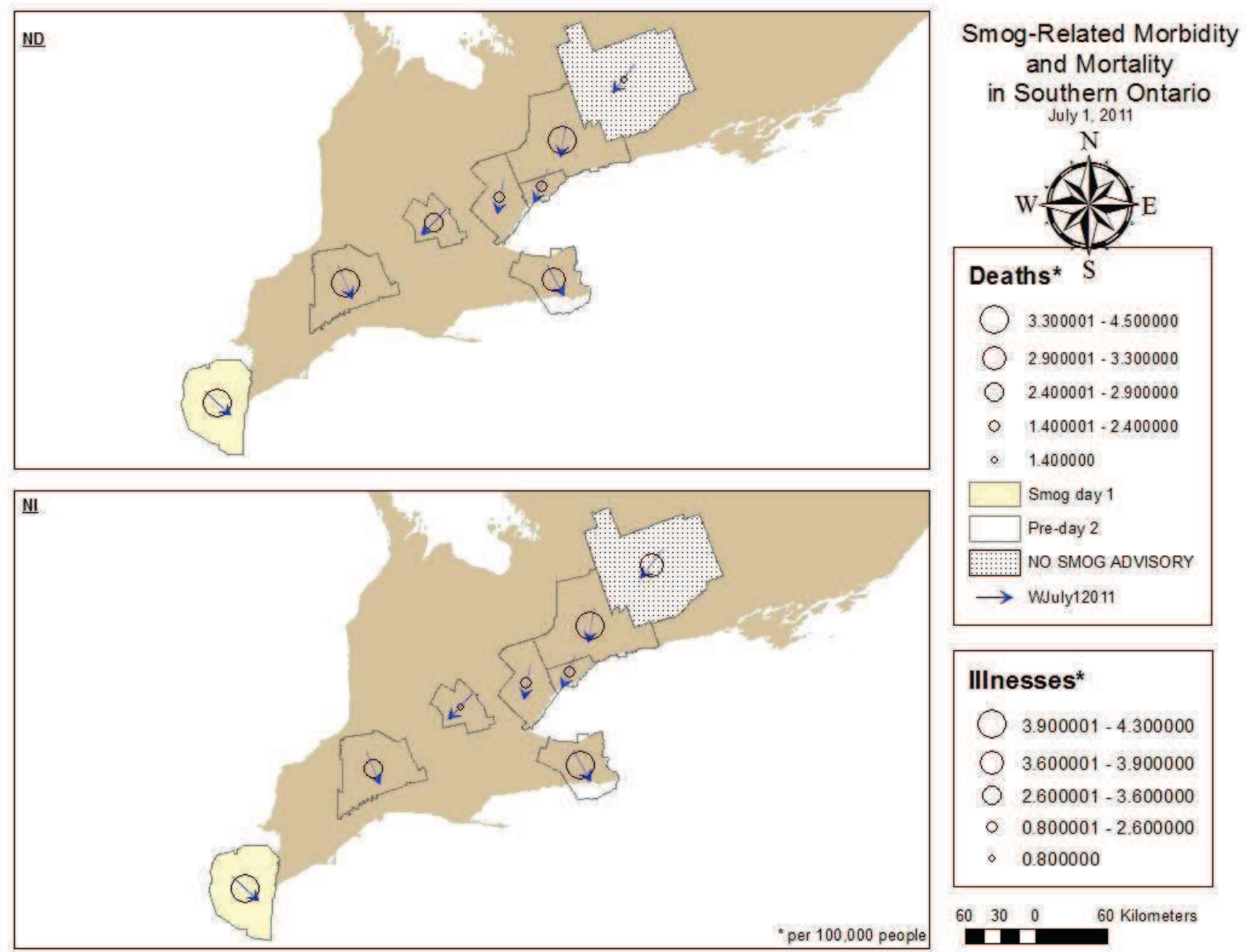
IIInesses*
$3.900001-4.300000$
() $3.600001-3.900000$
○ $2.600001-3.600000$
o $0.800001-2.600000$
- 0.800000

Figure 72: Map of Day 2 - July 1, 2011 
Day 3 - July 2, 2011 - On the third observation day, the Windsor-Essex region's death and illness rate increased to 5.3 deaths and 5.6 illnesses per 100,000 people. The wind direction for the region was from the southwest, supporting the hypothesis that the area with southwesterly winds would have the highest levels of deaths and illnesses.
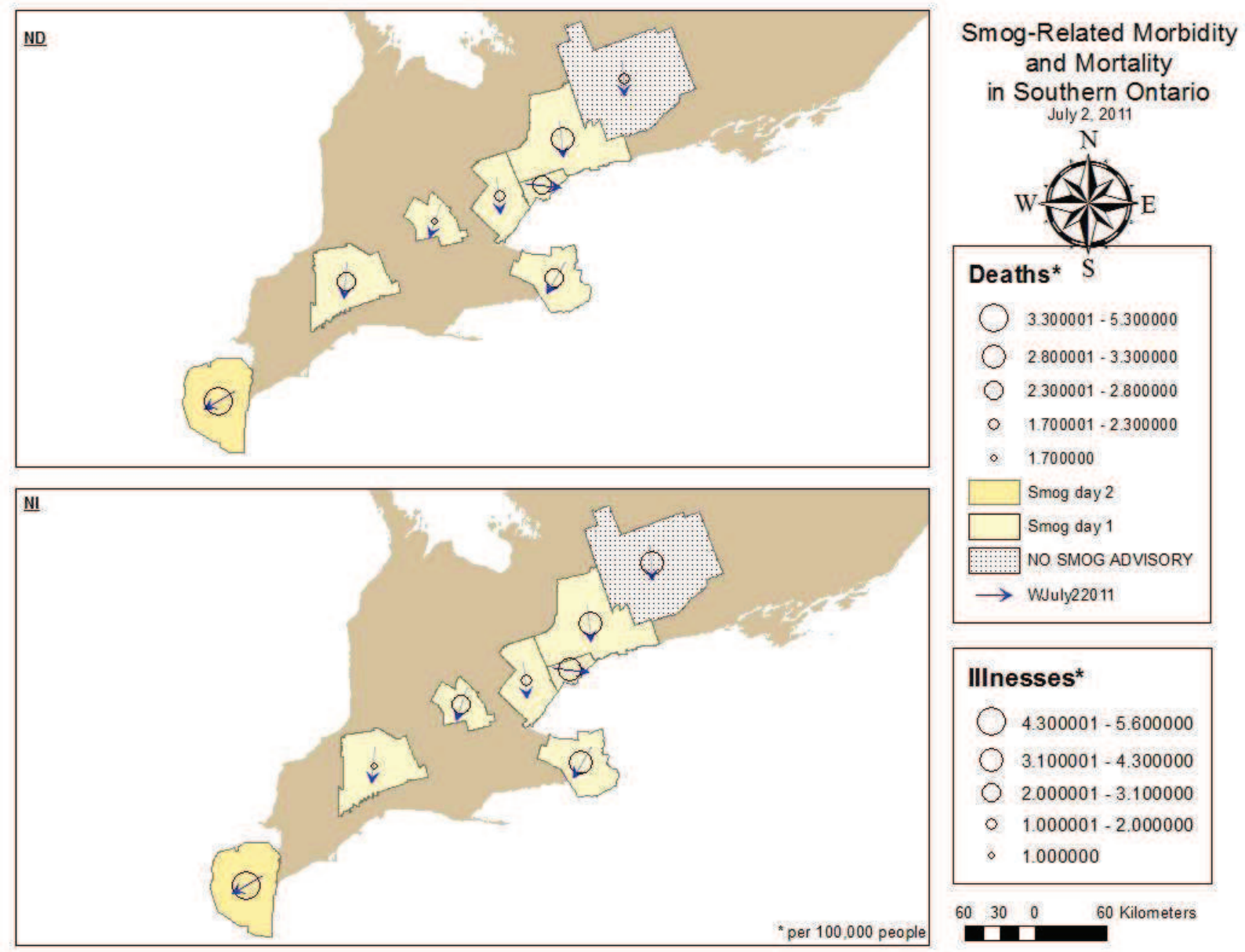
IIInesses*
( $4.300001-5.600000$
$3.100001-4.300000$
( 2.000001-3.100000
- $1.000001-2.000000$
- 1.000000

Figure 73: Map of Day 3 - July 2, 2011 
Day 4- July 3, 2011 - During the first post-day the number of illnesses and deaths decreased; this could be due to the lag effects felt in the first 2 to 3 smog days. The Windsor region had the highest death rate with 4.3 deaths per 100,000 people while experiencing winds from the southeast. The Niagara region had winds from the northwest and the highest illness rate during this day out of all regions at 4.2 illnesses per 100,000 people.
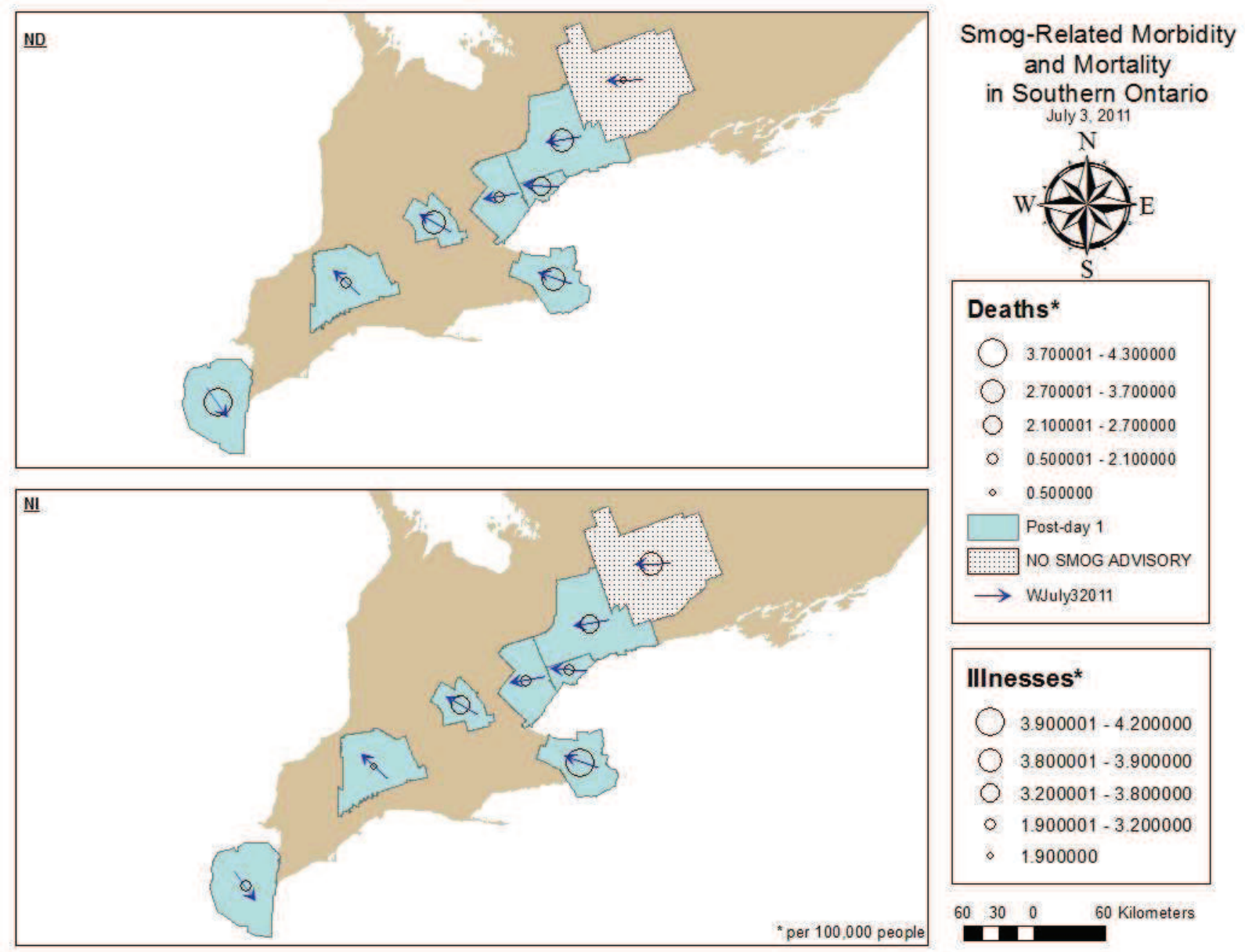

\section{IIInesses*}

$3.900001-4.200000$

( $3.800001-3.900000$

O $3.200001-3.800000$

- $1.900001-3.200000$

- 1.900000

60 Kilometers

Figure 74: Map of Day 4 - July 3, 2011 
Day 5- July 4, 2011 - On the second post-day after the smog event, the area with the highest deaths was the Windsor-Essex region with 9.4 deaths per 100,000, more than doubling from the previous day. Windsor also had the highest illness rate of 6.6 illnesses per 100,000 people. The average wind direction for Windsor-Essex during the second post-day was from the northeast.
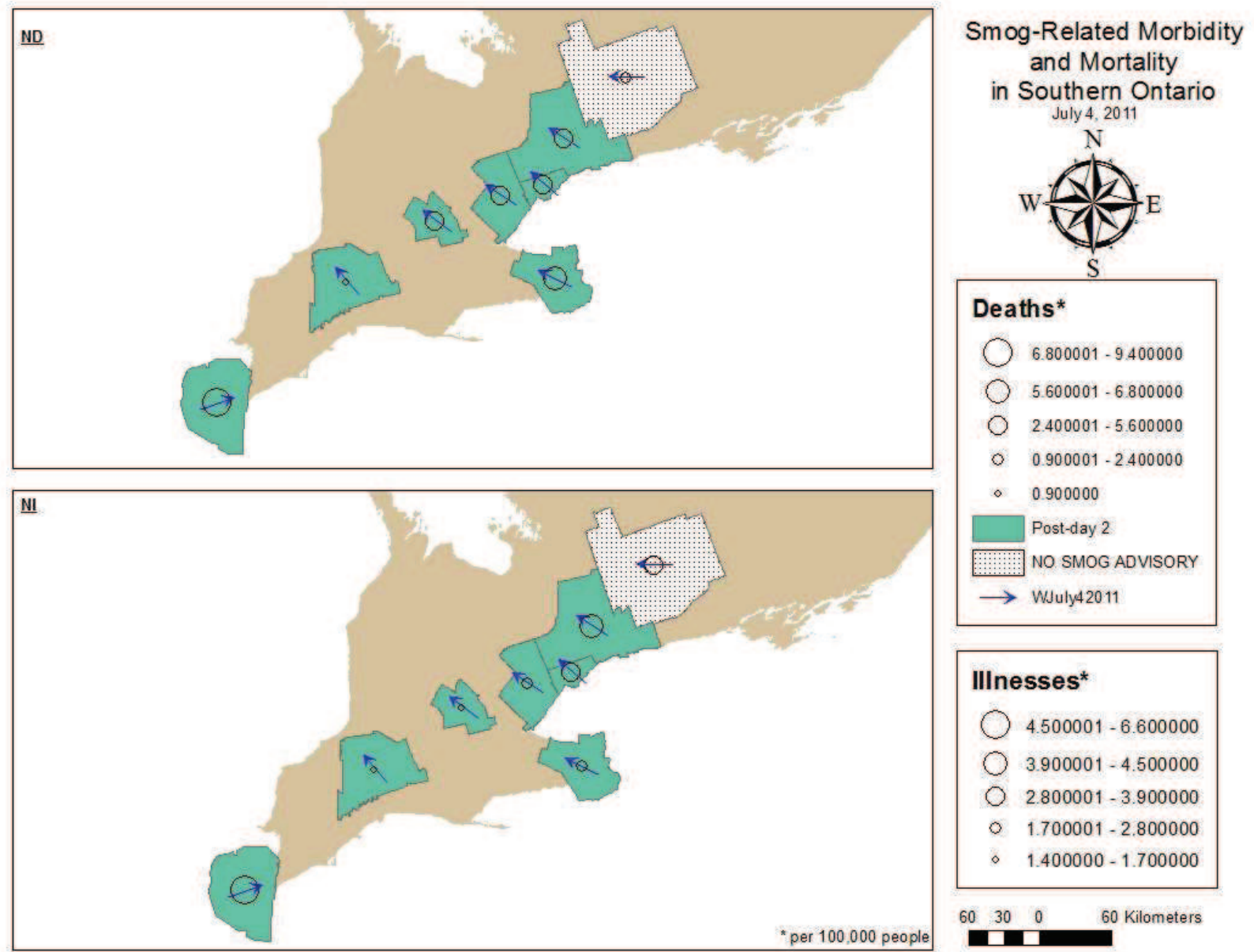

\section{IIInesses*}

$4.500001-6.600000$

$3.900001-4.500000$

$2.800001-3.900000$

$1.700001-2.800000$

- $1.400000-1.700000$

$\begin{array}{rrrr}60 & 30 & 0 & 60 \text { Kilometers }\end{array}$

Figure 75: Map of Day 5 - July 4, 2011

\section{Summary of Smog Event 2011:}

The highest death rate occurred in the Windsor region with 9.4 deaths per 100,000 on the second post-day. This could be due to the cumulative effects of the first 3 smog days. The average temperature for that day was 23.6 degrees Celsius with winds from the northeast. The lowest number of smog-related deaths occurred in the Peterborough-Kawartha Lakes region, at 0.5 
deaths per 100,000 people and winds from the west and an average temperature for that day of 23.7 degrees Celsius. This region was not under a smog advisory; therefore, it would be expected that there would be fewer smog-related deaths in Peterborough-Kawartha Lakes. The highest level of illnesses also occurred in Windsor, during the second post-day, at 6.6 illnesses per 100,000 people. This outcome was also anticipated since Windsor-Essex had the longest smog advisory out of all study sites, therefore it is expected that the number of deaths and illnesses would be the highest. The lowest number of illnesses occurred in the Waterloo-Kitchener area during pre-day 2 with 0.8 illnesses per 100,000 people. The average temperature for that day was 18.6 degrees Celsius with southwesterly winds.

\subsubsection{Summary of Lag Effects}

From the observations, the highest number of deaths and illnesses were discussed as well as what the direction of wind had been for that particular day. Since lag effects play an important role in the sequence of morbidity and mortality, it is crucial to consider the wind direction from days before the highest rates of cardiovascular and respiratory morbidity and mortality had occurred. Table 4 illustrates the direction of wind that had occurred 2-3 days before the highest recorded deaths and illnesses during the smog events from 2003-2011. The purpose of this table is to display what the wind directions would have been before the highest morbidity and mortality since it is expected that the highest response rates would have occurred 2-3 days after the smog advisory had begun. Some of the wind directions were not available based on the method of data collection; however, when viewing this table, many regions did show winds from the southwesterly direction. Areas that did not have wind direction data available showed that the highest death rates occurred during a pre-day. 
Table 4: Lag effects of death and illness based on wind direction.

\begin{tabular}{|l|l|l|l|l|l|}
\hline \multicolumn{2}{|c|}{ Smog Event } & \multicolumn{1}{|c|}{ Regions } & Highest Rate & \multicolumn{1}{|c|}{$\begin{array}{c}\text { Wind Direction } \\
\text { Day 2 }\end{array}$} & $\begin{array}{c}\text { Wind Direction } \\
\text { Day 3 }\end{array}$ \\
\hline \multirow{2}{*}{2003} & Deaths & Windsor & 7.4 & W & SSW \\
\cline { 2 - 6 } & Illnesses & Peterborough & 6.3 & SSW & --- \\
\hline \multirow{2}{*}{2004} & Deaths & Windsor & 6.4 & SE & ESE \\
\cline { 2 - 6 } & Illnesses & Peterborough & 8.2 & SSE & ESE \\
\hline \multirow{2}{*}{2005} & Deaths & Peterborough & 10.1 & SSE & S \\
\cline { 2 - 6 } & Illnesses & Peterborough & 8.7 & SE & ESE \\
\hline \multirow{2}{*}{2007} & Deaths & Peterborough & 7.2 & SSW & SSW \\
\cline { 2 - 6 } & Illnesses & Peterborough & 7.7 & --- & --- \\
\cline { 2 - 6 } & Deaths & Peterborough & 10.6 & --- & --- \\
\hline \multirow{2}{*}{2008} & Deaths & Waterloo & 11 & W & SSE \\
\cline { 2 - 6 } & Illnesses & Peterborough & 4.8 & --- & --- \\
\hline \multirow{2}{*}{2009} & Deaths & Peterborough & 7.7 & WSW & SW \\
\cline { 2 - 6 } & Illnesses & Peterborough & 7.2 & SW & S \\
\hline \multirow{2}{*}{2011} & Deaths & Windsor & 9.2 & SW & SW \\
\cline { 2 - 6 } & Illnesses & Peterborough & 7.2 & SW & WSW \\
\cline { 2 - 6 } & Deaths & Windsor & 9.4 & WSW & SE \\
\hline
\end{tabular}




\subsection{Regression Analysis for Smog Advisories}

After running a regression analysis of the variables for each smog advisory (2003-2011), each year yielded different results. The most successful regression analyses were for the following years; 2003-2005 and 2011. The smog events in 2006-2010 did not show a strong correlation between the wind classification and temperature value and the level of air pollutants, deaths and illnesses. For each smog advisory statistical analysis, each result was checked for normality to ensure that the data was normality distributed.

\subsubsection{Successful Regression Analysis}

\subsubsection{Smog Advisory:}

After running a linear regression for the 2003 variables, the following correlations are illustrated in Figure 76.

\begin{tabular}{|c|c|c|c|c|c|c|c|c|c|c|}
\hline \multirow[b]{3}{*}{ Model } & \multicolumn{9}{|c|}{ Model Summary ${ }^{e}$} & \multirow[b]{3}{*}{$\begin{array}{l}\text { Durbin- } \\
\text { Watson }\end{array}$} \\
\hline & \multirow[b]{2}{*}{$\mathrm{R}$} & \multirow[b]{2}{*}{ R Square } & \multirow[b]{2}{*}{$\begin{array}{l}\text { Adjusted R } \\
\text { Square }\end{array}$} & \multirow[b]{2}{*}{$\begin{array}{l}\text { Std. Error of } \\
\text { the Estimate }\end{array}$} & \multicolumn{5}{|c|}{ Change Statistics } & \\
\hline & & & & & $\begin{array}{c}\text { R Square } \\
\text { Change }\end{array}$ & F Change & df1 & df2 & Sig. F Change & \\
\hline 1 & $.543^{\mathrm{a}}$ & .295 & .284 & 151.27578 & .295 & 25.950 & 1 & 62 & .000 & \multirow[b]{4}{*}{1.944} \\
\hline 2 & $.585^{\mathrm{b}}$ & .342 & .321 & 147.31667 & .047 & 4.377 & 1 & 61 & .041 & \\
\hline 3 & $.642^{\mathrm{c}}$ & 412 & .383 & 140.45402 & .070 & 7.107 & 1 & 60 & .010 & \\
\hline 4 & $.675^{\mathrm{d}}$ & .455 & .418 & 136.30039 & .043 & 4.713 & 1 & 59 & .034 & \\
\hline \multicolumn{11}{|c|}{ a. Predictors: (Constant), PMLevel } \\
\hline \multicolumn{11}{|c|}{ b. Predictors: (Constant), PMLevel, Norm. IIInesses } \\
\hline \multicolumn{11}{|c|}{ c. Predictors: (Constant), PMLevel, Norm. Illnesses, Max Temperature $\left({ }^{\circ} \mathrm{C}\right)$} \\
\hline \multicolumn{11}{|c|}{ d. Predictors: (Constant), PMLevel, Norm. Illnesses, Max Temperature $\left({ }^{\circ} \mathrm{C}\right)$, Raw Deaths } \\
\hline \multicolumn{11}{|c|}{ e. Dependent Variable:V_TW } \\
\hline
\end{tabular}

Figure 76: Model Summary from SPSS for 2003 linear regression.

Since SPSS was set up to show only significant correlations, all four models in the above figure represent statistically significant relationships. The highest value for the R square was for Model 4 with a moderate success of $45.5 \%$ correlation or linearity. The value of the Durbin-Watson test indicates that there could or could not be autocorrelation; therefore the variables are likely to be different from each other. Durbin-Watson values within the 1.6-2.4 value indicate that a timeseries phenomenon had occurred, which is a value that would describe a smog event. 


\subsubsection{Smog Advisory:}

After running a regression analysis for the 2004 data, the following results are displayed in Figure 77.

\begin{tabular}{|c|c|c|c|c|c|c|c|c|c|c|}
\hline \multirow[b]{3}{*}{ Model } & \multirow[b]{3}{*}{$\mathrm{R}$} & \multirow[b]{3}{*}{ R Square } & \multirow[b]{3}{*}{$\begin{array}{l}\text { Adjusted R } \\
\text { Square }\end{array}$} & \multirow[b]{3}{*}{$\begin{array}{l}\text { Std. Error of } \\
\text { the Estimate }\end{array}$} & \multicolumn{6}{|c|}{ Model Summary" } \\
\hline & & & & & \multicolumn{5}{|c|}{ Change Statistics } & \multirow[b]{2}{*}{$\begin{array}{l}\text { Durbin- } \\
\text { Watson }\end{array}$} \\
\hline & & & & & $\begin{array}{c}\text { R Square } \\
\text { Change }\end{array}$ & F Change & df1 & df2 & Sig. F Change & \\
\hline 1 & $.431^{\mathrm{a}}$ & .186 & .168 & 157.32940 & .186 & 10.485 & 1 & 46 & .002 & \\
\hline 2 & $.632^{\mathrm{b}}$ & .399 & .373 & 136.59825 & .214 & 16.022 & 1 & 45 & .000 & \\
\hline 3 & $.749^{\mathrm{C}}$ & .561 & .531 & 118.06873 & .162 & 16.233 & 1 & 44 & .000 & \\
\hline 4 & $.798^{\mathrm{d}}$ & .636 & .603 & 108.71973 & .075 & 8.893 & 1 & 43 & .005 & 1.640 \\
\hline \multicolumn{11}{|c|}{ a. Predictors: (Constant), Norm. Deaths } \\
\hline \multicolumn{11}{|c|}{ b. Predictors: (Constant), Norm. Deaths, Max Temperature } \\
\hline \multicolumn{11}{|c|}{ c. Predictors: (Constant), Norm. Deaths, Max Temperature, Raw Deaths } \\
\hline \multicolumn{11}{|c|}{ d. Predictors: (Constant), Norm. Deaths, Max Temperature, Raw Deaths , PMLevel } \\
\hline \multicolumn{11}{|c|}{ e. Dependent Variable:Var_TW } \\
\hline
\end{tabular}

Figure 77: Model summary of linear regression for 2004 data.

The strongest correlation found was with model 4 . The independent variables that had a significant relationship with dependent variable achieved an R-squared of 63.6 per cent. All models formulated were statistically significant, however relationships were modest. The Durbin-Watson value of 1.640 indicates that, in this data set no autocorrelation occurred meaning that there is no similarity between each observation in the sequence within the time series.

\subsubsection{Smog Advisory:}

After running a linear regression against the 2005 data, the following results were found in figure 78.

\begin{tabular}{|c|c|c|c|c|c|c|c|c|c|c|}
\hline \multirow[b]{3}{*}{ Model } & \multirow[b]{3}{*}{$\mathrm{R}$} & \multirow[b]{3}{*}{ R Square } & \multicolumn{7}{|c|}{ Model Summary ${ }^{d}$} & \multirow[b]{3}{*}{$\begin{array}{c}\text { Durbin- } \\
\text { Watson }\end{array}$} \\
\hline & & & \multirow[b]{2}{*}{$\begin{array}{l}\text { Adjusted R } \\
\text { Square }\end{array}$} & \multirow[b]{2}{*}{$\begin{array}{l}\text { Std. Error of } \\
\text { the Estimate }\end{array}$} & \multicolumn{5}{|c|}{ Change Statistics } & \\
\hline & & & & & $\begin{array}{c}\text { R Square } \\
\text { Change }\end{array}$ & F Change & df1 & $\mathrm{df} 2$ & Sig. F Change & \\
\hline 1 & $.639^{\mathrm{a}}$ & .408 & .401 & 147.25566 & .408 & 59.324 & 1 & 86 & .000 & \multirow[b]{3}{*}{2.094} \\
\hline 2 & $.700^{\mathrm{b}}$ & .489 & .477 & 137.59527 & .081 & 13.500 & 1 & 85 & .000 & \\
\hline 3 & $.718^{\mathrm{c}}$ & .516 & .499 & 134.75944 & .027 & 4.615 & 1 & 84 & .035 & \\
\hline \multicolumn{11}{|c|}{ a. Predictors: (Constant), Max Temperature } \\
\hline \multicolumn{11}{|c|}{ b. Predictors: (Constant), Max Temperature, Raw Deaths } \\
\hline \multicolumn{11}{|c|}{ c. Predictors: (Constant), Max Temperature, Raw Deaths, PMLevels } \\
\hline \multicolumn{11}{|c|}{ d. Dependent Variable: V_TW } \\
\hline
\end{tabular}

Figure 78: Model summary of linear regression for 2005 data. 
The statistically significant outcomes were found in 3 models for which the relationship between temperature, raw deaths and PM levels showed an association with the dependent temperature-wind classification variable. This model had the highest $\mathrm{R}$ square value of 51.6 , indicating a moderate successful between the three independent variables. It is also important to consider that the initial statistically significant model by one variable begins at 40.8 percent, which indicates the prominent effect of temperature in this analysis. The Durbin-Watson value of 2.094 indicated that no autocorrelation occurred. Given the complexity of the environment being analyzed, these results could be considered moderately successful.

\subsubsection{Smog Advisory:}

After running a linear regression between the dependent and independent variables, the following statistically significant model was found in Figure 79.

\begin{tabular}{|c|c|c|c|c|c|c|c|c|c|c|}
\hline \multirow[b]{3}{*}{ Model } & \multirow[b]{3}{*}{$\mathrm{R}$} & \multirow[b]{3}{*}{ R Square } & \multirow[b]{3}{*}{$\begin{array}{l}\text { Adjusted R } \\
\text { Square }\end{array}$} & \multirow[b]{3}{*}{$\begin{array}{l}\text { Std. Error of } \\
\text { the Estimate }\end{array}$} & \multicolumn{6}{|c|}{ Model Summary } \\
\hline & & & & & \multicolumn{5}{|c|}{ Change Statistics } & \multirow[b]{2}{*}{$\begin{array}{l}\text { Durbin- } \\
\text { Watson }\end{array}$} \\
\hline & & & & & $\begin{array}{c}\text { R Square } \\
\text { Change }\end{array}$ & F Change & df1 & df 2 & Sig. F Change & \\
\hline 1 & $.731^{\mathrm{a}}$ & .534 & .432 & 146.51496 & .534 & 5.239 & 7 & 32 & .000 & 1.705 \\
\hline
\end{tabular}

Figure 79: Model summary of linear regression for 2011 data.

The statistically significant relationship that was generated involved all independent variables for the regression analysis. The overall correlation was 53.4 , this is a moderately successful relationship even though the results are not in the 70 percent or more range, based on the complexity of the study, this would be considered successful. The Durbin-Watson value of 1.705 indicated that no autocorrelation occurred which means that there is a pattern occurring in the time series.

\subsubsection{Smog Advisories Unrelated to Illness and Death:}

For the years 2006-2010, there were no correlations found between the independent variables of deaths, illnesses and pollution levels, and against the dependent temperature-wind 
classification variable. The smog advisory was considered strongly related to health effects if it had been associated with either morbidity or mortality variables or both along with maximum temperature and pollution levels. The Durbin-Watson values also had to be between 1.6 -2.4 to ensure that there was a time series. There are several reasons that relationships were not found with all the variables such as potential confounding outside factors that could be affecting the cardiovascular and respiratory diseases that occurred during the smog event. Although the outcomes of these regression analyses did not show the same relationship as the 'successful' smog advisories, they did show a correlation with maximum temperature, meaning there could be a relationship between the wind direction and maximum temperature. The output of each regression analysis can be found in Appendices 10-19. 


\subsection{Discussion}

The hypothesized west to east sequence of increasing numbers of illnesses and deaths following prevailing southwest winds was supported in some smog events, although some days during the smog advisory did show a high number of deaths and illness occurring when wind direction was from the southwesterly direction. It could be that the lag effects of smog days could also be associated with the wind direction as well since it is assumed that higher levels of pollutants would be the result of the transboundary contributions. During the smog episodes, Windsor-Essex always had the greatest number of smog days out of all the regions selected, which is possibly due to the transboundary contribution; however that was not verified in this study. Although the regression analysis did reveal some correlations with all the variables, it was only for some of the smog events and the associations were modest given that some of the variables could have been non-linear.

Although it is not unexpected since this region generally experiences days of poor air quality, the Peterborough region had the overall highest deaths and illnesses out of all the study sites during smog and some non-smog events. This study suggests there are likely other factors affecting the respiratory and cardiovascular health of the population in the Peterborough region which results in a higher morbidity and mortality rate. Peterborough could be an outlier to this study since it receives two sources of air pollution; both the transboundary and GTA contributions that are transported into the region move from the southwest. It could also be that the Peterborough region has higher asthma susceptibility but since disease susceptibility for each region was not studied, it is difficult to prove this to be the case. Another explanation for the effects in Peterborough could be the location of the jet stream, which was not taken into account. Temperature inversions could also account for different effects in all the study sites, whether 
there are lower deaths and illnesses that were experienced in the London region or high deaths and illnesses in Peterborough; however, it was not analyzed.

Although the Peterborough region did experience the highest normalized death and illness rate overall, it should be noted that the Toronto region experienced the highest absolute number of raw deaths and illnesses. It is interesting that the numbers for each area differ, such as the City of Toronto, which has relatively lower illnesses and deaths, but this region has the highest total population. Even though the rates were normalized for comparative purposes, we should acknowledge that areas which experienced the normalized highest deaths or illnesses had lower total populations.

Other interesting findings were observed in the ratio of deaths to illnesses; it would be assumed that the number of illnesses would be much greater than deaths; however it was found to be the opposite. There could be several reasons for this, perhaps those who have asthma and other respiratory illness effects may not have visited the doctor and may have taken precautionary measures such as using an inhaler, or because of the smog alert network, people may have been warned to spend more time inside their homes during the events. More people have air conditioning now, so this may the reason that illnesses are not as high as expected.

There were some variables that may have been useful that were not used in this study as there were limitations on the amount of information that could be recorded in the map series. The actual AQI index levels would have been useful for the map series if all the study years were available; however, the use of levels of air pollutants for the regression analysis did help in establishing an associating with the other variables. The wind speed was also not used; however, it would be an interesting measure if there were wind speeds that affected the sequence in the smog event. Since most of the smog events began in Windsor, it would be fascinating to see 
whether there was a shift in the level of air pollutants from one location to another related to wind speed along the corridor. Other variables must be considered such as topography, microclimates and proximity to waterbodies which may affect the human responses to smog advisories. Another factor that could explain why areas experienced low or high deaths and illnesses during a smog and non-smog event was the possible flaw in the classification of smog events where levels of air contaminants are not measured where people are directly affected. An example would be that a persons' FSA does not necessarily indicate that exposure was from that specific area; rather that person could have been in another area when the smog advisory was issued.

Baseline incidence rates for each region would have also helped to support the results; however, since they were not accessible for cardiovascular and respiratory illness and mortality, it made it difficult to compare the outcomes that occurred during and after a smog advisory. If a baseline rate was available for each region, then the number of morbidities and mortalities, that occurred during each day of the smog event, could have been compared to the baseline and determine the significance a smog episode has to the affected population. The use of the pre-day as a baseline rate may not have been an accurate measure due to potential conflicting factors that could affect the number of cardiovascular and respiratory deaths and illnesses that occurred during the pre-day.

Although this analysis was not completely consistent with the expected results it does create a spatial visual aid that would allow researchers to investigate how certain regions respond to smog events. The analysis could also be useful in more detailed investigations of smog-related mortality and morbidity. Even though this study may not have consistently fulfilled the hypothesis, the analysis did accomplish the following: it revealed a spatial west to east 
progression of air pollution-related illnesses in a province that has a substantial body of health data. The second accomplishment was the introduction of cardiovascular illness as another smog-related outcome given that recent studies have pointed directly to an association between air pollution and cardiovascular illness; this investigation took that recent evidence into account. The final accomplishment was the focus not solely on mortality but rather including morbidity as part of the study.

\subsection{Future Work:}

If we are able to determine the relation between a given smog event that can progress through Southern Ontario and the number of illnesses and deaths that have been documented for respiratory or cardiovascular disease, then the transboundary contributions to smog relatedhealth effects could be better understood and there could be measures taken by the healthcare system to better prepare for influxes of illnesses during these times. In order to better understand the phenomena that occur during a smog event more meteorological stations need to be set up where humans are likely to come in contact with high levels of air pollutants. The visual displays are limited in their ability to show a smooth progression because there are many maps on different pages; an animated display would better show the spatial progression of the changes that occur day to day during a smog event and may allow for better understanding of the phenomenon.

Another use of this type of analysis would be the gaining of knowledge of human responses in certain regions in Southern Ontario when the area experiences a smog event. There could be investigation of a sequential predictive pattern in which a smog event begins in the Windsor-Essex region, and the Halton-Peel region is alerted because it could potentially feel the 
brunt of a smog event a day or days later based on smog events that were experienced to the southwest and prevailing winds. 
6.0 Appendices 
Appendix 1 - Data for 2003 Smog Advisory 


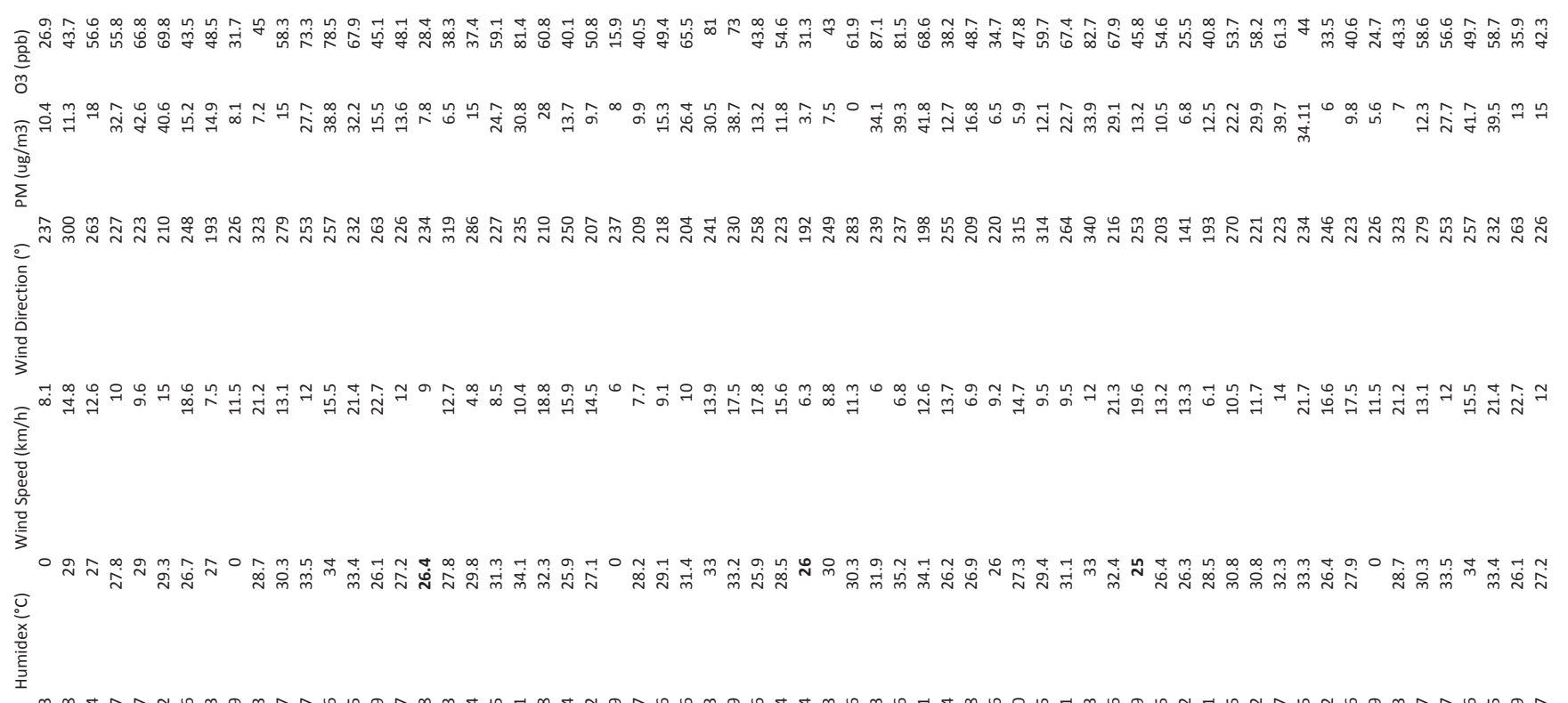

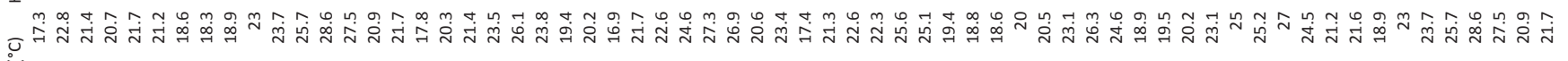

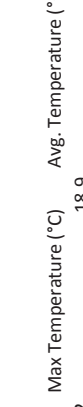

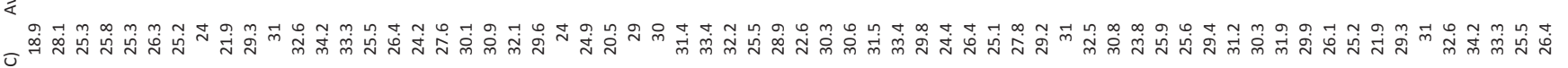
产

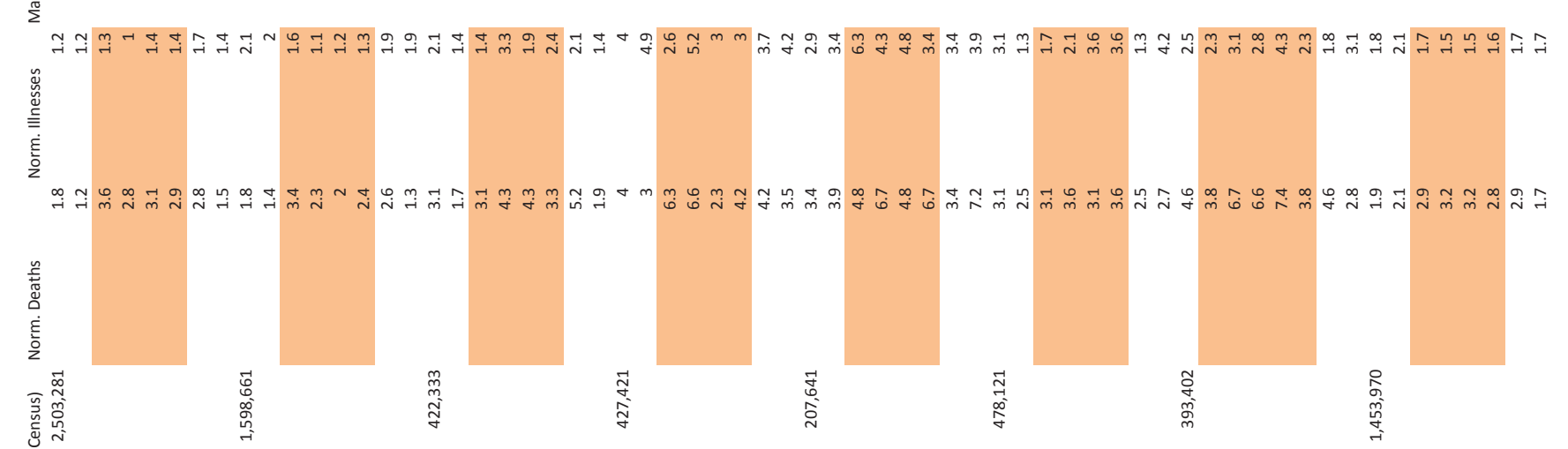

$$
\text { , }
$$

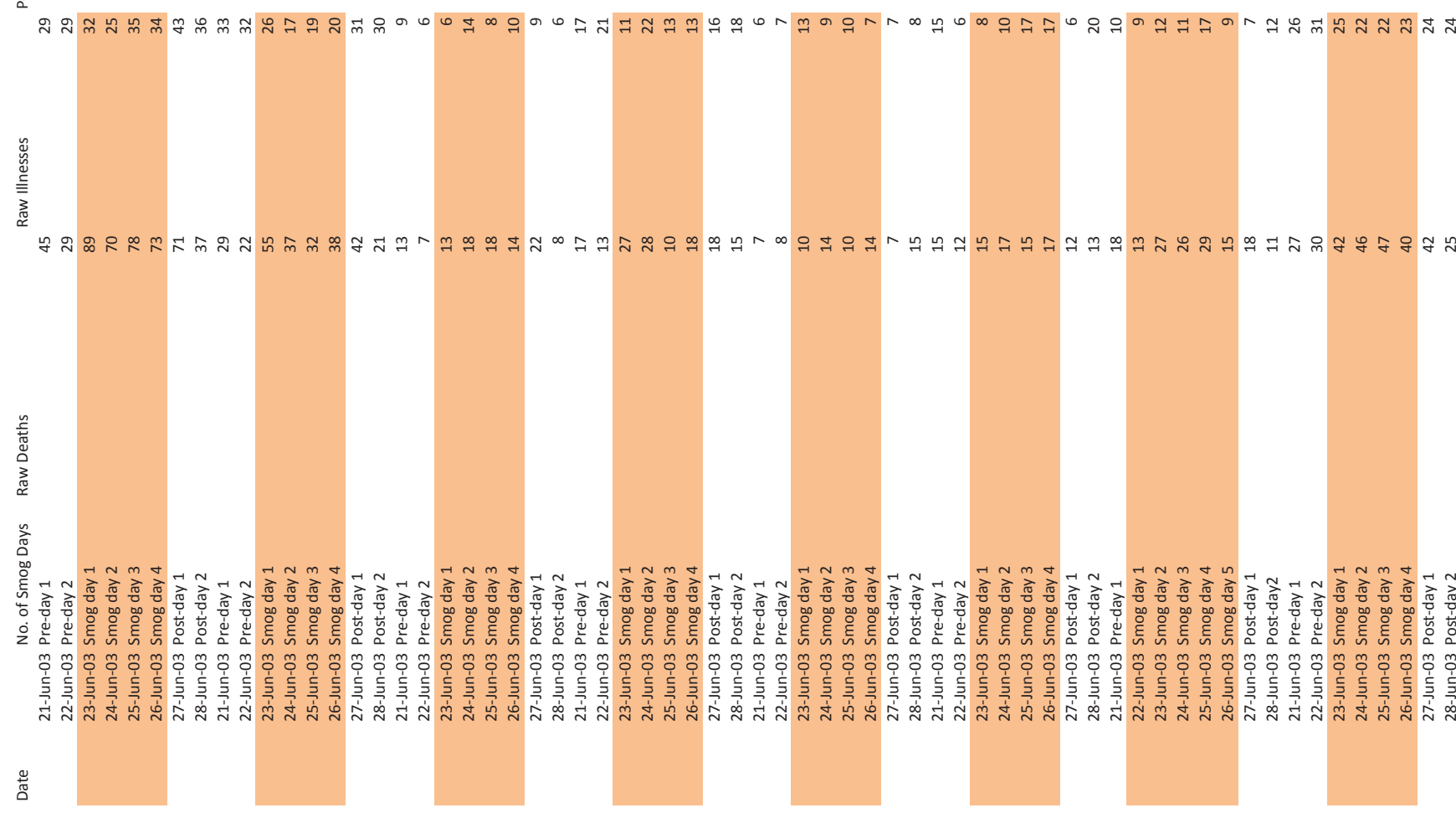
ะั้

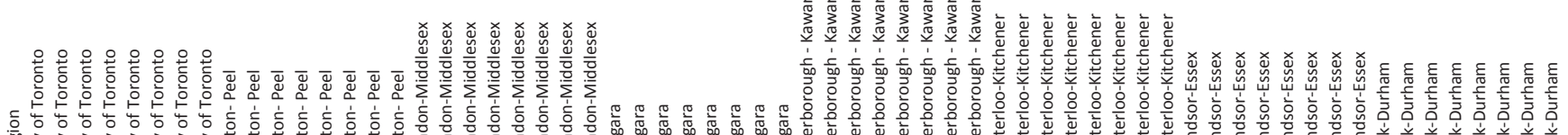

IInIm!

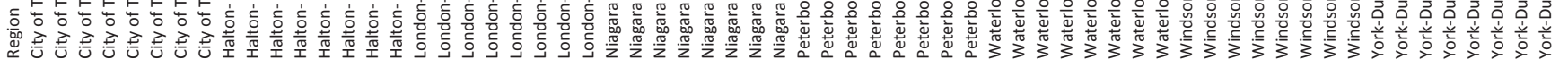


Appendix 2: Data for 2004 Smog Advisory 


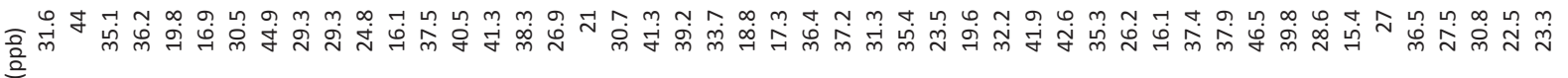
on

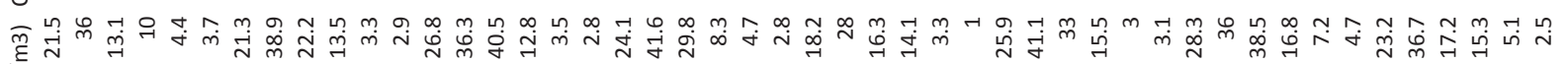

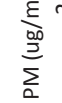

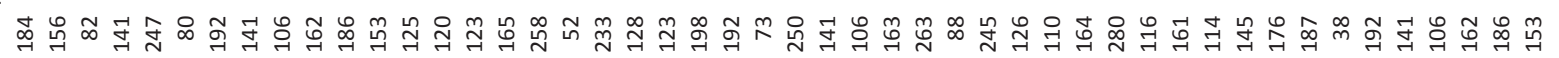

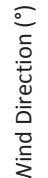

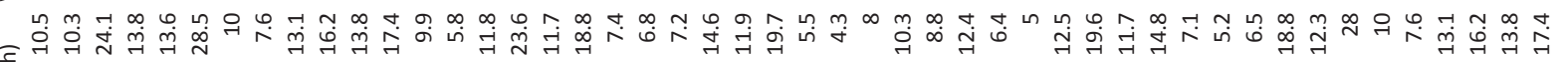

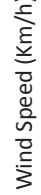

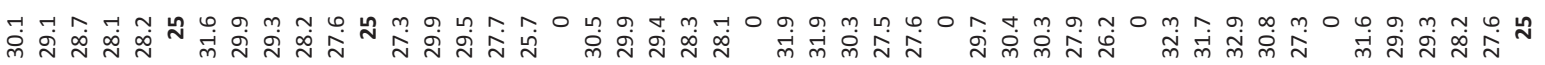

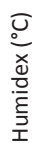

ত$$
\text { 产 }
$$

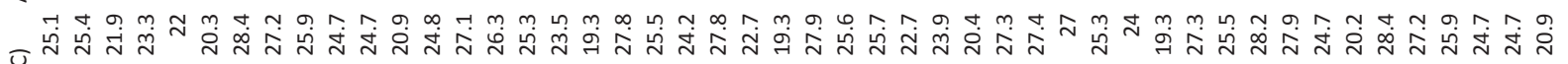$$
\text { 产 }
$$

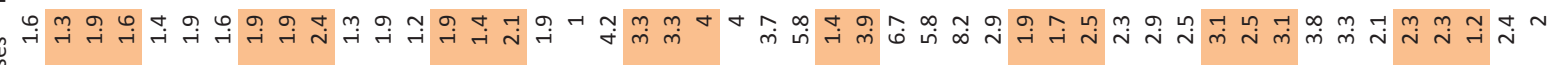

$$
\text { 产 }
$$

$$
\text { 营 }
$$

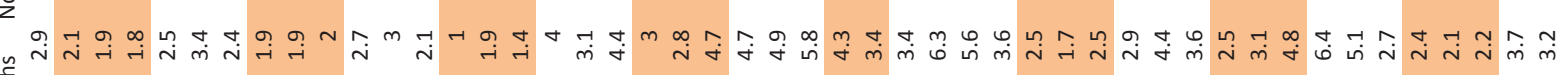
$\stackrel{\dot{\xi}}{\dot{\partial}}$
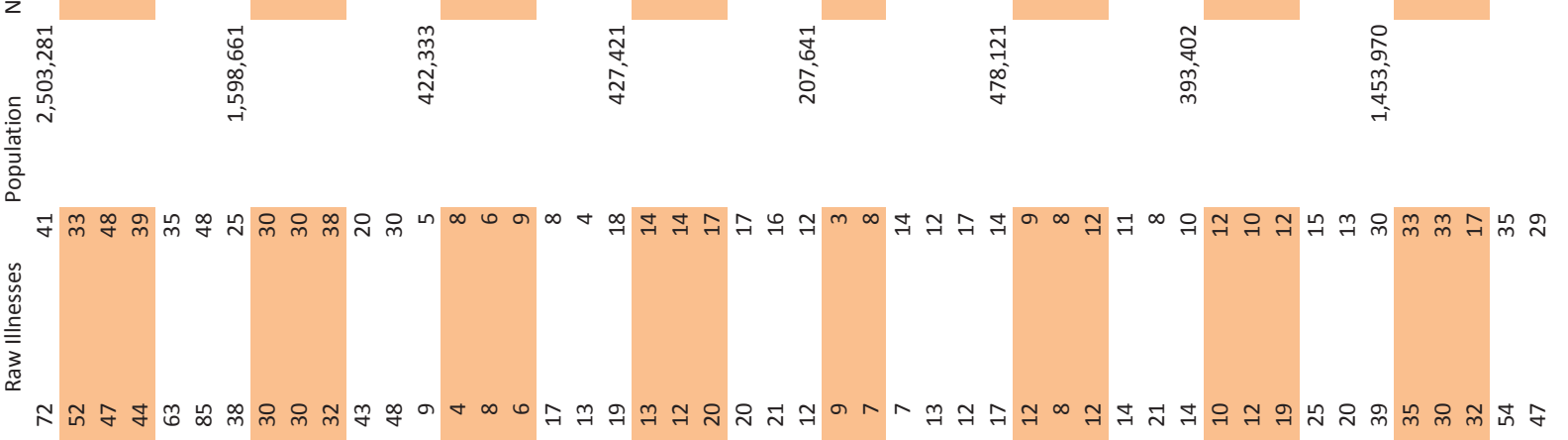

营

䓂

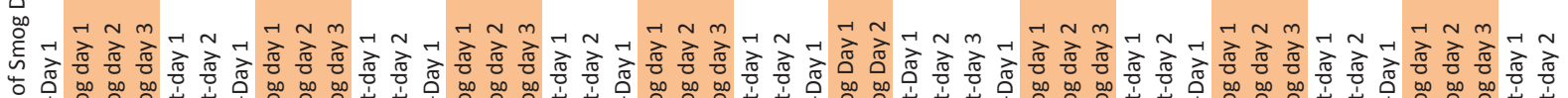

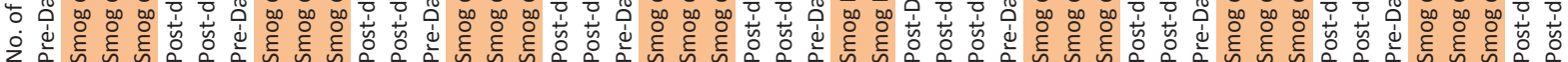

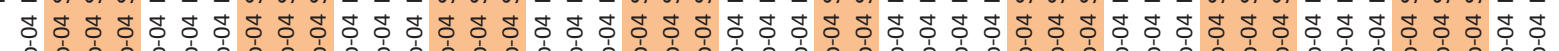

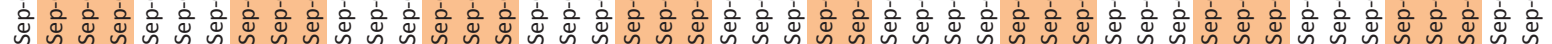

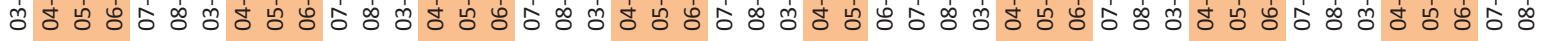

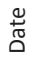
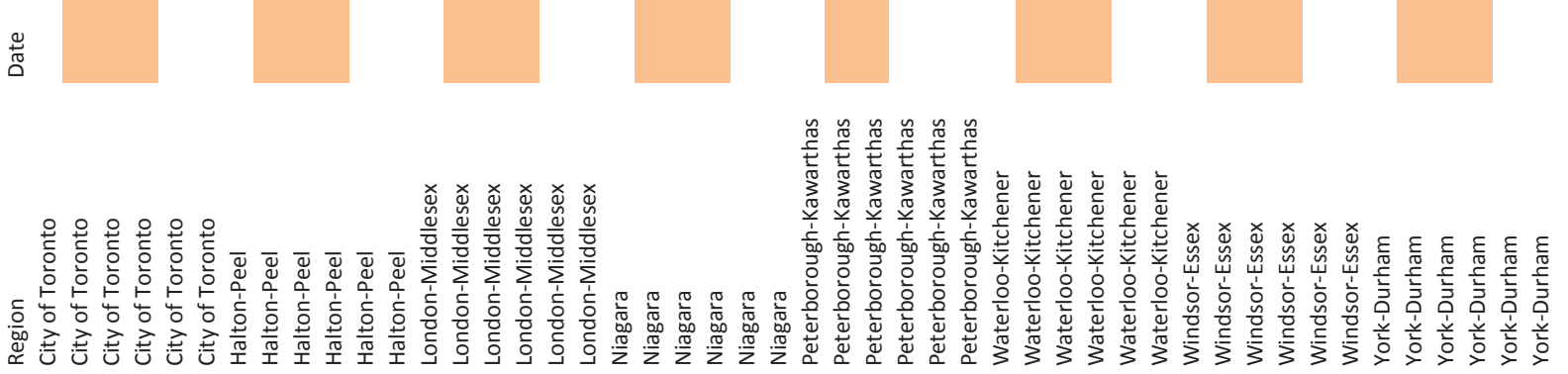
Appendix 3: Data for 2005 Smog Advisory 


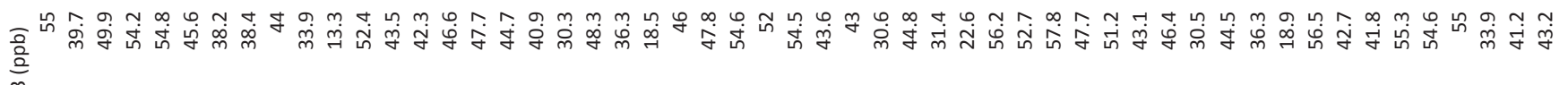
ח)

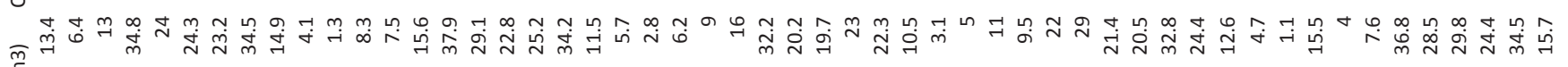
$\sum_{\substack{\text { of } \\ \sum}}^{\frac{1}{2}}$

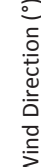

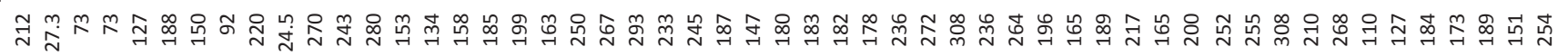

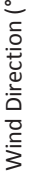

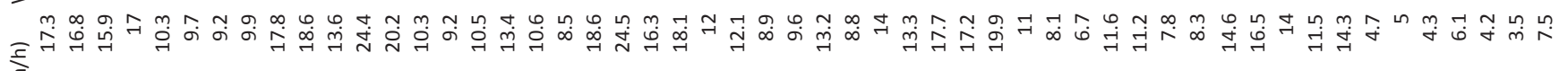

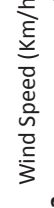

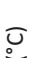

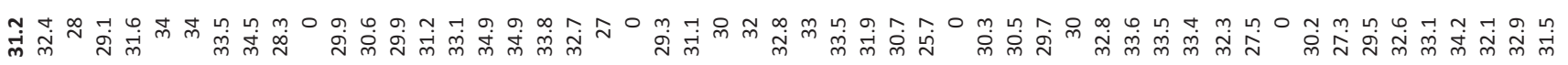

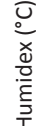

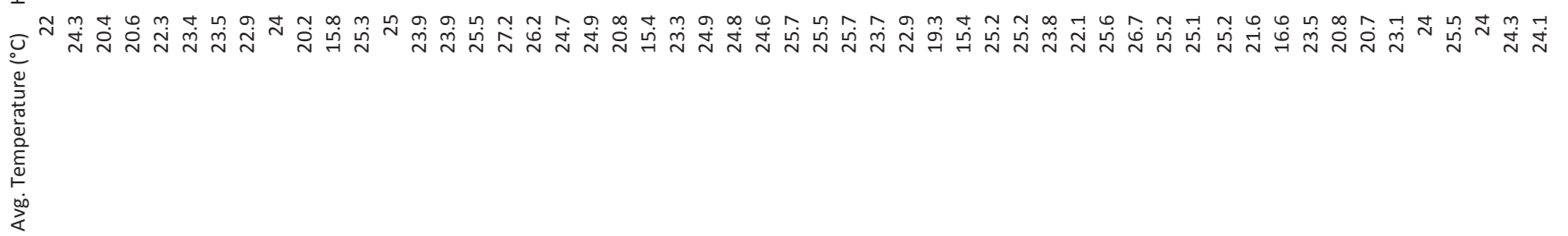

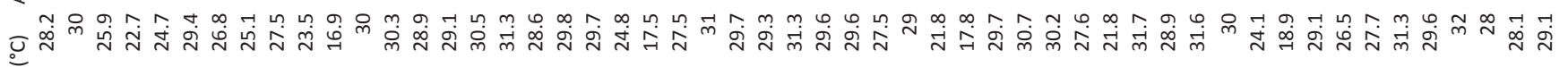$$
\text { 产竞 }
$$

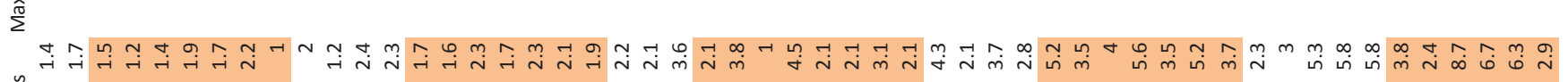

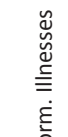
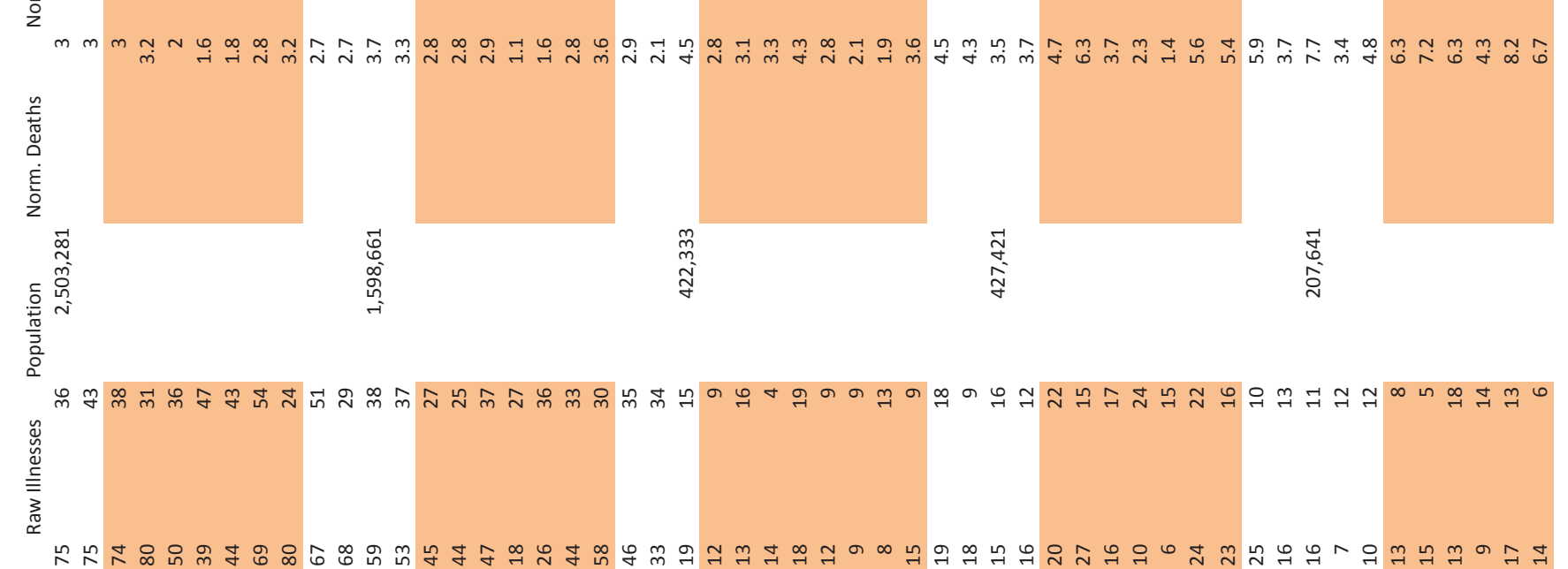

点

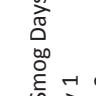

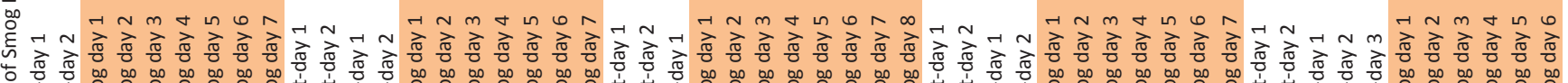

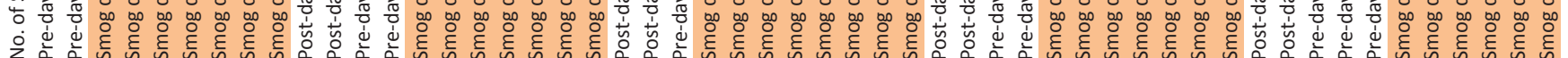

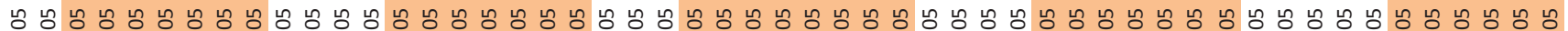

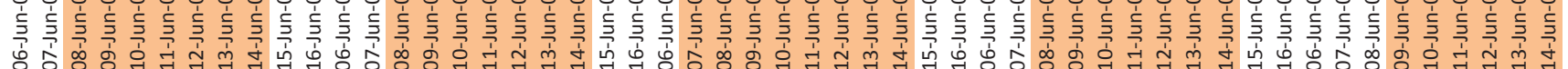
$\stackrel{\Perp}{\triangle}$

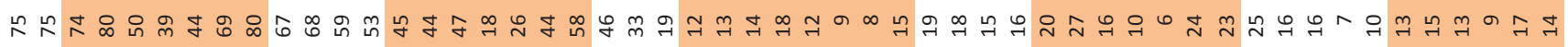
离
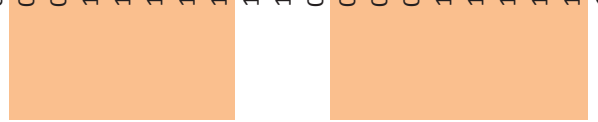


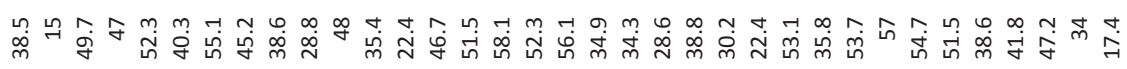

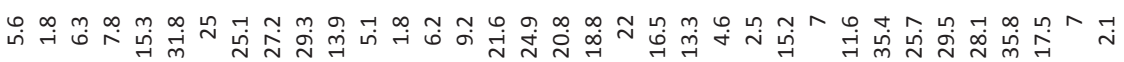

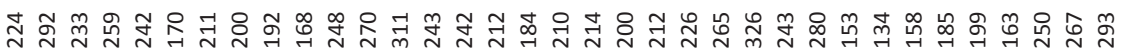

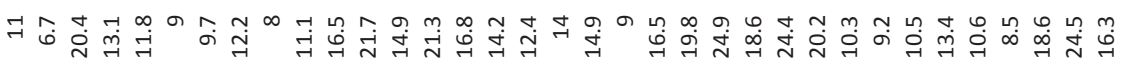

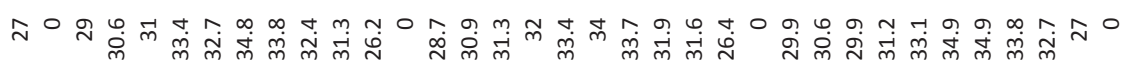

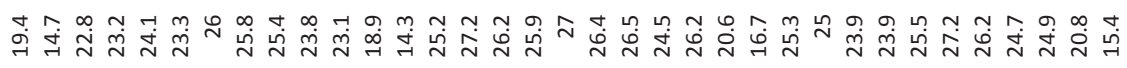

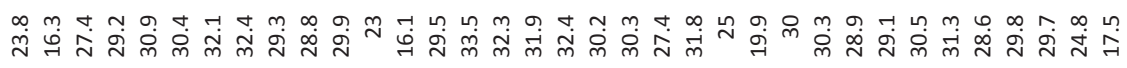

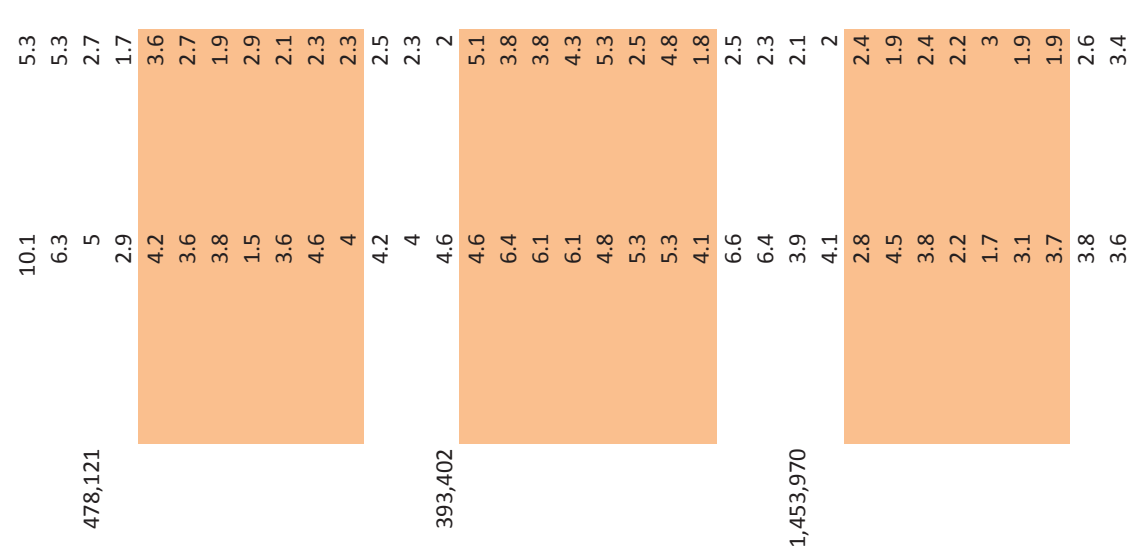

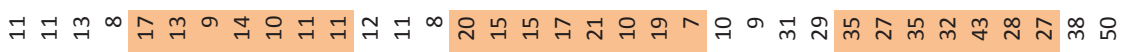

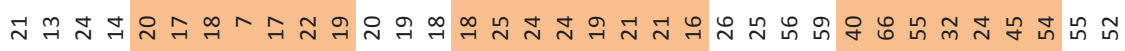

$\begin{array}{llllllllllll} & \\ 0\end{array}$

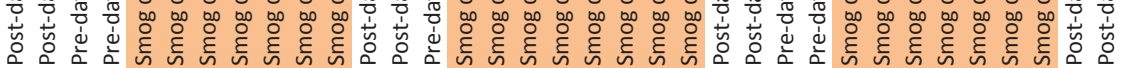

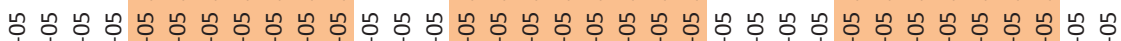

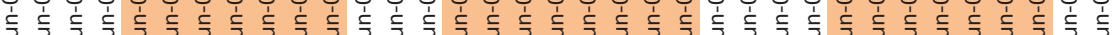

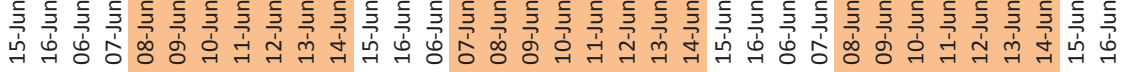

要劳

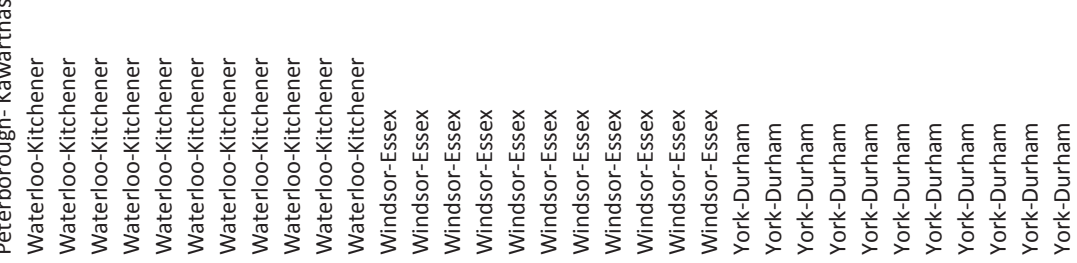


Appendix 4: Data for 2006 Smog Advisory 


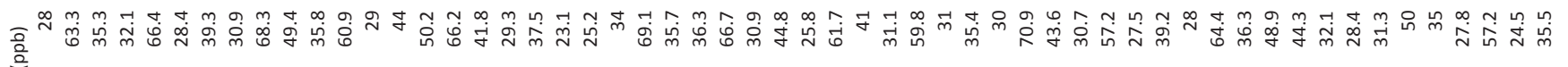
잉

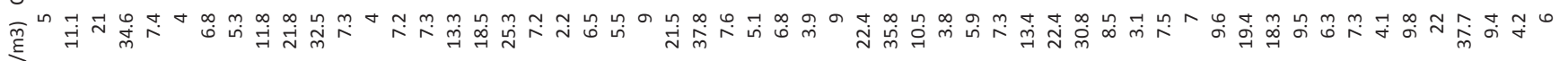

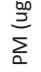

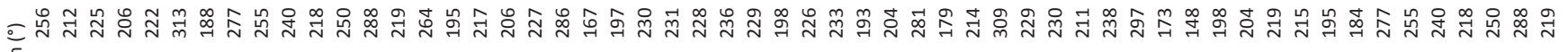

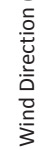

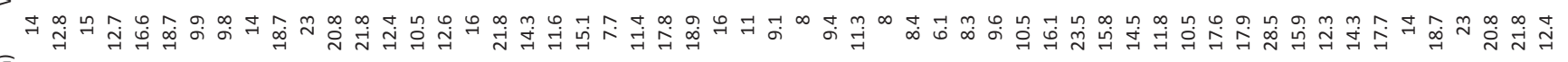

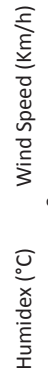

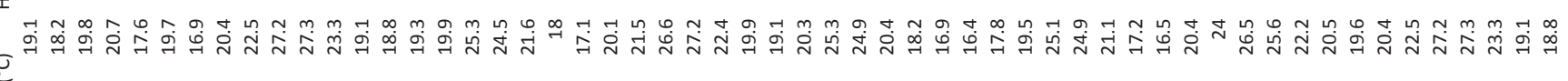

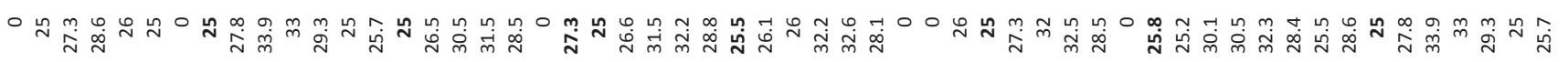
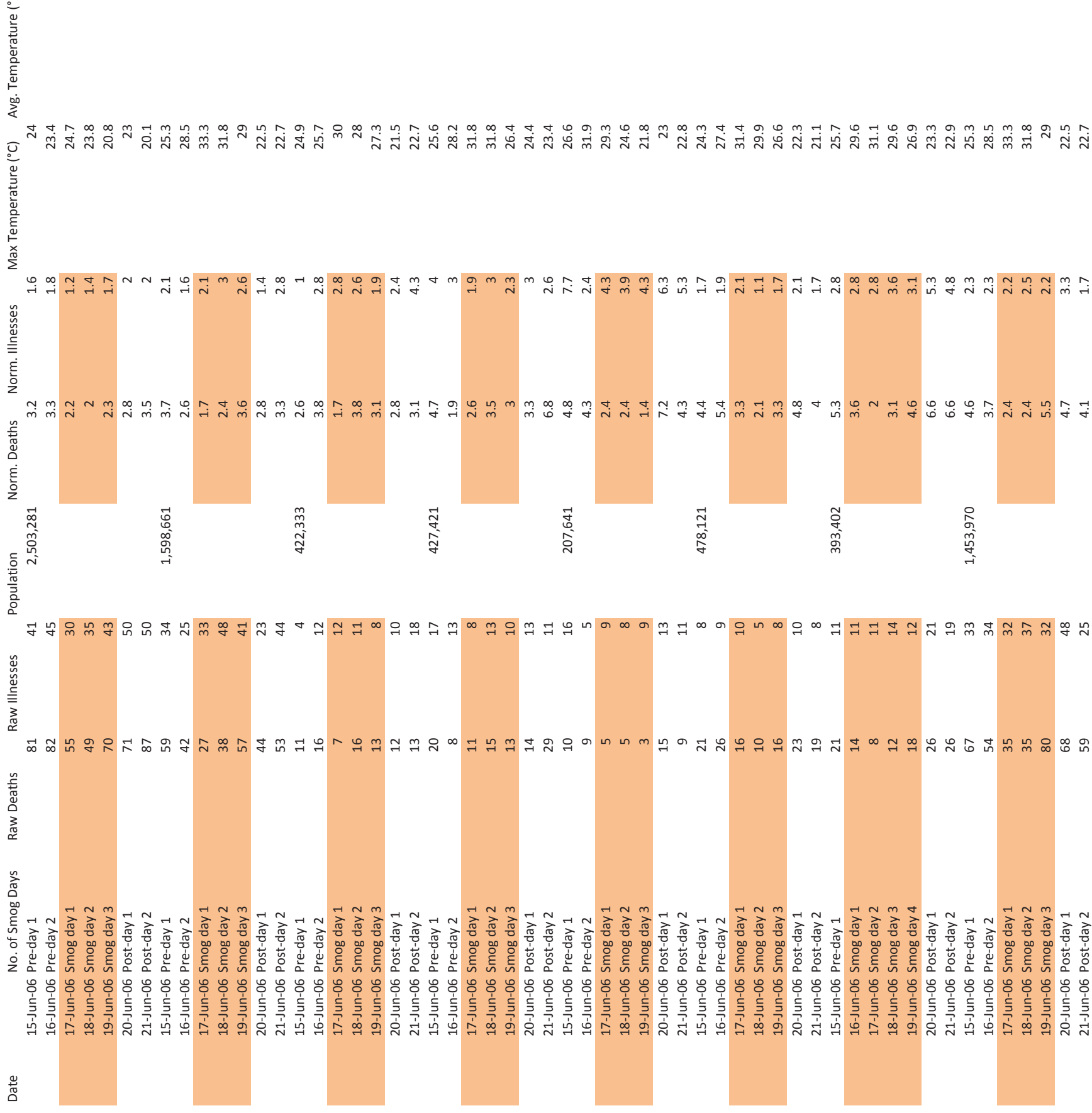

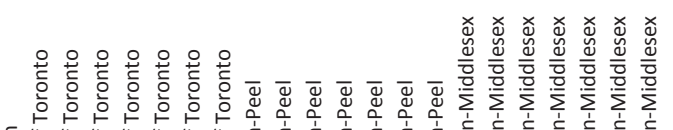

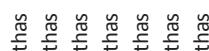


Appendix 5: Data for 2007 Smog Advisory 


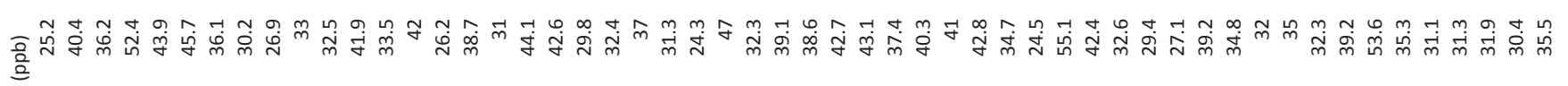
on

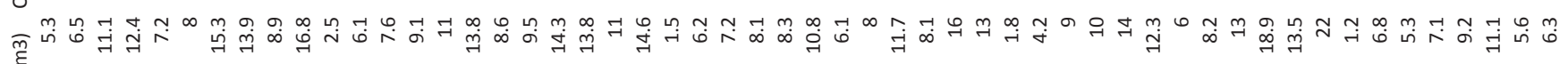

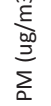

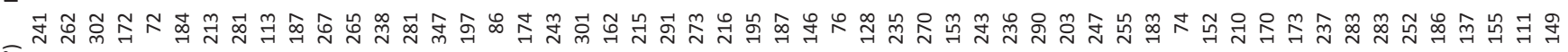
है

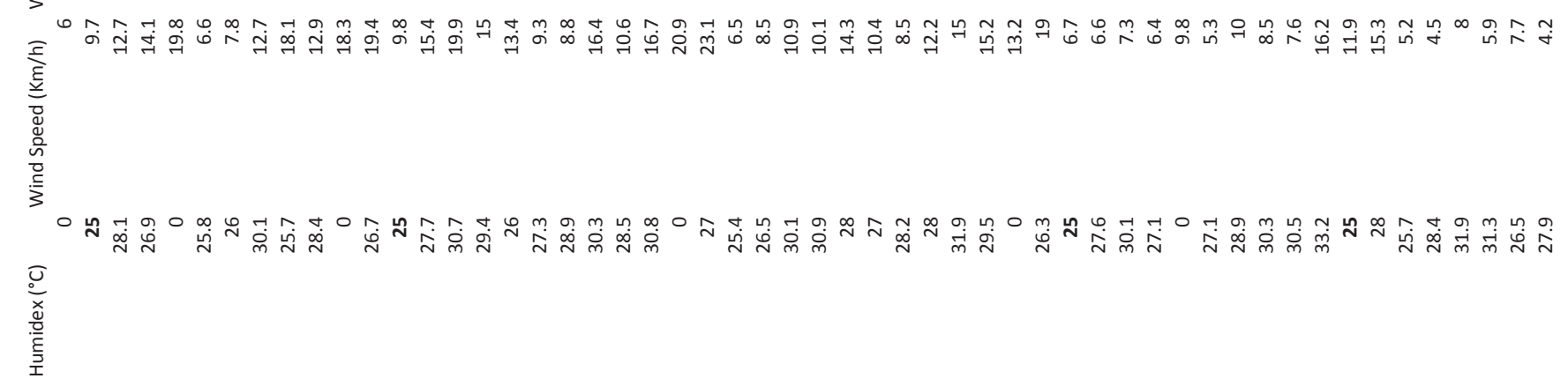

ত ס

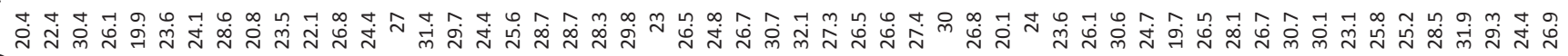

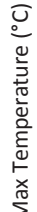

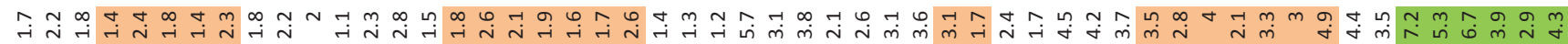

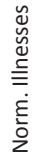

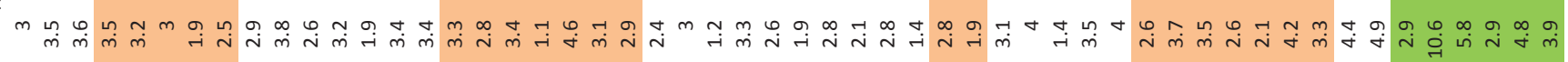

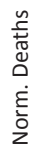

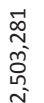

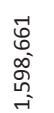

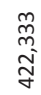

든
$\frac{0}{5}$
$\frac{0}{3}$
$\frac{0}{0}$

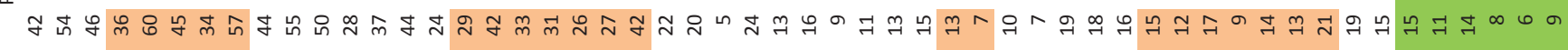

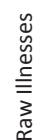

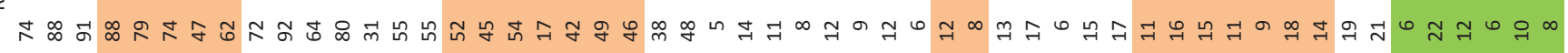
总

离

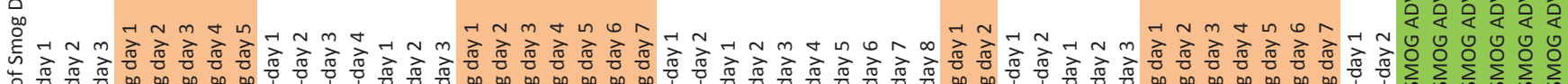

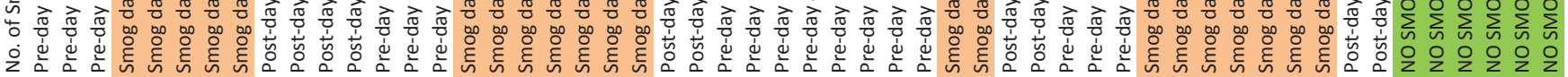

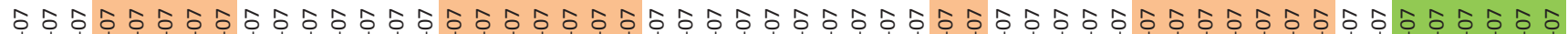

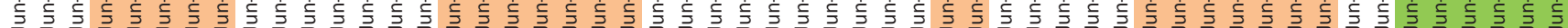

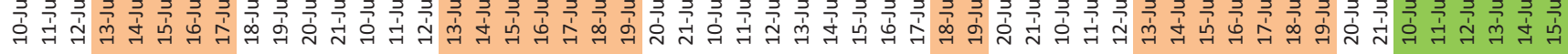
苋 


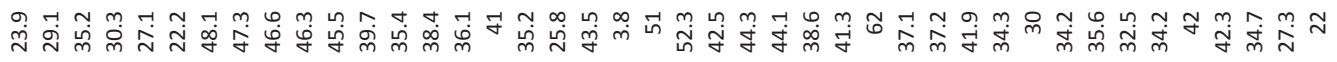

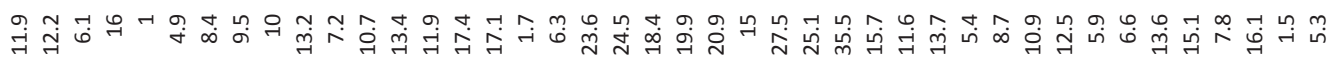

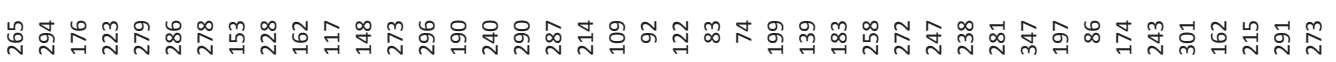

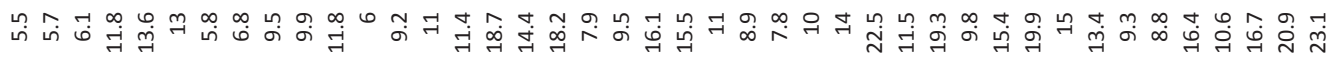

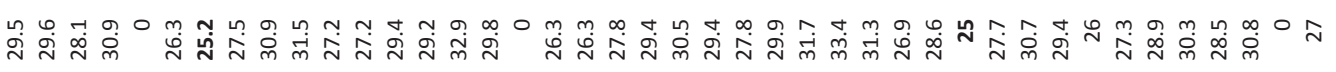

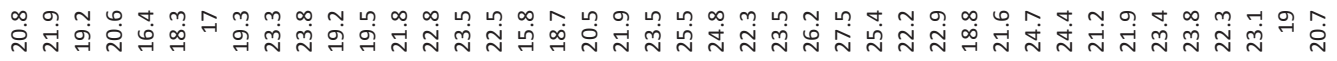

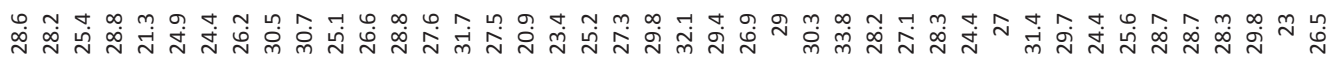
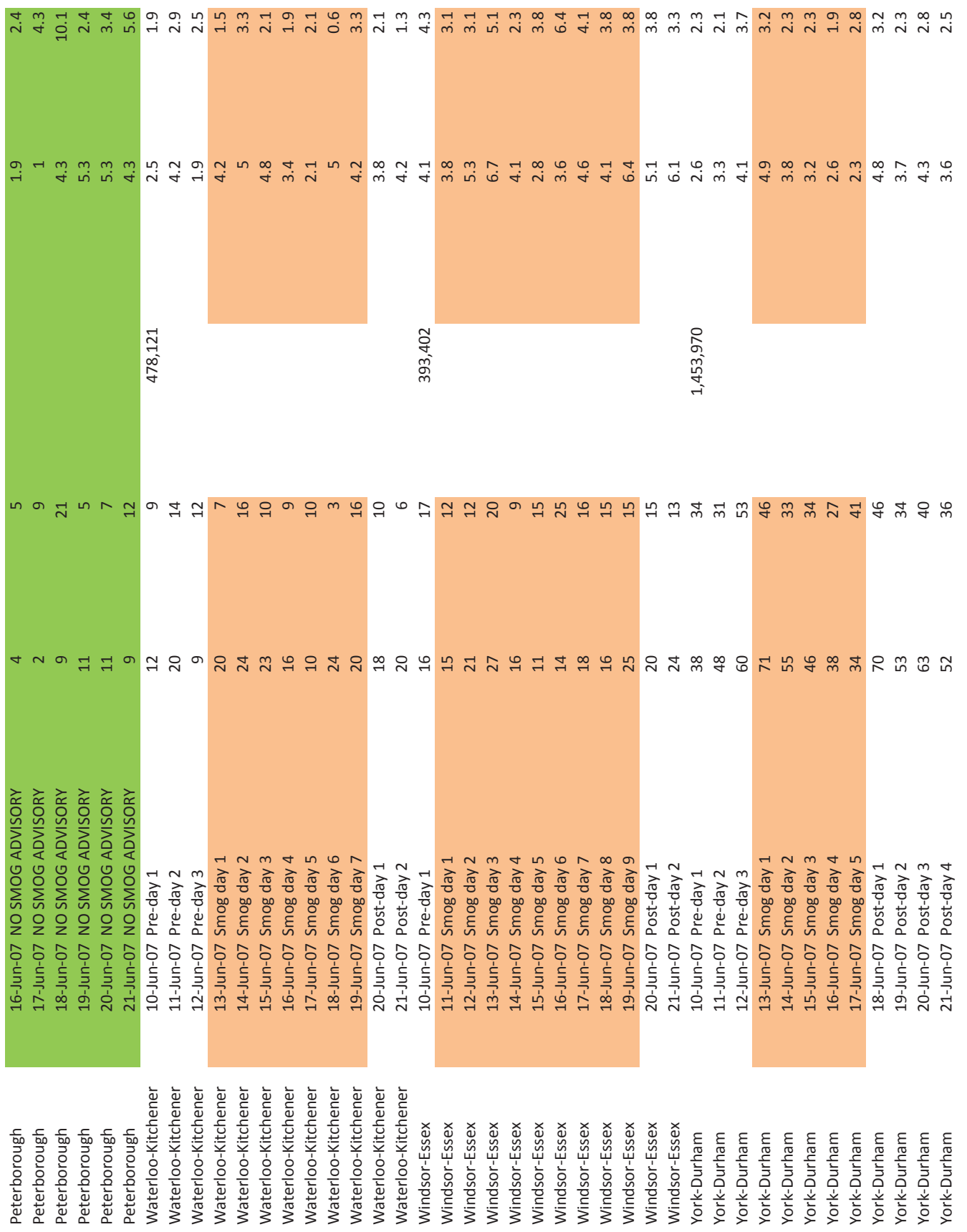
Appendix 6: Data for 2008 Smog Advisory 


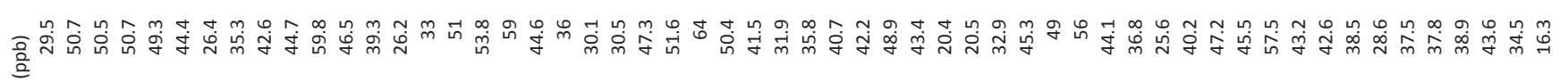
药

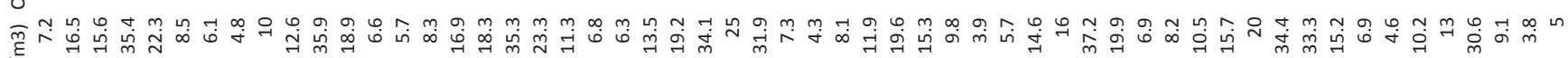

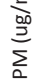

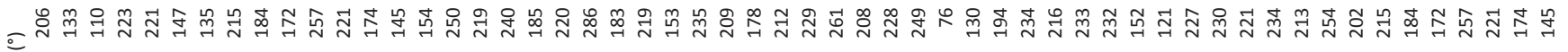

ᄃำ

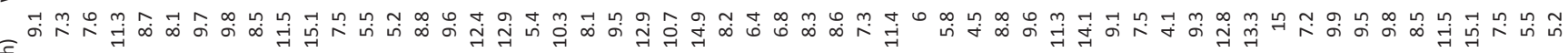

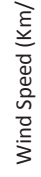

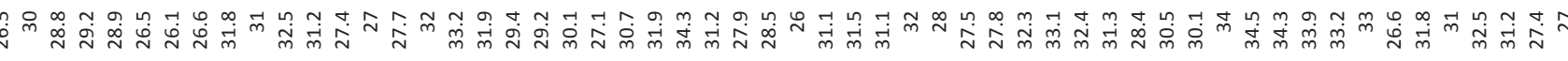
$\frac{\overline{0}}{\frac{0}{x}}$

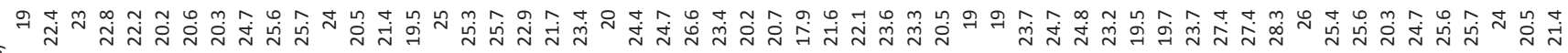

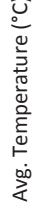

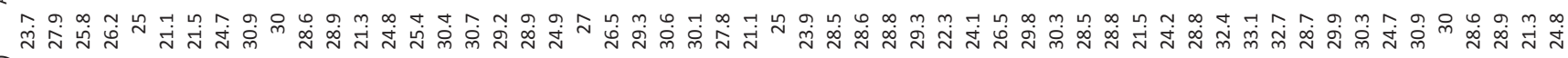

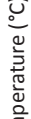

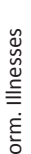

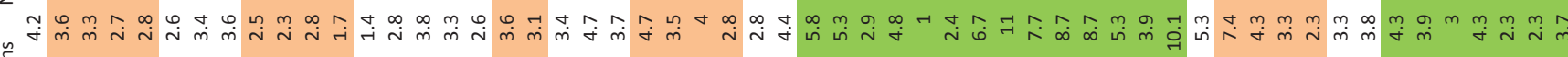
$\dot{\xi}$ 离 $\frac{\bar{\partial}}{2}$

₹亗

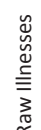

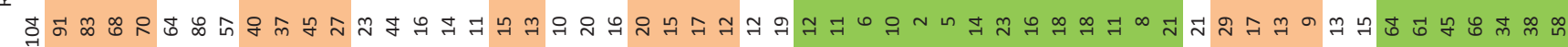

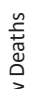
矛

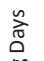

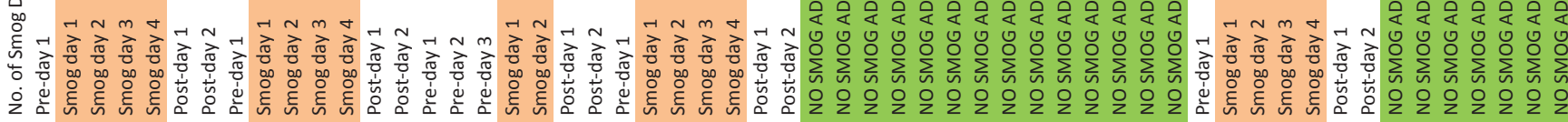

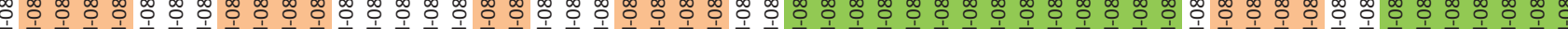

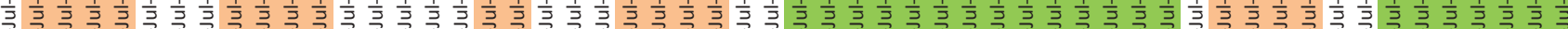

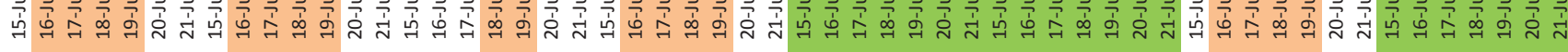
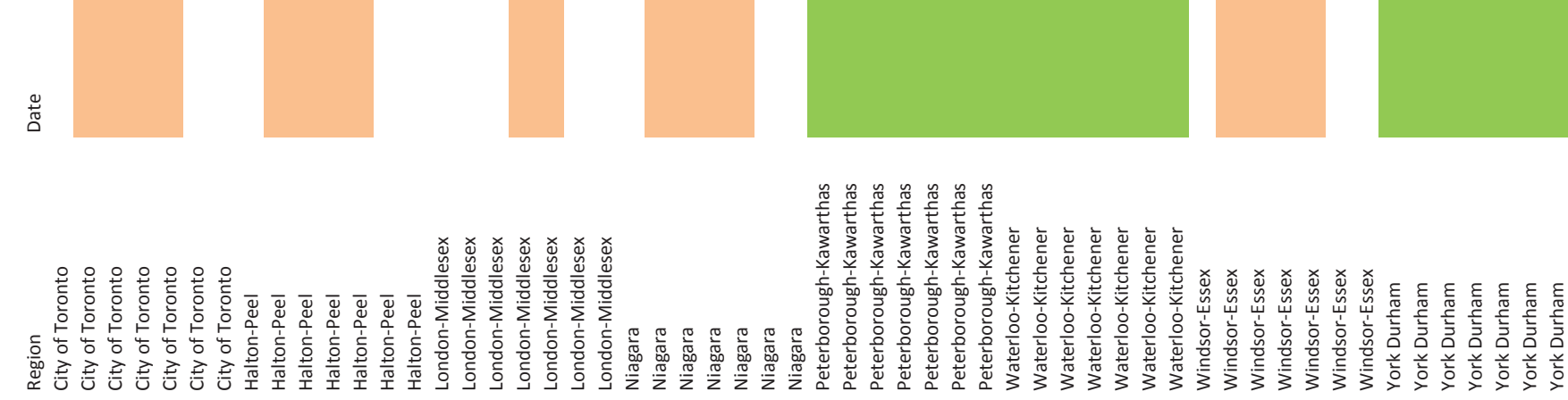
Appendix 7: Data for 2009 Smog Advisory 


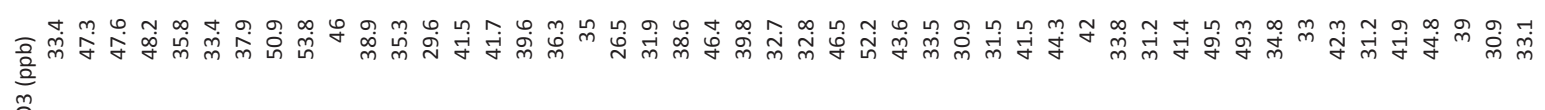
on

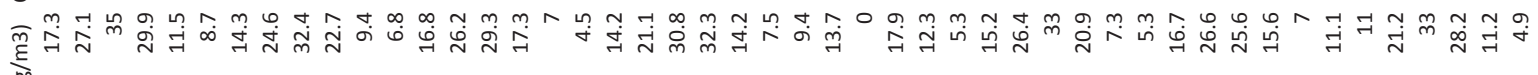

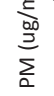

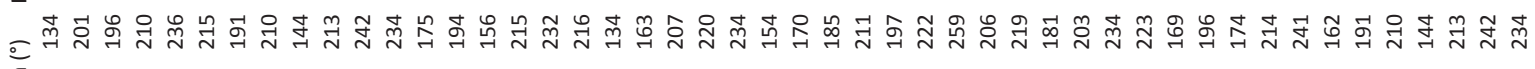
童

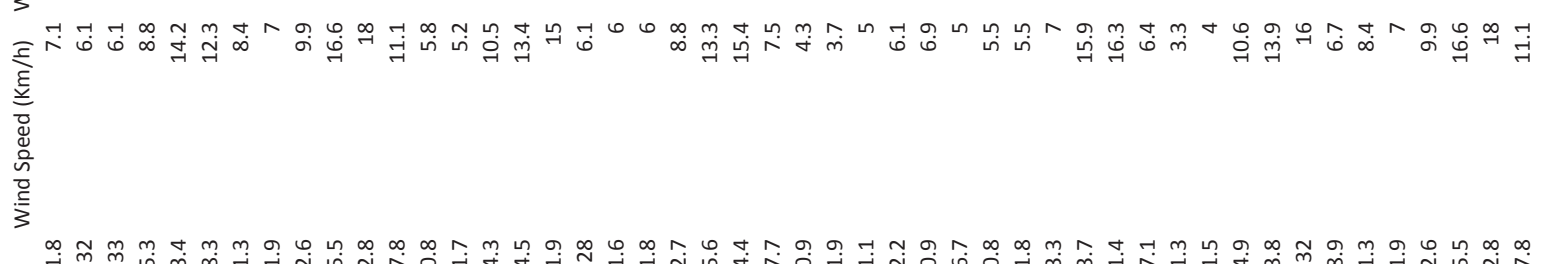

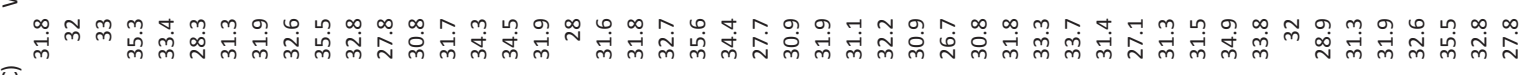

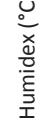

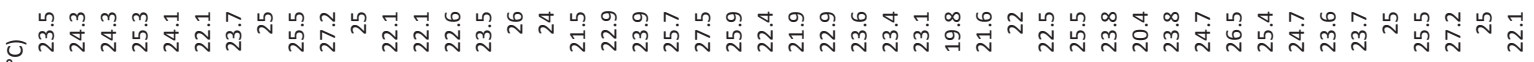

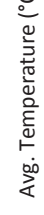

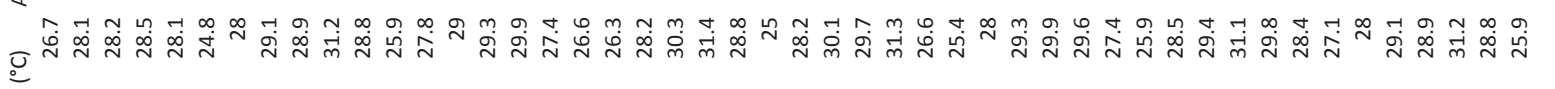
竞
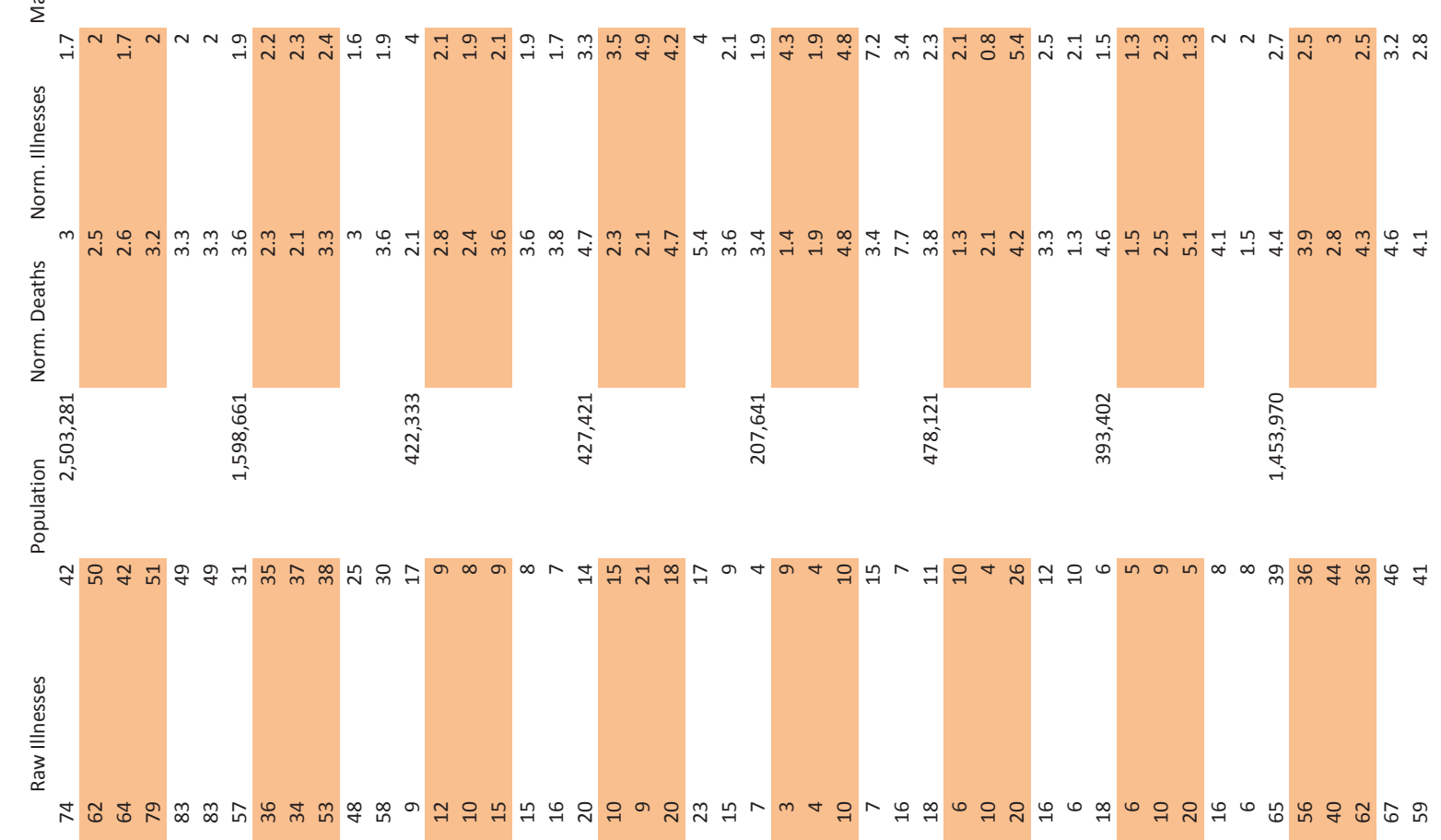

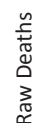

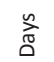

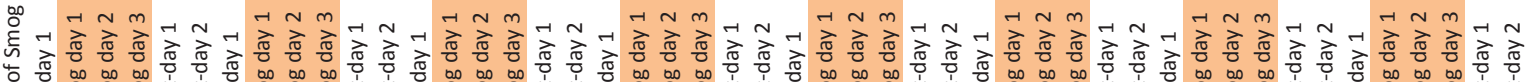

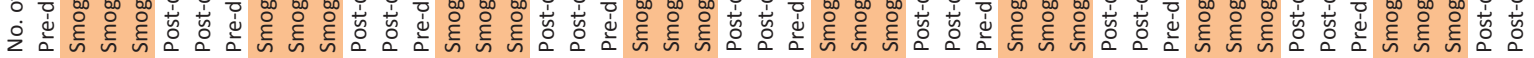

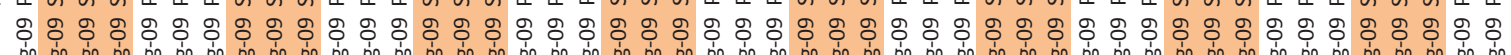

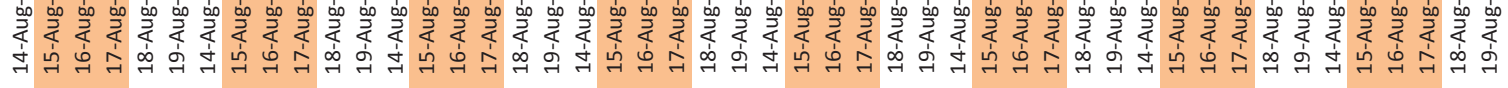

$\stackrel{\Perp}{\text { Iั }}$ (1)

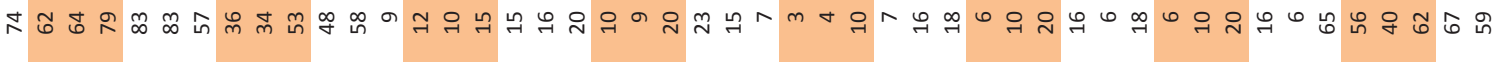
. 
Appendix 8: Data for 2010 Smog Advisory 


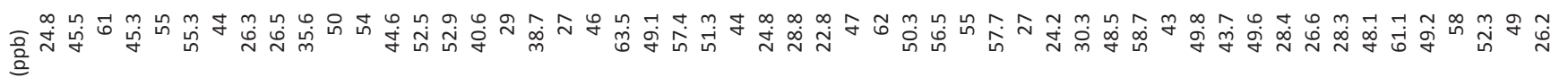
잉

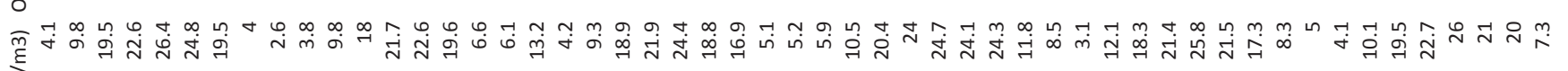

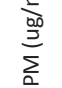

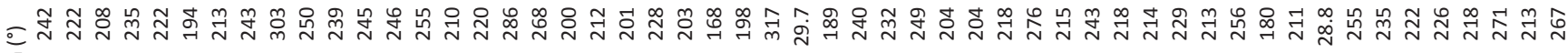
产

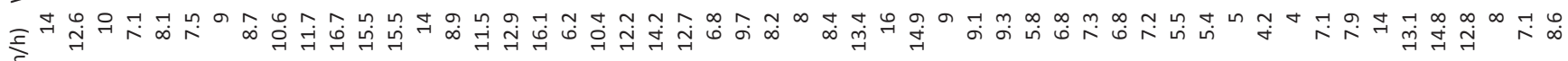
产

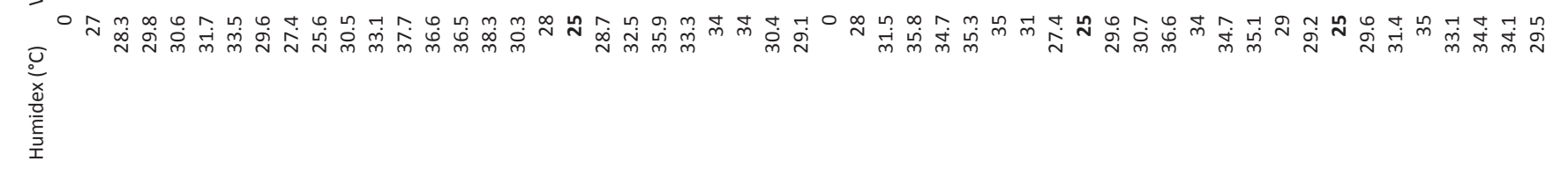

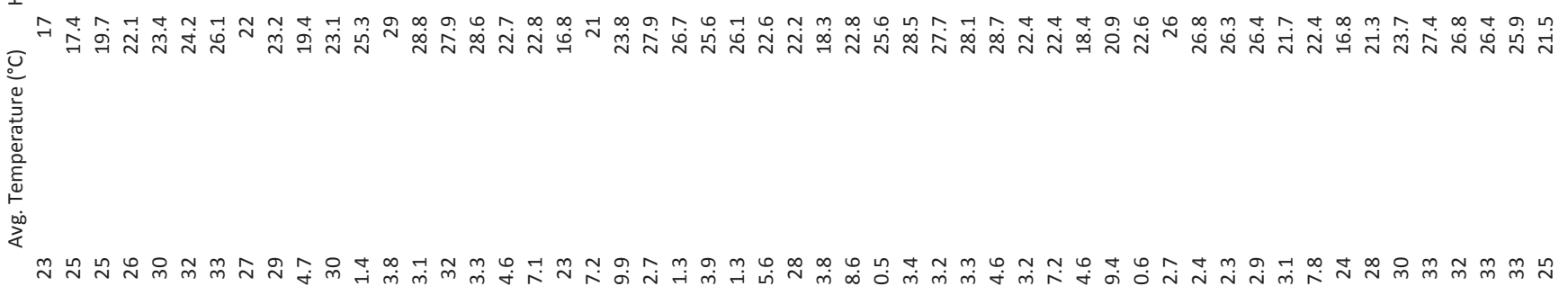

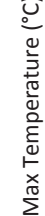

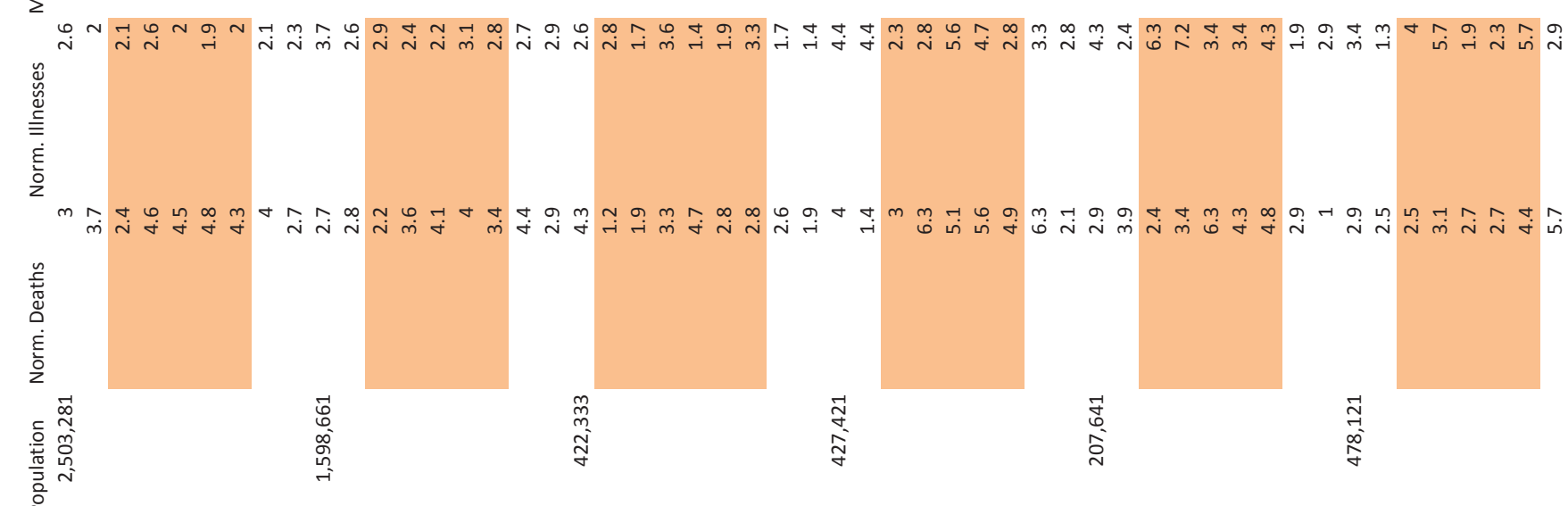

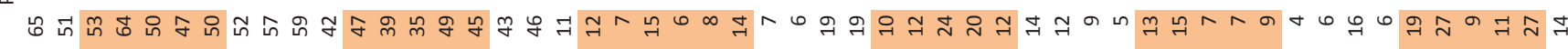

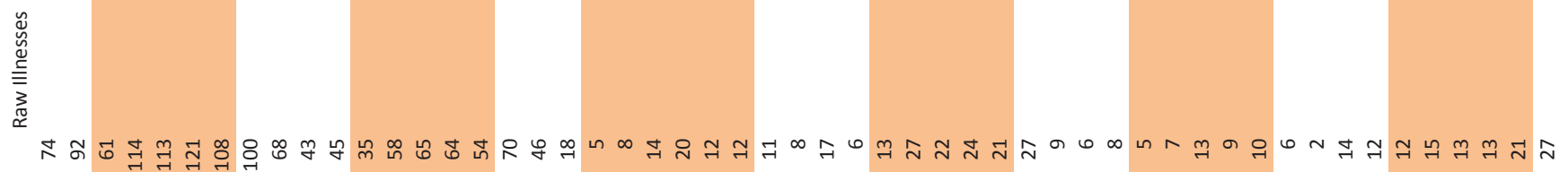

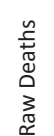

$\stackrel{n}{\stackrel{n}{0}}$

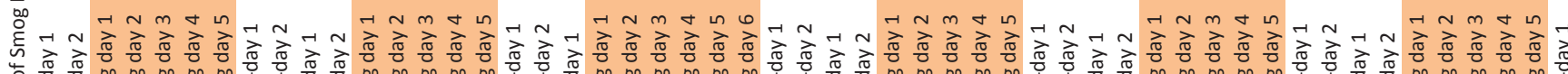

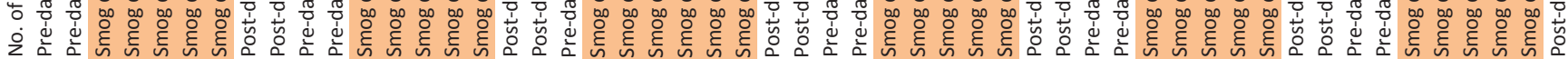

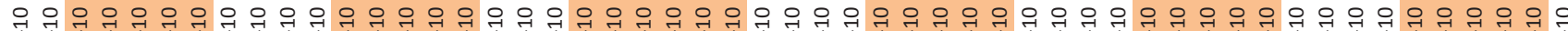

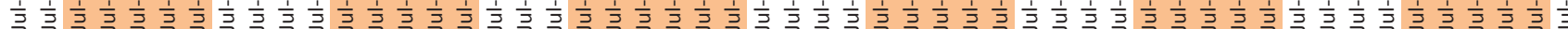

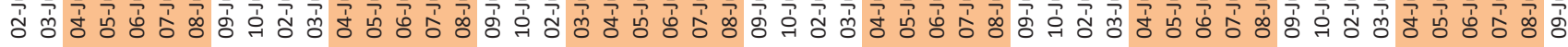

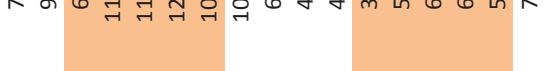




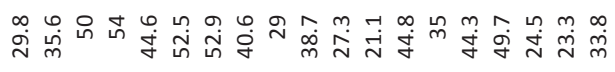

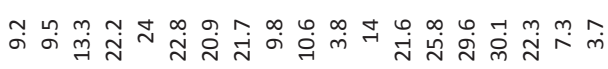

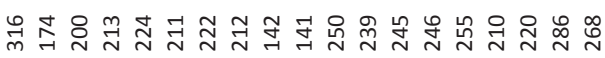

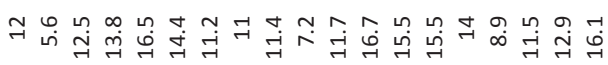

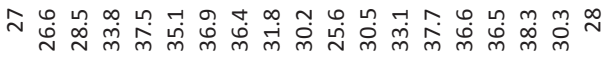

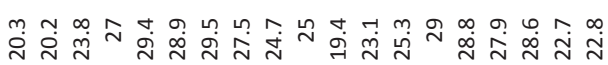

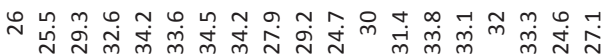

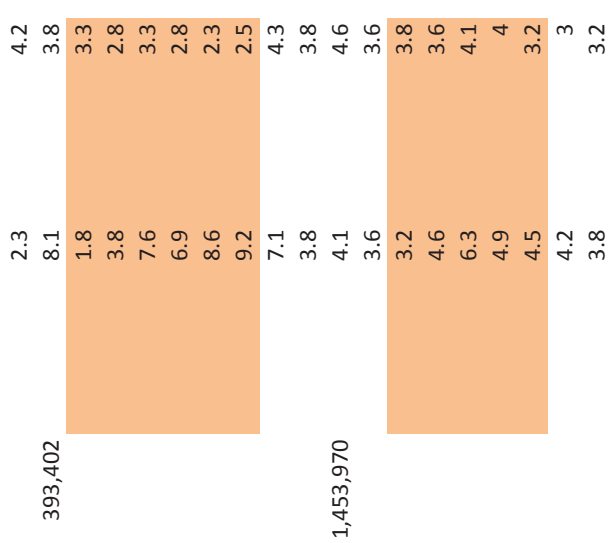

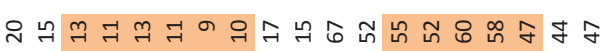

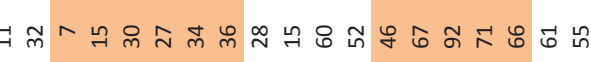

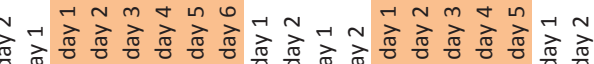

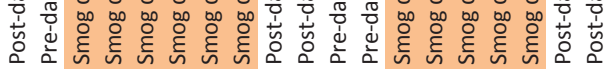

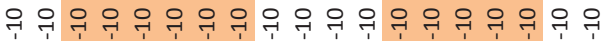

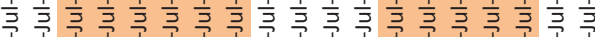

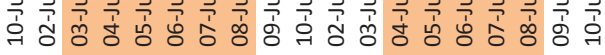

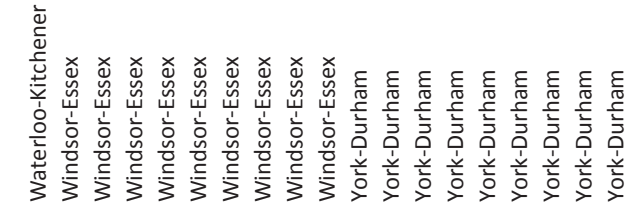


Appendix 9: Data for 2011 Smog Advisory 


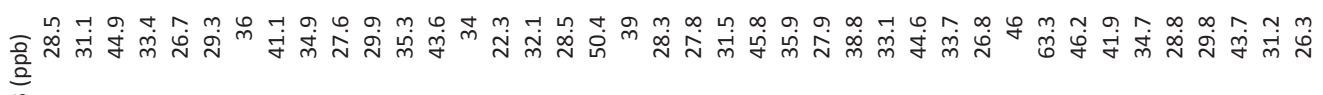
\%

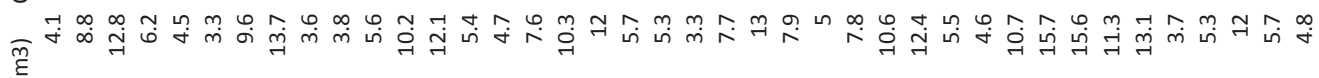
$\sum_{0}^{\frac{1}{00}}$

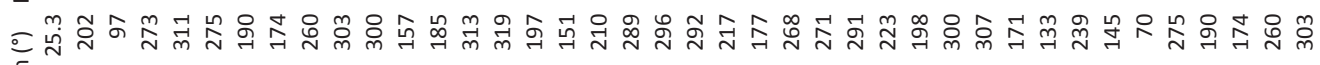

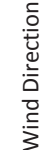
을

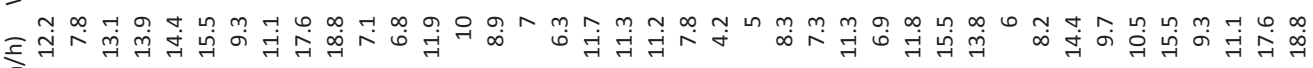
产

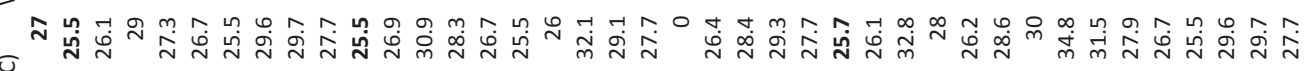

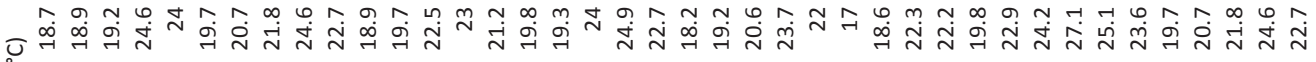

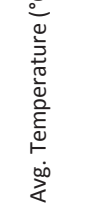

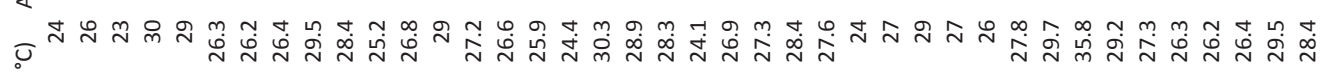$$
\text { 言 }
$$
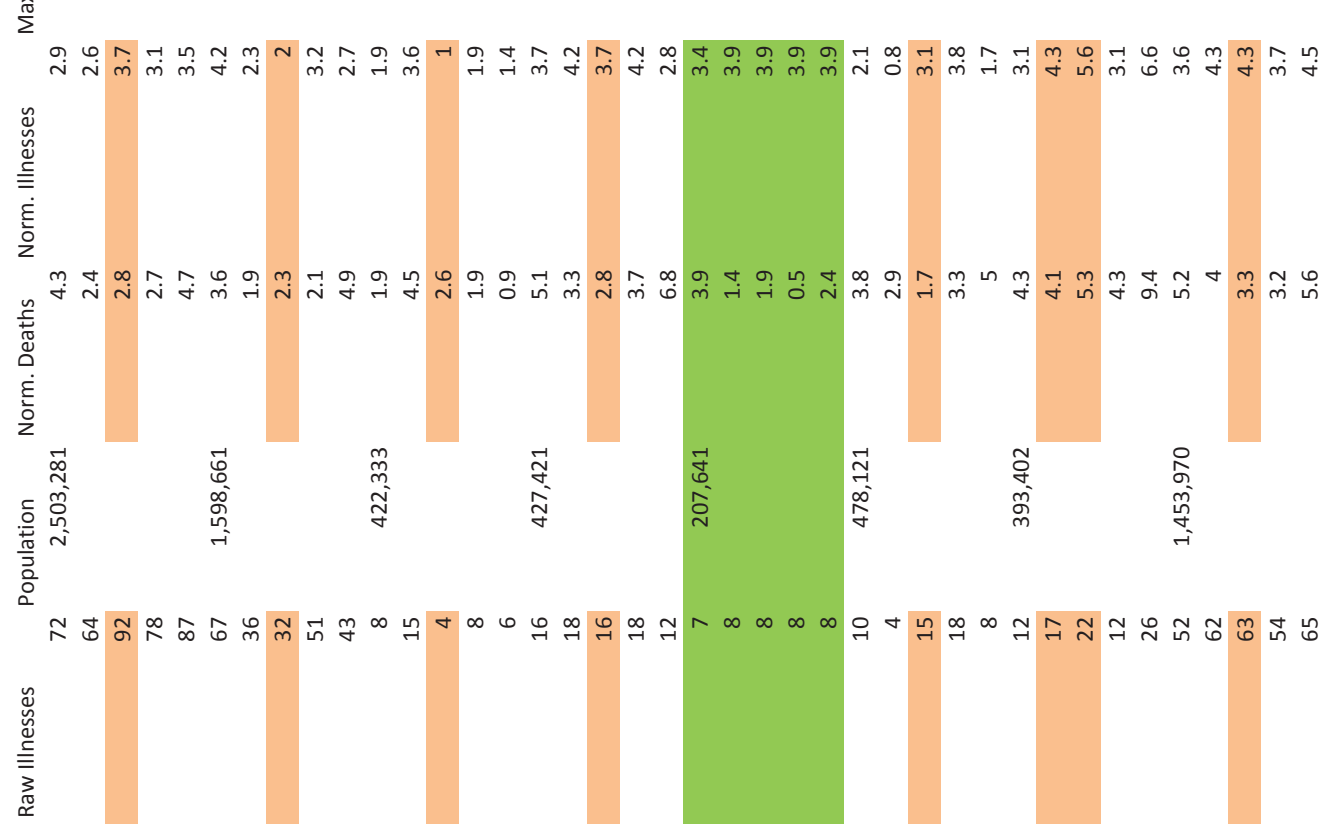

承 \&̊ำ

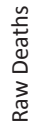

\section{商}

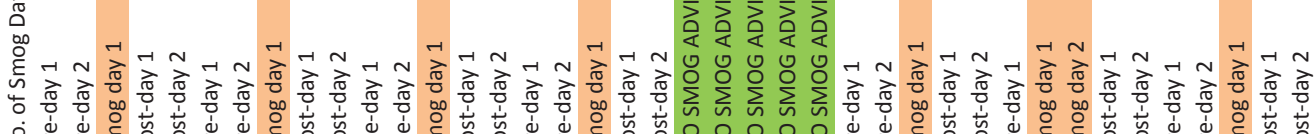

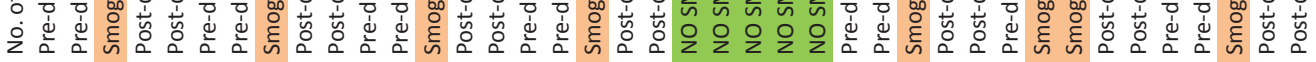

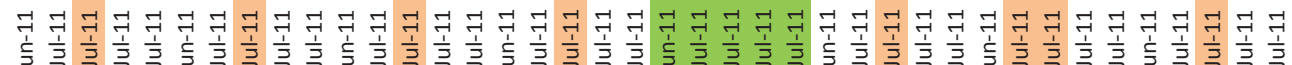

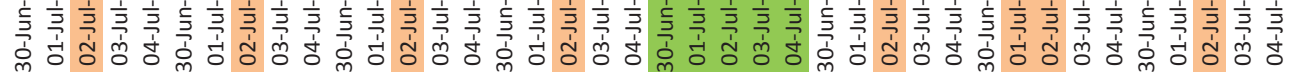

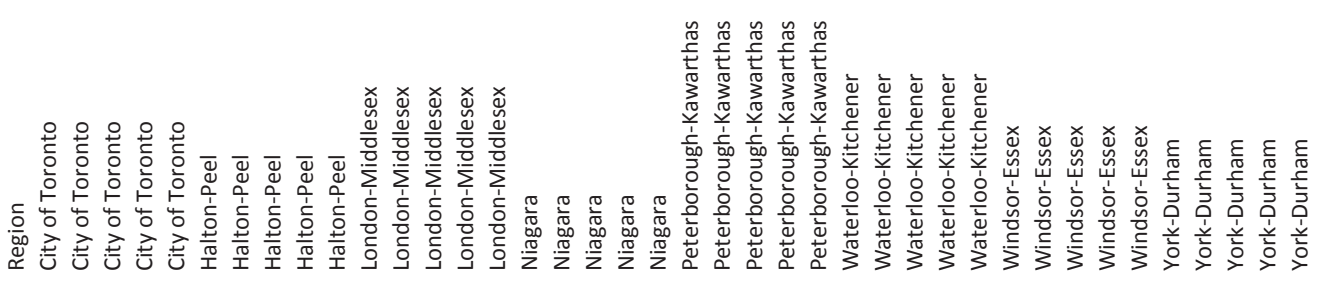




\section{Appendix 10: 2006 Smog Advisory Regression Analysis}

\begin{tabular}{|c|c|c|c|c|c|c|c|c|c|c|}
\hline \multirow[b]{3}{*}{ Model } & \multirow[b]{3}{*}{$\mathrm{R}$} & \multirow[b]{3}{*}{ R Square } & \multirow[b]{3}{*}{$\begin{array}{c}\text { Adjusted R } \\
\text { Square }\end{array}$} & \multirow[b]{3}{*}{$\begin{array}{l}\text { Std. Error of } \\
\text { the Estimate }\end{array}$} & \multicolumn{6}{|c|}{ Model Summary ${ }^{b}$} \\
\hline & & & & & \multicolumn{5}{|c|}{ Change Statistics } & \multirow[b]{2}{*}{$\begin{array}{l}\text { Durbin- } \\
\text { Watson }\end{array}$} \\
\hline & & & & & $\begin{array}{c}\text { R Square } \\
\text { Change }\end{array}$ & F Change & df1 & df 2 & Sig. F Change & \\
\hline 1 & $.702^{a}$ & .493 & .483 & 126.56972 & .493 & 52.448 & 1 & 54 & .000 & 2.290 \\
\hline
\end{tabular}

a. Predictors: (Constant), Max Temperature

b. Dependent Variable: V_TW

\section{Appendix 11: 2007 Smog Advisory Regression Analysis}

\begin{tabular}{|c|c|c|c|c|c|c|c|c|c|c|}
\hline \multicolumn{11}{|c|}{ Model Summary } \\
\hline \multirow[b]{2}{*}{ Model } & \multirow[b]{2}{*}{$\mathrm{R}$} & \multirow[b]{2}{*}{ R Square } & \multirow[b]{2}{*}{$\begin{array}{l}\text { Adjusted R } \\
\text { Square }\end{array}$} & \multirow[b]{2}{*}{$\begin{array}{l}\text { Std. Error of } \\
\text { the Estimate }\end{array}$} & \multicolumn{5}{|c|}{ Change Statistics } & \multirow[b]{2}{*}{$\begin{array}{l}\text { Durbin- } \\
\text { Watson }\end{array}$} \\
\hline & & & & & $\begin{array}{c}\text { R Square } \\
\text { Change }\end{array}$ & F Change & df1 & $\mathrm{df} 2$ & Sig. F Change & \\
\hline 1 & $.293^{\mathrm{a}}$ & .086 & .076 & 184.80232 & .086 & 8.795 & 1 & 94 & .004 & 1.997 \\
\hline
\end{tabular}

a. Predictors: (Constant), PMLevels

b. Dependent Variable: V_TW

\section{Appendix 12: 2008 Smog Advisory Regression Analysis}

\begin{tabular}{|c|c|c|c|c|c|c|c|c|c|c|}
\hline & & & & & lodel Summan & & & & & \\
\hline \multirow[b]{2}{*}{ Model } & \multirow[b]{2}{*}{$\mathrm{R}$} & \multirow[b]{2}{*}{ R Square } & \multirow[b]{2}{*}{$\begin{array}{c}\text { Adjusted R } \\
\text { Square }\end{array}$} & \multirow[b]{2}{*}{$\begin{array}{l}\text { Std. Error of } \\
\text { the Estimate }\end{array}$} & \multicolumn{5}{|c|}{ Change Statistics } & \multirow[b]{2}{*}{$\begin{array}{l}\text { Durbin- } \\
\text { Watson }\end{array}$} \\
\hline & & & & & $\begin{array}{c}\text { R Square } \\
\text { Change }\end{array}$ & F Change & df1 & $\mathrm{d} 22$ & Sig. F Change & \\
\hline 1 & $.623^{\mathrm{a}}$ & .388 & .376 & 123.58931 & .388 & 34.193 & 1 & 54 & .000 & 1.726 \\
\hline
\end{tabular}

a. Predictors: (Constant), Max Temperature

b. Dependent Variable: $V_{-} T W$

\section{Appendix 13: 2009 Smog Advisory Regression Analysis}

\begin{tabular}{|c|c|c|c|c|c|c|c|c|c|c|}
\hline \multirow[b]{3}{*}{ Model } & \multirow[b]{3}{*}{$\mathrm{R}$} & \multirow[b]{3}{*}{ R Square } & \multicolumn{7}{|c|}{ Model Summary ${ }^{d}$} & \multirow[b]{3}{*}{$\begin{array}{l}\text { Durbin- } \\
\text { Watson }\end{array}$} \\
\hline & & & \multirow[b]{2}{*}{$\begin{array}{l}\text { Adjusted R } \\
\text { Square }\end{array}$} & \multirow[b]{2}{*}{$\begin{array}{l}\text { Std. Error of } \\
\text { the Estimate }\end{array}$} & \multicolumn{5}{|c|}{ Change Statistics } & \\
\hline & & & & & $\begin{array}{c}\text { R Square } \\
\text { Change }\end{array}$ & F Change & df1 & $\mathrm{df} 2$ & Sig. F Change & \\
\hline 1 & $.385^{\mathrm{a}}$ & .148 & .130 & 110.93662 & .148 & 7.999 & 1 & 46 & .007 & \\
\hline 2 & $.519^{b}$ & .269 & .236 & 103.91088 & .121 & 7.431 & 1 & 45 & .009 & \\
\hline 3 & $.584^{\circ}$ & .341 & .296 & 99.74853 & .072 & 4.834 & 1 & 44 & .033 & 1.560 \\
\hline
\end{tabular}

a. Predictors: (Constant), Max Temperature

b. Predictors: (Constant), Max Temperature, PMLevel

c. Predictors: (Constant), Max Temperature, PMLevel, Raw Illnesses

d. Dependent Variable: V_TW

\section{Appendix 14: 2010 Smog Advisory Regression Analysis}

\begin{tabular}{|c|c|c|c|c|c|c|c|c|c|c|}
\hline & & & & & odel Summar & & & & & \\
\hline \multirow[b]{2}{*}{ Model } & \multirow[b]{2}{*}{$\mathrm{R}$} & \multirow[b]{2}{*}{$R$ Square } & \multirow[b]{2}{*}{$\begin{array}{l}\text { Adjusted R } \\
\text { Square }\end{array}$} & \multirow[b]{2}{*}{$\begin{array}{l}\text { Std. Error of } \\
\text { the Estimate }\end{array}$} & \multicolumn{5}{|c|}{ Change Statistics } & \multirow[b]{2}{*}{$\begin{array}{l}\text { Durbin- } \\
\text { Watson }\end{array}$} \\
\hline & & & & & $\begin{array}{c}\text { R Square } \\
\text { Change }\end{array}$ & F Change & df1 & df2 & Sig. F Change & \\
\hline 1 & $.519^{\mathrm{a}}$ & .270 & .259 & 143.99868 & .270 & 25.854 & 1 & 70 & .000 & 2.228 \\
\hline
\end{tabular}

a. Predictors: (Constant), 03Level

b. Dependent Variable: $V_{-} T W$ 


\subsection{References}

Ahrens, C. D. (2007). Meteorology Today: An Introduction to Weather, Climate, and the Environment. Ed. 8. Thomson Higher Education. Belmont: California.

Anderson, H. R. (2009). Air pollution and mortality: A history. Atmospheric Environment. 43: 142-152.

Boyd, J. T. (1960). Climate, Air Pollution and Mortality. Brit. J. prev. soc. Med. 14: 123-135.

Brook, J.R., Dann, T.F. and Burnett, R.T. (1997). The Relationships among TSP, PM10, PM2.5 and Inorganic Constituents of Atmospheric Particulate Matter at Multiple Canadian Locations. J. of Air \& Waste Management Assoc. 47: 2-19.

Canadian Medical Association (CMA; 2008). No Breathing Room: Illness Costs of Air Pollution. Technical Report.

Chauhan, A. J. and Johnston, S. L. (2003). Air pollution and infection in respiratory illness. British Medical Bulletin. 68: 95-112.

Cheng, C. S, M. Campbell, Q. Li, G. Li, H. Auid, N. Day, D. Pengelly, S. Gingrich, J. Klaassen, D. MacIver, N. Comer, Y. Mao, W. Thompson and H. Lin. (2008). Differential and combined impacts of extreme temperatures and air pollution on human mortality in south-central Canada. Part 1: Historical Analysis. Air Quality, Atmosphere and Health. 1: 209-222.

Davis, C. C. and Roney H. B. (1953). A Preliminary Study of Industrial Pollution in the Cleveland Harbor Area, Ohio. Ohio Journal of Science. 53:1:14-30

Diminici, F., Daniels, M., Zeger, S. L., and Samet, J. M. (2002). Air Pollution and Mortality: Estimating Regional and National Dose-Response Relationships. J. Am. Stat. Assoc. 97(457): 100-111.

Dockery, D.W., F.E. Speizer and C.A. Pope. (2000). Effects of Particulate Air Pollution Exposures. In Particle-Lung Interactions edited by P. Gehr and J. Heyder, University of Bern, Switzerland. p. 671-706.

Ellis, F. P. (1972). Mortality from heat-illness and heat-aggravated illness in the United States. Environmental Research. 15: 504-512.

Environment Canada. (2012). Canadian Smog Science Assessment: Highlights and Key Messages. Retrieved on September $28^{\text {th }} 2012$ from $<$ http://www.ec.gc.ca/Publications/AD024B6B-A18B-408D-ACA259B1B4E04863\%5CCanadianSmogScienceAssessmentHighlig htsAndKeyMessages.pdf> 
Flemming, G. (1996). The importance of air quality in human biometeorology. Int. $J$. Biometeorol. 39:192-196.

Fraser, D., Yap, D., Kiely, P., De Brou, G., Dong, W. and Debosz, J. (1997). Daily and Continuous Monitoring of PM10/PM2.5 in Ontario, Canada. Paper, AWMA 90 Annual Meeting, Toronto, Canada.

Hales, S., Salmond, C., Town, G. I., Kjellstrom, T., and Woodward, A. (2000). Daily mortality in relation to weather and air pollution in Christchurch, New Zealand. Aust N Z J Public Health. 24: 89-91.

Health Canada. (2003). Smog and Your Health. Retrieved on March $20^{\text {th }} 2012$ from $<$ http://www.hc-sc.gc.ca/hl-vs/iyh-vsv/environ/smog-eng.php>

Health Canada. (2011). Road Traffic and Air Pollution. Retrieved on March $20^{\text {th }} 2012$ from $<$ http://www.hc-sc.gc.ca/hl-vs/alt_formats/pdf/iyh-vsv/environ/traf-eng.pdf $>$

Jerret, M., Burnett, R. T., Ma, R., Pope III, C. A., Krewski, D., Newbold, K. B., Thurston, G., Shi, Y., Finkelstein, N., Calle, E. E., Thun, M. J. (2005). Spatial Analysis of Air Pollution and mortality in Los Angeles. Epidemology. 16(6): 727-736.

Jerret, M., Finkelstein, M. M., Brook, J. R., Arain, M. A., Kanaroglou, P., Stieb, D. M., Gilbert, N. L., Verma, D., Finkelstein, N., Chapman, K. R., and Serars, M. R. (2009). A Cohort Study of Traffic-Related Air Pollution and Mortality in Toronto, Ontario, Canada. Environ Health Perspect. 117:772-777.

Kampa, M. and Castanas, E. (2008). Human health effects of air pollution. Environmental Pollution. 151: 362-367.

Katsouyanni, K. (2003). Ambient air pollution and health. British Medical Bulletin. 68: 143-156.

Katsouyanni, K., Pantazopoulou, A., Touloumi, G., Tselepidaki, I., Moustris, K., Asimakopoulos, D., Poulopoulou, G., and Trichopoulos, D. (1993). Evidence for Interaction between Air Pollution and High Temperatures in the Causation of Excess Mortality. Archives of Environ. Health. 48(4): 235-242.

Kim, J. (2001). Air quality falls to poor. Peterborough Examiner. 15 June 2001: B1.

Klock, R., Simard, G., and Mullock, J. (2002). The Weather of Ontario and Quebec: Graphic Area Forecast 33. Retrieved on December 132012 from $<$ http://www.navcanada.ca/ContentDefinitionFiles/publications/lak/OnQc/OQ33EW.PDF $>$

Ladurantaye, S. (2002). Air quality in city worst in province. Peterborough Examiner. 12 June 2003: A1. 
Leikauf, G. D. (2002). Hazardous Air Pollutants and Asthma. Environ Health Perspect.110(4): $505-526$.

Lindgren, A. (2001). Rural Ontario hit hard by smog: Ozone levels soar in cottage country. Calgary Herald. 28 June 2001: A11.

Lipfert, F.W. and Morris, S. C. (2002). Temporal and spatial relations between age specific mortality and ambient air quality in the United States: regression results for counties, 1960-97. Occup Environ Med. 59:156-174.

Lippman, M., Ito, K., Hwang, J-S., Maciejczyk, P, and Chen L-C. (2006). Cardiovascular Effects of Nickel in Ambient Air. Environ Health Perspect. 114:11:1662-1669.

Lorraine, C., J.R. Brook, Q. Chiotti, B. Croes, S. Gower, A. Hedley, D. Krewski, A. Krupnick, M. Krzyzanowski, M.D. Moran, W. Pennell, J.M. Samet, J. Schneider, J. Shortreed, and M. Williams. (2008). Air pollutant and public health: a guidance document for risk managers. Journal of Toxicology and Environmental Health. 71: 588-698.

Martin, A. E. (1964). Mortality and Morbidity Statistics and Air Pollution. Proceedings of the Royal Society of Medicine. 57:11: 969-975.

McGeehin, M. A. and Mirabelli, M. (2001). The Potential Impacts of Climate Variability and Change on Temperature-Related Morbidity and Mortality in the United States. Environ Health Perspect. 109(2): 185-189.

Nafsted, P., Haheim, L. L., Oftedal, B., Gram, F., Holme, I., Hjermann, I., and Leren, P. (2003). Lung cancer and air pollution: a 27 year follow up of 16209 Norwegian men. Thorax. 58: 1071-1076.

Nel, A. (2005). Air Pollution-Related Illness: Effects of Particles. Science. 308: 804-806.

Ontario Medical Association. (OMA; 2000). Phase II: Estimating Health and Economic Damages - Illness Costs of Air Pollution. Retrieved on March $5^{\text {th }} 2012$ from $<$ https://www.oma.org/Resources/Documents/g2000IllnessCostsOfAirPollution.pdf $>$

Ontario Ministry of the Environment (MOE; 1999). A compendium of current knowledge on fine particulate matter in Ontario. Prepared by the MOE for The Ontario Smog Plan Steering Committee.

Ontario Ministry of the Environment (MOE;2005). Green Facts: Ontario Air Quality Index. Retrieved on September 52012 from $<$ http://www.ene.gov.on.ca/stdprodconsume/groups/lr/@ene/@resources/documents/reso urce/std01_079055.pdf> 
Ontario Ministry of the Environment (MOE;2010). Frequently Asked Questions: How is smog forecasted? Retrieved on October 26, 2012 from

$<$ http://airqualityontario.com/press/faq.php\#4>

Peng, D. R., Bell, M. L., Geyh, A. S., McDermott A., Zeger, S. L., Samet, J. M., and Dominici, F. (2009). Emergency Admissions for Cardiovascular and Respiratory Dieases and the Chemical Composition of Fine Particle Air Pollution. Environ. Health Perspect. 117(6): 957-963.

Peng, D. R., Dominici, F., Pastor-Barriuso, R., Zeger, S. L., and Samet, J. M. (2005). Seasonal Analyses of Air Pollution and Mortality in 100 US Cities. Am J Epidemiol. 161(6): 585594.

Pope III, C. A. and Dockery, D. W. (1992). Acute health effects of PM $_{10}$ pollution on symptomatic and asymptomatic children. Am. J. Respir. Crit. Care Med. 145:5:11231128.

Pope III, C.A., Bates, D. V., and Raizenne M. E. (1995). Health Effects of Particulate Air Pollution: Time for Reassessment. Environ. Health Perspect. 103:472-480.

Potter, M. (2010). U.S. crackdown clears our air: Southern Ontario to benefit from tough new rules on coal-fired pollution south of the border. Toronto Star: July 29, 2010, A. 1

Rainham, D. G. C. and Smoyer-Tomic, K. E. (2003). The role of air pollution in the relationship between a heat stress index and human mortality in Toronto. Environmental Research. 93: 9-19.

Rainham, D. G. C., Smoyer-Tomic, K. E., Sheridan, S. C., and Burnett, R. T. (2005). Synoptic weather patterns and modification of the association between air pollution and human mortality. In. J. Environ. Health Research.15(5): 347-360.

Sahsuvaroglu, T. and Jerret, M. (2007). Sources of uncertainty in calculating mortality and morbidity attributable to air pollution. J. Toxic. Environ. Health. 70: 243-260.

Samet, J., Zeger, S., Kelsall, J., Xu, J., and Kelkstein, L. (1998). Does Weather Confound or Modify the Association of Particulate Air Pollution with Mortality? Environmental Research. 77: 9-19.

Samet, J. M., Zeger, S. L., Dominici, F., Curriero, F., Coursac, I., Dockery, D. W., Schwartz, J., and Zanobetti, A. (2000). The National Morbidity, Mortality and Air Pollution Study Part II: Morbidity and Mortality from Air Pollution in the United States. Health Effects Institute (HEI). Research Report: 94: Part II.

Schenker, M. (1993). Air pollution and mortality. New Eng. J. Med. 329(24): 1807-1808. 
Schroeder, C. (2004). Graduate Project: Health Effects of Hydrogen Fuel Substitution in Public and Private Vehicles in The Greater Toronto Area. Ryerson University.

Semenza, J. C., Wilson, D. J., Parra, J., Bontempo, B. D., Hart, M., Sailor, D. J., and George, L. A. (2008). Public perception and behavior change in relationship to hot weather and air pollution. Environmental Research. 107: 401-411.

Smoyer, K. E., Rainham, D. G. C., and Hewko, J. N. (2000). Heat-stress related mortalities in five cities in Southern Ontario: 1980-1996. Int. J. Biometeorol. 44: 190-197.

Schwartz, J. (2000). Harvesting and long-term exposure effects in relation between air pollution and mortality. Am. J. Epidemiol. 151:440-448.

Tirabassi, T. (1991). Spectral Characteristics of Wind and Air Pollution Data in an Industrial Area. Il Nuovo Cimento. 14(3): 305-311.

Toronto Atmospheric Fund (TAF; 2007). Greenhouse Gases and Air Pollutants in the City of Toronto: Toward a Harmonized Strategy for Reducing Emissions. Retrieved on February $10^{\text {th }} 2012$ from $<$ http://www.toronto.ca/taf/pdf/ghginventory_jun07.pdf $>$

Unknown Author. (U.A.;1954). Smog. Tubercle. 35(2):44-46.

Vallero, D. (2008). Fundamentals of Air Pollution. $4^{\text {th }}$ ed. Academic Press, Burlington, MA, USA.

Wolf-Benning, U., Schultz, E., Dietze, V., Kaminski, U., and Endlicher, W. (2012). A comparative study of the carrying exposure to atmospheric fine and coarse particles under urban and rural conditions. Journ. Air \& Waste Manag. Assoc. 62: 1313-1328.

Wyzga, R. E. (1978). The Effect of Air Pollution upon Mortality: A Consideration of Distributed Lag Models. Journ. Amer. Stat. Assoc. 73(363): 463-472. 